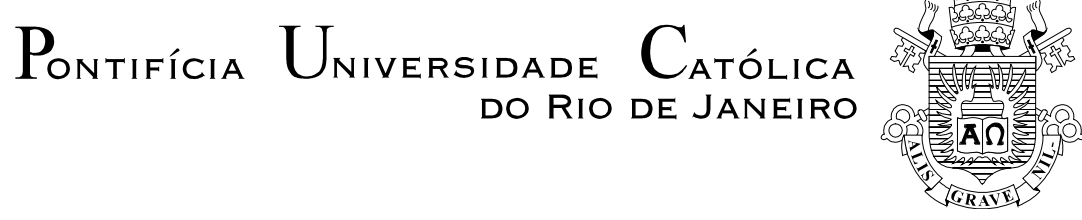

Andrea Margrit Hafner

\begin{abstract}
A evolução do licenciamento ambiental no Brasil à luz da análise dos impactos e medidas
\end{abstract}

Dissertação apresentada como requisito parcial para obtenção do grau de Mestre pelo Programa de PósGraduação em Engenharia Urbana e Ambiental do Departamento de Engenharia Civil da PUC-Rio.

Orientador: Prof. Celso Romanel

Co-orientador: Dr. Alexandre Barbosa Brandão da Costa 


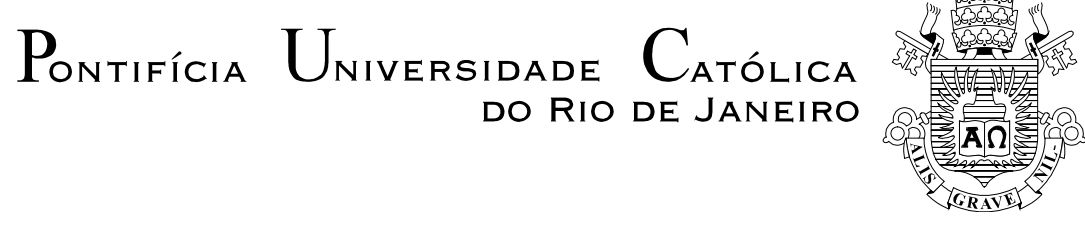

Andrea Margrit Hafner

\title{
A evolução do licenciamento ambiental no Brasil à luz da análise dos impactos e medidas
}

Dissertação apresentada como requisito parcial para obtenção do grau de Mestre em Engenharia Urbana e Ambiental (opção profissional) pelo Programa de Pós-Graduação em Engenharia Urbana e Ambiental da PUC-Rio. Aprovada pela Comissão Examinadora abaixo assinada.

\author{
Prof. Celso Romanel \\ Orientador - Presidente \\ Departamento de Engenharia Civil - PUC-Rio \\ Dr. Alexandre Barbosa Brandão da Costa \\ Co-orientador \\ Companhia de Planejamento do Distrito Federal
}

Prof. Ricardo Abranches Felix Cardoso Júnior

Universidade Federal Fluminense

Prof. Rafael Soares Gonçalves

PUC-Rio

Prof. Márcio da Silveira Carvalho

Coordenador Setorial de Pós-Graduação do Centro Técnico Científico - PUC-Rio 
Todos os direitos reservados. É proibida a reprodução total ou parcial do trabalho sem autorização da universidade, da autora e do orientador.

\section{Andrea Margrit Hafner}

Graduou-se em Engenharia Química pela Universidade Federal do Rio de Janeiro UFRJ em 1999. Pós graduou-se em Gestão Ambiental pela Universidade Federal de São Carlos em 2003. Trabalha desde 2002 com processos de licenciamento ambiental e gestão ambiental em mineradoras e siderúrgicas, tendo coordenado estudos de arqueologia, espeleologia, emissões atmosféricas, inventários de gases de efeito estufa, estudos ambientais e de componente indígena.

Ficha Catalográfica

Hafner, Andrea Margrit

A evolução do licenciamento ambiental no Brasil à luz da análise dos impactos e medidas / Andrea Margrit Hafner; orientador: Celso Romanel; co-orientador: Alexandre Barbosa Brandão da Costa. - 2016.

157 f. : il. color. ; $30 \mathrm{~cm}$

Dissertação (mestrado) - Pontifícia Universidade Católica do Rio de Janeiro, Departamento de Engenharia Civil, Programa de Pós-Graduação em Engenharia Urbana e Ambiental, 2016.

Inclui bibliografia

1. Engenharia Civil - Teses. 2. Engenharia Urbana e Ambiental - Teses. 3. Licenciamento ambiental. 4. Avaliação de impacto ambiental. 5. Impactos e programas socioambientais. 6. Estudo de impacto ambiental e relatório. I. Romanel, Celso. II. Costa, Alexandre Barbosa Brandão da. III. Pontifícia Universidade Católica do Rio de Janeiro. Programa de Pós-Graduação em Engenharia Urbana e Ambiental. IV. Título. 


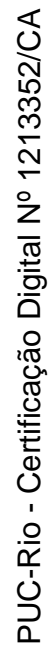

Dedico este trabalho à minha família e a quem mais interessar possa... 


\section{Agradecimentos}

Aos meus pais Betty e Hans, por sempre acreditarem que eu podia mais, ao apoio incondicional nestes anos todos.

A minha filha Nicole, que me incentiva a pensar no futuro com mais urgência e esperança de um mundo melhor.

As minhas irmãs Heidi e Ana, cunhados Christoph e Leonardo e sobrinhos Adrian, Patrick e Sabrina, pela companhia, apoio e compreensão.

Ao Prof Dr Alexandre Barbosa Brandão da Costa pela orientação

À Paula Enoy e ao Prof Dr Celso Romanel, pelo empenho na excelência do curso.

À banca examinadora.

Aos colegas e professores do mestrado.

Aos colegas e amigos do Ibama, onde esta historia começa.

Aos colegas de Vale na DIAM, DISG e DIRC e também aos que diretamente trabalharam comigo em Carajás, na ALPA, CSU, CSA, por me ensinarem sempre.

Aos consultores que confirmam a teoria que vivemos em universos paralelos e sempre é possível aprender mais.

Ao Juarez Sigwalt, Dimas Bahiense, Luiz Claudio Castro, Luana Martins Andrade, Liesel Filgueiras e Isis Pagy verdadeiros líderes, com quem muito aprendo.

Aos amigos, que tornaram tão interessantes e divertidos estes últimos anos em especial à Carla, Hara, Abreu, Macedo, Cecilia, Bernadette, Gervásio, Marcos, Ecila, Janaina e Silvinha. À Fernanda Marques pelo apoio.

Aos que estiveram aqui antes, com fabricas, pianos e trabalho duro, agindo com amor e fidelidade, servindo de exemplo.

A Deus, por tudo. 


\section{Resumo}

Hafner, Andrea Margrit; Romanel, Celso (Orientador); da Costa , Alexandre Barbosa Brandão (Co-orientador). A evolução do licenciamento ambiental no Brasil à luz da análise dos impactos e medidas. Rio de Janeiro, 2016, 157p. Dissertação de Mestrado - Departamento de Engenharia Civil, Pontifícia Universidade Católica do Rio de Janeiro.

Algumas críticas e dificuldades ao processo de licenciamento ambiental brasileiro têm sido apresentadas tanto pela academia, como por órgãos governamentais e setores empresariais. Das dificuldades identificadas, a relação entre identificação de impacto e a proposição de programas que os mitigue, compense ou potencialize motivou o Estudo de Caso, por ser a base do licenciamento e da avaliação de impactos. A pesquisa realizada foi em caráter exploratório, com base no conteúdo de análises documentais e estudo de caso de 35 processos de licenciamentos ambientais no Brasil, cujos EIA/RIMA foram apresentados ao órgão federal - Ibama entre 2001 e 2014 para verificar as semelhanças e divergências entre eles. Como resultado, foi verificado que a quantidade de impactos e programas identificados nos EIA/RIMA aumentaram ao se comparar dois momentos temporais: de 2001 a 2007 e de 2008 a 2014, particularmente os do meio antrópico. No entanto foi surpreendente verificar que alguns impactos e programas não guardam relação clara e direta entre si. Para a avaliação dos impactos do meio físico e biótico, claramente é possível a padronização na identificação de impactos e seus programas de forma a otimizar a análise efetiva dos impactos, facilitando a análise, reduzindo prazos e custos e trazendo mais informações para a sociedade como um todo.

\section{Palavras-chave}

Licenciamento Ambiental; Avaliação de Impacto Ambiental; Impactos e Programas Socioambientais; Estudo de Impacto Ambiental e Relatório. 


\section{Extended Abstract}

Hafner, Andrea Margrit; Romanel, Celso (Advisor); da Costa, Alexandre Barbosa Brandão (Co-Advisor). Changes in environmental licensing in Brazil considering the analysis of impacts and measures. Rio de Janeiro, 2016, 157p. MSc. Dissertation - Departamento de Engenharia Civil, Pontifícia Universidade Católica do Rio de Janeiro.

The main objective of this study is to evaluate the licensing process in Brazil, trying to understand how it has changed over the past few years and how it has been perceived by society.

Brazil, a continental country with an accelerated process of urbanization which requires investments in its industrial parks and infrastructure, shows an increasing number of environmental licensing processes. Environmental agencies and intervening organizations have resource deficits. Municipalities have difficulties to generate revenue and to enforce essential public policies. Society sees in the large investors a possible solution to attend suppressed demands to improved quality of life. This is the scenario in which enterprises need to be inserted and be licensed.

The environmental licensing process in Brazil can be conducted by environmental agencies of all three government levels (federal, state and municipal). Characteristics of the project and its location will determine which of them will lead the process. Although the licensing process is conducted by a single environmental agency, there is still the need for participation of other governmental entities linked to different Ministries. In Brazil there are currently 39 Ministries, and it cannot be expected for institutional interrelations to be well established and with a clear hierarchy.

The Preliminary License should be authorized upon determination of environmental viability, however with so many factors and stakeholders involved it is natural that conflicts should arise. The environmental licensing process in Brazil has been criticized by the various stakeholders involved.

While impacts to the physical and biotic environment generate fewer conflicts in the identification and proposal of measures, those impacts associated with social and economic aspects often arouse conflicts of difficult resolution that have often led to judicial processes. 
The resources required at the beginning of an environmental licensing process in Brazil are not trivial, nor are the processes speedy, but on the other hand they do not seem to be sufficient to mitigate the impacts, because the post-deployment monitoring and feedback required to improve the process have not been occurring in the way they should. This reinforces the perception that it is a formal process in which the interest is in the final result - licenses and conditions, and not effectively the participatory and consensual process involving the society and with the least possible negative impacts.

Environmental requirements and the environmental licensing process in Brazil started at the end of the military dictatorship period. The participation of the society has grown over the past 35 years, although it was already planned from the beginning under the influence of the models that were the basis for the process in Brazil.

In proposing the assessment of the licensing process, the intent is to verify the changes that have occurred over the past 35 years and the difficulties encountered so that, once the need for alterations have been identified, these actions are not implemented.

The environmental licensing process has in theory, as expressed legally, the goal of verifying the environmental feasibility prior to the implementation of an enterprise in a particular locality, and focusing on physical, biotic and anthropic aspects. In Brazil it has been particularly difficult to evaluate the social and economic impacts.

In the perception of part of society, however, what is desired is for the project to be able to boost the region from an economic point of view, with improvements in quality of life. Another part of society may wish for quality of life to be maintained as it is, in a more preservationist approach, including natural resources. As a result of the different interests within the same society that the licensing process has been noted, being almost the only instrument and forum in which society has to discuss its concerns.

Given the complexity of interests and stakeholders, the licensing process needs to be adjusted to meet the goals and expectations of society. 
Some criticisms and difficulties in the Brazilian environmental licensing process have been presented by academia, government agencies and corporate sectors. However, their implementation is not always trivial.

The environmental impact assessment, which is intended to be addressed in this study, has the potential to connect engineering projects with environmental protection and social development when used to refine interventions since its inception. In Brazil, environmental licensing is particularly relevant as the implementation of large enterprises in a sustainable manner is in the interest of the whole society. Much has been discussed about possible improvements in the process and some changes have already been implemented. When specifically investigating, through case studies, 35 different types of process it is likely that some improvements or recommendations can be presented and some actions strengthened to increase the satisfaction of society in the implementation of large projects.

Although the environmental licensing is an administrative procedure, the conduct and the consequences is permanent for the urban spaces and interfere in society as a whole, having a strong influence on the planning and balance of many Brazilian cities.

The research will be conducted in an exploratory manner, based on the content of the documental analyses and case studies of the environmental licensing processes in Brazil.

The theoretical analysis is composed of a review of the literature and current legislation.

In this stage of the work, the theoretical foundations related to relevant topics for the study will based on literature reviews to be conducted in books, thesis, journals and manuals, focusing on: Environmental Impact Assessment EIA; Environmental Licensing; Environmental Impact Assessment and its corresponding reports; and Social and Environmental Impacts and Programs.

This dissertation aims to verify the changes that occurred in the licensing process in Brazil, focusing on large enterprises licensed at the federal level. This study will be based on a series of studies and researchers who critically analyze the environmental licensing process in Brazil. These studies, in their majority, indicate weaknesses and points to be improved. To confirm some of the points presented as deficient, a case study was proposed. 
Although environmental licensing and impact assessment are applicable to a wide range of actions, policies and plans, in this particular study the focus was on projects, particularly large enterprises, whose potential to cause significant environmental and social impacts leads to the need for conducting Environmental Impact Assessments EIA and its corresponding report RIMA, in Portuguese.

Regarding the licensing processes conducted by environmental agencies at different government levels, it is to be expected that they will present specificities due to the greater or lesser political pressure, although they are governed by the same legislation. This analysis, although useful to an understanding of the Brazilian environmental licensing process, was not possible because there were not enough data available at the state and municipal levels to allow a comparison with the processes conducted by the federal environmental agency. Therefore in this study were only considered environmental licensing processes at the federal level.

The bibliographic and documental review indicated that there are a large number of government agencies and academic studies that contain critical evaluations of the environmental licensing process. However they almost always refer to a specific type of enterprise. In particular, the electricity production sector has been extensively studied in Brazil in recent years. One of the probable causes is the strong demand for energy in the country in recent years, and the frequent justification for delays of large projects due to the licensing process.

It is true that there are specific characteristics of each project typology that may require differentiated procedures, but one of the specific objectives of this study is to verify if it is really necessary to segregate the licensing process in different types and what are the similarities between them.

This study, therefore, will attempt to comparatively analyze the licensing process as a whole, covering different types of enterprises. For the case study 35 linear and plant projects were selected.

A number of factors can contribute and influence the outcome of the analysis of the efficiency of the licensing process, but not necessarily being closely related to the focus of this research. For example voluntary actions or those required to meet the Social License to Operate or Corporate Responsibility that an enterprise performs in a given community may not be directly related to the mitigation of impacts, and so can provide a false idea that the process has been better conducted. 
This study will not evaluate the conditions of each license that theoretically should complement the impacts and programs.

Local characteristics such as human, social, institutional, physical and cultural capital interfere decisively in the results of the implementation of an enterprise, which is why we will restrict the analysis of this dissertation to the stage involving the obtaining of the preliminary license, and more specifically on EIA / RIMA studies, particularly in the identification of impacts and programs.

To contextualize the Environmental Impact Assessment (EIA), strongly associated with environmental licensing in Brazil, it is necessary to resort to the international scene due to its influence.

The EIA formulation first occurred in the United States in 1969. It focused on the federal government agencies that should use a systematic and interdisciplinary approach in decision making and planning in projects that could have a social impact.

France was the first country in Europe to adopt the environmental impact assessment by means of two laws from 1976; however its legal system and administrative organization were very different from that of the United States. The EIA was adopted in France as a change in the licensing system / government authorization for industries and other activities that might cause impacts. The environmental impact studies should be done by the interested party, public or private. (SANCHEZ 2012)

A key point, according SANCHEZ 2013 is that the EIA is an instrument that was not born ready, but an idea to be developed. On the one hand the EIA resulted from a political process that sought to meet a social demand, which was more mature in the United States in the late 1960s. On the other hand, the licensing process has been improved as lessons are learned during practical experience. The process was changes and adapted as it was applied to other cultural and political contexts, but always within the primary objective to prevent environmental degradation and support a decision-making process so that the consequences are seized before each decision is made.

Multilateral financial agencies and other international organizations have played a central role in the adoption of the EIA Environmental Impact Assessment methodology by many developing countries, but internal conditions favored a 
more or less favorable acceptance of the principles of prevention and precaution inherent in AIA (MILARÉ 2007 p. 67).

Although, in Brazil, it is place since the $70 \mathrm{~s}$, in some states such as Rio de Janeiro, São Paulo, Minas Gerais and Bahia, the environmental licensing process was introduced to the entire country by the Law (Lei 6.938 / 81).

Environmental licensing in Brazil occurs through a single administrative process with the issuance of three successive licenses, with the aim of verifying whether a particular activity is actually appropriate to the environmental quality standards prescribed by law or by the competent environmental agency.

Over the past 35 years the environmental licensing process has been criticized and assessed, both by institutions as well as by society in general, which naturally promotes some legal, regulatory and practical procedural adjustments.

The main deficient issues pointed out in studies were:

1) Excess of normative acts, sometimes conflicting, and the fact that the license is the only instrument within the National Environmental Policy (Política Nacional do Meio Ambiente - PNMA) fully implemented.

According to a survey released by CNI, 2014:

... Environmental licenses in Brazil are regulated, directly or indirectly, by about 30000 different legal instruments produced by the federal and state governments...

Often incongruent and featuring overlaps that form a "legal tangle."

According to SAE 2009 p.4 "... the bureaucratic excesses often delay the process without any consideration of quality of the decision."

Although other territorial planning tools such as zoning and strategic environmental assessment are contemplated by Brazilian legislation, the fact that licensing is the only one effectively implemented ends up distorting its purpose, creating the feeling of inefficiency.

2) The time, cost and quality of preparation of the EIA, very focused on the diagnosis.

Environmental Impact Assessment studies and their reports (EIA/RIMA) take, on average, 9 to 18 months to be elaborated. They may have a few thousand 
pages and their costs can exceed a few million Reais, containing little information that actually enrich and broaden the knowledge.

The analysis of extensive studies, the need for public hearings and the legal deadlines are some of the factors that result in the definition phase of the locational viability take at least two years to be completed.

The slowness of the process eventually causes the submission of applications that are in the early stages of the design of engineering projects, which ultimately undermines the analysis and quantification of potential real impacts.

\section{3) Lack of data and environmental information systematized}

When information is available in Brazil, they are spread across various institutions, and are difficult to access. The studies conducted in each process are not systematized in databases, and thus cannot be utilized by other studies, resulting in a waste of knowledge, time and resources.

Municipal statistics and indicators are also precarious, hampering social and economic analyses.

\section{4) Lack of Structure and Personnel in Environmental Agencies (number of personnel and remuneration framework, professional qualification and average and backlogged demand).}

The increasing number of licensing processes at the federal agency in recent years has been accompanied by the growing number of analysts and their training. A series of procedures including the elaboration of guidelines/terms of reference for different enterprise types were implemented, with the procedural steps are quite clear and regulated. However there is still a repressed demand and the lack of resources in the state and municipal environmental agencies and in other intervening organizations result in the non-compliance with the deadlines legally established.

\section{5) Multiplicity of actors with discretionary powers}

The involvement of various governmental agencies and intervening organizations such as Funai (Indigenous Peoples), Palmares Cultural Foundation (slave descendants), Iphan (tangible and intangible heritage), Ministry of Health (malaria), ICMBio (environmental protection), in addition to offices and 
departments in the states and municipalities where the project will be implemented, and little institutional coordination between them, in addition to different interests, result in numerous parallel procedures to the licensing process.

6) Lack of regulatory frameworks for social issues and licensing conditional activities that go beyond the obligations of the entrepreneur and the licensor and deficiencies in public policies and services that undermine the environmental licensing process in Brazil

In the environmental licensing process, impacts on the physical and biotic environment can be relatively well defined spatially and are more local, whereas socioeconomic impacts have a much larger scope and difficult delimitation. They are also generally more complex and indirect. The establishment of programs for mitigation or compensation of socioeconomic impacts in a standardized way is more difficult because they depend on local arrangements and characteristics.

The limited scope of socioeconomic studies in the EIA and, therefore, within the formal licensing process, can be justified based on the history of the licensing process in Brazil and its structure within environmental agencies, as well as due to their complexity.

Limited interaction with other sectors and departments associated with socioeconomic issues also weaken the analyses and mitigation capacity.

In Brazil, due to the lack or deficiency of public policies, and severe limitations of public services (health, education, safety and sanitation), it is inevitable that there is an expectation for the enterprise to contribute with improvements in these areas. These actions, which should be voluntary as they are not directly related to the possible impacts, are instead incorporated into the licensing process and become a legal obligation associated with the implementation of the project, not only increasing the project's Capex but often also its Opex, through the maintenance and operation of structures that should be public.

7) Excessive constraints and lack of monitoring of their effectiveness and feedback based on the evaluation of the effectiveness of mitigation and compensation programs

Notwithstanding the existence of Terms of Reference, of extensive studies and the experience gained over more than 35 years of the environmental licensing 
process, there are still an excessive number of environmental licensing conditional actions, indicating that there is not a complete understanding of the licensor's expectations. On the other hand, monitoring of environmental licensing conditional actions and programs is based on whether they were "met, partially met or not met", without an assessment of the mitigation of impacts. Without this assessment, programs can be proposed to ensure that they are met or accomplished and, if they do not mitigate the impacts, they will continue to be designed and proposed, without improvement in the process.

\section{8) Inefficient use of Public Consultations and Public Hearings}

Public hearings are one of the means for participation and popular control of the public administration, allowing the exchange of information.

Information is a requirement for the participation of the populations involved in the licensing processes. In most cases the information presented is the Environmental Report RIMA, and public hearings provide the space for the communities to voice their opinions and concerns. Although some environmental agencies establish clear rules for the hearings, many end up dealing with topics not related to the licensing process itself.

\section{9) Excessive interventions from the Justice Department (Ministério} Público) and frequent judicial processes

According to SAE 2009 p. 6 :

The absence of rules ... extends the administrative discretionary powers of environmental technicians, and also extends to the possibility of legal challenges of the decisions.

... Instances in which the Justice Department (Ministério Público) disagrees with the decision of the environmental technicians and propose legal actions to challenge it are not uncommon.

To protect themselves from future judicial processes, technical staff adopt a defensive approach and make unnecessary requirements that are disproportionate to the impact of the project.

Of all the points identified as flawed or that cause bottlenecks in the process, we would like to test if a simpler process, where the impact matrix was already given so that in each project only their magnitude would be assessed, would result in shorter elaboration and analyses times, leaving resources for assessing the 
effective mitigation of impacts for programs that could provide feedback to the original impact matrix.

In this sense we propose a case study that instead of analyzing the characteristics of each project typology in isolation would analyses all projects together.

For the case study, we selected 35 large enterprises in different typologies, whose EIA / RIMA were presented to the federal licensing agency - IBAMA between 2001 and 2014, as follows in table 1 .

Table 1 - Projects selected by typology and period

\begin{tabular}{lccc}
\hline \multicolumn{1}{c}{ Type } & $2001-2007$ & 2008- 2014 & Total \\
\hline Railways & 1 & 3 & 4 \\
Duct & 2 & 3 & 5 \\
Transmission Line & 0 & 5 & 5 \\
Highway & 2 & 2 & 4 \\
Port & 0 & 4 & 4 \\
Mining & 1 & 3 & 4 \\
Industrial & 0 & 1 & 1 \\
Hydropower plant & 1 & 4 & 5 \\
Thermoelectric & 1 & 2 & 3 \\
Power Plant & & & 35 \\
Total & 8 & 27 & \\
\hline
\end{tabular}

The projects were divided into two groups:

- 18 linear projects (pipelines, transmission lines, railways and highways).

- 17 plant projects (mining, industrial, nuclear plants, ports, hydropower and thermoelectric power plants).

The quantitative analysis of impacts and programs did not demonstrate any correlation or temporal variation.

As we evaluated the impacts of the different environments (physical, biotic and socioeconomic), to see if there were changes in the time periods studied, we noted that, for the physical and biotic impacts, there were no significant changes in plant or linear projects during the periods studied. However it was found that a similar impact was classified using different nomenclatures and grouped into broad themes or detailed, generating a greater number of quantitative impacts. 
For the socioeconomic impacts, in particular, a number of new impacts were identified over the years. The same was true when we evaluated the socioeconomic programs.

These findings led us to believe that, in the first instance, there was a greater sensitivity in the identification and consequent mitigation and compensation in socioeconomic programs.

However, when trying to establish a correlation between impacts and socioeconomic programs, as unexpected result was that some impacts do not have associated programs, whereas some programs are not directly related to any impacts.

From these results we conclude that while still meeting the licensing ritual, the effectiveness of the mitigation of impacts may being disregarded and other claims unrelated to direct impacts are being incorporated into the licensing process.

Of the advances that were identified, we can highlight the greater participation of society, the more effective inclusion of the intervening organizations, and the structure of the federal environmental agency.

As difficulties that remain to be overcome, we can highlight the difficulty of access to systematized data, the quality of studies and the lack of planning of the licensing process integrated with other municipal deficiencies and needs.

For immediate adoption and improvement we suggest the standardization of the impact matrix, the establishment of closer links between the impacts and programs, including an assessment of their effectiveness, thus creating a continuous cycle of improvement through lessons learned.

Focusing on the quantification of the impact matrix will result in shorter times for elaboration of studies, make the analyses easier and with greater depth as the engineering design stage may already be more detailed.

\section{Keywords}

Environmental Licensing; Social and Environmental Issues; Environmental Study and Report; Environmental Impact Assessment. 


\section{Sumário}

1. O Licenciamento Ambiente no Brasil 22

1.1. Introdução 22

1.2. Objetivos 23

1.2.1. Objetivo Geral 23

1.2.2. Objetivo Específico 23

1.3. Contextualização 25

1.4. Delimitação do Estudo 32

1.5. Metodologia 32

2. Histórico da Avaliação de Impacto AIA - Cenário Internacional 34

2.1. Histórico e Legislação 34

2.2 AIA e EIA 43

3. O Processo de Licenciamento Ambiental no Brasil 45

3.1. O Licenciamento Ambiental no Brasil 45

3.2. Dificuldades do Processo de Licenciamento na Prática 51

4. O Processo de Licenciamento na Prática - Estudo de Caso 71

5 Conclusões e Proposições 106

6 Referências Bibliográficas $\quad 116$

7. Anexos 122

7.1. Empreendimentos Pontuais 122

7.2. Empreendimentos Lineares 139 


\section{Lista de tabelas}

Table 1 - Projects selected by typology and period 15

Tabela 1 - Empreendimentos selecionados por tipologia e período 75

Tabela 2 - Quantitativo de impactos e programas associados a cada meio nos empreendimentos selecionados

Tabela 3 - Impactos físicos/ estudos em empreendimentos lineares e pontuais, em dois períodos temporais $\quad 86$

Tabela 4 - Programas do meio físico $\quad 87$

Tabela 5 - Relação entre Impactos e Programas do Meio Físico $\quad 88$

Tabela 6 - Impacto biótico/ estudos em empreendimentos lineares

e pontuais, em dois períodos temporais. 91

Tabela 7 - Relação temporal dos Programas dos projetos $\quad 92$

Tabela 8 - Impactos com os programas do meio biótico 94

Tabela 9 - Impactos socioeconômicos - estudos em

empreendimentos lineares e pontuais em dois períodos temporais 96

Tabela 10 - Relação temporal dos programas dos projetos $\quad 98$

Tabela 11 - Impactos e programas socioeconômicos 100

Tabela A - Empreendimentos Pontuais 122

Tabela B - Empreendimentos Lineares $\quad 139$

\section{Lista de quadros}

Quadro 1 - Marcos da introdução da AIA em alguns países desenvolvidos selecionados

Quadro 2 - Macos da institucionalização da AIA em alguns países em desenvolvimento 


\section{Lista de siglas}

$\begin{array}{ll}\text { AAE } & \text { Avaliação Ambiental Estratégica } \\ \text { ABEMA } & \text { Associação Brasileira de Entidades Estaduais de Meio } \\ & \text { Ambiente } \\ \text { AIA } & \text { Avaliação de Impacto Ambiental } \\ \text { APP } & \text { Área de Preservação Permanente } \\ \text { BID } & \text { Banco Interamericano de Desenvolvimento } \\ \text { CAPEX } & \text { Capital Expenditure } \\ \text { CECA } & \text { Comissão Estadual de Controle Ambiental (RJ) } \\ \text { CEQ } & \text { Council on Environmental Quality - Conselho de } \\ & \text { Qualidade Ambiental } \\ \text { CNI } & \text { Confederação Nacional da Indústria } \\ \text { CF 88 } & \text { Constituição Federal de 1988 } \\ \text { CNPJ } & \text { Cadastro Nacional de Pessoas Jurídicas } \\ \text { Comperj } & \text { Complexo Petroquímico do Rio de Janeiro } \\ \text { Conama } & \text { Conselho Nacional de Meio Ambiente } \\ \text { Consema } & \text { Conselho Estadual do Meio Ambiente } \\ \text { CTF } & \text { Cadastro Técnico Federal } \\ \text { DILIC } & \text { Diretoria de Licenciamento Ambiental } \\ \text { DNPM } & \text { Departamento Nacional de Produção Mineral } \\ \text { EIA } & \text { Estudo de Impacto Ambiental } \\ \text { EIA/RIMA } & \text { Estudo de Impacto Ambiental/Relatório de Impacto } \\ & \text { Ambiental } \\ \text { EIS } & \text { Environmental Impact Statement } \\ \text { EPE } & \text { Empresa de Planejamento Energético } \\ \text { ESMPU } & \text { Escola Superior do Ministério Público da União } \\ \text { EU } & \text { União Europeia } \\ \text { FAP } & \text { Formulário de Solicitação de Abertura de Processo } \\ \text { FCP } & \text { Fundação Cultural Palmares } \\ \text { FEEMA } & \text { Fundação Estadual de Engenharia do Meio Ambiente } \\ \text { FPE } & \text { Fundo de Participação dos Estados } \\ \text { FPM } & \text { Fundo de Participação dos Municípios } \\ \text { Funai } & \text { Fundação Nacional do Índio } \\ \text { IBAMA } & \text { Instituto Brasileiro do Meio Ambiente e dos Recursos } \\ & \text { Naturais Renováveis } \\ \text { IBGE } & \text { Instituto Brasileiro de Geografia e Estatística } \\ \text { ICMBio } & \text { Instituto Chico Mendes de Conservação da } \\ \text { lema ES } & \text { Biodiversidade } \\ \text { IN } & \text { Instituto Estadual de Meio Ambiente e Recursos Hídricos } \\ \text { Inea } & \text { Instrução Normativa } \\ \text { Iphan } & \text { Instituto Estadual do Ambiente do Rio de Janeiro } \\ \text { LC 140/2011 } & \text { Instituto do Patrimônio Histórico e Artístico Nacional } \\ \text { LI } & \text { Lei Complementar 140/2011 } \\ \text { LO } & \text { Licença de Instalação } \\ \text { LP } & \text { Licença de Operação } \\ \text { LSO } & \text { Licença Prévia } \\ & \text { Licença Social para Operar } \\ & \end{array}$




$\begin{array}{ll}\text { LT } & \text { Linha de Transmissão } \\ \text { MJ } & \text { Ministério da Justiça } \\ \text { MMA } & \text { Ministério do Meio Ambiente } \\ \text { MP } & \text { Ministério Público } \\ \text { MPF } & \text { Ministério Publico Federal } \\ \text { MS } & \text { Ministério da Saúde } \\ \text { NEPA } & \text { National Environmental Policy Act } \\ \text { NLA } & \text { Núcleo de Licenciamento Ambiental } \\ \text { OCDE } & \text { Organização para Cooperação e Desenvolvimento } \\ & \text { Econômico } \\ \text { OEMA } & \text { Órgãos Estaduais de Meio Ambiente } \\ \text { OIT } & \text { Organização Internacional do Trabalho } \\ \text { OMS } & \text { Organização Mundial da Saúde } \\ \text { ONGs } & \text { Organizações Não Governamentais } \\ \text { ONU } & \text { Organização das Nações Unidas } \\ \text { OPEX } & \text { Operational Expenditure } \\ \text { PBA } & \text { Plano Básico Ambiental } \\ \text { PL } & \text { Projeto de Lei } \\ \text { PNMA } & \text { Política Nacional do Meio Ambiente } \\ \text { PNUD } & \text { Programa das Nações Unidas para o Desenvolvimento } \\ \text { RIMA } & \text { Relatório de Impacto Ambiental } \\ \text { PUC-RJ } & \text { Pontifícia Universidade Católica do Rio de Janeiro } \\ \text { RL } & \text { Reserva Legal } \\ \text { SAE } & \text { Secretaria de Assuntos Estratégicos da Presidência da } \\ & \text { República } \\ \text { SEA } & \text { Strategic Environmental Assessment } \\ \text { SINDISEP-DF } & \text { Sindicato dos Servidores Públicos Federais do Distrito } \\ & \text { Federal } \\ \text { TCU } & \text { Tribunal de Contas da União } \\ \text { TR } & \text { Termo de Referência } \\ \text { UC } & \text { Unidade de Conservação } \\ \text { UHE } & \text { Usina Hidro Elétrica } \\ \text { USAID } & \text { U.S. Agency for International Development } \\ \text { UTE } & \text { Usina Termo Elétricas }\end{array}$




\section{1}

\section{O Licenciamento Ambiental no Brasil}

O objetivo deste capítulo é apresentar o tema de estudo, justificando e contextualizando o problema, inclusive em relação à linha de pesquisa do curso de pós-graduação em engenharia urbana e ambiental da PUC-RJ.

Adicionalmente será apresentada a metodologia traçada para atender ao objetivo.

\section{1. Introdução}

Muito embora o processo de avaliação dos impactos ambientais tanto no Brasil, como em outros países, já exista a algumas décadas, é possível observar que alguns ajustes vêm sendo realizados, demonstrando dinamismo nas abordagens metodológicas e na legislação. No Brasil a avaliação de impactos ambientais está fortemente inserida nos processos de licenciamento ambiental.

Os processos de licenciamento ambiental são normalmente avaliados em função do seu resultado, ou seja, em função da quantidade de licenças obtidas e do número de condicionantes atendidas, o que seria suficiente se considerarmos que o objetivo do licenciamento é a avaliação prévia da viabilidade socioambiental que um projeto.

No entanto, no caso brasileiro, se transfere para o licenciamento ambiental outras funções que devem ser contempladas para atender as expectativas da sociedade. O sucesso do processo passa, portanto, a ser avaliada em sua forma de condução, avaliando a participação da sociedade e demais órgãos ambientais e intervenientes.

A implantação de grandes empreendimentos em pequenos ou médios municípios causa bastante temor por parte da sociedade e queixas principalmente de ordem socioeconômicas. Isto porque o histórico destes processos tem mostrado que é comum o agravamento de problemas sociais devido ao crescimento demográfico explosivo que leva a elevação do custo de vida e a pressão sobre os equipamentos públicos como, por exemplo, ocorreu em Macaé e Açu no Rio de Janeiro. 
Problemas:

O processo de licenciamento ambiental no Brasil tem se alterado ao longo dos anos? É possível estabelecer relações entre os impactos e programas de várias tipologias a fim de simplificar o processo, partindo da matriz de impacto?

\section{2.}

\section{Objetivos}

\subsection{1.}

Objetivo geral

Avaliar os avanços e dificuldades nos processos de licenciamento ambiental realizados em nível federal no Brasil nos últimos anos

\subsection{2.}

\section{Objetivos específicos}

- Identificar os ritos no processo de licenciamento brasileiro e possíveis alterações temporais que contribuem para seu avanço

- Verificar se há similaridades entre as diferentes tipologias de empreendimentos no que se refere à identificação de impactos e programas

\section{Termos e Variáveis:}

Licenciamentos ambientais e socioambientais serão usados neste estudo como sinônimos, uma vez que o termo ambiental inclui a dimensão física, biótica e antropológica ou socioeconômica.

Neste estudo específico, o foco será em grandes empreendimentos, aqueles com potencial de causar impactos socioambientais significativos, sendo no caso brasileiro, aqueles que por lei, necessitam de um Estudo de Impacto Ambiental EIA e um Relatório de Meio Ambienta - RIMA.

O licenciamento ambiental no Brasil, segundo IBAMA, 2002 é um processo administrativo sistemático das consequências ambientais da atividade que se pretende desenvolver, desde sua fase de planejamento, e das medidas adotadas para seu controle. Incluindo os procedimentos de acompanhamento das licenças 
concedidas, por meio de inspeções e verificações periódicas realizadas pelos órgãos ambientais.

O impacto ambiental é conceituado pela Resolução Conama n. $^{0} 1 / 86$, do Conselho Nacional do Meio Ambiente - CONAMA, em seu artigo $1 .^{\circ}$, da seguinte forma:

Impacto ambiental é qualquer alteração das propriedades físicas, químicas e biológicas do meio ambiente, causada por qualquer forma de matéria ou energia resultante das atividades humanas que, direta ou indiretamente, afetam:

I - a saúde, a segurança e o bem-estar da população;

II - as atividades sociais e econômicas;

III - a biota;

IV - as condições estéticas e sanitárias do meio ambiente;

$\mathrm{V}$ - a qualidade dos recursos ambientais.

Impacto significativo é considerado no sentido de considerável, suficientemente grande e/ou importante.

Os impactos podem ser positivos, negativos ou ambos, a depender do enfoque. Segundo MOTA, 199, p. 220 exemplifica: “... regularização de um rio, evita inundações, mas altera a dinâmica de fertilização das margens,...".

A maioria dos impactos socioeconômicos são indiretos ou difusos, desencadeando uma série de outros impactos fortemente dependentes das vulnerabilidades locais como capital humano e social.

Para definir a mitigação de um impacto consideraremos o que SANCHEZ, 2013, p 384 diz: "medidas mitigadoras são ações propostas com a finalidade de reduzir a magnitude ou a importância dos impactos ambientais adversos. (...) modificações de projeto para evitar ou reduzir impactos adversos também são medidas mitigatórias".

A Resolução CONAMA 01/86, determina que o EIA deve identificar os impactos negativos ao ambiente, mas também art. 6 III “definição de medidas mitigadoras dos impactos negativos, entre elas os equipamentos de controle e sistemas de tratamento de despejos, avaliando a eficiência de cada uma delas". Esse tipo de medida de mitigação era fortemente voltado para os impactos ao meio físico e focado mais para alterações em projetos de engenharia, mesmo que de forma de "end of pipe". 
Já as compensações dos impactos podem ser técnica ou financeira. Exemplos de compensações associadas a impactos são o plantio de espécies frutíferas em outra área para compensar a supressão de espécies nativas, a implantação de tanques de criação de peixes, pelo uso dos corpos hídricos que promovam a redução da possibilidade de pesca e o plantio de "cortina" de árvores para compensar/ mitigar a alteração da paisagem pela construção de edificações.

Compensações devem ser associadas com o impacto, não se tratando de uma mera compensação financeira por um dano inevitável, até porque muitas vezes os danos não são mensuráveis em espécies pecuniárias. Exemplo: Quanto vale ser acordado com o canto de passarinhos, que a necessidade de remoção involuntária para outra área possivelmente não mais permitirá?

\section{3.}

\section{Contextualização}

Nas ultimas décadas, o processo de urbanização no Brasil foi mais acelerado que no restante do mundo já dito desenvolvido. Nas ultimas seis décadas a população das cidades de escassos 15 milhões passou para cerca de 180 milhões de habitantes, formando 20 metrópoles (acima de 1 milhão de habitantes) e duas megalópoles (acima de 10 milhões de habitantes). Este movimento resultou também em um enorme passivo socioambiental, no que se refere à mobilidade, ao saneamento e à moradia, por exemplo.

Enfrentar esse enorme passivo herdado do século passado e que caracteriza nossas cidades faz com que o processo de licenciamento seja ainda mais complexo e abrangente aumentando a expectativa da sociedade para questões que vão além dos objetivos do licenciamento.

Os impactos que um grande empreendimento poderá causar dependerão de aspectos relacionados ao porte do empreendimento e sua característica, mas também das condições sociais, políticas e institucionais dos locais onde se pretende instalar este empreendimento. $\mathrm{O}$ fator local no caso brasileiro é bastante importante uma vez que há déficits de atendimento básico a serviços na grande maioria dos municípios. Trazendo para o processo de licenciamento expectativas, custos, conflitos e demandas não previstas inicialmente. Dificultando o processo, uma vez 
que atores não bem articulados e preparados, não conseguirão chegar a consensos, judicializando os processos.

A cidade que corresponde ao ideário contemporâneo tem na agenda uma democratização das cidades. Isto é, reduzir as gigantescas desigualdades urbanas; garantir que os serviços públicos alcancem todos os cidadãos, que as exigências ambientais sejam consideradas, que se preserve o bom espaço público, o lugar de interação social. O desenvolvimento neste século XXI, inclusive o econômico, só se dará com boas cidades. (Magalhães, 2014, p. 19)

As grandes obras no Brasil tendem a provocar mudanças estruturais nos municípios nos quais elas se instalam e nos arredores. Uma das primeiras mudanças a serem sofridas é o aumento demográfico, por vezes explosivo, de população, mesmo na fase prévia, ou seja, na fase de planejamento e licenciamento prévio, decorrente da expectativa que o empreendimento possa trazer, sem que qualquer estaca tenha sido fincada. Os principais impactos socioeconômicos começam a ocorrer enquanto a viabilidade técnica e econômica ainda está sendo avaliada e os recursos e ações de mitigação estão em estudo.

Frente ao crescimento rápido os gestores dos municípios precisaram se reestruturar e atender as novas obrigações impostas pela Constituição Federal de 1988. A sobrecarga de obrigações, a escassez de recursos, as leis de controle e a pressão da sociedade por serviços fizeram com que os municípios precisassem lidar com o planejamento e a gestão de forma eficiente. No entanto a grande maioria apresenta déficits nestas áreas.

É particularmente nos pequenos e médios municípios, de perfil mais rural, que o anuncio de intensão de implantação de um grande empreendimento pode trazer transformações desde o primeiro momento. As incertezas, a expectativa de crescimento populacional rápido e desordenado, a invasão de mão de obra mais especializada de fora do município e a não absorção da mão de obra local, e dos fornecedores locais, a especulação imobiliária, a piora da qualidade ambiental, a piora no atendimento aos serviços básicos e o aumento do custo de vida, são expectativas comuns que se aplica a muitos processos, quando se trata de um novo empreendimento. 
Segundo MILARÉ, 2007, p. 354

...todo e qualquer projeto de desenvolvimento interfere no meio ambiente, e da mesma forma, certo que o crescimento socioeconômico é um imperativo, insta, pois discutir os instrumentos e mecanismos que os conciliem, minimizando quanto possível os impactos ecológicos negativos e, consequentemente, os custos econômicos e sociais.

O histórico de implantação de empreendimento colabora para as expectativas negativas quanto ao real poder de alavancagem e promoção de desenvolvimento de um novo empreendimento em municípios fragilizados institucionalmente, já com déficits na prestação de serviços essenciais e fiscalização e com poucos recursos.

Para alterar este quadro seria necessário que os municípios conseguissem absorver em reduzido espaço de tempo estas alterações, e implementassem com eficácia um novo planejamento municipal, captando e destinando recursos em infraestrutura e serviços e fiscalização que minimize os efeitos adversos.

As exigências legais para o licenciamento, notadamente a obrigatoriedade de elaboração de um EIA/RIMA quando o empreendimento tem potencialidade para causar impactos ambientais significativos, não tem acompanhado os anseios e preocupações da sociedade, fazendo com que uma série de estudos complementares e ações sejam necessárias para que principalmente os impactos socioeconômicos sejam mitigados ou potencializados.

Para o desenvolvimento de uma região, está superada a ideia de que bastava a implantação de um empreendimento que trouxesse emprego e renda, e, portanto ganhos econômicos. Após a tentativa, embora frustrada na maioria dos municípios brasileiros de implantação de uma agenda 21 local, o que se almeja é um desenvolvimento sustentável.

Sendo o licenciamento ambiental o único instrumento da Politica Nacional de Meio Ambiente que foi implementado efetivamente, a expectativa de que ele solucione demandas que não pertencem ao seu escopo é enorme e pode levar a frustações e descredito do processo de licenciamento.

Características locais como capital humano, social, institucional, físico e cultural, interfere de forma decisiva para a mitigação dos impactos negativos e potencialização dos positivos. 
Embora a realidade dos municípios brasileiros seja bastante diversas em termos de dificuldade de gestão, captação de recursos e apoio institucional, algumas características podem ser comuns aos 5567 municípios, variando apenas em intensidade.

Sem a coordenação e participação de todos os agentes envolvidos, principalmente os locais, quando da instalação do empreendimento a maior parte dos danos e expectativas da ordem ambiental e social já terão sido deflagrados quando o empreendimento chegar para se instalar.

No processo de licenciamento com subsidiariedade, ou seja, mais próximo de onde se pretende instalar o empreendimento, possui a vantagem da proximidade e, portanto maior sensibilidade e participação pública para avaliação dos impactos e expectativas, mas por outro lado, tem maior chance de sofrer pressões políticas e atender a interesses de grupos específicos.

O processo de licenciamento ambiental no Brasil é visto como bastante rigoroso e burocrático, porém não tem se mostrado suficiente para a aprovação por parte da comunidade envolvida nos novos empreendimentos. Uma série de estudos e ações são cada vez mais demandados em conjunto com o processo formal de licenciamento ambiental, são as chamadas "licença social para operar" exigindo uma análise territorial mais profunda e um processo de negociação com as partes envolvidas, sem que seja institucionalizado por leis ou regulamentos.

Outra questão também bastante levantada sobre o processo de licenciamento ambiental no Brasil se refere ao tempo longo para obtenção de licenças e os altos custos dos estudos.

ANTUNES, 2007, p 223 observa que "(...) entidades empresariais..., com frequência, tem se manifestado contrariamente à "lentidão" do licenciamento ambiental,...".

Segundo MILARÉ, 2009 p 369:

O EIA não pode ser um entrave à liberdade de empreender, pois Política Nacional do Meio Ambiente tem como objetivo, "compatibilização do desenvolvimento econômico-social com a preservação da qualidade do meio ambiente e do equilíbrio ecológico". Por seu alto custo e complexidade, o EIA deve ser usado com parcimônia e prudência, de preferencia para os projetos mais importantes sob a ótica ambiental.

O desenvolvimento de uma região não se dá apenas com investimentos financeiros que levam ao crescimento econômico e a ação dos gestores públicos na 
promoção da infraestrutura. A participação efetiva da sociedade é primordial para o desenvolvimento de uma região.

\section{Motivação do Estudo}

O processo de licenciamento ambiental no Brasil tem sido criticado pelos diversos atores envolvidos.

Enquanto impactos ao meio físico e biótico geram menos conflitos na identificação e na proposição de medidas, os associados ao meio socioeconômico muitas vezes despertam conflitos, de difícil resolução que tem levado os processos a judicialização.

Os processos seguem um rito bem regularizado no que se refere à quantidade de leis, decretos, resoluções e instruções normativas, mas carecem de transparência no que se referem aos demais interesses, principalmente aqueles que só atenderão a um grupo específico e não necessariamente a coletividade. Carecem da mesma forma de uma maior articulação entre instituições de governo para a resolução de problemas pré-existentes que podem em muito serem agravados pela implantação de um grande empreendimento sem o devido planejamento e estruturação.

Não são poucos os recursos envolvidos no processo inicial de um licenciamento no Brasil, nem são processos rápidos, mas por outro lado não parecem ser capaz de mitigar os impactos, até porque o monitoramento pósimplantação e a retroalimentação para a melhoria do processo não tem acontecido da forma como deveria. Reforçando-se assim a percepção de que se trata de um processo formal em que o interesse é o resultado final - licenças e condicionantes, e não efetivamente o processo participativo e consensual da sociedade e com o menor impacto negativo possível.

As mudanças no processo de licenciamento ambiental brasileiro podem ser avaliadas sob os seguintes aspectos:

- Estatístico (licenças emitidas ou recusadas e numero de condicionantes)

- Resultado (capacidade de mitigação e/ou compensação dos impactos pelos programas propostos)

- Percepção (conforto da sociedade em relação à implantação do empreendimento) 
Sendo o licenciamento ambiental o único instrumento da Politica Nacional de Meio Ambiente efetivamente implantado, recai sobre ele uma série de atribuições que ele não tem condições de resolver.

$\mathrm{Na}$ tentativa de resolver algumas expectativas e demandas, muitas vezes, ações e programas não associados aos impactos diretos são incluídos no processo de licenciamento, aumentando seu custo e dificultando a previsibilidade das demandas e condicionantes.

A geração de empregos e arrecadações tributárias diretas (impactos socioeconômicos positivos) só começam a ocorrer em média de 5 a 10 anos após o anuncio do empreendimento. E neste meio tempo é necessário que o poder público reveja seu planejamento urbano para uma nova realidade e encontre outros meios de atender as demandas crescentes nos serviços públicos e não necessariamente embutindo ao empreendedor, que a depender do "custo brasil" pode decidir não investir.

Estudos que avaliem a capacidade de uma localidade em suportar um grande empreendimento, como os estudos de Avaliação Ambientais Estratégicas são realizados em outros países e em alguns casos no Brasil.

Os municípios e a sociedade precisam avaliar e aceitar e, se for o caso, se ajustar aos empreendimentos com os ganhos e as perdas e dentre elas está o crescimento populacional e transformações decorrentes que ocorrerão. O incremento de arrecadação e maior participação nos recursos estaduais e federais Fundo de Participação Estadual-FPE e Fundo de Participação Municipal - FPM que são proporcionais ao tamanho populacional, precisam ser avaliados frente a real capacidade de sanar déficits em serviços básicos já preexistentes e que podem se intensificar.

Não há vantagem para o empreendedor em se instalar em um município com grandes déficits sociais, pois a partir da sua inserção territorial podem ser atribuídos ao empreendimento reclamações da comunidade e também de seus funcionários, em função da qualidade dos serviços públicos e tecidos sociais. É bastante prejudicial para a imagem da empresa e em termos de investimentos, além de dificultar a retenção de mão de obra especializada.

Pertinência do tema - justificativa do ponto de vista científico e de aplicação para a sociedade 
A avaliação de impacto ambiental, que se pretende abordar neste estudo, tem o potencial de ligar projetos de engenharia com a proteção ambiental e ao desenvolvimento social quando usado para aperfeiçoar as intervenções desde a sua concepção.

No Brasil, o licenciamento é extremamente relevante, pois a implantação de empreendimentos de grande porte de forma sustentável é de interesse de toda a sociedade.

Muito já foi discutido sobre possíveis melhoras no processo e algumas já foram implementadas. Ao se estudar especificamente, por meio de estudo de caso, 35 processo de diferentes tipologias é esperado que algumas melhorias ou encaminhamentos possam ser apresentados, ou algumas ações reforçadas como o aprimoramento do processo por meio da legislação e procedimentos já existentes e a avaliação da necessidade de outros procedimentos para aumentar a satisfação da sociedade na implantação de grandes empreendimentos.

\section{Alinhamento com as linhas de pesquisa do curso}

O tema se torna pertinente para o curso de Pós-graduação em Engenharia Urbana e Ambiental do departamento de Engenharia Civil da Pontifícia Universidade Católica do Rio de Janeiro dentro da linha de pesquisa de Planejamento e Sustentabilidade, uma vez que o processo de licenciamento ambiental não é meramente uma autorização para um projeto, mas sim uma licença que atesta a viabilidade socioambiental de um determinado empreendimento buscando a compatibilidade de múltiplos interesses de cunho econômico, político, ambiental, social e cultural que pode interferir e provocar modificações profundas em determinados ambientes urbanos, unindo assim as questões associadas ao licenciamento socioambiental com a ocupação territorial. Embora o licenciamento ambiental seja um processo administrativo, o desenrolar e as consequências são permanentes para os espaços urbanos e interferem na sociedade como um todo. 


\section{4. \\ Delimitação do estudo}

Embora a participação pública, as relações sociais e os múltiplos interesses sejam extremamente importantes tanto no licenciamento de empreendimentos como no planejamento e uso urbano, não será um ponto no qual aprofundaremos neste trabalho.

Particularmente os pequenos e médios municípios têm mais dificuldades, pela menor experiência de arrecadação, de planejamento, de atendimento aos serviços básicos e de articulação entre demais entes e órgãos, sendo estes os que priorizaremos neste estudo, evitando-se os municípios em regiões metropolitanas, assim ditos periféricos, pela influência que podem ter dos grandes centros.

Os empreendimentos considerados neste estudo serão aqueles que necessitam de um EIA/RIMA para seu licenciamento, em função do potencial impacto.

\section{5. Metodologia}

Será realizada uma pesquisa em caráter exploratório, com base no conteúdo de análises documentais e estudo de caso de processos de licenciamentos ambientais no Brasil.

A análise teórica é composta pelo levantamento bibliográfico e da legislação vigente.

Nesta etapa do estudo, será realizado um levantamento bibliográfico em livros, teses, periódicos e manuais, dos fundamentos teóricos relacionados aos temas relevantes para o estudo. Serão pesquisados documentos com o enfoque em: Avaliação de Impacto Ambiental AIA, Licenciamento Ambiental; Estudo de Impacto Ambiental e seu Relatório EIA/RIMA e Impactos e Programas Socioambientais.

Uma vez identificado o histórico do processo de avaliação de impacto ambiental, sua relação com o processo de licenciamento brasileiro, a legislação, os ritos do processo e aspectos mais práticos, um estudo de caso será utilizado para analise mais detalhada das diferenças temporais e por tipologia dos impactos e programas propostos.

A metodologia do Estudo de Caso será detalhada no Capitulo 4 
A dissertação de mestrado está dividida em 5 capítulos, assim identificados.

Capitulo 1 - Introdução, metodologia e justificativa

Capitulo 2 - Levantamento documental e legal

Capitulo 3 - o processo de licenciamento e sua avaliação

Capítulo 4 - Estudo de Caso e resultados

Capítulo 5 - Conclusões e Recomendações

Como conclusão do capitulo 1 temos que o processo de licenciamento e a avaliação de impacto precisam ser avaliados quanto aos seus objetivos a fim de atender as expectativas da sociedade, sob o risco de se tornar um processo meramente burocrático e desacreditado.

Mostrou-se necessário verificar como os demais países lidam com a avaliação de impacto e as demais expectativas e demandas da sociedade, uma vez que mesmo em contextos históricos e institucionais diferentes, podem ajudar a entender o processo brasileiro. 


\section{2 \\ Histórico da Avaliação de Impacto Ambiental AIA - Cenário Internacional}

O objetivo deste capítulo 2 é levantar o histórico da aplicação da Avaliação de Impacto Ambiental.

Para contextualizar a Avaliação Impacto Ambiental AIA e o licenciamento ambiental no Brasil é necessário recorrer ao cenário internacional pela sua influencia.

\section{1.}

\section{Histórico e Legislação}

Segundo SANCHEZ, 2013 p. 48 a formulação da AIA ocorreu pela primeira vez nos Estados Unidos, em 1969. Conhecida como NEPA National Environmental Policy Act, a lei entrou em vigor no dia $1^{\circ}$ de janeiro de 1970. Estava voltada para as agências do governo federal que deveriam utilizar uma abordagem sistemática e interdisciplinar nas tomadas de decisões e planejamentos em projetos que poderiam ter um impacto sobre o ambiente humano.

A instituição criada pelo NEPA, o Council on Environmental Quality- CEQ, publicou em $1^{\circ}$ de agosto de 1973 , suas diretrizes para a elaboração e apresentação do environmental impact statement -EIS, que corresponde ao Estudo de Impacto Ambiental EIA, no Brasil.

Segundo ANTUNES, 2014, p. 587:

... os EUA são a nação que mais "exportou" a sua legislação de proteção ambiental para outras terras. .... A NEPA é uma lei fundamental para o direito ambiental dos Estados Unidos, sobretudo em razão de sua reprodução pelos estados e pelo que influenciou na produção legislativa de outros países, dentre os quais o Brasil.

A adoção da AIA em seguida pelas ex-colônias britânicas, como o Canadá e Nova Zelândia em 1973 foi facilitada em função do sistema jurídico e político serem semelhante ao dos Estados Unidos e à similaridade de seus problemas ambientais decorrentes do estilo de desenvolvimento adotado. Sendo os primeiros países a adotarem políticas determinando que a avaliação dos impactos ambientais devesse preceder decisões governamentais importantes. (Sanchez 2012) 
A França foi o primeiro país da Europa a adotar a avaliação de impacto ambiental por meio de duas leis de 1976, no entanto seu sistema jurídico e organização administrativa eram muito diferentes dos Estados Unidos. A AIA foi adotada na França como uma modificação no sistema de licenciamento/ autorização governamental para indústrias e outras atividades que possam causar impactos. Os estudos de impacto ambiental deveriam ser feito pelo próprio interessado, sendo ele público ou privado. (Sanchez 2012)

Um aspecto relevante da AIA na França é que os procedimentos instituídos em 1976 introduziram uma nova exigência - a apresentação previa de estudo de impacto- a um processo de licenciamento que já vigorava para algumas atividades desde 1917. Mesmo procedimentos de consulta pública já existiam para obras que necessitassem de um decreto de utilidade pública para fins de desapropriação.

DESPAX 1980, apud ANTUNES, 2014, p. 591 afirmou que "uma das “importações jurídicas” das mais felizes ocorridas na França foi à exigência dos estudos de impacto ambiental, que segundo ANTUNES, 2014, p. 591 se trata de um reconhecimento da marcante influência da NEPA na legislação francesa".

Não obstante, uma das diferenças entre os países é que enquanto na França a AIA estava mais focada em projetos, nos Estados Unidos estava mais voltado para políticas e programas.

As dificuldades de adaptação da diretiva europeia ao ordenamento jurídico de cada país-membro decorreram da existência anterior, nesses países, de exigências de planejamento territorial e de controle de poluição, que precisaram ser modificadas para incorporar o novo instrumento sem que fossem postas em risco as garantias representadas por essas leis. (Sanchez 2012)

A difusão da AIA para outros países desenvolvidos continuou durante a década de 1990, como pode ser verificado no Quadro 1, alcançando o Japão e Hong Kong - então colônias britânicas e depois a China. Ao mesmo tempo em países onde a prática já era bem estabelecida, como o Canadá, Austrália e Nova Zelândia, os processos foram fortalecidos por meio da criação de leis ou reformas de procedimentos. (Sanchez 2012) 
Quadro 1 - Marcos da Introdução da AIA em alguns países desenvolvidos selecionados

(Continua)

\begin{tabular}{|c|c|c|}
\hline Jurisdição & $\begin{array}{c}\text { Ano de } \\
\text { Introdução }\end{array}$ & Principais Instrumentos Legais \\
\hline $\begin{array}{l}\text { Estados } \\
\text { Unidos da } \\
\text { América }\end{array}$ & 1970 & $\begin{array}{l}1970 \text {-NEPA National Environmental Policy Act. Voltada } \\
\text { para as agências do governo federal que deveriam utilizar } \\
\text { uma abordagem sistemática e interdisciplinar nas tomadas } \\
\text { de decisões e planejamentos em projetos que poderiam ter } \\
\text { um impacto sobre o ambiente humano. } \\
1973 \text { Diretrizes para a elaboração e apresentação do } \\
\text { environmental impact statement -EIS. }\end{array}$ \\
\hline Canadá & 1973 & $\begin{array}{l}\text { Decisão do Conselho de Ministros de estabelecer um } \\
\text { processo de avaliação e exame ambiental em } 20 \text { de } \\
\text { dezembro de } 1973 \text {, modificado em } 15 \text { de fevereiro de } \\
1977 \text {. } \\
\text { Decreto sobre as diretrizes do processo de avaliação e } \\
\text { exame ambiental em } 22 \text { de junho de } 1984 \text {. } \\
\text { Lei Canadense de Avaliação Ambiental, sancionada em } \\
23 \text { de junho de } 1992 \text {. }\end{array}$ \\
\hline $\begin{array}{l}\text { Nova } \\
\text { Zelândia }\end{array}$ & 1973 & $\begin{array}{l}\text { Procedimentos de proteção e melhoria ambiental de } 1973 \\
\text { Lei de Gestão de Recursos de julho de } 1991\end{array}$ \\
\hline Austrália & 1974 & $\begin{array}{l}\text { Lei de Proteção Ambiental (Impactos de Propostas), de } \\
\text { dezembro de 1974, modificada em } 1987 . \\
\text { Lei de Proteção Ambiental e Proteção da Biodiversidade } \\
\text { de } 1999\end{array}$ \\
\hline França & 1976 & $\begin{array}{l}\text { Lei } 629 \text { de Proteção da Natureza, de } 10 \text { de julho de } 1976 . \\
\text { Lei } 663 \text { sobre as Instalações Registradas para a Proteção } \\
\text { do Ambiente, de } 19 \text { de julho de } 1976 \text {. } \\
\text { Decreto } 1.133 \text {, de } 21 \text { de setembro de } 1977 \text {, sobre } \\
\text { instalações registradas. } \\
\text { Decreto1. } 141 \text {, de } 12 \text { de outubro de } 1977 \text {, para aplicação } \\
\text { da Lei de Proteção da Natureza } \\
\text { Lei } 630 \text {, de } 12 \text { de julho de } 1983 \text {, sobre a democratização } \\
\text { das consultas públicas. }\end{array}$ \\
\hline $\begin{array}{l}\text { União } \\
\text { Europeia }\end{array}$ & 1985 & $\begin{array}{l}\text { Diretiva } 85 / 337 / \mathrm{EEC} \text {, de } 27 \text { de junho de } 1985 \text {, sobre a } \\
\text { avaliação dos efeitos ambientais de certos projetos } \\
\text { públicos e privados. } \\
\text { Modificada pela Diretiva } 97 / 11 / \mathrm{EC} \text {, de } 3 \text { de março de } \\
1997 \text {. }\end{array}$ \\
\hline
\end{tabular}


Quadro 1 - Marcos da Introdução da AIA em alguns países desenvolvidos selecionados

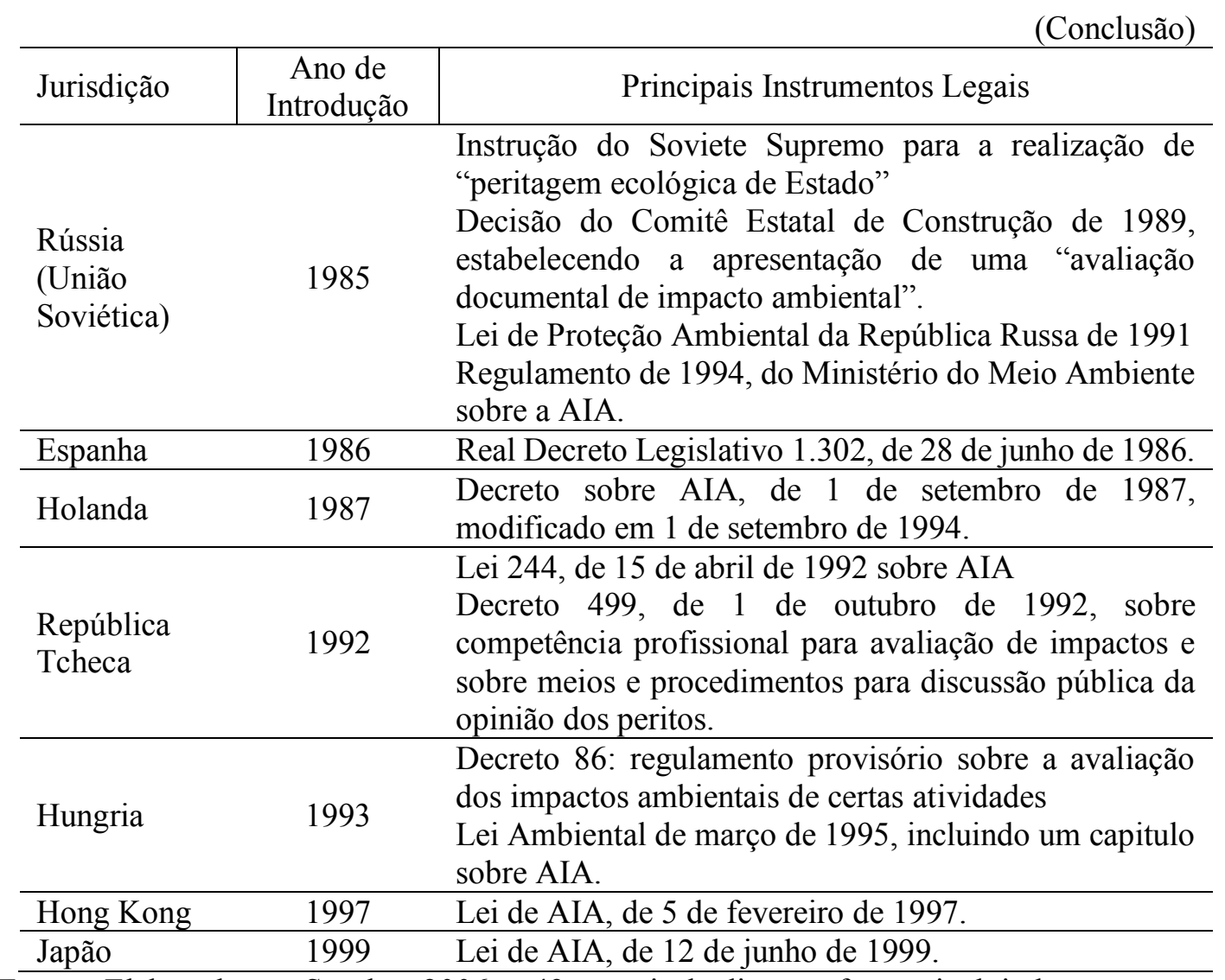

Fontes: Elaborado por Sanchez 2006 p. 49 a partir de diversas fontes, incluindo prospectos editados por organismos governamentais, sites governamentais e Bellinger ET AL. (2000).

\section{O papel das Agencias de Fomento ao Desenvolvimento}

A lei americana de cooperação para o desenvolvimento (Foreign Assistence $A c t$ ) foi modificada em 1978 e passou a impor a necessidade formal de preparação de estudos de impacto ambiental para os projetos de cooperação (Runnals, 1986).

As agências de fomento ao desenvolvimento, como a U.S. Agency for International Development (USAID) e suas congêneres dos países da OCDE (Organização para Cooperação e Desenvolvimento Econômico), assim como as agências multilaterais, que são os bancos de desenvolvimento, como o Banco Mundial e o Banco Interamericano de Desenvolvimento (BID) tiveram um importante papel na adoção do instrumento de AIA nos países da América Latina e da África. (Sanchez 2012)

Outra recomendação do Conselho da OCDE, aprovada em 23 de outubro de 1986, conclamava os países-membro a assegurarem a provisão de recursos humanos e financeiros para os países em desenvolvimento que desejem melhorar sua capacidade para realizar avaliações ambientais. 
Com estas medidas, não só muitos projetos foram avaliados individualmente, mas houveram programas de cooperação voltados especificamente ao fortalecimento institucional e a formação de recursos humanos envolvidos em avaliação ambiental nos países em desenvolvimento.

Os Bancos de Desenvolvimento também começaram a adotar, por pressão da sociedade de países desenvolvidos, estudos de avaliação de impacto ambiental, no fomento ao desenvolvimento em países não desenvolvidos. Desta forma, mesmo países em desenvolvimento, que não tinham legislação específica, foram submetidos a esta análise em projetos, criando a cultura de estudos que depois levaria a uma legislação sobre o tema AIA. (Sanchez 2012)

\section{AIA nos Países em Desenvolvimento}

Os países em desenvolvimento também passaram a adotar leis sobre a avaliação de impacto ambiental, uma vez que estavam diretamente envolvidos através dos tratados e dos financiamentos. A implantação na forma de leis da AIA em países em desenvolvimento pode ser verificada no Quadro 2.

Quadro 2 - Marcos da institucionalização da AIA em alguns países em desenvolvimento

(Continua)

\begin{tabular}{|c|c|c|}
\hline Jurisdição & $\begin{array}{c}\text { Ano de } \\
\text { Introdução }\end{array}$ & Principais Instrumentos Legais \\
\hline Colômbia & 1974 & $\begin{array}{l}\text { Código Nacional de Recursos Naturais Renováveis e de } \\
\text { Proteção do Meio Ambiente, de } 18 \text { de dezembro de } 1974 \text {. } \\
\text { Lei } 99 \text { de } 1993 \text { sobre licenças ambientais e decreto } \\
\text { regulamentador } 2.820 \text { de } 2010\end{array}$ \\
\hline Filipinas & 1978 & $\begin{array}{l}\text { Decreto sobre Política Ambiental } \\
\text { Decreto sobre Sistema de Estudos de Impacto Ambiental, } \\
\text { de } 1978 \text {. } \\
\text { Regulamentos sobre EIAs do Conselho Nacional de } \\
\text { Proteção Ambiental, de } 1979 \text {. }\end{array}$ \\
\hline China & 1979 & $\begin{array}{l}\text { "Lei "Provisória" de Proteção Ambiental, revista e } \\
\text { promulgada em } 26 \text { de dezembro de } 1989 \text {. } \\
\text { Decreto de } 1981 \text { sobre Proteção Ambiental de Projetos de } \\
\text { Construção, modificado em } 1986 \text { e em } 1998 \text {. } \\
\text { Decreto de } 1990 \text { sobre procedimentos de AIA } \\
\text { Lei de Avaliação de Impacto Ambiental, de } 28 \text { de outubro } \\
\text { de } 2002 \text {, em vigor desde setembro de } 2003 \text {. }\end{array}$ \\
\hline Brasil & 1981 & $\begin{array}{l}\text { Lei da Política Nacional do Meio Ambiente de } 31 \text { de } \\
\text { agosto de } 1981 \\
\text { Resolução Conama } n^{\circ} 1 \text { detalha os estudos de impacto } \\
\text { ambiental de empreendimentos, de } 23 \text { de janeiro de } 1986 \text {. }\end{array}$ \\
\hline
\end{tabular}


Quadro 2 - Marcos da institucionalização da AIA em alguns países em desenvolvimento

(Conclusão)

\begin{tabular}{|c|c|c|}
\hline Jurisdição & $\begin{array}{c}\text { Ano de } \\
\text { Introdução }\end{array}$ & Principais Instrumentos Legais \\
\hline México & 1982 & $\begin{array}{l}\text { Lei Federal de Proteção Ambiental, de } 1982 \text {. } \\
\text { Lei geral do equilíbrio Ecológico e da Proteção do } \\
\text { Ambiente, de } 28 \text { de janeiro de } 1988 \text {. } \\
\text { Regulamento de } 30 \text { de maio de } 2000\end{array}$ \\
\hline Indonésia & 1986 & $\begin{array}{l}\text { Lei de Provisões Básicas para Gestão Ambiental, de } 1982 . \\
\text { Regulamento } 29 \text { de 1986, sobre análise de impacto } \\
\text { ambiental, modificado pelo Regulamento } 51 \text {, de } 1993 \text { e } \\
\text { pelo regulamento 27, de 1999, incluindo mecanismos de } \\
\text { participação pública. }\end{array}$ \\
\hline Malásia & 1987 & $\begin{array}{l}\text { Lei de } 1985 \text {, que modifica a Lei de Qualidade Ambiental } \\
\text { de } 1974 . \\
\text { Decreto sobre Qualidade Ambiental (Atividades } \\
\text { Controladas) } 1987\end{array}$ \\
\hline $\begin{array}{l}\text { África do } \\
\text { Sul }\end{array}$ & 1991 & $\begin{array}{l}\text { Art. } 39 \text { da Lei de Mineração de } 1991 \\
\text { Lei de Conservação Ambiental de } 1989 \text { e Regulamento } \\
\text { sobre Avaliação de impacto Ambiental, d } 1^{\text {0 }} \text { de setembro } \\
\text { de } 1997 . \\
\text { Lei Nacional de Gestão Ambiental de } 2006 \text { e regulamentos } \\
\text { subsequentes; última modificação em } 18 \text { de junho de } 2010 \text {. }\end{array}$ \\
\hline Tunísia & 1991 & $\begin{array}{l}\text { Decreto de } 13 \text { de março de } 1991 \text { sobre os estudos de } \\
\text { impacto ambiental }\end{array}$ \\
\hline Bolívia & 1992 & $\begin{array}{l}\text { Lei } n^{\circ} 1.333 \text { de } 27 \text { de abril de } 1992 \text { sobre os estudos } \\
\text { Decreto } 24.176 \text { de } 1996\end{array}$ \\
\hline Chile & 1994 & $\begin{array}{l}\text { Lei de Bases do Meio Ambiente, de } 3 \text { de março de } 1994 . \\
\text { Regulamento do Sistema de Avaliação de Impacto } \\
\text { Ambiental, de } 3 \text { de abril de 1997, modificado em } 7 \text { de } \\
\text { dezembro de } 2002 \text {. }\end{array}$ \\
\hline Uruguai & 1994 & $\begin{array}{l}\text { Lei } 16.246 \text {, de } 8 \text { de abril de } 1992 \text {, requer AIA para } \\
\text { atividades portuárias. } \\
\text { Lei de Prevenção e AIA } 16.466 \text {, de } 19 \text { de janeiro de } 1994 . \\
\begin{array}{l}\text { Decreto 435/994, de } 21 \text { de setembro de } 1994 \\
\text { (regulamento). }\end{array}\end{array}$ \\
\hline Bangladesh & 1995 & $\begin{array}{l}\text { Lei de Conservação Ambiental de } 1995 \\
\text { Regras de Conservação Ambiental de } 1997\end{array}$ \\
\hline Moçambique & 1997 & $\begin{array}{l}\text { Lei do Ambiente de } 7 \text { de outubro de } 1997 \\
\text { Decreto } 45 \text { de } 29 \text { de setembro de } 2004 \text { que regulamenta o } \\
\text { processo de AIA }\end{array}$ \\
\hline Angola & 1998 & $\begin{array}{l}\text { Lei de Bases do ambiente de } 19 \text { de junho de } 1998 \\
\text { Decreto } 51 \text { de } 23 \text { de julho de } 2004 \text { sobre AIA }\end{array}$ \\
\hline
\end{tabular}

Fonte: Sanchez 2012, elaborado a partir sites governamentais e Ahammed e Harvey (2004), Mao e Hills (2002), Memon (2000) e Purnama 2003) e Zhu e Lam (2010).

Um ponto fundamental, segundo SANCHEZ 2013, é que a AIA é um instrumento que não nasceu pronto, mas uma ideia a ser desenvolvida.

Se por um lado a AIA resultou de um processo político que buscou atender a uma demanda social, que estava mais madura nos Estados Unidos no final dos anos 
1960. Por outro lado, a AIA evoluiu ao longo do tempo e foi modificada conforme lições são aprendidas na experiência prática.

$\mathrm{O}$ arcabouço legal nos Estados Unidos se modificou e adaptou-se conforme foi aplicado em outros contextos culturais e políticos, mas sempre dentro do objetivo primário de prevenir a degradação ambiental e de subsidiar um processo decisório, para que as consequências sejam apreendidas antes mesmo de cada decisão ser tomada.

Segundo MILARÉ, 2007, embora alguns documentos não possuam autoridades jurídicas strito sensu, revestem-se de uma autoridade de outra natureza. É o que se passa com textos oficiais da Organização das Nações Unidas (ONU) e de suas agências (PNUD, OMS, OIT e outras). Há documentos, como convenções e tratados que implicam determinado grau de obrigatoriedade, na medida em que são formalmente subscritos por governos, no todo ou em parte.

A Declaração do Rio e a Agenda 21 são documentos cuja preparação requereu intensas negociações internacionais, inclusive com a participação de ONGs e outros grupos de interesse.

A Declaração do Rio estabelece em seu princípio 17, a aplicação da AIA como instrumento nacional, sempre que atividade proposta tenha possibilidade de causar impacto adverso significativo.

$\mathrm{Na}$ linguagem da Agenda 21, as considerações ambientais abrem caminho para o tratamento de questões socioeconômicas, e vice-versa.

Durante o período preparatório da Conferencia do Rio e nos anos que se seguiram, novos países incorporaram a AIA em suas legislações, principalmente na América Latina, na África e na Europa Oriental. (Sanchez 2012)

Portanto, além das leis nacionais e subnacionais, a AIA é promovida por inúmeros documentos de âmbito internacional, que preconizam seu uso, voluntário ou obrigatório, para diferentes finalidades de planejamento ou auxilio a decisão. Cada vez mais a AIA vem atender a uma necessidade de estabelecer mecanismos de controle social e de decisão participativa acerca de projetos e iniciativas de desenvolvimento econômico. (Sanchez 2012)

Quando da realização do encontro em Estocolmo, em 1972, existiam apenas 11 órgãos ambientais nacionais, a maioria em países industrializados. Em 1981, já eram 106 órgãos ambientais, a maioria em países em desenvolvimento. Em 1991, 
praticamente todos os países dispõem de algum tipo de instituição similar (Monosowski, 1993, p.3).

Atualmente, quase a totalidade dos países em desenvolvimento tem leis nacionais que exigem a preparação prévia de estudos de impacto ambiental. O processo de difusão e consolidação da AIA continua, mesmo após a adoção de leis nacionais. Cerca de duas centenas de países incorporam às suas legislações nacionais provisões requerendo a avaliação prévia dos impactos ambientais. Somam-se os procedimentos formais seguidos pelas agencias bi e multilaterais de desenvolvimento, pode-se afirmar que a AIA é hoje universalmente empregada. (Sanchez 2012)

\section{A AIA no Brasil}

Os primeiros estudos ambientais preparados no Brasil foram realizados para alguns grandes projetos hidrelétricos durante os anos 1970, com demandas originárias no exterior. (Sanchez 2009).

A atuação de agentes financeiros multilaterais e de outras organizações internacionais teve um papel central na adoção da metodologia de Avaliação de Impacto Ambiental AIA por muitos países em desenvolvimento, porém foram condições internas que propiciaram uma acolhida mais ou menos favorável para que se pusessem em prática os princípios de prevenção e precaução inerente a AIA (Milaré 2007 pág. 67).

A década de 1970 no Brasil foi marcada pelo significativo crescimento da atividade econômica e pela expansão das fronteiras econômicas internas. A expansão econômica e territorial foi impulsionada por investimentos governamentais de grande monta em projetos de infraestrutura, tais como a rodovia Transamazônica, a barragem de Itaipu, e o Grande Projeto Carajás.

Nesta mesma época, os estados de São Paulo e Rio de Janeiro editaram leis e instituíram órgãos para controlar a poluição, notadamente das águas e do ar, realizando o licenciamento ambiental descentralizado como instrumento do controle de poluição e zoneamento industrial. Essas leis levaram a interdição de algumas fábricas importantes e o Governo Federal, em pleno regime militar, respondeu autoritariamente com um decreto-lei 1.413 de 14 de agosto de 1975, 
proibindo estados e municípios de interditar indústrias, reservando esse ato ao Presidente da República. (Milare 2007, p. 309)

Foi uma conjunção de fatores internos e externos, segundo Pádua 1991, que propiciou um avanço das políticas ambientais no Brasil e acabou levando o poder Executivo a formular o projeto de lei sobre Política Nacional do Meio AmbientePNMA, aprovado pelo Congresso em 31 de agosto de 1981 e que incluía a avaliação de impacto ambiental como um dos instrumentos para atingir os objetivos dessa lei. (Sanchez 2012 p. 66)

Durante as décadas de 1970 e de 1980, apesar das restrições à democracia impostas pelo governo militar, o movimento ambientalista foi paulatinamente se firmando e legitimando seu discurso (Silva- Sanchez 2010; Viola, 1987, 1992), tendo os impactos socioambientais dos grandes projetos estatais e privados como um dos focos da crítica ao modelo de desenvolvimento adotado, visto como socialmente excludente e ecologicamente destrutivo (Lutzemberger 1980; Sanchez 1983)

Segundo MILARÉ, 2007, p. 355

Inspirada no direito americano (National Environmental Policy Act- Nepa de 1969), a Avaliação de Impacto Ambiental foi introduzida em nosso Direito positivo, de forma tímida, pela Lei 6.803, de 02.07.1980, que "dispõe sobre as diretrizes básicas para o zoneamento industrial nas áreas críticas de poluição".

$\cdots$

A partir da mobilização social que se assistiu no Brasil na década de 80 , principalmente com o surgimento do movimento ambientalista e no apagar das luzes do regime autoritário, ganha a AIA nova função e amplitude através da Lei 6.938 de 31.08 .1981 .

Em termos de institucionalização, a avaliação de impacto ambiental chegou ao Brasil por meio das legislações estaduais do Rio de Janeiro e de Minas Gerais, adiantando-se à legislação federal. (Sanchez 2012)

A origem da AIA no Rio de Janeiro está ligada à implementação de um sistema estadual de licenciamento de fontes de poluição em 1977 (Moreira, 1988), que atribuiu à Comissão Estadual de Controle Ambiental (Ceca) a possibilidade de estabelecer os instrumentos para a análise dos pedidos de licenciamento.

Entre 1980 e 1983 houve um programa de capacitação dos técnicos da Feema, com a assistência do Programa das Nações Unidas para o Meio Ambiente, que incluiu intercâmbios internacionais. 
A Política Nacional de Meio Ambiente, estabelecida pela Lei 6.938 de 1981, que incorporou os conceitos da AIA, estabeleceu a criação do Conama, Conselho Nacional de Meio Ambiente, que por meio de suas Resoluções estabeleceria a forma da regulamentação da AIA, definindo escopo mínimo dos estudos de impactos ambientais e listando os empreendimentos que estariam sujeitos a estes estudos.

\section{2.}

\section{AIA e EIA}

A Política Nacional de Meio Ambiente PNMA (Lei 6.938/81) estabeleceu em seu art. $9^{\circ}$ que os instrumentos da política, entre outros, são:

- A avaliação de impactos ambientais;

- O licenciamento e a revisão de atividades efetivas ou potencialmente poluidoras.

A avaliação de impactos ambientais seria o estudo aprofundado da qualidade ambiental de um bioma, de um ecossistema, de uma empresa ou de um país, que pode ser realizado tanto pelo poder público quanto pela iniciativa privada, podendo ocorrer dentro ou fora de um processo administrativo de licenciamento ambiental.

Segundo MILARÉ, 2007, p 356:

O Decreto 88.351, de 01.06.1983 - depois substituído pelo Decreto 99.274/1990 - ao regulamentar a Lei 9.638/1981, vinculou a avaliação de impactos ambientais aos sistemas de licenciamento, outorgando ao Conselho Nacional de Meio AmbienteConama competência para "Fixar os critérios básicos segundo os quais serão exigidos estudos de impacto ambiental para fins de licenciamento", com poderes, para tal fim, de baixar as resoluções que entender necessárias.

Seriam, portanto dois instrumentos distintos, no entanto é bastante comum a Avaliação de Impacto Ambiental ser incorporada aos Estudos de Impacto Ambiental, e este se passarem pelo outro.

A Resolução Conama n ${ }^{\circ}$. 01/86 colaborou para esta percepção, quando tendo como objetivo o estabelecimento de definições, de critérios e de diretrizes para uso e implantação da avaliação de impactos ambientais, acabou tratando apenas do estudo de impacto ambiental e do relatório de impacto ambiental. 
Reforçado pela Constituição Federal de 1988, que determina no art. 225, $\S 1^{\circ}$ inciso IV, a exigência pelo Poder Público de estudo prévio de impacto ambiental a que se dará publicidade para instalação de obra ou atividade potencialmente causadora de significativa degradação do meio ambiente, não fazendo, no entanto, qualquer referencia a avaliação de impacto ambiental.

Como consequência, a avaliação de impacto ambiental mais aplicada no Brasil se dá durante o processo de licenciamento ambiental, particularmente na etapa de obtenção da licença prévia, sendo uma etapa obrigatória nos estudos de impacto ambiental e seu relatório.

Cabe aos órgãos ambientais a análise dos estudos para verificar previamente a viabilidade ambiental. Esta análise é feita dentro de um contexto de cumprimento legal, com escopo e requisitos a serem cumpridos.

\section{Conclusão do capitulo 2}

Verificada a influência do histórico de implantação de procedimentos e legislação a respeito do processo de avaliação de impacto ambiental e sua particularidade, é necessário verificar com maior profundidade o processo de licenciamento, a fim de avaliar as nuances das modificações ao longo dos últimos anos. Já que a base legal pouco se alterou. 


\section{3}

\section{O Processo de Licenciamento Ambiental no Brasil}

Conhecido o histórico da avaliação de impacto ambiental no Brasil e do processo de licenciamento, neste capitulo se pretende aprofundar a identificação das etapas e procedimentos previstos, assim como levantar as dificuldades do processo de licenciamento brasileiro na prática.

\section{1. O Licenciamento Ambiental no Brasil}

Apesar de vigorar desde a década de 70, em alguns estados como Rio de Janeiro, São Paulo, Minas Gerais e Bahia, o licenciamento ambiental foi instituído para todo o país pela Lei 6.938/81, regulamentado primeiramente pelo Decreto 88.351/83, que vinculou o Licenciamento Ambiental a AIA e em seguida pelo Decreto 99.274/90.

A partir da Lei 6.938/81 PNMA art. 10 passa a ser exigido que:

...a construção ou instalação e funcionamento de estabelecimentos ou atividades utilizadoras de recursos ambientais, considerados efetiva ou potencialmente poluidores, bem como os capazes de, sob qualquer forma, causar degradação ambiental dependerão de prévio licenciamento por órgão estadual competente ou pelo Ibama (órgão ambiental federal).

O impacto ambiental é conceituado pela Resolução n. ${ }^{\circ} 1 / 86$, do Conselho Nacional do Meio Ambiente - CONAMA, em seu artigo $1 .^{\circ}$, da seguinte forma:

Impacto ambiental é qualquer alteração das propriedades físicas, químicas e biológicas do meio ambiente, causada por qualquer forma de matéria ou energia resultante das atividades humanas que, direta ou indiretamente, afetam:

I - a saúde, a segurança e o bem-estar da população;

II - as atividades sociais e econômicas;

III - a biota;

IV - as condições estéticas e sanitárias do meio ambiente;

$\mathrm{V}-\mathrm{a}$ qualidade dos recursos ambientais.

A Resolução Conama n. ${ }^{\circ}$ 237, de 19 de dezembro de 1997, em seu artigo 1. ${ }^{\circ}$, inciso III, estabeleceu as definições, as responsabilidades, os critérios básicos e as diretrizes gerais para uso e implantação da AIA. Esta norma determinou que o 
licenciamento de atividades modificadoras do meio ambiente depende da elaboração de EIA e do respectivo Relatório de Impacto Ambiental (RIMA).

O licenciamento ambiental no Brasil, segundo IBAMA 2002 é um processo administrativo sistemático das consequências ambientais da atividade que se pretende desenvolver, desde sua fase de planejamento, e das medidas adotadas para seu controle, incluindo os procedimentos de acompanhamento das licenças concedidas, por meio de inspeções e verificações periódicas realizadas pelos órgãos ambientais.

\section{Etapas do Licenciamento Ambiental}

O licenciamento ambiental no Brasil ocorre por meio de um único processo administrativo com a emissão de três licenças sucessivas, com o objetivo de verificar se uma determinada atividade está efetivamente adequada aos padrões de qualidade ambiental prescrito pela legislação ou pelo órgão ambiental competente.

O art. 19 do Decreto 99.247/90 dispõe que o processo administrativo de licenciamento ambiental se desdobra em três etapas, devendo cada uma das três etapas resultar na concessão da licença ambiental compatível com o andamento processual.

O art. $8^{\circ}$ da Resolução 237/97 do CONAMA denomina e explica com idêntica redação ao Decreto 99.247/90 as três espécies de licença ambiental que são a licença prévia, a licença de instalação e a licença de operação.

As três etapas que compõem cada processo de licenciamento são bem definidas e neste estudo focaremos na primeira etapa, que é o da obtenção da licença prévia.

OLIVEIRA, 2005 adverte que a licença prévia desempenha um papel de maior importância dentro do licenciamento ambiental em relação à licença de instalação e à licença de operação, visto que é nessa fase em que se levantam as consequências da implantação e da operação do empreendimento e que se determina a localização do empreendimento.

A Cartilha de Licenciamento Ambiental, 2004 do Tribunal de Contas da União, destaca a importância da licença prévia no atendimento aos princípios da prevenção e da precaução, tendo em vista ser nessa fase que os impactos ambientais são levantados e avaliados e que são determinadas as medidas mitigatórias ou 
compensatórias em relação a esses impactos. É nessa fase também que o projeto é discutido com a comunidade, especialmente nos casos em que ocorre audiência pública, e que o órgão administrativo de meio ambiente competente toma a decisão a respeito da concessão ou não dessa licença ambiental. (TCU 2004)

\section{Licença Prévia}

O art. 19 do Decreto 99.247/90 e o art. $8^{\circ}$ da Resolução 237/97 do CONAMA definem a licença prévia como a licença ambiental concedida na fase preliminar do planejamento do empreendimento ou atividade aprovando sua localização e concepção, atestando a viabilidade ambiental e estabelecendo os requisitos básicos e condicionantes a serem atendidos nas próximas fases de sua implementação.

Se, de acordo com o caput do art. 10 da Lei $n^{\circ}$. 6.938/81 o licenciamento ambiental é exigido em relação às atividades efetiva ou potencialmente poluidoras, já o estudo e o relatório de impacto ambiental são exigidos apenas em relação às atividades potencial ou efetivamente causadores de significativa degradação ambiental (CF 88).

Dessa forma, no que diz respeito às atividades sujeitas ao licenciamento ambiental somente daquelas de maior potencial poluidor é que se exige o estudo e o relatório de impacto ambiental - EIA/RIMA.

Se o impacto ambiental não for significativo, deverão ser aplicados os estudos ambientais, de natureza menos complexa, elencados no inciso III do art. $1^{\circ}$ da Resolução 237 do CONAMA tais como: relatório ambiental, plano e projeto de controle ambiental, relatório ambiental preliminar, diagnóstico ambiental, plano de manejo, plano de recuperação de área degradada e análise preliminar de risco.

\section{Procedimentos para a obtenção da Licença Prévia com EIA/RIMA}

A Instrução Normativa Ibama 184 de 17 de julho de 2008 em seu Art. $2^{\circ}$ determina que os procedimentos para o licenciamento ambiental federal deverão obedecer as seguintes etapas:

- Instauração do Processo;

- Licenciamento Prévio;

- Licenciamento de Instalação; 
- Licenciamento de Operação

Segundo a IN 184/2008 Art. $2^{\circ}$ a etapa de Instauração do Processo se dá com as seguintes ações:

- Inscrição do empreendedor no Cadastro Técnico Federal - CTF do Ibama (http://www.ibama.gov.br/cogeq) na categoria Gerenciador de Projetos;

- Acesso aos Serviços on line - Serviços - Licenciamento Ambiental pelo empreendedor, utilizando seu número de CNPJ e sua senha emitida pelo CTF e a verificação automática pelo sistema da vigência do Certificado de Regularidade, em consonância a Instrução Normativa 96/2006;

- Preenchimento pelo empreendedor do Formulário de Solicitação de Abertura de Processo - FAP e seu envio eletrônico ao Ibama pelo sistema;

- Geração de mapa de localização utilizando as coordenadas geográficas informadas na FAP, como ferramenta de auxílio à tomada de decisão;

- Verificação da competência federal para o licenciamento.

- Abertura do processo de licenciamento.

- Definição dos estudos ambientais e instância para o licenciamento (DILIC ou NLA).

A Solicitação de Abertura do Processo da licença prévia é realizada quando o projeto está na fase de planejamento. Sua viabilidade técnica e financeira se mostram favoráveis ao avanço dos estudos. O empreendedor então preenche a Ficha de Abertura do Processo, no qual são apresentadas informações gerais do empreendimento, as possíveis localizações e informações básicas levantadas com dados secundários, como por exemplo, possíveis interferências com comunidades tradicionais e indígenas e áreas especialmente protegidas ambientalmente.

Segundo o Art. $8^{\circ}$ da IN 184/2008, instaurado o processo, o empreendedor deverá providenciar o envio pelo Serviços on line de proposta de Termo de Referência - TR para elaboração do Estudo Ambiental, com base no Termo de 
Referência Padrão da tipologia específica do empreendimento, disponibilizado no site do Ibama/Licenciamento.

A existência de Termos de Referencia Padrão por tipologia é considerado um avanço no processo de licenciamento ambiental brasileiro, uma vez que reforça os pontos mais importantes para aquela tipologia em função dos potenciais impactos já identificados.

Os analistas dentro do órgão licenciador federal são divididos em equipes e tendem a analisar sempre a mesma tipologia ou grupo de tipologia, se especializando desta forma e podendo levar o conhecimento adquirido para outros processos.

O IBAMA, considerando as contribuições dos órgãos intervenientes (FUNAI, FCP, IPHAN, MS, OEMA) conforme previsto na Portaria Interministerial MMAMJ-MS 60/2015 e Lei Complementar 140/2011 emite o Termo de Referência - TR.

A emissão de um TR facilita o processo de contratação da equipe que irá elaborar o EIA uma vez que estabelece o escopo da especificação técnica para a contratação. A equipe técnica que elabora o EIA deve utilizar o TR como um balizador, como critérios mínimos, porém não precisa se limitar a ele.

Para reforçar a importância do cumprimento do TR, o Ibama e outros órgãos de licenciamento tem adotado uma verificação do estudo (check list), que consiste em verificar se itens do TR foram contemplados no EIA.

Segundo Art. $18^{\circ}$ da IN 184/2008, a análise só será iniciada se houver a aceitação. Muitos EIA/RIMA já apresentam na sua itemização a correlação com o TR. Esta medida já foi uma melhoria implementada pelos órgãos para o processo de licenciamento uma vez que evita que estudos "incompletos" sejam analisados, otimizando o tempo dos analistas dos órgãos e do processo.

\section{Conteúdo Padrão do Termo de Referência}

O escopo básico dos EIA/RIMA é composto de avaliação de alternativas locacionais e tecnológicas, interferência com Programas e Planos de Governo, sinergia com outros empreendimentos, caracterização do empreendimento, diagnostico dos meios físico, biótico e antrópico ou socioeconômico, prognóstico com e sem o empreendimento, avaliação integrada dos impactos, e programas com 
medidas para evitar, mitigar ou compensar os impactos negativos e potencializar os positivos.

O diagnóstico ambiental busca definir, para fins de estudo, a área de influência do projeto, descrevendo e analisando os recursos ambientais e suas interações, de modo a demonstrar a situação ambiental da área antes da implantação da atividade.

O diagnóstico ambiental deve considerar, conforme as alíneas do inciso I, artigo $6^{\circ}$ da Resolução Conama 1/86:

a) o meio físico - o subsolo, as águas, o ar e o clima, destacando os recursos minerais, a topografia, os tipos e aptidões do solo, os corpos d'água, o regime hidrológico, as correntes marinhas, as correntes atmosféricas;

b) o meio biológico e os ecossistemas naturais - a fauna e a flora, destacando as espécies indicadoras da qualidade ambiental, de valor científico e econômico, raras e ameaçadas de extinção e as áreas de preservação permanente;

c) o meio socioeconômico - o uso e ocupação do solo, os usos da água e a socioeconômica, destacando os sítios e monumentos arqueológicos, históricos e culturais da comunidade, as relações de dependência entre a sociedade local, os recursos ambientais e a potencial utilização futura desses recursos.

A etapa de prognóstico é a previsão de como a região ficará com o empreendimento. Há quem compare o diagnóstico e o prognóstico com fotografias do agora e do como será.

A próxima etapa do estudo, elencada pelo inciso II artigo $6^{\circ}$ da Resolução 1/86 do CONAMA, consiste na identificação dos impactos ambientais positivos e negativos do projeto e suas alternativas.

Os impactos são comumente classificados numa Matriz de Impacto que avalia quanto a critérios tais como: diretos e indiretos, imediatos e a médio e longo prazo, temporários e permanentes, bem como seu grau de reversibilidade e magnitude.

$\mathrm{O}$ próximo passo diz respeito à definição de medidas mitigadoras dos impactos negativos, constantes no inciso III, (Resolução n. ${ }^{\circ}$ 237, de 19 de dezembro de 1997, em seu artigo 1.) que consiste em evitar o impacto negativo ou procurar corrigi-lo, recuperando o meio ambiente.

Por fim, o inciso IV (Resolução n. ${ }^{\circ}$ 237, de 19 de dezembro de 1997, em seu artigo $1^{\circ}$ ) determina a elaboração do programa de acompanhamento e monitoramento dos impactos positivos e negativos, indicando fatores e parâmetros 
a serem considerados, no intuito de prever os acontecimentos ambientais decorrentes da execução do projeto e as condições e meios necessários ao manejo de seus efeitos.

Para sintetizar os potenciais impactos e seus respectivos programas a Matriz de Impacto é utilizada, em função da sua leitura direta, sendo normalmente disponível também no RIMA.

\section{Finalidade do Licenciamento Ambiental}

Conforme visto anteriormente, o EIA/RIMA auxilia o tomador de decisão do órgão ambiental a respeito da viabilidade socioambiental de um empreendimento. Porém em função dos procedimentos e resultados que envolvem toda a sociedade a avaliação da viabilidade do empreendimento precisa de uma avaliação mais ampla.

Segundo CAMARA, 2015, p.86 o processo de licenciamento precisa atender ao seu objetivo primordial que é o de garantir a preservação ambiental e a sustentabilidade dos empreendimentos licenciados.

\section{2. \\ Dificuldades do Processo de Licenciamento na Prática}

Ao longo dos últimos 35 anos o processo de licenciamento ambiental vem sofrendo críticas e avaliações, tanto de instituições como da sociedade em geral, o que naturalmente promove alguns ajustes legais/normativos e de ordem prático/processual.

O Ibama publicou em 2002 documento para auxiliar nos entendimentos de licenciamento no âmbito federal intitulado: Licenciamento Ambiental Federal Manual de Procedimentos.

Já em 2004 a Escola Superior do Ministério Público da União elaborou o documento: Deficiências em Estudos de Impacto Ambiental: Síntese de uma Experiência. (ESMPU, 2004). No mesmo ano, o Tribunal de Contas da União (TCU, 2004) publicou: Cartilha de Licenciamento Ambiental.

Em 2008, o Banco Mundial estudou os processos de licenciamento de empreendimentos hidroelétricos. (Banco Mundial, 2008). 
Segundo estudo sobre licenciamento ambiental realizado pela Secretaria de Assuntos Estratégicos da Presidência da República (SAE) em 2009, “o problema radical (...) do licenciamento em particular, seria a" anomia" - ausência de lei do licenciamento ambiental no Brasil, sendo o "reino da discricionariedade" administrativa".

Segundo o mesmo estudo, a legislação brasileira a respeito do licenciamento seria escassa e desatualizada. Outro problema apontado também seria a excessiva interpretação do uso do princípio da precaução e a inexistência de processo de avaliação ambiental estratégica integrada, provocando o deslocamento de decisões políticas para o processo de licenciamento.

A Associação Brasileira de Entidades Estaduais de Meio Ambiente -Abema apresentou em 2013 estudo intitulado "Novas Propostas para o Licenciamento Ambiental no Brasil" no qual enfatizava os principais óbices do licenciamento no âmbito dos estados, as dificuldades conceituais, metodológicas e operacionais que estão dificultando a utilização deste instrumento da Política Nacional e seus reflexos para a proteção do meio ambiente e para o desenvolvimento sustentável dos estados e do Brasil.

Mesmo a academia tem participado com a análise de processos de licenciamento, particularmente para algumas tipologias de empreendimentos. BARÃO, 2007 e BRITTO, 2014 fizeram avaliações críticas para o setor hidrelétrico, REIS, 2015 para usinas fotovoltaicas, PEREIRA, 2014 analisou criticamente uma linha de transmissão e LIMA, 2009 avaliou um ramal ferroviário. Já BURMANN, 2012 analisou o processo de licenciamento no âmbito municipal, particularmente do Rio Grande do Sul.

Mais recentemente, o documento intitulado: "Gargalos do Licenciamento Ambiental Federal no Brasil" elaborado a pedido da Câmara dos Deputados em julho de 2015, consolida as críticas de estudos anteriores realizados até então, e apresenta as causas e propões ações de melhoria.

Os problemas apontados com mais frequência no processo de licenciamento brasileiro serão apresentados a seguir agrupados em 9 temas principais com alguns fatores que se relacionam. Sempre que possível as causas identificadas nos estudos anteriores serão apresentadas no intuito de verificar a dificuldade de melhoria. 


\section{1) Grande número de atos normativos e falta de regulamentação e aplicação de instrumentos}

Conforme levantamento divulgado pela CNI, 2014:

... as licenças ambientais no Brasil são reguladas, direta ou indiretamente, por cerca de 30 mil diferentes instrumentos legais produzidos pelos governos federal e estaduais.... Muitas vezes incongruentes e apresentando sobreposições formando um "emaranhado jurídico".

A ABEMA, 2013 p.92, chama a atenção para a expansão do arcabouço legal brasileiro nos últimos anos por meio de normas legais e infra legais e de normas inferiores.

CAMARA, 2015 levantou que entre 2007 e 2015, em referência ao licenciamento ambiental, foram editadas: 11 Instruções Normativas do Ibama; 2 Instruções Normativas do ICMBio; 2 Instruções Normativas Conjuntas Ibama/ICMBio; 1 Portaria Ibama; 6 Portarias Conjuntas MMA com outros ministérios; 9 Portarias do MMA; 1 Instrução Normativa do MMA; 2 Instruções Normativas da Funai; 1 Instrução Normativa do IPHAN; 1 Instrução Normativa da Fundação Palmares.

Thomáz, Diretor de Licenciamento do Ibama em Seminário promovido pelo MPF em 6 de novembro de 2015 em Brasília, destacou ainda as 23 Resoluções Conama que tratam do tema licenciamento, desde 1986.

Estão em tramitação, na Casa Legislativa, mais de uma dezena de projetos de lei relacionados ao processo de licenciamento ambiental. Alguns são voltados para a avaliação de eficiência dos programas em substituição a mera avaliação do atendimento de condicionantes, outros versam sobre a proposição da obrigatoriedade de avaliações ambientais estratégicas.

O processo de criação de uma nova lei no Brasil costuma levar alguns anos, sem revogar ou incorporar leis anteriores. Desta maneira a aprovação de uma nova lei, quase sempre não garante uma melhora no processo uma vez que há medidas conflitantes sendo propostas e permanece a fragmentação de normas.

Segundo MILARÉ, 2007 p. 286: 
A Política Nacional do Meio Ambiente, editada com a Lei 6.938/1981, que estabelece as grandes diretrizes (princípios, objetivos, instrumentos), (...) recepcionada pela Constituição Federal de 1988, representa o instrumento legal maior na condução de todas as iniciativas que têm sido e venham a ser tomadas no relacionamento da sociedade brasileira com o meio ambiente, em especial no que se refere aos processos econômicos e aos setores produtivos que empregam recursos naturais e geram resíduos.

A Constituição de 1988 preconizou a necessidade de atuação dos três níveis da Federação. Somente com a aprovação da Lei Complementar 140 em 2011 estas competências ficaram mais claras, embora tal lei ainda careça de regularização.

No sentido de organizar os processos de licenciamento ambiental federal garantindo maior qualidade, agilidade e transparência, a Instrução Normativa Ibama 184 de 2008 foi publicada, revogando a IN Ibama 65/2005.

A ABEMA, 2013 chama a atenção para o momento da avaliação ambiental e a pressão que a não implantações dos outros instrumentos da PNMA traz para o processo de licenciamento, como o zoneamento para a discussão da variável locacional.

Segundo o SAE, 2009 p.4"... os excessos burocráticos frequentemente atrasam o processo sem qualquer contrapartida de qualidade da decisão”.

No entanto MILARÉ, 2007 p 391 defende que:

... O EIA/RIMA, no Direito brasileiro, conquanto ainda em processo de amadurecimento (...) representa hoje um instrumento fundamental de proteção ambiental, elemento inestimável no controle da qualidade das decisões públicas e privadas que afetam o meio ambiente.

Não se trata de mais uma exigência burocrática ou modismo sem efeitos concretos palpáveis (...) o EIA/RIMA desempenha um papel essencial de garantia de um meio ambiente equilibrado e saudável.

Nada obstante (...) não podemos negar que ainda há, infelizmente, uma enorme distância entre aquilo que prevê e exige a lei e o que ocorre, de fato, na realidade deste imenso Brasil.

(...) resta esperar que, para o empreendedor brasileiro - público e privado-, o EIA/RIMA se torne algo mais que um mero requisito formal de licenciamento ambiental. Os recursos técnicos, materiais e humanos, os levantamentos regionais e a participação comunitária envolvidos na sua elaboração podem transformar o EIA/RIMA - mais ainda em um país carente de recursos como o Brasil - em uma alavanca importante de planejamento ambiental e de tomada de consciência mais profunda da problemática local, regional e global do meio ambienta.

SANCHEZ, 2015, em Seminário promovido pelo MPF em 6 de novembro de 2015 em Brasília, recomenda que propostas de reformas nos processos devam ser consideradas fundamentadas em evidencias coletadas por procedimentos 
sistemáticos com solida fundamentação na medida em que são reproduzidas, mais que percepções individuais. A experiência adquirida pelos consultores, empreendedores, analistas dos órgãos, organizações da sociedade civil e comunidades locais devem ser consideradas para embasar uma proposta coerente e consistente de reforma, considerando as diferentes visões.

Segundo CAMARA, 2015, p.56: "a quantidade crescente de normativos tem dificultado o entendimento integrado da matéria".

A ABEMA, 2013 p. 92 recomenda:

... que esforços sejam concentrados nas revisões das Resoluções Conama 01/86, 237/97 e outras que dispõem sobre o licenciamento, para que o detalhamento se dê de forma consolidada, reunindo num instrumentos todas as medidas balizadoras do licenciamento em nível nacional,... eliminando zonas de sombra e lacunas que dão margem a interpretações contraditórias e paralisantes.

Conforme verificado no capitulo 2, alguns países utilizam-se da avaliação ambiental estratégica para planejamento ambiental.

Thomáz, Diretor de Licenciamento do Ibama em Seminário promovido pelo MPF em 6 de novembro de 2015 em Brasília, afirmou que não há no Brasil a cultura do planejamento ambiental.

Segundo o SAE, 2009 p. 5

\begin{abstract}
Não existe no país um foro, em nível nacional, que debata e defina as prioridades de investimento em infraestrutura e de preservação ambiental.

A avaliação ambiental estratégica é um mecanismo que insere a variável ambiental precisamente no momento de planejamento de políticas de construção de infraestrutura.

Deve-se criar, no primeiro escalão do governo federal, instituição com competência para gerir a elaboração plano... resultante da avaliação ambiental estratégica. ( para obras de infraestrutura).

Isso requer, todavia, leve alteração nos processos de tomada de decisão do Poder Executivo.
\end{abstract}

Já em 2002, o MMA ao elaborar um dos primeiros documentos no Brasil sobre o tema destacava que a AAE tem natureza política e de decisão, mais do que técnica e deveria ser integrada de forma harmônica com o processo de planejamento, sem a criação de nova etapa, similar ao licenciamento, como previsto em projetos de lei que por ora tramitam. 
A ABEMA, 2013 recomendou que a responsabilidade pela implementação da AAE fosse atribuída às Agencias Reguladoras ou aos órgãos e entidades responsáveis pelas políticas setoriais.

\section{2) A qualidade dos estudos de EIA, muito focado no diagnóstico se tornando estudos extensos, custosos e demorados .}

A primeira etapa do processo de licenciamento, a de obtenção da LP, com a elaboração do EIA/RIMA é segundo a CAMARA 2015, p.86 um processo lento, caro e complexo, sendo essencial que o objetivo de garantir a preservação ambiental e a sustentabilidade dos empreendimentos seja alcançado.

Bessa Antunes p 223 observa que há "(...) entidades empresariais que, com frequência, tem se manifestado contrariamente à "lentidão" do licenciamento ambiental,...”.

Estudo realizado pelo Banco Mundial em 2008 para empreendimentos hidroelétricos encontrou: "... estudos de EIA/RIMA geralmente extensos e bastante detalhados, porém focados principalmente no diagnóstico, sem contribuição efetiva, para o atendimento das questões específicas do licenciamento".

Os estudos de EIA/RIMA levam de 9 a 18 meses, em média, para serem elaborados, podendo ter alguns milhares de páginas e os custos podem ultrapassar alguns milhões de reais, com pouca incorporação ao conhecimento nacional.

Isto porque, o Brasil ainda apresenta grandes lacunas de conhecimentos científicos, particularmente no que se refere aos meios bióticos e antrópico. Resultando para o licenciamento a necessidade de levantamentos de campo, com grandes equipes de especialistas (IN Ibama 13/2013 estabelece pelo menos 7 grupos faunísticos a serem amostrados), que precisam levantar informações em poucas campanhas, considerando a sazonalidade. A sazonalidade para diagnóstico da fauna, e as licenças requeridas para tanto costumam ser o "caminho crítico" do EIA, em termos de prazos e custos. Os resultados são estudos focados nos diagnósticos, extensos, porém com pouco respaldo para a avaliação prévia. Frequentemente são solicitados para as etapas seguintes levantamentos mais detalhados $\mathrm{e}$ monitoramentos.

A análise dos estudos extensos, a necessidade de audiências públicas e os prazos legais, que preveem 12 meses de analise para EIA/RIMA são alguns dos 
fatores que fazem esta etapa prévia durar cerca de 2 anos, somente para verificar a viabilidade locacional.

Em função deste tempo de analise requerido no processo normal de licenciamento, o que se verifica é que os processos de licenciamentos se iniciam com projetos "tipo", assim que há a intenção de um empreendimento, sem que a engenharia básica ou detalhada do empreendimento específico tenha sido construída. Com isso, a avaliação do impacto fica comprometida, uma vez que será mais qualitativa que quantitativa. Por vezes o projeto apresentado para a obtenção da LI é bastante diferente do original, apresentado na LP, e não há uma nova avaliação dos impactos pela sociedade.

O projeto "tipo" se propaga então para a próxima etapa, para o Plano Básico Ambiental PBA uma vez que seus programas são construídos em cima da matriz de impacto da LP.

Segundo Sanchez, 2013, p. 444:

\begin{abstract}
Um balanço adequado entre descrição e análise, rigor metodológico e isenção são as três principais qualidades de todo estudo ambiental. Um estudo exaustivamente descritivo, sem interpretação dos dados e com parca aplicação destes para a análise dos impactos, tem tão pouca utilidade quanto uma coleção de opiniões que não esteja solidamente ancorada em dados rigorosamente coletados e compilados. Da mesma forma, um texto que "defenda" o projeto, apenas apontando suas vantagens e minimizando seus inconvenientes, é inútil como fundamento para qualquer tomada de decisões...
\end{abstract}

Segundo levantamento feito pelo MPF em 2004, aspectos como escopos que não levam em conta os aspectos fundamentais, a não apresentação de alternativas locacionais e de rotas tecnológicas, são algumas das falhas mais encontradas nos estudos. As medidas mitigadoras genéricas que não são capazes de mitigar os impactos e a falta de monitoramento pós-implantação, também são criticas bastante frequentes, além das limitações da analise pontual de um empreendimento no momento da implementação e da fraca analise dos efeitos socioeconômicos.

\title{
3) Ausência de dados e informações ambientais sistematizadas
}

O Banco Mundial 2008 já apontava como um dos gargalos do processo de licenciamento em empreendimentos hidroelétricos a ausência de dados e informações ambientais. 
Contradizendo com o alto custo do levantamento de diagnósticos no estudo que não alimentarão bancos de dados. Quando existentes as informações no Brasil, estas são pulverizadas por diversas instituições e de acesso ainda precário.

Segundo o ex Ministro do Meio Ambiente, José Carlos Carvalho, em Seminário sobre Licenciamento Ambiental em outubro de 2013, (www.mma.gov.br/port/conama/reuniao/dir1641/transcricao_seminario.pdf em 18/02/2015) “o Estado brasileiro pede ao empreendedor informações que ele deveria ter, porque não tem zoneamento ecológico e econômico, não tem Planos de Bacia".

Embora existam algumas plataformas de armazenamento de dados em diferentes órgãos públicos, os diagnósticos dos EIAs não são enviados em formato compatível e os próprios servidores do IBAMA, em CARTA, 2015 manifestaram a necessidade de bancos de dados compartilhados. Segundo eles, com informações geoespaciais, as análises seriam mais efetivas, rápidas e o número de estudos e programas poderiam ser reduzidos e otimizados.

\section{4) Recursos para os Órgãos Ambientais.}

O licenciamento ambiental pode ser conduzido pelo órgão ambiental federal, ou órgãos estaduais ou municipais. A Lei Complementar 140/2011 e o Decreto $8.437 / 2015$ estabelecem as tipologias de empreendimentos e atividades cujo licenciamento ambiental será de competência da União. No entanto a condução por um órgão não impede a participação dos demais e de outros órgãos intervenientes conforme previsto nas Portarias Interministeriais 419/2011 e 60/2015.

O distanciamento da realidade em que o empreendimento irá se instalar, a baixa experiência profissional, os salários pouco expressivos em relação a outras carreiras, as pressões políticas internas e a responsabilidade direta dos analistas que frequentemente tem que responder ao Ministério Público, sendo réus em ações sem poder contar com apoio de advogados da AGU faz com que haja uma grande rotatividade no quadro pessoal dos órgãos ambientais, com perdas para o processo, já que as competências profissionais sustentam as competências organizacionais.

A ABEMA 2013 aponta para a fraca capacidade institucional e fragilidade da capacitação técnica dos quadros estaduais de forma geral, como um grande desafio à melhoria das análises e processos. 
Thomáz, Diretor de Licenciamento do Ibama em Seminário promovido pelo MPF em 6 de novembro de 2015 em Brasília, apresentou a evolução, mostrando que de 160 técnicos dedicados ao licenciamento ambiental em 2003 atualmente há cerca de 420 (2015), O que foi possível por meio de 3 concursos e recrutamentos internos. Apresentou ainda os esforços em termos de capacitação do corpo técnico com cursos e oficinas de treinamento. Destacou o crescimento desproporcional da demanda de análise de processos frente à capacidade de recrutamento de técnicos, principalmente a partir de 2008. Mostrou preocupação na avaliação das estruturas dos órgãos estaduais, uma vez que a partir de 2011 com o LC 140 há um movimento de descentralização dos processos de licenciamento, sendo os órgãos estaduais e municipais os que devem ser mais demandados.

Consenso parece ser que não obstante o esforço do órgão federal, em acompanhar o aumento da demanda e número de processos com aumento do quadro técnico, sua capacitação e retenção por meio de plano de carreira, o esforço se torna inócuo se os órgãos intervenientes e estaduais não se aprimorarem. Somente para exemplificar, enquanto o Ibama conta hoje com cerca de 420 servidores dedicados ao licenciamento, o Iphan possui 6 e a Funai 13.

\section{5) Muitos atores com poderes discricionários e interesses variados, sem governança entre eles}

Segundo MILARÉ, 2007, p. 286 “... pelo preceito constitucional, os atores responsáveis pela qualidade ambiental no Brasil são o Poder Público e a sociedade".

MACHADO, 2009, p.171 chama atenção para a forma como o poder público se estrutura no Brasil para tratar do assunto, por meio do Ministério do Meio Ambiente, mas também para a interface, em função da transversalidade do tema com outros 13 Ministérios.

O estudo do Banco Mundial de 2008 para empreendimentos hidroelétricos mapeou como um dos gargalos ao licenciamento: “... multiplicidade de atores com grande poder discricionário e poucos incentivos de colaboração, com destaque para a atuação do Ministério Público (MP)"'. Apontando ainda a ausência de cooperação entre os diversos órgãos competentes, como outro gargalo que dificulta o licenciamento de empreendimentos hidroelétricos. 
O estudo SAE, 2009 p. 4 aponta que há desvirtuação do verdadeiro propósito do processo de licenciamento em função da falta de delimitação da discricionariedade dos agentes públicos e aos excessos ideológicos.

A ABEMA 2013 chama a atenção para: “... a existência de instancias decisórias paralelas em um quadro de confusão institucional no qual se incluem os órgãos ambientais e as instituições intervenientes".

A competência para conduzir o licenciamento ambiental ficou vulnerável a questionamentos até 2011 quando foi editada a Lei Complementar 140 e mesmo depois da edição do Decreto 8.437/2015 ainda está pendente a regularização de comissões tripartites. O estabelecimento de critérios objetivos sejam eles relacionados à territorialidade, natureza, porte ou potencial poluidor, daria segurança jurídica ao empreendimento e evita questionamentos de competências.

A CAMARA, 2015 p. 27 e 36 chama a atenção para:

\begin{abstract}
Um dos desafios do licenciamento ambiental no Brasil é evoluir na inter e transdisciplinaridade dos pareceres técnicos...

Trata-se de método multidisciplinar que, embora favoreça a excelência técnica de cada segmento (meios físicos, bióticos e socioeconômicos), prejudica a análise integrada e a visão holística do cenário projetado.

Com isso, a ponderação dos impactos globais (benéficos e adversos) fica prejudicada.

O Brasil vive um cenário de extrema confusão institucional no que se refere à temática ambiental, com órgãos desempenhando atividades fragmentadas paralelamente, sem que haja uma relação hierárquica com o ente responsável pela visão integrada de todo o processo: a autoridade licenciadora. Com isso, o poder decisório fica comprometido.
\end{abstract}

Segundo CAMARA, 2015 p. 37:

As demandas de diferentes instituições são incorporadas ao licenciamento sem julgamento de valor, sem integração. Essa prática deturpa o licenciamento, pois a visão do tripé da sustentabilidade não se faz com visões fragmentadas, é legitimo e pertinente que cada ator busque garantir seus interesses, mas cabe à autoridade licenciadora interpretar e decidir sobre como contemplar cada reivindicação e opinião na análise global.

O que de certa forma reforça o poder discricionário do analista, exigindo julgamento de temas fora da sua competência e dando margem para intervenção frequente do Ministério Público.

A Portaria Interministerial MMA-MS-MJ-MC 60/2015, reforça o papel de decisão final ao IBAMA no que se refere ao licenciamento. Independente dos 
desconfortos e discussões que ocorrem, ao estabelecer prazos legais para a tramitação dos documentos entre os órgãos, o processo de obtenção da LP teve um aumento de pelo menos 6 meses, não havendo na referida portaria nenhuma punição ao não cumprimento dos prazos.

6) Falta de marco regulatórios para as questões sociais e condicionantes que extrapolam as obrigações do empreendedor, além de deficiências de políticas e serviços públicos.

O Banco Mundial 2008 aponta como gargalo:

- falta de marco regulatório específico e detalhado para tratar de questões sociais (ex: compensação social) frequentemente incorporadas no licenciamento ambiental e que, via de regra, extrapolam a responsabilidade legal do proponente;

- falta de profissional da área social no órgão licenciador;

A viabilidade ambiental das transformações do espaço, em função das decisões adotadas, pode ser sentida de diferentes maneiras. Para Sanchez (2006), o conceito de viabilidade ambiental não é único. Para a análise ambiental, um projeto pode ser viável sob determinados pontos de vista, desde que certas condições sejam observadas, como o atendimento a requisitos legais, por exemplo.

No processo de licenciamento ambiental os impactos sobre o meio físico e biótico podem ser relativamente bem delimitados do ponto de vista espacial e são mais locais, já os socioeconômicos tem uma abrangência bem maior e de difícil delimitação. São em geral também mais complexos e indiretos. O estabelecimento de programas para mitigação ou compensação de forma padronizada para o meio socioeconômico são mais difíceis, pois dependem mais de arranjos e características locais.

Ao avaliar históricos de licenciamento verificamos que um fator que pode influência a boa gestão dos impactos socioeconômicos é o momento dos impactos em relação à disponibilidade de investimentos. Os impactos associados à atratividade de pessoas ocorrem a partir do anuncio da intenção do empreendimento. Já os empregos e arrecadações tributárias diretas (impactos socioeconômicos positivos) só começarão a ocorrer em média de 5 a 10 anos após o anuncio do empreendimento. E neste meio tempo é necessário que o poder público 
reajuste seu planejamento urbano para uma nova realidade e encontre outros meios de atender as demandas crescentes nos serviços públicos.

Diante das dificuldades de gestão enfrentadas pelos pequenos e médios municípios no que tange a gestão dos impactos e dos recursos, inclusive de pessoal, a percepção que se tem é que uma das alternativas seria imputar ao empreendedor a resolução de parte desta deficiência, elevando em muito a responsabilidade e os custos de implantação de empreendimentos no Brasil.

Se uma parte do licenciamento é a verificação do cumprimento de normas legais, a possibilidade de existência de normas facilita e reduz a subjetividade da análise. No Brasil, o detalhamento técnico das leis tem ocorrido por meio de Resoluções do Conama. Este Conselho se reúne e emite resoluções desde 1986, porém resoluções a cerca de emissões atmosféricas de fontes pontuais e lançamento de efluentes só foram emitidas em 2007 e 2005 respectivamente.

Para os impactos socioambientais, nem sempre quantificáveis de forma direta ou parametrizável por normas, cabe à avaliação considerando os benefícios econômicos e sociais que a atividade pode trazer dando a sensação de maior subjetividade ao processo pela falta de uso de indicadores.

Os impactos socioambientais de um projeto distribuem-se de maneira desigual. Segundo Coelho (2004) o que é considerado positivo para uma classe social pode não ser para outra, ou ainda, o que é tido como positivo em um determinado momento do processo pode não ser nos demais.

O pouco desenvolvimento dos estudos socioeconômicos dentro do EIA e, portanto dentro do processo de licenciamento formal, pode ser explicado, além da sua complexidade, pelo histórico do processo de licenciamento no Brasil e sua estruturação nos órgãos ambientais. A baixa interatividade com outros setores e secretarias associadas à temática socioeconômica, acabam fragilizando a análise e a capacidade de mitigação.

A ABEMA 2013 chama a atenção para: ““‘... imposição de uma série de compensações pelos órgãos intervenientes que nada tem a ver com os impactos ambientais causados, para suprir carências institucionais e operacionais não atendidas pelo poder público.

Muitos estudos e ações de socioeconômica são demandados ao empreendedor como condicionantes de licenças ambientais, que não são relacionados ao impacto do empreendimento ou em princípio caberiam ao poder público. Por exemplo: a 
construção de escolas em função do aumento populacional da cidade. Ou mais recentemente a reestruturação da Funai local em Altamira, em função do empreendimento Belo Monte. (o Globo, 16 jan 2016 p. 31).

O SAE, 2009 p. 25 chama a atenção para a frequência com que condicionantes ditas "gerais" aparecem nas licenças, temas e obrigações impostas por outras instituições. Como exemplo bastante frequente inclusive nos programas é o detalhamento do atendimento à saúde do trabalhador, extrapolando a competência e atribuição do órgão licenciador.

Segundo Acórdão 3.413/2012 - TCU (www.tcugov.br/consultas/juris/judoc/ acord/20130225/ac_3413_46_12_p.doc em 23/05/2015).“Dentro da complexidade do processo de licenciamento e mesmo com a participação de órgão intervenientes como o IPHAN, FUNAI e Fundação Palmares,...” ainda não há definição legal para estabelecer responsáveis para o acompanhamento da questão social no processo de licenciamento."

THOMÁZ, Diretor de Licenciamento do Ibama em Seminário promovido pelo MPF em 6 de novembro de 2015 em Brasília, chamou a atenção para a real capacidade dos órgãos ambientais, em termos de ter ferramentas disponíveis, para avaliarem todos os impactos e deu como exemplo a melhoria da qualidade de vida de remanejados por hidroelétricas citando recomendação a TCU acordão $3.413 / 2012$ sobre a necessidade de envolvimento de novos atores.

O levantamento de dados e a sistematização de informações socioambientais é uma das melhorias que frequentemente são apontadas pelos analistas dos órgãos. Estudo contratado pelo IBAMA em 2015 para buscar indicadores de eficiência administrativa em 8 países encontrou dificuldades, segundo relato de THOMÀZ, 2015.

Particularmente no Brasil, em função da falta ou deficiência das políticas públicas, com severas carências de infraestrutura de serviços públicos (saúde, educação, segurança e saneamento) é inevitável que haja expectativa de melhoria nestas áreas, sem as quais, a implantação de um grande empreendimento de fato pode contribuir para uma piora da qualidade de vida da região. A realização de zoneamentos ambientais e estudos de avaliação ambientais estratégicos poderiam apontar o diagnóstico e a responsabilidade destas demandas. Alguns processos no Brasil já foram precedidos de $\mathrm{AAE}$, o que não necessariamente resultou em novas políticas públicas e muitas vezes houve o aceite do empreendedor em 
condicionantes além do impacto em função da intensão de empreender naquele lugar.

O Iema -ES, assim como outros órgãos estaduais, estabelece com os empreendimentos Termos de Compromissos Socioambientais ou instrumentos similares que visam investimentos em infraestrutura e equipamentos público trazendo na forma de condicionante a execução de políticas públicas para o licenciamento.

Para os investidores, o que poderia ser uma ação "voluntária" se torna obrigatória, como cumprimento de lei uma vez sendo estabelecida como condicionante de licença. Entrando na conta do investimento de implantação, e por vezes da operação se forem ações continuadas.

Como há um limite na interferência de política pública, normalmente o que é proposto são estruturas físicas, cabendo ao ente responsável pela operacionalização e manutenção. Assim, apesar de vultosos recursos serem aplicados em estruturas pelos empreendedores, a falta de capacidade de operacionalizar muitas vezes faz com que efeito esperado não seja satisfatório.

\section{7) Excesso de condicionantes e falta de acompanhamento da sua efetividade e retroalimentação com avaliação de eficiência dos programas de mitigação e compensação}

Não obstante os Termos de Referência, os extensos estudos e a experiência adquirida ao longo de mais de 30 anos de licenciamento, ainda se verifica um número excessivo de condicionantes, indicando que não há pleno entendimento das expectativas do licenciador. Por outro lado, o acompanhamento das condicionantes e programas se dá na forma de "atendida, parcialmente atendida ou não atendida", sem que haja uma avaliação sobre a mitigação do impacto. Sem esta verificação, programas podem ser propostos para serem atendidos, e caso não mitiguem impactos, continuarão a ser propostos, podendo levar a frustração dos atingidos em relação ao processo de licenciamento.

No sentido de evitar que estudos sejam postergados como condicionantes o Acórdão 1.869/2006 -TCU- Plenário (www.tcu.gov.br/consultas/juris/docs/judoc/ RELAC/20061013/BZ044-41-06-P.doc em 24/05/2015) determina que o órgão ambiental não possa admitir a postergação de estudos de diagnósticos próprios da 
fase prévia para as fases posteriores sob a forma de condicionantes do licenciamento.

Já o Acórdão 2.212/2009-TCU-Plenária (www.tcu.gov.br/consultas/juris/ docs/judoc/acord/20091002/009-362-2009-4-min-AC. doc. em 24/05/2015) detectou carência de padronização dos procedimentos; excesso de discricionariedade no processo de licenciamento ambiental; excesso de condicionantes e ausência de acompanhamento dos benefícios potenciais e efetivos decorrentes do licenciamento de obras.

Mais adiante o Acórdão 2.828/2011-TCU-Plenária (www.tcu.gov.br/ consultas/juris/docs/judoc/acord/20111031/AC_2828_44_11_P.doc em 24/05/2015) reconhece, entre outros aspectos, que:

a Diretoria de Licenciamento (Dilic) desenvolveu maturidade nas fases introdutórias da Avaliação de Impacto Ambiental (AIA), notadamente na fase de licença prévia, mas destaca que a fase de acompanhamento das condicionantes ainda precisa ser aprimorada, constituindo um dos principais desafios da Dilic.

Segundo SINDSEP-DF, 2015, esforços devem ser desviados do processo documental para a fase de acompanhamento e fiscalização, extremamente importante e que pouco é acompanhado até o momento no Brasil.

A CAMARA, 2015 p.19 apresenta como uma das soluções para os gargalos:.. "a elaboração de manuais que retirem do licenciamento assuntos recorrentes..." retirando o foco dos planos e programas formais, e passando para a fiscalização prática.

Segundo alguns autores, inclusive SANCHEZ, 2013p. 106, se outros instrumentos como o zoneamento de uso do solo urbano, assim como manuais de boas práticas e delimitações de padrões fossem realizados pelos órgãos de governo responsáveis, o licenciamento poderia ser mais eficiente, focado na mitigação dos impactos.

O estudo do Banco Mundial 2008 para empreendimentos hidroelétricos apontou como um dos gargalos: “... sistemática ausência de monitoramento, fiscalização e acompanhamento geral dos projetos licenciados, basicamente decorrentes da limitada capacidade institucional.”. 
Segundo SAE, 2009 p. 6:

Os órgãos ambientais brasileiros concentram todos os seus esforços na avaliação prévia do impacto ambiental do empreendimento. Uma vez emitidas as licenças e inaugurado o empreendimento, raramente a fiscalização volta a ser realizada.

...

Boa parte dos danos ambientais ocorre não no momento do lançamento do empreendimento, mas em momento subsequente, durante sua operação, independentemente das medidas mitigadoras e compensatórias previstas no licenciamento.

A Presidente do Ibama Marilene Ramos em entrevista ao jornal "Estadão" de 30/05/2015 mostrou abertura para alterações no órgão quando afirmou: "Mais do que emitir licenças, o que queremos é ampliar o monitoramento de ações de compensação após o licenciamento".

\section{8) Uso Ineficiente da Consulta Popular e das Audiências Públicas}

A audiência pública é uma das formas de participação e de controle popular da Administração Pública, permitindo a troca de informações, regulamentada em Resolução Conama desde a década de 1990.

A informação é requisito indispensável à participação das populações envolvidas nos processos de licenciamento. A informação que é disponibilizada na maioria das vezes é o Relatório de Impacto Ambiental RIMA e o espaço para que a comunidade se manifeste normalmente são as Audiências Públicas.

Embora alguns órgãos ambientais estabeleçam regras claras durante as audiências, muitas acabam tratando de temas não relacionados ao processo de licenciamento em si, por ser este um dos poucos fóruns de reunião e exposição da sociedade.

Estudo realizado por ASSUNÇÃO, 2010 verificou diferentes graus de participação da sociedade, que variam em função da situação socioeconômica da população a ser afetada pelo empreendimento, da qualidade e do estoque de recursos ambientais.

9) Intervenção excessiva do Ministério Público e Frequente judicialização dos processos

Segundo o SAE, 2009 p. 6:

A ausência de regras... amplia a discricionalidade administrativa dos técnicos ambientais, amplia-se também a possibilidade de contestação judicial das decisões.

... não são raros os casos em que o Ministério Público discorda da decisão do técnico ambiental e propõe ações judiciais para contestá-la 
Para resguardar-se de futuro processo judicial, os técnicos adotam postura defensiva e passam a fazer exigências desnecessárias e desproporcionais ao impacto do empreendimento.

Segundo CAMARA, 2015, p. 41 as principais causas judicialização de processos de licenciamento são:

- a postergação de obrigações;

- a subjetividade dos termos técnicos;

- divergência com o tipo de estudo exigido

- opiniões diferentes sobre o grau de cumprimento das condicionantes;

- discussão de competência do licenciamento e

- falta ou insuficiência de participação popular.

Apontando a insuficiência de padrões para o estabelecimento de condicionantes, assim como falta de metodologia institucionalizada para o acompanhamento de sua efetividade como causa das divergências.

Segundo a mesma CAMARA, 2015, p. 59 a partir da Lei 7.347/85 e da Lei 9.605/98 conhecida como Lei de Crimes Ambientais, o MP foi transformado em um dos agentes de fiscalização do cumprimento da política ambiental, impondo os procedimentos do licenciamento ambiental e o pagamento de indenizações por danos ambientais causados por agentes públicos ou privados.

O grande numero de processos judicializados, associados a uma atuação intensiva do Ministério Público leva alguns a crerem, inclusive a Presidente do Ibama em entrevista ao jornal "Estadão" de 30/05/2015, que é o temor de uma interpretação do MP ou de responsabilização do servidor, que leva a estes terem uma postura mais conservadora e um rigor excessivo na análise. Esta impressão foi negada pelos servidores por meio da SINDSEP-DF ,2015.

Verificado também, segundo CAMARA, 2015, p.43 foi a divergência da base técnica com os dirigentes da autarquia (IBAMA), quando decisões sobre o processo de licenciamento são tomadas em contrariedade às sugestões pelos técnicos.

Tal percepção já havia sido apresentada pelo SAE 2008, quando verificou que poucos são os processos de licenciamento ambiental que tem a licença negada, demonstrando a enorme pressão política aos órgãos ambientais. 
Neste sentido foi instituída uma comissão de avaliação e aprovação de licenças ambientais, por meio da IN IBAMA 11/2010, para assessorar o presidente na concessão das licenças sob sua competência.

A Presidente do Ibama Marilene Ramos em entrevista ao jornal "Estadão" de 30/05/2015 afirmou que:

...de fato temos de fazer uma requalificação do licenciamento, retirando certos excessos e complementando lacunas que, muitas vezes, recaem numa agenda muito mais voltada a temas de desenvolvimento social do que ambiental.

\section{Vários Pontos de Vistas, alguma Concordância, porém de difícil coordenação para resolução.}

Segundo MILARE, 2007 p 369

O EIA não pode ser um entrave à liberdade de empreender, pois Política Nacional do Meio Ambiente tem como objetivo, "compatibilização do desenvolvimento econômico-social com a preservação da qualidade do meio ambiente e do equilíbrio ecológico".

Uma das possibilidades de redução deste descompasso entre os primeiros impactos de crescimento populacional e a efetiva implantação do empreendimento, seria a redução do tempo de elaboração dos estudos e análise da viabilidade que pode levar mais de dois anos.

Segundo ANTUNES, 2014 p 199 “O licenciamento ambiental que deveria ser uma mera atividade rotineira, ao contrário é um dos temas mais complexos que se apresenta no Direito Ambiental brasileiro, com muitas dificuldades de natureza prática".

Algumas das mudanças positivas identificadas no processo em várias partes do mundo foram a maior participação pública e a criação de legislação e unidades administrativas específicas para tratar da avaliação de impacto ambiental.

Estas dificuldades e a "falta de eficiência" da avaliação de impacto ambiental também foram sentidas em outros países que a adotaram e promoveu algumas adaptações quer na forma de leis ou guias de melhores práticas. Muitos realizaram uma análise e reforma destas práticas, não revogando a avaliação de impacto ambiental, mas acrescentando outros instrumentos para uma análise mais específica, conforme o caso demandava. Exemplos destes instrumentos são: a 
Avaliação Ambiental Estratégica AAE (SEA em inglês), a Avaliação de Impacto na Saúde ou Social e a Análise do Ciclo de Vida.

Segundo apresentação do então Presidente do Ibama, Volney Zanardi, (http://avaliacaodeimpacto.org.br/wp-content/uploads/2014/11/Palestra-VolneyZanardi-J\%C3\%BAnior.pdf) nos anos de 2011 a 2013 foram emitidas 2.153 licenças e 8 foram indeferidas, sendo devolvidos para adequação 22 estudos. $\mathrm{Ou}$ seja, menos de $2 \%$ dos estudos analisados deixam de ser aprovado, o que poderia representar que os estudos são bem embasados, que os procedimentos são claros e que há a efetiva participação da sociedade.

Como não tem sido esta a percepção, segundo levantamento realizado, entendemos que seria interessante analisar os estudos ambientais na forma de um estudo de caso, para verificar se nesta etapa tão essencial de identificação de impactos, proposição dos programas e participação da sociedade haveria oportunidades de melhorias.

\section{Conclusão do capitulo 3}

Neste capitulo foram apresentados os ritos do processo de licenciamento brasileiro e estudos críticos que identificam algumas melhorias já implementadas, mas principalmente oportunidades e necessidades para um licenciamento mais eficiente.

A avaliação entre os principais problemas identificados para o processo de licenciamento mostrou que há alguma associação entre as causas, mas que, no entanto, a resolução ou melhoria nem sempre é fácil ou direta.

Dos pontos destacados e que necessitam aperfeiçoamento, alguns exigem mudanças estruturais e demandarão prazos e discussões maiores como as alterações legais para unificação do processo ou mesmo reformas institucionais.

Dos problemas apresentados, o que mais nos chamou a atenção foi o relacionado à identificação de impactos por ser esta etapa a base para se pensar a mitigação ou compensação e assim tornar a implantação do projeto viável/interessante para a sociedade. Sem o correto diagnóstico dos impactos e sua mitigação todo o processo fica comprometido, se tornando apenas uma prática cartorial e burocrática, dispendiosa em recursos e prazos, que nada contribui para a preservação da qualidade socioambiental. E de nada adiantariam a melhoria nos demais gargalos e dificuldades apresentados. 
Para uma análise mais detalhada, no capitulo seguinte um estudo de caso será proposto, avaliando especificamente os impactos e os programas propostos em EIA/RIMAs para diferentes tipologias. 


\section{4 \\ O Processo de Licenciamento na prática - Estudo de Caso}

Neste capitulo se pretende por meio de estudo de caso, verificar a efetividade dos processos de licenciamento brasileiro no que se refere à identificação de impactos e programas propostos para mitigá-los ou formas de compensá-los. As seguintes perguntas devem ser respondidas com o estudo de caso:

1) Nos últimos anos houve aumento na identificação de impactos e programas?

2) Houve alterações na identificação de impactos e proposição de programas relacionados ao meio físico?

3) Houve alterações na identificação de impactos e proposição de programas relacionados ao meio biótico?

4) Houve alterações na identificação de impactos e proposição de programas relacionados ao meio antrópico/socioeconômico?

\section{Metodologia}

No contexto da metodologia aplicada no Estudo de Caso, foram estabelecidas algumas perguntas que deviam ser respondidas. Portanto será explicitado na forma de perguntas o aspecto a ser verificado seguido da justificativa. Quando necessário serão explicitados ajustes necessários na apresentação dos resultados dos estudos.

Para atingir o objetivo proposto, as seguintes etapas foram necessárias:

1) Selecionar os estudos a serem analisados;

2) Verificar se a amostragem é representativa para a análise;

3) Levantar os impactos e programas dos meios físicos, bióticos e socioeconômicos;

4) Verificar as alterações quantitativas nos dois períodos temporais selecionados;

5) Verificar a relação dos impactos com os programas;

6) Apresentar resultados dos estudos;

7) Apresentar as conclusões.

\section{Considerações a cerca do Estudo de Caso Proposto}


Foram considerados estudos disponíveis em sítios eletrônicos de órgão ambientais que realizam licenciamento no Brasil. Foram feitas procuras de EIA/RIMAs de empreendimentos, em função da potencialidade de significativo impacto ambiental, a fim de analisar se houve variação na identificação de impactos e proposição de programas em diferentes períodos.

Para este estudo foram escolhidos empreendimentos, que são causadores de impacto ambiental significativo, real ou potencial, razão pela qual são submetidos a um EIA/RIMA em seu processo de Licenciamento Prévio, seja ele na esfera estadual ou federal. Normalmente, são empreendimentos que tem interferência direta em mais de um município. Neste estudo não avaliaremos ou faremos comparações com processos de licenciamento municipais, em função da sua baixa abrangência espacial.

A escolha dos estudos que compõem a amostra levou em conta a proximidade de grandes centros. Neste estudo consideraremos preferencialmente empreendimentos a serem instaladas em pequenos e médios municípios, em municípios que não pertençam a regiões metropolitanas ou estejam próximos a capitais de estados. Em função do poder de transformação que um grande empreendimento pode causar em municípios cuja experiência com licenciamento e existência de grandes empreendimentos seja baixa.

Portanto o contexto de pequenos e médios municípios (inferior a 500.000 habitantes) se refere mais a características associadas a pouca urbanização e experiência de governança do que questões vinculadas às rápidas mudanças com a implantação de um empreendimento do que de fato ao tamanho populacional, embora ambos tendam a estar relacionados.

O porte do empreendedor, questões reputacionais, a capacidade financeira e o grau de inserção territorial desejado e sua cultura coorporativa podem interferir na proposição de programas e na capacidade de investimento dos projetos, embora sejam de difícil analise direta e fujam do pretendido por este estudo.

Da mesma forma as exigências, experiências e expectativas tanto da sociedade como dos órgãos licenciadores e governantes podem interferir diretamente no escopo dos estudos, percepções de impactos, programas, condicionantes e ajustes propostos, razão pela qual as conclusões podem não ser diretas, mas indicar tendências.

\section{Premissas da Amostragem}


Para traçar comparativos e verificar semelhanças se agrupou os empreendimentos por tipologia, considerando que pode haver coerência na identificação de impactos e programas.

Para a analise dos impactos típicos de cada tipologia de empreendimento e seus respetivos programas de mitigação foram considerados EIA/RIMAs com as seguintes premissas:

- Fossem de fácil acesso a qualquer interessado, ou seja, estivessem disponíveis em sítios de internet oficiais dos órgãos públicos brasileiros (Ibama, MMA, Inea RJ, Iema ES, etc).

- Estivessem disponíveis nos meses de agosto a outubro de 2014;

- Seleção não aleatória de estudos. Buscaram-se diferentes empreendedores e diferentes empresas de consultorias. Uma vez que a abrangência e profundidade dos estudos, impactos e medidas de mitigação podem ser influenciadas pela experiência e interesse dos envolvidos.

- Mantendo foco no objetivo da pesquisa, avaliando as tipologias de empreendimentos que teriam maior interação com questões relacionadas ao desenvolvimento ecológico ou socioeconômico local e com o planejamento urbano.

- Particularmente empreendimentos off shore não serão analisados neste estudo em função de algumas características próprias, como por exemplo a distância do empreendimento de comunidades, embora alguns municípios fossam sofrer as consequências.

- Empreendimentos que precisassem de EIA/RIMA capazes de influenciar/impactar significativamente em pequenos e médios municípios não metropolitanos, por seu poder poluidor, volume de investimentos, ocupação territorial, atratividade de mão de obra- poder de transformação.

- Tivessem sido elaborados nas seguintes faixas temporais: de 2001 a 2007 e de 2008 a 2014, a fim de se verificar tendências entre dois períodos temporais iguais, recentes, sem que haja um marco legal ou político para tal divisão.

O resultado do levantamento pode ser verificado nos anexos tabelas A e B.

Não são objetivos deste levantamento: 
- Avaliar se EIA/RIMAs foram bem feitos ou cumpriram Termos de Referencia;

- Fazer análise crítica de empreendedores, empresas de consultorias e órgão licenciadores, não sendo, portanto questionados os programas escolhidos por cada empresa/consultoria para mitigar os impactos, nem o parecer do órgão ambiental, sendo os programas e impactos apresentados como estão disponíveis nos documentos públicos;

- Avaliar as condicionantes impostas na LP, mesmo que estas complementem os programas;

- Considerar as demais ações realizadas ou propostas pelas empresas para mitigar os impactos que não estejam descritas na forma de programas e no texto pesquisado (EIA/RIMA), ações de investimento social, responsabilidade social ou de relacionamento;

- Avaliar as razões pelas quais estudos elaborados entre 2001 e 2007 ainda estão em analise no Ibama. Tendem a serem empreendimentos com restrições, porém para a análise de identificação dos impactos e seus programas, o histórico do processo não será levantado;

- Verificar os resultados e a eficiência das medidas propostas nos programas, para tanto seria necessário ter monitoramento pós-empreendimento, o que ainda não ocorre no Brasil;

- Avaliar as condições regionais que podem trazer diferenciação na avaliação de impactos.

\section{Amostragem Ibama}

Inicialmente foram analisados os EIA/RIMAs em análise/disponíveis no site do Ibama: www.ibama.gov.br/licenciamento ambiental

O resultado do levantamento foram 35 empreendimentos, de 9 tipologias em dois períodos temporais conforme a tabela 1 . 
Tabela 1 - Empreendimentos selecionados por tipologia e período

\begin{tabular}{lccc}
\hline \multicolumn{1}{c}{ Tipologia } & 2001 a 2007 & 2008 a 2014 & Total \\
\hline Ferrovias & 1 & 3 & 4 \\
Duto & 2 & 3 & 5 \\
Linha de Transmissão & 0 & 5 & 5 \\
Rodovia & 2 & 2 & 4 \\
Porto & 0 & 4 & 4 \\
Mineração & 1 & 3 & 4 \\
Industrial & 0 & 1 & 1 \\
UHE & 1 & 4 & 5 \\
UTE & 1 & 2 & 3 \\
\hline Total & 8 & 27 & 35
\end{tabular}

\section{Verificação da amostragem:}

- Para a primeira faixa temporal de 2001 a 2007 foi possível identificar 8 empreendimentos, sendo contempladas 6 das 9 tipologias;

- Para a segunda faixa temporal de 2008 a 2014 foram levantados 27 empreendimentos, com ao menos 2 projetos por tipologias, exceção na tipologia industrial onde havia apenas 1 empreendimento disponível;

- A intensão inicial era ter entre 4 e 5 empreendimentos para analise em cada tipologia, porém para UTE havia apenas 2 empreendimentos disponíveis para o período de 2008 a 2014 e 1 para o período de 2001 a 2007;

- Para a tipologia Linha de Transmissão, como não havia empreendimento disponível para o período de 2001 a 2007 e por haverem 5 empreendimentos disponíveis para o período de 2008 a 2014, se optou pelo uso dos 5 na análise;

- A quantidade de estudos identificados foi considerada suficiente para a análise;

- Não serão considerados nesta análise os parques eólicos, mesmo os licenciados pelo Ibama, em função de nenhum apresentar um EIA/RIMA. O processo de licenciamento ocorre por meio de RAS - Relatórios Ambientais Simplificados. 
- Os empreendimentos nas áreas de petróleo/gás também não serão considerados na analise que se segue, embora seu licenciamento possa se dar na forma de EIA/RIMA, uma vez que os potenciais impactos e consequentes programas socioeconômicos são pouco relacionados aos objetivos deste estudo, em função da sua característica marinha no Brasil.

Os Empreendimentos foram divididos em dois grupos:

1) 18 Empreendimentos lineares (dutos, LT, ferrovias e rodovias).

2) 17 Empreendimentos pontuais (mineração, industriais, portos, UHE, UTE).

\section{Empreendimentos Lineares}

Como empreendimento linear nesta amostragem temos 5 dutos (minerodutos e gasodutos), 5 linhas de transmissão, 4 ferrovias e 4 rodovias totalizando os 18 empreendimentos lineares que serão analisados neste estudo.

Os empreendimentos lineares se caracterizam por ocuparem faixas de poucos metros de largura (intervenção + uma faixa de servidão/domínio de aproximadamente 40 a 100 metros para cada lado) e quilômetros de comprimento, atravessando muitos municípios e por vezes, mais de um estado, sendo o licenciamento realizado principalmente na esfera federal e estadual.

O traçado pode ser feito evitando áreas mais sensíveis ecologicamente e socialmente, como aglomerações residenciais, Terras Indígenas, Unidades de Conservação, APP.

Uma das características é a necessidade de negociação com diversos proprietários. Na maioria dos casos não sendo necessária a desapropriação, mas sim uma autorização de uso ou passagem e uma eventual compensação pela restrição de uso e mudança de benfeitorias.

As linhas de transmissão, as ferrovias e as rodovias são consideradas empreendimentos de utilidade pública, mesmo que estejam a cargo de concessionários privados.

Não obstante as facilidades que ser considerada de utilidade pública possam trazer nos processos de desapropriação e supressão de vegetação, a preferencia de traçado será sempre o mais curto em função de custo/benefício, perpassando preferencialmente áreas rurais, sem vegetações nativas ou áreas especialmente protegidas e com poucas benfeitorias, procurando evitar aglomerados urbanos. 
O traçado leva em conta os custos econômicos dos desvios e prolongamento versus os entraves e conflitos de áreas sensíveis. Tendendo a minimizar a interferência com áreas de vegetação especialmente protegidas, interferência com comunidades indígenas, quilombola e tradicionais e povoamentos, em função dos conflitos que podem ser gerados, acarretando custo, mas principalmente comprometendo prazos.

Para a maioria dos empreendimentos lineares, os impactos mais significativos são durante a fase de implantação, quando há deslocamento pelos municípios de grande quantidade de empregados e prestadores de serviços.

Embora a implantação do empreendimento linear possa ser realizada em várias frentes, normalmente há um avanço cadencial sobre o território, sendo concentrado em cada localidade, mas por curtos espaços de tempo, alguns meses. O montante de empregados nesta fase de implantação é significativo, na ordem de milhares para grandes empreendimentos, sendo muitas vezes necessário construir alguns alojamentos ao longo do empreendimento, além dos canteiros.

No Brasil, em função do histórico de ocupação e investimento em infraestrutura, as maiores obras atualmente são realizadas em áreas menos habitadas, distantes do litoral, principalmente nas regiões Norte, Nordeste e CentroOeste. Muitos dos empreendimentos de ferrovias e rodovias não são empreendimentos novos, mas ampliações/duplicações de ferrovias e rodovias, assim como asfaltamento de vias antigas.

Ferrovias e rodovia são indutores de ocupação ao longo do seu traçado na fase de operação. Já as linhas de transmissões e os dutos não costumam causar mudanças definitivas socioambientais a não ser a restrição do uso do solo na faixa de servidão.

Nenhum empreendimento linear é gerador de empregos ou renda significativa durante a operação. Embora possam trazer benefícios socioeconômicos indiretos, como o aumento ou melhoria da capacidade de transporte de cargas e pessoas e a maior disponibilização de energia.

Não é incomum no Brasil a ocupação irregular das faixas de domínio das rodovias e ferrovias, causando incômodos adicionais relacionados a ruídos e materiais particulados, assim como risco de acidentes. 


\section{Empreendimentos Pontuais}

Como empreendimentos pontuais nesta amostragem temos 4 empreendimentos de portos, 4 de mineração, 1 industrial, 5 de usinas hidroelétricas e 3 de usinas termoelétricas, totalizando os 17 empreendimentos pontuais que serão analisados neste estudo.

Empreendimentos pontuais tendem a ter uma relação mais intensa com a comunidade vizinha, normalmente concentrados em poucos municípios e que perdurará durante o tempo de vida do empreendimento, causando alterações permanentes no modo de vida da cidade e de seus habitantes.

$\mathrm{O}$ aumento do fluxo migratório em busca de emprego ou melhores oportunidades é um dos indutores dos principais impactos em empreendimentos pontuais e ocorre desde o anuncio da intenção de implantação de um empreendimento. $\mathrm{O}$ crescimento explosivo destes municípios, principalmente em pequenos municípios sem capacidade de resposta rápida em termos de planejamento e estruturas provocam pressões e conflitos, aumentando o déficit de serviços públicos, ocupações irregulares, pressão sobre áreas ambientalmente sensíveis, como exemplo.

As questões socioeconômicas tendem portanto, a demandarem maior atenção em empreendimentos pontuais. Ao avaliar o panorama geral dos programas em dois períodos de tempo distintos, poderemos, mesmo com a diversidade dos empreendimentos pontuais, verificar tendências de avanços nos programas socioeconômicos propostos.

Há potenciais impactos negativos significantes tanto na fase de implantação como na de operação, enquanto que os impactos positivos de aumento da oferta de emprego e renda e a arrecadação de tributos tentem a ser mais significativos na fase de operação.

\section{Dados Levantados}

Para a análise pretendida a primeira tabulação foi feita considerando os seguintes dados: 
1) Órgão ambiental e tipologia de empreendimento

2) Nome do Projeto/ empreendedor e Estado do empreendimento

3) Características gerais do projeto como extensão, municípios diretamente afetados e quantidade de mão de obra prevista (direta e indiretamente na fase de implantação e operação).

4) Ano em que EIA/RIMA foi elaborado

5) Empresa de Consultoria

6) Relação dos Impactos identificados (meio físico/biótico/socioeconômico)

7) Relação dos Programas identificados (meio físico/biótico/socioeconômico)

\section{Justificativas:}

\section{1) Órgão ambiental e tipologia de empreendimento}

Uma das questões que gostaríamos de verificar é a existência de diferenças entre os EIA/RIMAs em função da tipologia do empreendimento, uma vez que dentro do mesmo órgão, normalmente há equipes diferentes para cada tipologia, podendo seguir um mesmo Termo de Referencia básico por Tipologia. Conforme a tipologia, mesmo em empreendimentos de mesmo tipo, como os lineares, os impactos socioeconômicos pós-obras podem ser bastante diferentes, como por exemplo: a ocupação que uma rodovia promove e que não deve ocorrer ao longo do traçado de um duto.

\section{2) Nome do Projeto/ empreendedor e Estado do empreendimento}

Sempre que possível se buscou estudos com empreendedores diferentes, uma vez que as grandes corporações podem ter padrões nas formas de gerenciamento dos impactos. A localização do empreendimento, em função das condições heterogênicas do Brasil, pode influenciar a demanda por determinados programas.

\section{3) Características gerais do projeto como extensão, municípios} diretamente afetados e quantidade de mão de obra prevista na fase de implantação e operação.

A extensão/tamanho de um empreendimento, bem como a quantidade de municípios envolvidos pode influenciar a proposição de Programas. Empreendimentos lineares tendem a interferir em muitos municípios, por vezes 
ultrapassando estados, com pouca geração de impostos e empregos na fase da operação. Já empreendimentos pontuais conviverão com uma mesma sociedade por anos, bem mais próximos das comunidades e sob acompanhamento constantes delas.

\section{4) Ano em que EIA/RIMA foi elaborado}

Embora não haja nenhum marco legal para diferenciar os dois períodos temporais escolhidos (de 2001 a 2007 e de 2008 a 2014) a maturidade do processo de licenciamento e pressões e mudanças nacionais e mundiais podem levar a alterações nas considerações dos impactos e consequentes programas associados.

\section{5) Empresa de Consultoria}

Pelo mesmo motivo da diversidade dos empreendedores, se buscou diferentes consultorias ambientais, para que estas com suas metodologias e equipes não influenciassem a analise. Algumas vezes, em espaços temporais diferentes pode ser interessante ter empreendedores ou consultorias repetidas para certificar que as diferenças de programas se devem a outros fatores como questões temporais ou locacionais, mais do que poder de investimento ou experiência técnica na proposição de mitigação.

\section{6) Relação dos Impactos identificados (meio físico/biótico/socioeconômico)}

A análise quantitativa dos impactos identificados pode dar indicativos de alteração na percepção dos impactos, que resultarão em programas ou não. A descrição dos impactos permite analisar as alterações temporais nos impactos de forma mais qualitativa à medida que ele pode ser associado a programas e comparados em períodos temporais.

\section{7) Relação dos Programas identificados (meio físico/biótico/socioeconômico)}

Ao se comparar programas de um mesmo meio poderemos estabelecer semelhanças e diferenças, demandadas por questões legais, temporais, características da tipologia e dos impactos associados ou de localização.

O resultado do levantamento pode ser verificado nas tabelas 13 e 14 (Ver Capítulo 7 - Anexos).

O início da nossa análise se dá com a seguinte pergunta: 
Pergunta: Nos últimos anos houve aumento na identificação de impactos e programas?

Para tanto, foram listados os empreendimentos, com o número de impactos e programas nos meios físico, biótico e socioeconômico conforme pode ser verificado na Tabela 2. 
Tabela 2 - Quantitativo de impactos e programas associados a cada meio nos empreendimentos selecionados

(Continua)

\begin{tabular}{|c|c|c|c|c|}
\hline Tipologia & Empreendimento & & Impactos & Programas \\
\hline Ferrovia & FNS Norte Sul Valec & 2002 & 5 físicos, 6 biótico e 4 socioeconômico & 4 físico, 5 biótico e 3 socioeconômico \\
\hline Ferrovia & EF334 TO BA Valec & 2009 & 1 físico, 2 biótico e 7 socioeconômico & 6 físico, 5 biótico e 5 socioeconômico \\
\hline Ferrovia & EF 354 GO Valec & 2010 & 13 físico, 9 biótico e 11 socioeconômico & 5 físico, 6 biótico e 10 socioeconômico \\
\hline Ferrovia & FerroNorte ALL & 2010 & 7 físico, 12 biótico e 17 socioeconômico & 7 físico, 6 biótico e 11 socioeconômico \\
\hline Mineroduto & MMX Minas - Rio & 2006 & 5 físico, 10 biótico e 6 socioeconômico & 6 físico, 11 biótico e 11 socioeconômico \\
\hline Mineroduto & Ferrous Pres Kennedy ES & 2010 & 9 físico, 15 biótico e 10 socioeconômico & 8 físico, 12 biótico e 9 socioeconômico \\
\hline Gasoduto & G Caragua. - Taubate Petro & 2006 & 3 físico 2 biótico e 8 socioeconômico & 5 físico, 4 biótico e 5 socioeconômico \\
\hline Gasoduto & G.S - N Capixaba Petrobras & 2011 & 1 físico, 5 biótico e 9 socioeconômico & 2 físico, 0 biótico e 3 socioeconômico \\
\hline Gasoduto & G. Rota 3-Comperj & 2014 & 4 físico, 4 biótico e 13 socioeconômico & 6 físico, 5 biótico e 5 socioeconômico \\
\hline LT & Linha Taubaté - SP N. Iguaçu RJ & 2012 & 5 físico, 4 biótico e 11 socioeconômico & 5 físico, 5 biótico e 5 socioeconômico \\
\hline LT & ATEXVI -Milagres Ce, PB e RN & 2014 & 5 físico, 8 biótico e 24 socioeconômico & 5 físico, 8 biótico e 8 socioeconômico \\
\hline LT & IEGuaranhuns PE,Al & 2012 & 9 físico, 6 biótico e 23 socioeconômico & 5 físico, 5 biótico e 8 socioeconômico \\
\hline LT & TransNorte - Manaus Boa Vista & 2014 & 7 físico, 6 biótico e 24 socioeconômico & 3 físico, 8 biótico e 6 socioeconômico \\
\hline LT & ATE XVI -Miracema To - BA & 2013 & 5 físico, 8 biótico e 24 socioeconômico & 4 físico, 8 biótico e 13 socioeconômico \\
\hline Rodovia & DNIT BR $101 \mathrm{AL}, \mathrm{SE}$ e BA & 2007 & 6 físico, 5 biótico e 10 socioeconômico & 6 físico, 6 biótico e 6 socioeconômico \\
\hline Rodovia & DNIT BR 163/PA e 230/PA & 2002 & 12 físico, 6 biótico e 21 socioeconômico & 3 físico, 3 biótico e 9 socioeconômico \\
\hline Rodovia & DNIT BR 290 RS & 2010 & 8 físico, 11 biótico e 12 socioeconômico & 9 físico, 6 biótico e 5 socioeconômico \\
\hline Rodovia & DNIT BR $135 \mathrm{MG}$ & 2013 & 12 físico, 8 biótico e 32 socioeconômico & 5 físico, 7 biótico e 7 socioeconômico \\
\hline Porto & BTP Santos & 2008 & 13 físico, 11 biótico e 22 socioeconômico & 13 físico, 4 biótico, 4 socioeconômico \\
\hline Porto & Brites Santos & 2009 & 12 físico, 10 biótico e 18 & 9 físico, 12 biótico e 8 socioeconômico \\
\hline Porto & Porto Sul BA & 2011 & 20 físico, 26 biótico e 24 socioeconômico & 15 físico, 8 biótico e 14 socioeconômico \\
\hline
\end{tabular}


Porto $\quad \mid$ Ferrous $\quad|2010| 4$ físico, 10 biótico e 19 socioeconômico $\quad \mid 14$ físico, 5 biológico, 8 socioeconômico

Tabela 2 - Quantitativo de impactos e programas associados a cada meio nos empreendimentos selecionados

\begin{tabular}{l|l|l|l|l}
\hline Mineração & Platô Bacaba - MRN- PA & 2007 & 11 físico, 11 biótico e 10 socioeconômico & 4 físico, 5 biótico e 3 socioeconômico \\
Mineração & Ferro Carajás S11D- Vale PA & 2010 & 8 físico, 11 biótico e 15 socioeconômico & 5 físico, 6 biótico e 11 socioeconômico \\
Mineração & Projeto Retiro - RGM -RS & 2014 & 5 físico, 6 biótico e 14 socioeconômico & 4 físico, 8 biótico e 6 socioeconômico \\
Mineração & Santa Quitéria CE & 2014 & 13 físico, 11 biótico e 21 socioeconômico & 15 físico, 8 biótico e 9 socioeconômico \\
Industrial & Complexo Industrial Pecem CE & 2009 & 6 físico, 5 biótico e 4 socioeconômico & 13 físico, 6 biótico e 11 socioeconômico \\
UHE & AHE Paulista - Furnas GO/MG & 2005 & 7 físico, 5 biótico e 14 socioeconômico & 8 físico, 4 biótico e 6 socioeconômico \\
UHE & UHE Santo Antonio do Jirau & 2009 & 22 físico, 46 biótico e 40 socioeconômico & 3 físico, 7 biótico e 10 socioeconômico \\
UHE & UHE Pai Querê - SC e RS & 2011 & 12 físico, 21 biótico e 22 socioeconômico & 6 físico, 9 biótico e 8 socioeconômico \\
UHE & UHE Davinópolis - Cemig MG & 2012 & 7 físico, 8 biótico e 16 socioeconômico & 7 físico, 7 biótico e 10 socioeconômico \\
UHE & UHE Itaocara RJ MG & 2014 & 21 físico, 13 biótico e 38 socioeconômico & 8 físico, 15 biótico e 14 socioeconômico \\
UTE & UTE Tres Lagoas MS Petrobras & 2001 & 6 físico, 3 biótico e 5 socioeconômico & 4 físico, 1 biótico e 2 socioeconômico \\
UTE & UTE Porto de Itaqui- MPX & 2008 & 9 físico, 5 biótico e 21 socioeconômico & 7 físico, 4 biótico e 7 socioeconômico \\
UTE & UTE Pampa Sul-RS & 2013 & 13 físico, 12 biótico e 12 socioeconômico & 7 físico, 7 biótico e 6 socioeconômico \\
\hline
\end{tabular}


Não há uma uniformidade no quantitativo de impactos, nem nos programas para um mesmo tipo de empreendimento. Da mesma forma como não é possível diferenciar o quantitativo de impactos e programas nos períodos temporais. Também não foi possível verificar correlações quantitativas diretas entre os impactos e programas. Para o propósito deste estudo se recomenda que uma análise mais detalhada seja feita.

Os impactos de um modo geral são apresentados de forma superficial, de forma mais qualitativa e pouco quantitativa. Escolhemos avaliar os impactos da forma como são apresentados no RIMA, pois é esta informação que a sociedade e principais interessados têm acesso no processo de licenciamento.

Partimos então para a análise mais detalhada dos impactos e programas separandoos por meio físico, biótico e antrópico ou socioeconômico.

\section{Meio Físico}

Pergunta: Houve alterações na identificação dos impactos relacionados ao meio físico?

Os impactos relacionados ao meio físico estão na sua grande maioria associados ao período de obra e são associados a: alterações no solo como erosão, contaminação, carreamento, instabilidades de taludes durante a terraplanagem; alterações na qualidade do ar em função de emissões de material particulado e gases da movimentação de solo e equipamentos; alterações nos corpos hídricos (superficiais e subterrâneos) por interferências e carreamentos e alterações em função de vibrações e ruídos dos equipamentos de obras.

No entanto não se verificou uma padronização na identificação destes impactos, dificultando a comparação. Para conseguir comparar, mesmo que em termos de quantidade, algumas considerações foram necessárias. Para o objetivo deste estudo, se agrupou em grandes temas alguns impactos ao invés de considerar a forma como estavam descritos, sem que a essência do impacto fosse alterada. Por exemplo, um dos estudos apresentou os seguintes potenciais impactos: desencadeamento de processos erosivos, impacto decorrente da ruptura de taludes e impactos decorrentes de recalques e rupturas de solos moles na fundação. Embora sejam impactos distintos e provavelmente pertinentes para fins de comparação com 
os demais estudos foram considerados como impactos relacionados aos temas: solo e erosão.

Entendemos que estas simplificações neste estudo específico foram necessárias para poder atender ao objetivo que é comparar estudos tão díspares e fazer uma análise de tendência. Os impactos tais como foram apresentados nos estudos, sempre poderão de novo ser verificados nas Tabelas A e B no Anexo.

Da mesma forma, verificamos que alguns impactos são classificados como pertencentes a diferentes meios (físico, biótico ou antrópico) nos estudos em função da perspectiva de analise. Como exemplo temos o risco de intervenção a cavidades, que embora a formação da cavidade estejam relacionadas a aspectos geológicos, sua proteção se dá em função da importância de preservação do patrimônio, podendo assim ser considerado um impacto sobre o meio físico ou antrópico.

Para uma melhor análise nos propósitos deste estudo se fez necessário o "reenquadrar", uniformizando o meio de descrição desses impactos. Os impactos que foram atribuídos a meios diferentes e "uniformizados" neste estudo foram:

- Interferência em concessão minerária, neste estudo classificado como sendo do meio físico, por entender que as ações são mais de pesquisa e negociação junto aos detentores de autorização do DNPM, do que de impactos socioeconômicos pela não exploração;

- Interferência em cavernas/espeleológicos, neste estudo classificado como sendo do meio socioeconômico, embora estejam relacionadas à geologia do local, em função de sua valorização como patrimônio cultural, histórico, paisagístico ou científico;

- Alteração na paisagem, embora as primeiras alterações sejam associadas ao meio físico e biótico e bastante concreto, o maior impacto se dará pela percepção e incômodo da comunidade, sendo neste estudo classificado como sendo do meio socioeconômico.

A escolha do meio a ser considerado neste estudo, se deu, considerando principalmente a lógica impacto - programa de mitigação, embora nos estudos elas fossem encontradas em diferentes meios, sem que necessariamente estivessem errada. A alteração do "meio original” para o meio agora considerado foi necessária para que os impactos e programas do estudo pudessem ser comparados. 
A síntese dos impactos físicos em empreendimentos lineares e pontuais pode ser verificado na tabela 3 , onde entre parênteses temos o número de vezes que tal tema aparece nos estudos/ o numero de estudos avaliados naquele período.

Tabela 3 - Impactos físicos/ estudos em empreendimentos lineares e pontuais, em dois períodos temporais

\begin{tabular}{|c|c|c|c|c|}
\hline \multirow{2}{*}{ Impactos no Meio Físico } & \multicolumn{2}{|c|}{ Lineares } & \multicolumn{2}{|c|}{ Pontuais } \\
\hline & $\begin{array}{c}2001 \mathrm{a} \\
2007\end{array}$ & $\begin{array}{c}2008 \mathrm{a} \\
2014\end{array}$ & $\begin{array}{c}2001 \mathrm{a} \\
2007\end{array}$ & $\begin{array}{c}2008 \mathrm{a} \\
2014\end{array}$ \\
\hline $\begin{array}{l}\text { Qualidade da água (superficial e } \\
\text { subterrânea) }\end{array}$ & $(4 / 5)$ & $(10 / 13)$ & $(3 / 3)$ & $(14 / 14)$ \\
\hline Dinâmica hídrica/drenagem & $(4 / 5)$ & $(5 / 13)$ & $(2 / 3)$ & $(13 / 14)$ \\
\hline Erosão & $(3 / 5)$ & $(11 / 13)$ & $(3 / 3)$ & $(11 / 14)$ \\
\hline Solo/ poluição & $(5 / 5)$ & $(10 / 13)$ & $(1 / 3)$ & $(9 / 14)$ \\
\hline Qualidade do ar & $(4 / 5)$ & $(7 / 13)$ & $(2 / 3)$ & $(10 / 14)$ \\
\hline Ruído/ vibração & $(3 / 5)$ & $(4 / 13)$ & $(1 / 3)$ & $(9 / 14)$ \\
\hline Poluição acidente & $(2 / 5)$ & $(8 / 13)$ & $(2 / 3)$ & $(9 / 14)$ \\
\hline Minerária & $(1 / 5)$ & $(8 / 13)$ & $(1 / 3)$ & $(3 / 14)$ \\
\hline Clima & $(1 / 5)$ & $(1 / 13)$ & $(1 / 3)$ & $(2 / 14)$ \\
\hline Eletromagnético & & $(1 / 13)$ & & \\
\hline Conhecimento científico & & & & $(1 / 14)$ \\
\hline
\end{tabular}

Analise dos resultados dos potenciais impactos identificados no meio físico em empreendimentos lineares e pontuais demonstram certa uniformidade, mesmo quanto à variação temporal e tipológica, demonstrando ser possível uma consolidação na identificação dos impactos.

O que se verifica é que alguns potenciais impactos são bastante recorrentes quando se trata de impacto sobre meio físico, particularmente durante a obra. Não se tratando, portanto de potencial impacto, mas impacto certo. É previsível que o processo de terraplanagem para qualquer tipo de empreendimento provoque interferência em corpos hídricos e gere emissões atmosféricas e ruído em função da movimentação de equipamentos e solo.

Nestes casos de impactos certos e conhecidos, os estudos poderiam trazer dados mais precisos e diretos, informando, por exemplo, a extensão e local da área da obra, a quantidade de meses e horários de trabalhos e a interferência em corpos hídricos, já prevendo suas consequências. 


\section{Pergunta: Houve alterações em termos de programas do meio físico proposto nos dois períodos?}

Em relação aos programas, se verifica que alguns são bastante específicos e se optou por não agregar em grandes temas.

A tabela 4 nos mostra a relação temporal dos programas dos projetos. Os números entre parênteses informam respectivamente (numero de Programas no tema/ numero total de EIA/RIMA considerados neste período).

Tabela 4 - Programas do meio físico

\begin{tabular}{|c|c|c|c|c|}
\hline \multirow{2}{*}{ Programas Físicos } & \multicolumn{2}{|c|}{$\begin{array}{l}\text { Empreendimentos } \\
\text { lineares }\end{array}$} & \multicolumn{2}{|c|}{$\begin{array}{l}\text { Empreendimentos } \\
\text { Pontuais }\end{array}$} \\
\hline & $\begin{array}{l}2001 \mathrm{a} \\
2007\end{array}$ & $\begin{array}{c}2008 \mathrm{a} \\
2014\end{array}$ & $\begin{array}{c}2001 \mathrm{a} \\
2007\end{array}$ & $\begin{array}{c}2008 \mathrm{a} \\
2014\end{array}$ \\
\hline Gestão Ambiental & $(3 / 5)$ & $(9 / 13)$ & $(1 / 3)$ & $(9 / 14)$ \\
\hline $\begin{array}{l}\text { Controle Ambiental da Construção } \\
\text { Gestão de Risco e Plano de Emergência }\end{array}$ & $(4 / 5)$ & $(8 / 13)$ & & $(11 / 14)$ \\
\hline Individual & $(3 / 5)$ & $(11 / 13)$ & & $(7 / 14)$ \\
\hline Qualidade águas / recursos hídricos & $(3 / 5)$ & $(5 / 13)$ & $(3 / 3)$ & $(11 / 14)$ \\
\hline Controle Processo Erosivo & $(4 / 5)$ & $(8 / 13)$ & $(2 / 3)$ & $(5 / 14)$ \\
\hline Ruído & $(1 / 5)$ & $(6 / 13)$ & & $(5 / 14)$ \\
\hline direitos minerários & $(1 / 5)$ & $(6 / 13)$ & $(1 / 3)$ & $(2 / 14)$ \\
\hline Gerenciamento de Resíduos & $(2 / 5)$ & $(4 / 13)$ & $(2 / 3)$ & $(5 / 14)$ \\
\hline Gerenciamento de Efluentes & $(1 / 5)$ & $(4 / 13)$ & $(1 / 3)$ & $(6 / 14)$ \\
\hline Sedimentos/dragagem/batimetria & $(1 / 5)$ & $(1 / 13)$ & $(1 / 3)$ & $(9 / 14)$ \\
\hline emissões atmosféricas/qualidade ar & & $(4 / 13)$ & $(3 / 3)$ & $(7 / 14)$ \\
\hline Controle Poluição & & $(4 / 13)$ & & $(2 / 14)$ \\
\hline Passivos & & $(1 / 13)$ & & \\
\hline Canteiro & & $(1 / 13)$ & & \\
\hline Eletromagnetismo & & $(1 / 13)$ & & \\
\hline $\begin{array}{l}\text { lençol freático/ águas subterrâneas } \\
\text { sismológico/hidrodinâmicos/oceanográfico }\end{array}$ & & & $(1 / 3)$ & $(9 / 14)$ \\
\hline s climatológico & & & $(1 / 3)$ & $(7 / 14)$ \\
\hline linha da costa & & & & $(4 / 14)$ \\
\hline auditoria ambiental (obrigatório porto) & & & & $(5 / 14)$ \\
\hline monitoramento e qualidade de solos & & & & $(3 / 14)$ \\
\hline monitoração radiológica & & & & $(1 / 14)$ \\
\hline Descomissionamento & & & & $(1 / 14)$ \\
\hline
\end{tabular}

Houve um considerável aumento dos programas propostos tanto para empreendimentos lineares como nos pontuais quando comparados os dois períodos temporais. 
Embora o Programa de Controle Ambiental da Construção esteja associado aos impactos relativos à obra, a sua proposição que pode contemplar a gestão dos resíduos, emissões atmosféricas e monitoramentos de qualidade do ar e de recursos hídricos, processos erosivos, ruídos e vibrações, em termos de esclarecer para a sociedade o que esta sendo proposto é vago, não sendo de fácil associação aos impactos previstos. $\mathrm{O}$ que se verifica é a sua frequente proposição, funcionando quase como um programa "coringa" onde tudo cabe sem especificar de fato o que será realizado. O mesmo ocorrendo com o Programa de Gestão Ambiental.

Os Programas de Gestão de Risco e o Plano de Emergência Individual, assim como o de Auditorias Ambientais se tornaram mandatórios para alguns empreendimentos pontuais como os portos, o que pode explicar o aumento significativo de sua proposição.

Pergunta: Há relação entre os impactos e programas identificados para

\section{o meio físico?}

Ao relacionarmos os impactos e programas, obtivemos a tabela 5.

Tabela 5 - Relação entre Impactos e Programas do Meio Físico

\begin{tabular}{|c|c|}
\hline Impactos no Meio Físico & Programas do Meio Físico \\
\hline $\begin{array}{l}\text { Qualidade da água } \\
\text { (superficial e subterrânea) }\end{array}$ & $\begin{array}{l}\text { Qualidade águas / recursos hídricos } \\
\text { Gerenciamento de Efluentes }\end{array}$ \\
\hline Dinâmica hídrica/drenagem & Lençol freático/ águas subterrâneas \\
\hline Erosão & $\begin{array}{l}\text { Controle Processo Erosivo } \\
\text { Linha da costa } \\
\text { Sismológico/hidrodinâmicos/oceanográficos } \\
\text { Sedimentos/dragagem/batimetria }\end{array}$ \\
\hline Solo/ poluição & $\begin{array}{l}\text { Monitoramento e qualidade de solos } \\
\text { Monitoração radiológica } \\
\text { Passivos }\end{array}$ \\
\hline Qualidade do ar & Emissões atmosféricas/qualidade ar \\
\hline Clima & Climatológico \\
\hline \multirow[t]{3}{*}{ Ruído/ vibração } & Ruído \\
\hline & Gerenciamento de Resíduos \\
\hline & Canteiro \\
\hline
\end{tabular}


Tabela 5 - Relação entre Impactos e Programas do Meio Físico

\begin{tabular}{l|l|l|}
\hline & $\begin{array}{l}\text { Controle Poluição } \\
\text { Gestão de Risco e Plano de Emergência } \\
\text { Individual } \\
\text { Poluição acidente }\end{array}$ & \\
\hline Minerária & direitos minerários & \\
\hline Eletromagnético & Descomissionamento & \\
\hline Conhecimento científico & & \\
\hline
\end{tabular}

A maioria dos impactos e programas guarda relação direta entre si e são facilmente identificáveis de forma qualitativa. Difícil é a identificação, pela matriz, da extensão destes impactos e da capacidade de mitigação dos programas.

O programa relacionado a resíduos sólidos pode ter sido proposto em função da legislação ambiental específica, sem que a geração seja um impacto significante.

O Programa de Canteiros, embora tenha uma vertente física em função do espaço que ocupa, da geração de efluentes e resíduos, parece ter origem e estar associado à necessidade de uso de mão de obra externa aos municípios próximos que muito podem impactar também sob o prisma da socioeconomia.

Para o impacto positivo de conhecimento científico para o meio físico não foi proposto nenhum programa específico, sendo identificado como um impacto positivo, sem que, no entanto se proponha programa para potencializar.

O Programa de Auditoria Ambiental está claramente associado a uma obrigação prevista em lei para atividades portuárias estando associado ao risco de acidentes.

O Programa de Passivos no meio físico é associado à interferência em solos contaminados.

A proposta de estabelecer procedimentos padrões na identificação dos impactos e proposição de programas, em análise pelo órgão ambiental federal, parece de fato ser aplicável para o meio físico, onde os impactos tem uma relação estreita com soluções de engenharia e onde padrões podem ser facilmente 
estabelecidos e controlados. Exigindo-se, desta forma, as melhores tecnologias disponíveis.

\section{MEIO BIÓTICO}

Pergunta: Houve alterações na identificação dos impactos relacionados ao meio biótico?

Os impactos no meio biótico são fortemente associados à fase de obras, principalmente em áreas não urbanas, quando a primeira etapa é a supressão da vegetação e com ela a retirada ou afugentamento da fauna e a alteração de habitat.

Os impactos sobre o meio biótico para empreendimentos lineares e pontuais tendem a ser diferentes em função das características de ocupação do solo. Sendo mais impactante e definitivo para empreendimentos pontuais, enquanto que particularmente para ferrovias e rodovias, com relação ao risco de atropelamento de fauna, tenda a ser permanente durante toda a operação.

Da mesma forma foi necessário, para os objetivos deste estudo, juntar impactos com temas similares. Por exemplo: mesmo que num mesmo estudo existissem o impacto de afugentamento da mastofauna e atropelamento da herpetofauna, o impacto considerado foi impacto à fauna. Esta generalização do impacto, para este estudo específico foi necessário para que a análise da lógica impacto - programa pudesse ser verificada e comparada nos diversos estudos.

Embora a identificação de animais peçonhentos esteja associada a acidentes com empregados durante as obras, neste caso, em função da sua identificação serem feita por biólogos, a sua análise será no meio biótico.

A tabela 6 apresenta os impactos do meio biótico em empreendimentos lineares e pontuais os números entre parênteses informam respectivamente (numero de impactos no tema/ numero total de EIA/RIMA considerados neste período). 
Tabela 6 - Impacto biótico/ estudos em empreendimentos lineares e pontuais, em dois períodos temporais.

\begin{tabular}{llll|l|l}
\hline \multicolumn{1}{c}{ Impactos no Meio Biótico } & \multicolumn{3}{c}{ Lineares } & \multicolumn{2}{c}{ Pontuais } \\
\hline Impacto fauna & 2001 a 2007 & 2008 a 2014 & 2001 a 2007 & 2008 a 2014 \\
\cline { 2 - 6 } Mortandade fauna & $(5 / 5)$ & $(11 / 13)$ & $(3 / 3)$ & $(14 / 14)$ \\
Supressão & $(4 / 5)$ & $(11 / 13)$ & $(2 / 3)$ & $(13 / 14)$ \\
Habitats & $(5 / 5)$ & $(10 / 13)$ & $(3 / 3)$ & $(11 / 14)$ \\
Diversidade fauna & $(5 / 5)$ & $(9 / 13)$ & $(2 / 3)$ & $(12 / 14)$ \\
Caça & $(2 / 5)$ & $(6 / 13)$ & $(2 / 3)$ & $(12 / 14)$ \\
Incêndios & $(1 / 5)$ & $(7 / 13)$ & $(1 / 3)$ & $(7 / 14)$ \\
Espécies exóticas/vetores & $(2 / 5)$ & $(3 / 13)$ & & $(8 / 14)$ \\
Fragmentação & $(1 / 5)$ & $(8 / 13)$ & & $(1 / 14)$ \\
APP, RL, UC. & $(2 / 5)$ & $(4 / 13)$ & & $(7 / 14)$ \\
Barreira & $(1 / 5)$ & $(5 / 13)$ & & $(6 / 14)$ \\
Animais Peçonhentos & $(1 / 5)$ & $(1 / 13)$ & & $(2 / 14)$ \\
\hline
\end{tabular}

Analise dos resultados dos impactos do meio biótico em empreendimentos lineares e pontuais demonstram que os temas são os mesmos para os dois grupos de empreendimentos.

Particularmente para empreendimentos pontuais, quando comparado os dois períodos temporais, houve um aumento considerado nos temas abordados, se equiparando aos temas dos empreendimentos lineares.

Uma das possíveis causas é a localização remota destes empreendimentos, ou o aumento das exigências dos estudos bióticos, mesmo em áreas já antropizadas, na fase de implantação.

Mais uma vez os resultados mostraram que a análise dos impactos de forma qualitativa, como é realizada atualmente, pouca informação é capaz de fornecer sobre a intensidade dos impactos.

Pergunta: Houve alterações em termos de Programas do meio biótico proposto nos dois períodos?

A tabela 7 nos mostra a relação temporal dos programas dos projetos. Os números entre parênteses informam respectivamente (numero de Programas no tema/ numero total de EIA/RIMA considerados neste período). 
Tabela 7 - Relação temporal dos Programas dos projetos

\begin{tabular}{|c|c|c|c|c|}
\hline & \multicolumn{2}{|c|}{ linear } & \multicolumn{2}{|c|}{ Pontual } \\
\hline Programas biótico & $\begin{array}{c}2001 \mathrm{a} \\
2007\end{array}$ & $\begin{array}{c}2008 \text { a } \\
2014\end{array}$ & $\begin{array}{c}2001 \mathrm{a} \\
2007\end{array}$ & $\begin{array}{c}2008 \mathrm{a} \\
2014\end{array}$ \\
\hline Monitoramento e proteção de fauna & $(05 / 05)$ & $(10 / 13)$ & $(02 / 03)$ & $(14 / 14)$ \\
\hline Compensação ambiental e florestal & $(02 / 05)$ & $(10 / 13)$ & $(02 / 03)$ & $(12 / 14)$ \\
\hline $\begin{array}{l}\text { Plantio (recuperação de áreas degradadas, passivos, } \\
\text { Mata ciliar, APP, RL) }\end{array}$ & $(05 / 05)$ & $(10 / 13)$ & $(02 / 03)$ & $(10 / 14)$ \\
\hline Monitoramento e proteção da Flora (resgate) & $(03 / 05)$ & $(07 / 13)$ & $(02 / 03)$ & $(10 / 14)$ \\
\hline Afugentamento e resgate de fauna & $(01 / 05)$ & $(05 / 13)$ & $(01 / 03)$ & $(07 / 14)$ \\
\hline Supressão de vegetação & $(01 / 05)$ & $(07 / 13)$ & & $(06 / 14)$ \\
\hline Germoplasma & $(02 / 05)$ & $(06 / 13)$ & & $(02 / 14)$ \\
\hline $\begin{array}{l}\text { Monitoramento e mitigação de atropelamento de } \\
\text { fauna (acidente, peçonhentos) }\end{array}$ & & $(05 / 13)$ & & $(06 / 14)$ \\
\hline $\begin{array}{l}\text { Prevenção de queimadas (monitoramento e } \\
\text { combate) }\end{array}$ & $(02 / 05)$ & $(01 / 13)$ & & \\
\hline Manutenção da faixa de servidão/domínio & & $(03 / 13)$ & & \\
\hline $\begin{array}{l}\text { Manejo de fauna (introdução de espécies nativas } \\
\text { para sucessão ecológica) }\end{array}$ & & $(01 / 13)$ & & \\
\hline Compensação gases de efeito estufa & & $(01 / 13)$ & & \\
\hline Averbação de reserva legal & & $(02 / 13)$ & & \\
\hline Construção de passagem de fauna & $(01 / 05)$ & & & $(01 / 14)$ \\
\hline Plantio paisagístico (funcional) & $(01 / 05)$ & & & $(02 / 14)$ \\
\hline
\end{tabular}

Houve aumento significativo na identificação de programas considerando os dois momentos temporais. Os novos programas propostos podem ser classificados, em termos temáticos, como um detalhamento dos programas macros propostos anteriormente.

De modo geral os programas relativos ao meio biótico poderiam ser concentrados e parametrizados em 6 programas/temas principais. São eles:

- Programa de Monitoramento e Proteção da Fauna, cabendo como subprograma o manejo de fauna, a ampliação do conhecimento científico, os mecanismos de evitar acidentes como transposições e passagens de fauna, a reintrodução de espécies, os monitoramentos de espécies específicas de especial interesse)

- Programa de Compensação Ambiental e Programa de Compensação Florestal. Ambas são obrigações previstas legalmente e já possuam procedimentos e regras claras de aplicabilidade, tanto para o calculo dos recursos devidos como para a sua aplicação, devendo ser informado quando já previsto o quantitativo a ser plantado ou investido e o local) 
- Programa de Recuperação de áreas degradadas, em áreas alteradas diretamente pela obra ou em função de passivos locais ou necessidade de recuperação de áreas prioritárias e com obrigações legais (Áreas de Preservação Permanente, Reserva Legais, nascentes, matas ciliares etc.). Se dá normalmente com o plantio de espécies vegetais ou sua indução e o monitoramento por alguns anos.

- Programa de Monitoramento e Proteção da Flora, cabendo os subprogramas de resgate de espécies como epífitas, banco de germoplasma, sementes e monitoramentos. As áreas recuperadas e com replantio florestal também podem fazer parte do programa maior de proteção da flora. Se associado com a fauna pode gerar um programa maior de preservação da biodiversidade de uma área ou bioma.

- Programa de Supressão Vegetal, que envolve o controle da área a ser suprimida buscando a minimização, o acompanhamento para afugentamento e resgate de fauna e a recuperação posterior, se for o caso. É nesta etapa que podem ocorrer acidentes com a fauna e, portanto fazendo parte do subprograma de afugentamento e resgate.

Desta forma, entendemos que mesmo os programas poderiam ser padronizados pelos órgãos ambientais, estabelecendo parâmetros para os programas em função da experiência já adquirida.

Particularmente para o meio biótico um tratamento especial deveria ser dado ao conhecimento adquirido e ao armazenamento dos dados, considerando que alguns monitoramentos são feitos de forma permanente.

Os estudos, em função dos recursos dispendidos, poderiam ser utilizados para o aumento não só do conhecimento, mas do conhecimento científico, como é o caso dos programas associados ao resgate de germoplasma e o estudo de espécies raras e sob risco e/ou pouco conhecidas. Precisando para tanto haver interação entre os órgãos ambientais e os institutos de pesquisa e academia científica.

Pergunta: Há relação entre os impactos e programas identificados para o meio biótico?

A tabela 8 compara os impactos com os programas do meio biótico. 
Tabela 8 - Impactos e Programas do Meio Biótico

\begin{tabular}{ll}
\hline \multicolumn{1}{c}{ Impactos meio biótico } & \multicolumn{1}{c}{ Programas meio biótico } \\
\hline $\begin{array}{l}\text { Impacto à fauna } \\
\text { Mortandade fauna }\end{array}$ & Monitoramento e proteção de fauna \\
\hline Barreira à fauna & $\begin{array}{l}\text { Monitoramento e mitigação de } \\
\text { atropelamento de fauna (acidente, } \\
\text { peçonhentos) }\end{array}$ \\
\hline Animais Peçonhentos & Construção de passagem de fauna \\
\hline Diversidade fauna & $\begin{array}{l}\text { Manejo de fauna (introdução de espécies } \\
\text { nativas para sucessão ecológica) }\end{array}$ \\
Caça & $\begin{array}{l}\text { Afugentamento e resgate de fauna } \\
\text { Supressão de vegetação }\end{array}$ \\
\hline Supressão & $\begin{array}{l}\text { Compensação ambiental e florestal } \\
\text { Germoplasma }\end{array}$ \\
\hline Habitats & $\begin{array}{l}\text { Monitoramento e proteção da Flora } \\
\text { (resgate) }\end{array}$ \\
\hline Espécies exóticas/vetores & Manutenção da faixa de servidão/domínio \\
\hline Fragmentação/ Barreira & $\begin{array}{l}\text { Plantio (recuperação de áreas degradadas, } \\
\text { passivos, Mata ciliar, APP, RL) }\end{array}$ \\
\hline Averbação de reserva legal \\
\hline APP, RL, UC. & $\begin{array}{l}\text { Prevenção de queimadas (monitoramento e } \\
\text { combate) }\end{array}$ \\
\hline Incêndios & Plantio paisagístico (funcional) \\
\hline Paisagem (meio socioeconômico) & Compensação gases de efeito estufa \\
\hline
\end{tabular}

$\mathrm{Na}$ comparação os impactos e programas do meio biótico nos diferentes estudos foram identificados facilmente considerando os temas gerais. Os programas associados a plantio paisagístico e compensação por gases de efeito estufa são referentes a impactos identificados, porém por decisão deste estudo foram classificados como sendo pertencentes a outros meios embora a forma de mitigação seja com plantio associado ao meio biótico.

\section{Conclusão parcial meio físico e biótico}

Particularmente para o meio biótico em um país com dimensões continentais e diversidade biológica pouco estudada e conhecida, em função da sua complexidade, não é possível afirmar que todos os impactos são plenamente identificados, evoluindo com o estado da arte dos conhecimentos acadêmicos a respeito. 
Fazendo uma analise preliminar, verificamos que quando se trata de impactos no meio físico e biótico, a sua abrangência e relação direta, bem como os programas para sua mitigação parece estar consolidada no estado da arte dos conhecimentos dos processos de licenciamento, pois embora tenham aumentado ligeiramente são mais fruto de um detalhamento maior de um mesmo impacto do que a identificação de um novo impacto.

A experiência adquirida ao longo das ultimas décadas e os avanços tecnológicos e da ciência, permitem a previsibilidade das alternativas de mitigação ou monitoramento. Com isso não se pretende dizer que estão plenamente solucionados e que não sejam ajustáveis conforme a evolução do conhecimento científico. Particularmente a sinergia entre os impactos ecológicos é um grande desafio para a academia, associada ao pouco recurso disponibilizado para tanto e a riqueza biológica.

Para o meio biótico a sistematização dos dados e informações influenciariam na qualidade da análise.

\section{MEIO ANTROPICO/SOCIOECONOMICO}

Pergunta: Houve alterações na identificação dos impactos do meio socioeconômico nos dois períodos?

Embora a identificação e sintetização de impactos sobre o meio socioeconômico não seja trivial, nesta fase da pesquisa se buscou algumas características comuns à maioria dos empreendimentos, de forma a permitir a análise.

A tabela 9 apresenta os temas mais abordados nos estudos, os números entre parênteses informam respectivamente (numero de impactos no tema/ numero total de EIA/RIMA considerados neste período). 
Tabela 9 - Impactos socioeconômicos -estudos em empreendimentos lineares e pontuais em dois períodos temporais

\begin{tabular}{|c|c|c|c|c|}
\hline Impactos no Meio Socioeconômico & Lineares & & Pontuais & \\
\hline & $\begin{array}{l}2001 \mathrm{a} \\
2007\end{array}$ & $\begin{array}{l}2008 \mathrm{a} \\
2014\end{array}$ & $\begin{array}{c}2001 \mathrm{a} \\
2007\end{array}$ & $\begin{array}{c}2008 \mathrm{a} \\
2014\end{array}$ \\
\hline Pressão sobre infraestrutura e serviços & $(3 / 5)$ & $(9 / 13)$ & $(1 / 3)$ & $(14 / 14)$ \\
\hline Emprego/capacitação mão de obra & $(5 / 5)$ & $(11 / 13)$ & $(3 / 3)$ & $(11 / 14)$ \\
\hline Aumento da arrecadação tributária & & $(8 / 13)$ & $(2 / 3)$ & $(12 / 14)$ \\
\hline Incomodo por alteração no modo de vida & $(4 / 5)$ & $(10 / 13)$ & $(1 / 3)$ & $(11 / 14)$ \\
\hline Questões fundiárias e imobiliárias & $(4 / 5)$ & $(11 / 13)$ & $(1 / 3)$ & $(10 / 14)$ \\
\hline Dinamização do mercado/economia & $(3 / 5)$ & $(9 / 13)$ & $(2 / 3)$ & $(11 / 14)$ \\
\hline $\begin{array}{l}\text { Patrimônio arqueológico, histórico ou } \\
\text { cultural }\end{array}$ & $(4 / 5)$ & $(11 / 13)$ & $(2 / 3)$ & $(11 / 14)$ \\
\hline $\begin{array}{c}\text { Aumento de Tráfego/ pressão sobre } \\
\text { transporte }\end{array}$ & $(1 / 5)$ & $(11 / 13)$ & & $(9 / 14)$ \\
\hline Oferta de serviços (transporte/ energia/água) & $(3 / 5)$ & $(11 / 13)$ & $(2 / 3)$ & $(6 / 14)$ \\
\hline Alteração na paisagem & $(2 / 5)$ & $(7 / 13)$ & $(1 / 3)$ & $(10 / 14)$ \\
\hline Expectativa da comunidade & $(2 / 5)$ & $(9 / 13)$ & $(2 / 3)$ & $(9 / 14)$ \\
\hline Alteração na renda & $(2 / 5)$ & $(8 / 13)$ & & $(9 / 14)$ \\
\hline Perdas produtivas/econômicas & $(1 / 5)$ & $(8 / 13)$ & $(2 / 3)$ & $(8 / 14)$ \\
\hline Aumento de acidentes & $(2 / 5)$ & $(8 / 13)$ & $(2 / 3)$ & $(6 / 14)$ \\
\hline $\begin{array}{l}\text { Impacto sobre comunidades tradicionais ou } \\
\text { acampamentos }\end{array}$ & $(1 / 5)$ & $(8 / 13)$ & & $(2 / 14)$ \\
\hline Endemias /saúde & $(1 / 5)$ & $(6 / 13)$ & $(1 / 3)$ & $(7 / 14)$ \\
\hline Migração & $(1 / 5)$ & $(2 / 13)$ & $(2 / 3)$ & $(6 / 14)$ \\
\hline Patrimônio espeleológico/paleontológico & & $(6 / 13)$ & & $(3 / 14)$ \\
\hline Resíduos & & $(3 / 13)$ & & $(5 / 14)$ \\
\hline Turismo & & $(3 / 13)$ & & $(2 / 14)$ \\
\hline Aumento conhecimento científico & & $(2 / 13)$ & & $(2 / 14)$ \\
\hline Violência & & $(3 / 13)$ & & $(1 / 14)$ \\
\hline Ruído na Operação & & $(2 / 13)$ & & \\
\hline Campo eletromagnético & & $(1 / 13)$ & & \\
\hline Expansão urbana & & & & $(2 / 14)$ \\
\hline Habitação & & & & $(4 / 14)$ \\
\hline Relações sociais & & & & $(5 / 14)$ \\
\hline Responsabilidade do poder público & & & & $(1 / 14)$ \\
\hline
\end{tabular}

De onde se verifica que nos processos de licenciamento federal os impactos socioeconômicos na sua grande maioria são comuns para empreendimentos lineares e pontuais.

Novos temas/impactos foram identificados, nos dois períodos temporais para ambos os grupos de empreendimentos. Alguns claramente associados a novas exigências legais como a percepção de impacto sobre bens espeleológicos e paleontológico e sobre comunidades tradicionais e resíduos. 
Destaca- se o desdobramento dos impactos associados a grande quantidade de mão de obra como a migração, violência, saúde, dificuldade de moradia, pressão sobre as infraestruturas e serviços, turismo e habitação, como os mais frequentes.

Para o foco do nosso estudo, particularmente interessante é verificar os impactos diretos às comunidades como acidentes e alteração da paisagem e sobre a capacidade do poder público de atuar, considerando que o aumento da arrecadação tributária passa a ser frequente nos estudos assim como a necessidade da aplicação se reverter para minimizar os impactos, como ampliação da responsabilidade do poder público, frente ao aumento das pressões sobre infraestrutura e serviços.

Um grupo específico de impactos relacionados ao processo de urbanização como aumento de tráfego, questões fundiárias, habitação, aceleração da expansão urbana, conflitos e alteração das relações sociais, disposição de resíduos, passa a ser considerado e mais frequente.

A maior participação de órgãos intervenientes a partir de 2011 e da sociedade, por meio de audiências públicas, pode influenciar a variação no número de impactos socioeconômicos, na relação temporal, que propriamente características relacionadas à tipologia do empreendimento. A atuação dos órgãos como consequência de demandas da sociedade, pode ter causado o aumento do numero de impactos associados ao empreendimento.

Também para a identificação dos impactos socioeconômicos, uma boa base de dados, principalmente com indicadores municipais, poderia influenciar na qualidade dos estudos.

Pergunta: Houve alterações em termos de Programas do meio antrópico proposto nos dois períodos?

A tabela 10 nos mostra a relação temporal dos programas dos projetos. Os números entre parênteses informam respectivamente (numero de Programas no tema/ numero total de EIA/RIMA considerados neste período). 
Tabela 10 - Relação temporal dos programas dos projetos

\begin{tabular}{|c|c|c|c|c|}
\hline \multirow[t]{2}{*}{ Programas Socioeconômicos } & \multicolumn{2}{|c|}{ Lineares } & \multicolumn{2}{|c|}{ Pontuais } \\
\hline & $\begin{array}{c}2001 \mathrm{a} \\
2007\end{array}$ & $\begin{array}{c}2008 \mathrm{a} \\
2014\end{array}$ & $\begin{array}{c}2001 \mathrm{a} \\
2007\end{array}$ & $\begin{array}{c}2008 \mathrm{a} \\
2014\end{array}$ \\
\hline Educação Ambiental & $(5 / 5)$ & $(13 / 13)$ & $(3 / 3)$ & $(14 / 14)$ \\
\hline $\begin{array}{l}\text { Comunicação Social e Relacionamento } \\
\text { Institucional }\end{array}$ & $(4 / 5)$ & $(12 / 13)$ & $(3 / 3)$ & $(14 / 14)$ \\
\hline Arqueologia e Educação Patrimonial & $(5 / 5)$ & $(11 / 13)$ & $(1 / 3)$ & $(12 / 14)$ \\
\hline Desapropriação (Faixa de Servidão) & $(4 / 5)$ & $(11 / 13)$ & $(1 / 3)$ & $(7 / 14)$ \\
\hline $\begin{array}{l}\text { Travessias/ acessibilidade/ } \\
\text { segurança/mobilidade }\end{array}$ & $(1 / 5)$ & $(6 / 13)$ & & $(7 / 14)$ \\
\hline $\begin{array}{l}\text { Contratação e Capacitação da Mão de } \\
\text { Obra Local }\end{array}$ & $(2 / 5)$ & $(5 / 13)$ & $(1 / 3)$ & $(7 / 14)$ \\
\hline $\begin{array}{l}\text { Relacionadas à Saúde e Segurança dos } \\
\text { Trabalhadores }\end{array}$ & $(1 / 5)$ & $(4 / 13)$ & & $(6 / 14)$ \\
\hline Infraestrutura e serviços & & $(3 / 13)$ & & $(6 / 14)$ \\
\hline Prefeitura & $(1 / 5)$ & $(1 / 13)$ & & $(6 / 14)$ \\
\hline Desenvolvimento & $(1 / 5)$ & & & $(5 / 14)$ \\
\hline Apoio aos Serviços Públicos (Saúde) & & $(4 / 13)$ & & $(4 / 14)$ \\
\hline $\begin{array}{l}\text { Vetores Relacionados a Doenças } \\
\text { Tropicais }\end{array}$ & & $(1 / 13)$ & $(1 / 3)$ & $(3 / 14)$ \\
\hline Plano diretor & & $(2 / 13)$ & & $(1 / 14)$ \\
\hline Fornecedores & & $(1 / 13)$ & & $(1 / 14)$ \\
\hline Gestão e Monitoramento socioambiental & $(1 / 5)$ & $(1 / 13)$ & & $(2 / 14)$ \\
\hline Gestão Paleontológica & & $(3 / 13)$ & & \\
\hline Proteção Espeleológica & & $(1 / 13)$ & & \\
\hline Apoio a Comunidades Tradicionais & $(1 / 5)$ & $(3 / 13)$ & & \\
\hline Plano de Desativação & & $(2 / 13)$ & & \\
\hline Entorno Reservatório & & & $(1 / 3)$ & $(4 / 14)$ \\
\hline Pesca & & & & $(5 / 14)$ \\
\hline Habitação & & & & $(2 / 14)$ \\
\hline Migração & & & & $(2 / 14)$ \\
\hline Incêndios e acidentes & & & & $(1 / 14)$ \\
\hline Entendimento com Comunidade & & & & $(1 / 14)$ \\
\hline Turismo & & & & $(1 / 14)$ \\
\hline Pequeno Produtor & & & & $(1 / 14)$ \\
\hline $\begin{array}{l}\text { Estimulo a participação da população } \\
\text { Atingida }\end{array}$ & & & & $(1 / 14)$ \\
\hline
\end{tabular}

Em relação aos programas do meio antrópico, bastante marcante é o aumento dos programas quando consideramos os dois períodos temporais. Embora os programas tenham aumentados para as duas tipologias, os programas são bastante distintos. 
Os programas relacionados à Educação Ambiental, Comunicação e Arqueologia estão presentes na grande maioria, se não em todos, EIAs analisados. Estes temas possuem legislação que os torna obrigatórios.

Em empreendimentos lineares, até pela sua característica extensão, os programas tentem a serem focado em programas de mitigação aos incômodos à comunidade afetada e ao cumprimento da lei, com apoio mais pontuais a prefeituras e programas de desenvolvimento local.

Já alguns temas novos para empreendimentos pontuais estão claramente relacionados a especificidades da tipologia do projeto. Assim surgirão programas relacionados ao uso do entorno de reservatórios e a pesca, associados aos empreendimentos de usinas hidroelétricas.

\section{Pergunta: Há relação entre os Impactos do meio socioeconômico identificado e os Programas que os mitigariam?}

Para esta análise, em função da quantidade de amostra que dispomos e interesse do estudo, iremos considerar apenas os empreendimentos lineares e pontuais nos períodos de 2008 a 2014. Os títulos dos temas são os mesmos apresentados nas tabelas anteriores, porém em função da similaridade entre alguns, os apresentaremos mais agrupados.

As correspondências entre os impactos e os programas socioeconômicos são apresentadas na tabela 11 . 
Tabela 11 - Impactos e programas socioeconômicos

\begin{tabular}{|c|c|c|c|}
\hline $\begin{array}{c}\text { Impactos } \\
\text { Lineares } \\
2008 \text { a } 2014\end{array}$ & $\begin{array}{l}\text { Programas } \\
\text { Lineares } \\
2008 \text { a } 2014\end{array}$ & $\begin{array}{l}\text { Impactos } \\
\text { Pontuais } \\
2008 \text { a } 2014\end{array}$ & $\begin{array}{l}\text { Programas } \\
\text { Pontuais } \\
2008 \text { a } 2014\end{array}$ \\
\hline $\begin{array}{l}\text { Emprego/capacitação mão de obra } \\
(11 / 13)\end{array}$ & $\begin{array}{l}\text { Contratação e Capacitação da Mão de } \\
\text { Obra Local (5/13) }\end{array}$ & $\begin{array}{l}\text { Emprego/capacitação mão de obra } \\
(11 / 14)\end{array}$ & $\begin{array}{l}\text { Contratação e Capacitação da Mão } \\
\text { de Obra Local (7/14) }\end{array}$ \\
\hline Alteração na renda $(7 / 13)$ & & Alteração na renda $(7 / 14)$ & \\
\hline Arrecadação tributária $(9 / 13)$ & & Arrecadação tributária (11/14) & \\
\hline \multirow{2}{*}{$\begin{array}{l}\text { Dinamização do mercado/economia } \\
(10 / 13)\end{array}$} & \multirow{2}{*}{$\begin{array}{l}\text { Apoio Desenvolvimento Regional } \\
\text { (Planos Diretores, Prefeituras, } \\
\text { Fornecedores) (5/13). }\end{array}$} & $\begin{array}{l}\text { Dinamização do mercado/economia } \\
(12 / 14)\end{array}$ & Apoio Fornecedor e Turismo (2/14) \\
\hline & & $\begin{array}{l}\text { Ampliação responsabilidades poder } \\
\text { público }(1 / 14)\end{array}$ & $\begin{array}{l}\text { Apoio Desen. Regional e } \\
\text { institucional (P. Diretor, Prefeituras, } \\
\text { planejamento) }(10 / 14) .\end{array}$ \\
\hline $\begin{array}{l}\text { Oferta de serviços (transporte/ } \\
\text { energia/água) }(12 / 13)\end{array}$ & & $\begin{array}{l}\text { Oferta de serviços (transporte/ } \\
\text { energia/água) }(6 / 14)\end{array}$ & \\
\hline Expectativa da comunidade $(9 / 13)$ & $\begin{array}{l}\text { Comunicação Social e } \\
\text { Relacionamento Institucional (12/13) }\end{array}$ & Expectativa da comunidade (10/14) & $\begin{array}{l}\text { Comunicação Social e } \\
\text { Relacionamento Institucional (14/14) } \\
\text { Atendimento protocolo de } \\
\text { entendimento com comunidade } \\
(1 / 14)\end{array}$ \\
\hline $\begin{array}{l}\text { Incomodo por alteração no modo de } \\
\text { vida }(12 / 13)\end{array}$ & & $\begin{array}{l}\text { Incomodo por alteração no modo de } \\
\text { vida }(10 / 14)\end{array}$ & \\
\hline \multirow[t]{2}{*}{$\begin{array}{l}\text { Questões fundiárias e imobiliárias } \\
(10 / 13)\end{array}$} & $\begin{array}{l}\text { Indenização, Reassentamento e } \\
\text { Desapropriação (Faixa de Servidão) } \\
\text { (11/13). }\end{array}$ & $\begin{array}{l}\text { Questões fundiárias e imobiliárias } \\
(9 / 14)\end{array}$ & $\begin{array}{l}\text { Indenização, Reassentamento e } \\
\text { Desapropriação (7/14). }\end{array}$ \\
\hline & & Habitação (3/14) & Habitação (2/14) \\
\hline
\end{tabular}


Tabela 11 - Impactos e programas socioeconômicos

\section{Perdas produtivas/econômicas (11/13)}

Pressão sobre infraestrutura e serviços $(10 / 13)$

Endemias /saúde (5/13)

Aumento de acidentes (10/13)

Migração (3/13)

Migração (3/13)

Aumento de Tráfego/ pressão sobre

transporte $(10 / 13)$

Ruído (2/3)

Alteração na paisagem (4/13)

Violência (2/13)

Patrimônio arqueológico, histórico ou Arqueologia e Educação Patrimonial cultural (10/13). $(11 / 13)$

\section{Patrimônio}

espeleológico/paleontológico (4/13)

Impacto sobre comunidades

tradicionais ou acampamentos $(8 / 13)$
Proteção Espeleológica (1/13)

paleontologia (3/13)

Apoio a Comunidades Tradicionais

(3/13)
Gestão Socioambiental da Operação $(1 / 13)$

(Continuação)

Perdas produtivas/econômicas Apoio geração de renda pesca e/ou (11/13) produtor rural (6/14)

Uso entorno reservatório e adequação infraestrutura (6/14) serviços (13/14)

Vetores Relacionados a Doenças $\quad$ Endemias /saúde (6/14)

Saúde (Trabalhador, vetores, endemias ou geral (13/14).

Relacionadas à Saúde e Segurança $\quad$ Aumento de acidentes (7/14)

Atendimento a emergências (1/14)

Migração (6/14)

Migração (2/14)

Aceleração da expansão urbana

$(1 / 14)$

Indicadores socioeconômicos (2/14)

Aumento de Tráfego/ pressão sobre transporte (8/14)

Relações/ problemas sociais (6/14)

Interferências Tráfego (7/14)

Estimulo a participação da pop.

Atingida (1/14). Alteração na paisagem (9/14)

Segmentação de município (1/14)

Patrimônio arqueológico, histórico ou cultural $(11 / 14)$.

\section{Patrimônio}

espeleológico/paleontológico (4/14)

\section{Impacto sobre comunidades}

tradicionais $(1 / 14)$
Arqueologia e Educação Patrimonial, histórico, cultural (12/14) 
Tabela 11 - Impactos e programas socioeconômicos

Resíduos (2/13)

Aumento conhecimento científico

$(2 / 13)$

Campo eletromagnético (1/13)
Educação Ambiental (13/13) Resíduos (5/14)

$(2 / 14)$
Educação Ambiental (trabalhadores e/ou comunidade) (14/14)

Plano de Desativação (3/13) 
Verificamos que há alguns grupos de impactos e programas.

Identificamos que há aqueles que são relacionados aos aspectos econômicos diretos, normalmente avaliados como positivos como geração de empregos, renda, tributos e dinamização da economia e disponibilização de serviços e produtos. Associado ainda consideramos o impacto de ampliação da responsabilidade do poder público, que embora ocorra em função do crescimento populacional como consequência da migração, acarretará um novo plano de desenvolvimento.

O segundo grupo que identificamos está associado a impactos diretos e indiretos, relacionado às expectativas e mudanças que ocorrem nas comunidades, como migração, violência, custo de vida.

O terceiro grupo está associado a obrigações legais como levantamento arqueológico, espeleológico, paleontológico, educação ambiental e impactos sobre comunidades tradicionais e indígenas.

No quarto grupo colocamos os impactos sem relação com os demais e que são específicos de algumas tipologias de empreendimentos, como o plano de desativação associado a uma obrigação do setor minerário, ou a interferência com campo eletromagnético entre ferrovia e as linhas de transmissão.

Como resultado temos que embora alguns impactos tenham sido claramente identificados, não foi possível identificar programas para mitigá-los ou potencializar. Alguns dos motivos podem ser a sua baixa significância ou a impossibilidade de mitigação. Pode ser ainda uma limitação de análise deste estudo, uma vez que não se aprofunda no escopo dos programas, porém esta mesma dificuldade teriam os demais interessados, quer seja a comunidade quer seja o órgão licenciador.

No entanto houve pelo menos um caso em que o Programa (desenvolvimento de Plano Diretor de um município) não estava relacionado a nenhum impacto direto identificado, indicando uma possível relação com a licença social para operar.

Surpreendente foi verificar que em termos de relação direta impacto programa para alguns temas bastante relevantes por desencadearem uma série de impactos decorrentes, como a contratação e capacitação da mão de obra local, alteração de renda, arrecadação tributária e a dinamização da economia, a quantidade de programas propostos foram em número bem menor que os impactos levantados. 
De um modo geral, há mais impactos identificados que programas que os mitiguem ou potencializem sendo propostos.

\section{Conclusão do Capitulo 4 Estudo de Caso}

A análise que este estudo se propôs teve êxito, uma vez que foi possível identificar e analisar 35 empreendimentos licenciados pelo órgão ambiental federal do Brasil (Ibama).

Foi possível constatar que houve alteração na identificação de impactos e nos programas propostos dentro do processo formal de licenciamento. As mudanças foram no sentido de se identificar mais impactos socioeconômicos e o aumento dos programas socioeconômicos durante os dois períodos temporais avaliados. Embora nem todos os impactos levantados fossem atendidos por programas que os mitigassem.

As dificuldades que tivemos em comparar impactos e programas de estudos diferentes considerando as informações disponíveis nos RIMAs são as mesmas que a sociedade enfrenta para entender as consequências do empreendimento, uma vez que normalmente são estas as informações que são disponibilizadas.

A diversidade de formas de descrever um impacto e seus programas são tantas que uma análise direta do numero de impacto identificado e os supostos respectivos programas poucas informações fornecem.

Reforçando a percepção e sugestões de alguns órgãos ambientais para que haja uma parametrização na classificação do impacto. Esta ação além de facilitar o entendimento do impacto pela comunidade poderia facilitar a análise pelo órgão ambiental e causar menor insegurança jurídica e intervenção do ministério público.

Como aperfeiçoamento propomos a associação de estimativas quantitativas às informações qualitativas. Como exemplo, adicionar a extensão da supressão de vegetação na fase de discussão do projeto, ou mesmo os impactos efetivos na qualidade dos corpos hídricos, ao invés de informações qualitativas apenas e propostas de monitoramento como mitigação.

Estas lacunas de informações na etapa de análise do EIA/RIMA na qual a sociedade efetivamente participa pode contribuir para a sensação de um processo administrativo meramente processual, sem efeitos práticos para uma discussão mais qualificada sobre a pertinência de um empreendimento em certa localidade ou não. 
Com a redução do tempo de análise e a padronização das informações requeridas, o processo pode ser iniciado em uma etapa em que os projetos de engenharia estejam mais avançados, tornando a análise dos impactos e sua mitigação e compensação mais efetiva.

Com o impacto claramente identificado, inclusive de sua extensão e com esforços voltados para os programas mais significativos, mais energia poderia ser dispendida para verificar a efetividade das medidas, promovendo melhorias sempre que necessárias.

Ainda para finalizar, a verificação e incorporação das medidas mais efetivas, bem como a troca de experiência nos impactos conhecidos em diferentes tipologias e diferentes instituições pode promover o fortalecendo das instituições. Assim, não só a experiência não é perdida com a substituição dos analistas, mas também há menos questionamentos jurídicos, evitando-se inclusive solicitações não associadas aos impactos, que poderiam ser corretamente endereçadas. 


\section{5 \\ Conclusões e Proposições}

O Objetivo principal desta dissertação foi fazer a avaliação do processo de licenciamento no Brasil, verificando de que forma tem se alterado ao longo dos últimos anos.

A presente dissertação se enquadra dentro da linha de pesquisa de Planejamento e Sustentabilidade do curso de Pós-graduação em Engenharia Urbana e Ambiental do departamento de Engenharia Civil da PUC-Rio em parceria com a Universidade Carollo de Braunschweig. Isto porque, o processo de licenciamento ambiental não é meramente uma autorização para um projeto, mas sim uma licença que atesta a viabilidade socioambiental de um determinado empreendimento buscando a compatibilidade de múltiplos interesses de cunho econômico, político, ambiental, social e cultural que pode interferir e provocar modificações profundas em determinados ambientes urbanos, unindo assim as questões associadas ao licenciamento socioambiental com a ocupação territorial.

Embora o licenciamento ambiental seja um processo administrativo, o desenrolar e as consequências são permanentes para os espaços urbanos e interferem na sociedade como um todo, tendo forte influência no planejamento e equilíbrio de muitas cidades brasileiras.

Para verificar os principais pontos associados ao licenciamento ambiental no Brasil, uma pesquisa exploratória foi conduzida onde foram consultados legislações, artigos, livros e sítios eletrônicos que tratassem de Avaliação de Impacto Ambiental e Processos de Licenciamento Ambiental.

Para avaliar os avanços e dificuldades, primeiramente se levantou o arcabouço legal internacional e o histórico em função da influencia que estes podem ter sobre o processo brasileiro.

Do estudo da legislação em outros países e no Brasil se chegou à conclusão que as implantações de leis de avaliação de impacto ocorreram inicialmente nos EUA, no final da década de 1960, mas se espalharam rapidamente pelos demais países.

A formulação da AIA nos Estados Unidos estava voltada para as agências do governo federal que deveriam utilizar uma abordagem sistemática e interdisciplinar 
nas tomadas de decisões e planejamentos em projetos que poderiam ter um impacto sobre o ambiente humano.

A França foi o primeiro país da Europa a adotar a avaliação de impacto ambiental por meio de duas leis de 1976, no entanto seu sistema jurídico e organização administrativa eram muito diferentes da dos Estados Unidos. A AIA foi adotada na França como uma modificação no sistema de licenciamento/ autorização governamental para indústrias e outras atividades que possam causar impactos. Os estudos de impacto ambiental deveriam ser feito pelo próprio interessado, sendo ele público ou privado. (Sanchez 2012).

Verificou-se, desta forma, que embora a legislação brasileira tenha seguido às orientações das normas americanas, estas estariam mais voltadas para planos e políticas e deveriam ser desenvolvidas pelo Estado. Neste sentido, seguir o processo francês, voltado para projetos e realizado pelo empreendedor, teria sido mais próximo da realidade brasileira.

No entanto, os financiamentos por instituições americanas para grandes empreendimentos na época, possibilitaram uma série de intercâmbios e capacitações entre órgãos públicos, o que acabou por influenciar o arcabouço legal brasileiro no tema.

Próximo à década de 1990, alguns países acrescentaram leis no seu arcabouço, incorporando estudos mais abrangentes como as Avaliações Ambientais Estratégicas e outros relacionados à Saúde e questões sociais.

O Brasil não alterou substancialmente o escopo do processo de licenciamento ambiental desde a criação da Política em 1981 e das Resoluções Conama 01/86 e $237 / 97$.

Para avaliar os avanços, foram levantados ainda os processos e ritos do caso brasileiro e se concluiu que o processo é bem estruturado com normas que os regulamentam dentro dos órgãos e instituições nos últimos anos.

O MMA juntamente com o Ibama tem se preocupado em aprimorar o rito de licenciamento, estabelecendo termos de referências para as diferentes tipologias, fazendo com que o processo seja informatizado e que os documentos estejam disponíveis para consulta.

Não obstante o esforço do órgão federal há alguns estudos e levantamentos que tratam das dificuldades e gargalos do licenciamento brasileiro, realizados tanto pela academia como por setores empresariais e públicos no intuito de aprimorar o 
processo de licenciamento brasileiro. Sendo as críticas ao processo mais comuns que o relato de avanços, não só nos estudos no Brasil, mas também em outros países.

Desta forma os avanços ao processo de licenciamento só puderam ser percebidos de forma indireta, pelas ações que ainda carecem de melhorias apontadas em estudos sobre o licenciamento ambiental no Brasil.

Destes estudos e críticas, destacamos a seguir os principais pontos de interesse desta dissertação:

1) Há muitos atos normativos, por vezes conflitante e fragmentado por normas de diversas instituições, criando necessidade de muitos processos paralelos ao licenciamento. $\mathrm{O}$ fato do licenciamento ser o único instrumento da PNMA plenamente implementado, faltando, entre outros como exemplo, o zoneamento territorial que em muito poderia contribuir para o planejamento urbano, carrega para o processo de licenciamento outras expectativas e demandas que o rito do licenciamento, por si só, não consegue absorver.

2) Há a ausência de dados e informações ambientais sistematizadas, exigindo muitas vezes a coleta de dados primários, que por sua vez não são aproveitamento para outros estudos ou para o conhecimento acadêmico. Contribuindo para a pouca qualidade dos estudos.

3) Os EIAs com baixa qualidade, muito focado no diagnóstico e que levam muito tempo para serem produzidos acaba fazendo com que o empreendedor inicie o processo de licenciamento com projetos pouco maduros do ponto de vista de desenvolvimento de engenharia, usando projetos “tipo". Desta forma os reais impactos que serão gerados não são apontados, o que dificulta a análise dos órgãos responsáveis e trazem dúvidas para a sociedade como um todo, gerando um circulo vicioso de má qualidade, custo e tempo.

4) A restrição de recursos nos órgãos ambientais e intervenientes provoca uma concentração dos processos na esfera federal. A forma como o rito está estruturado, faz com que os processos sejam centrados nos analistas dos órgãos. Com insuficiência de recursos, esforços ficam concentrados na fase inicial do processo de licenciamento. Neste cenário, a rotatividade de servidores acaba sendo alta, fazendo com que se perca conhecimento que não são institucionalizados. Desta forma capacitações frequentes são necessárias e a incorporação de melhorias no processo é pequena. 
5) Em função dos recursos limitados há a falta de acompanhamento das demais etapas do licenciamento, ou seja, fiscalização e avaliação da efetividade dos programas propostos. Não havendo a análise da efetiva mitigação dos impactos ou uma avaliação de custo/beneficio e os conhecimentos de cada processo não alimentam os seguintes.

6) A multiplicidade de atores com poderes discricionários sem uma governança que os façam convergir, se reflete na multiplicidade de normas e procedimentos a serem atendidos paralelos ao rito de licenciamento. O rito do licenciamento prevê a discussão com a sociedade nas audiências públicas, porem não há participação destas etapas paralelas.

7) As Audiências Públicas, na forma como são previstas no rito do processo de licenciamento, não são suficientes para as discussões de um novo empreendimento em função das demais demandas que não podem ser cobertos apenas por este instrumento.

8) Alguns estudos apontam a falta de marcos regulatório para as questões sociais como um gargalo no processo de licenciamento. Conforme verificado, os impactos ao meio físico e biótico são mais facilmente delimitados e regulados. Alguns temas sociais são de reponsabilidade de outros órgãos e instituições públicas sendo recente a discussão do tema para e no licenciamento. Desta forma as condicionantes do meio socioeconômico variam muito, e por vezes são mais voltadas para redução de deficiências dos serviços públicos que associadas a um impacto do empreendimento. Incorporando a "licença social para operar" no processo de licenciamento.

9) O excesso de condicionantes, que por vezes demandam mais estudos, nos licenciamentos é interpretado por alguns autores como a não compreensão do escopo dos Termos de Referência. Outros, no entanto, apontam os estudos de baixa qualidade como possível causa. A padronização de alguns procedimentos recorrentes para alguns temas poderia reduzir estas incertezas e dificuldades.

10) Frente às deficiências e dificuldades no processo de licenciamento, da falta de fóruns para discussões e da necessidade de mediação de conflitos e diferentes interesses é previsível a necessidade de intervenção do Ministério Público e frequente judicialização dos processos. 
Desta forma, embora as dificuldades e gargalos sejam bem delimitados, sua origem pode ser diversa e complexa e sua resolução não ser trivial.

Dos problemas apresentados, o que mais nos chamou a atenção foi a pouca relevância dada à avaliação de impacto, por ser esta etapa a base para se pensar a mitigação ou compensação e assim tornar a implantação do projeto viável/interessante para a sociedade.

Se os estudos não são bem feitos, se há dúvidas quanto aos impactos o processo não está atingindo seu objetivo básico que é fornecer informação para a análise da viabilidade.

Sem o correto diagnóstico dos impactos e sua mitigação todo o processo fica comprometido, se tornando apenas uma prática cartorial e burocrática, dispendioso em recursos e prazos, que nada contribui para a preservação da qualidade socioambiental. E de nada adiantariam a melhoria nos demais gargalos e dificuldades apresentados se a informação que chega para a sociedade na forma da matriz de impacto dos RIMA não permitir uma discussão qualificada.

Para aprofundar mais a análise, um estudo de caso foi proposto, avaliando os impactos e programas propostos por 35 empreendimentos de grande porte de diferentes tipologias protocolados de 2001 a 2014 no órgão ambiental federal.

Os estudos que procuram fazer uma análise parecida, normalmente são direcionados para uma tipologia de empreendimento.

A análise meramente quantitativa do numero de impactos e programas identificados nos estudos não demonstraram nenhuma correlação ou variação temporal, mesmo numa mesma tipologia.

Razão pela qual foi necessário preparar as tabelas do anexo e aprofundar a análise.

Como resultado, foi verificado que a quantidade de impactos e programas identificados nos EIA/RIMA aumentaram ao se comparar dois momentos temporais: de 2001 a 2007 e de 2008 a 2014.

Como resultado verificamos que não obstante alguns impactos serem bastante específicos para a tipologia em análise e, portanto o uso de um Termo de Referência Específico ser apropriado, a maior parte dos impactos identificados são comuns a todos os tipos de empreendimentos, variando mais na magnitude e em função de características locais que propriamente necessitando um tratamento diferenciado para sua identificação. 
Para o meio físico e biótico não houve alterações significativas nem para empreendimentos pontuais nem lineares, nos períodos analisados.

No entanto se verificou que um impacto semelhante era classificado com nomenclaturas diferentes e se apresentavam agrupados em grandes temas ou na forma detalhada gerando um número quantitativo maior de impactos.

Para os impactos socioeconômicos, particularmente, houve uma série de novos impactos identificados com o avanço dos anos. O mesmo foi verificado quando foram avaliados os programas do meio socioeconômico tanto para tipologias lineares como pontuais.

Levando a crer, em primeira análise, que houve uma maior sensibilidade na identificação e consequente mitigação e compensação por programas de temas socioeconômicos.

Porém ao tentar estabelecer uma correlação dos impactos e programas socioeconômicos, como resultado tivemos que alguns impactos não possuem programas, assim como havia alguns programas sem estar relacionados diretamente a impactos.

Como causa podemos supor a maior participação da sociedade e dos órgãos intervenientes, uma vez que não houveram alterações nas normas e leis associadas.

Foi verificado também, o tratamento diferenciado de alguns temas entre as tipologias, sem que haja ligação com potencialidade do impacto, como é o caso da espeleologia. Fazendo-nos supor que seja reflexo das exigências contidas nos Termos de Referência Específicos e, portanto dependente da equipe que está analisando, mesmo o órgão ambiental federal sendo único.

Neste sentido, sugerimos uma avaliação interna ao órgão federal, objetivando a padronização dos procedimentos, sem desconsiderar as especificidades do empreendimento.

Entendemos que o estabelecimento de alguns procedimentos padrões poderia inclusive melhorar o processo de licenciamento como um todo, uma vez que a etapa de diagnóstico poderia ser focada no projeto real a ser licenciado, bem quantificado, permitindo uma melhor discussão com a sociedade e de esforços para as demais etapas.

Da mesma forma , certa padronização técnicas nos programas de mitigação poderia facilitar a análise de eficiência e retroalimentar o processo. 
Além da melhora da Avaliação de Impacto, o processo de licenciamento estará atingindo seu objetivo, estritamente, na medida em que forneça informações aos tomadores de decisão de forma prévia. No entanto, o licenciamento de grandes empreendimentos tende a causar grandes mudanças nos municípios brasileiros onde serão implementados, gerando expectativas em toda a sociedade.

Assim verificamos que, independente dos objetivos do processo administrativo estabelecido em ritos, os seguintes interesses estão presentes nos processos de licenciamento:

- Os analistas dos órgãos ambientais e intervenientes desejam um processo baseado em análises técnicas evitando terem que fazer a intermediação de conflitos e sofrer pressões políticas;

- O empreendedor deseja um processo curto, sem acréscimo de prazos e custos além dos planejados e associados ao empreendimento;

- As comunidades desejam manter ou melhorar a sua qualidade de vida;

- Os movimentos civis desejam transparência na discussão dos diferentes interesses;

- Os governantes desejam investimentos e geração de riqueza nos municípios;

- O Ministério Público deseja que os direitos sejam respeitados e as leis cumpridas.

É nesse cenário com diversos atores e interesses, que o processo de licenciamento ambiental brasileiro se desenvolve.

O Brasil ainda não encontrou o melhor fórum para a discussão e envolvimento dos diversos interesses que envolvem as transformações socioeconômicas de um grande empreendimento em municípios pouco preparados. Por enquanto o processo formal acolhe parte destas expectativas.

O processo de licenciamento é dinâmico e necessita de ajustes nos seus ritos para fazer frente aos objetivos e as expectativas da sociedade, que mudam com os anos. O que era a implantação de um empreendimento na década 1980 está longe de ser o mesmo de hoje em dia.

O envolvimento de diversos setores, desenvolvendo estudos para avaliar e melhorar o processo de licenciamento é uma clara demonstração que há o envolvimento e interesse de toda a sociedade na busca de melhorias no processo. 
Os processos de análise ainda são conduzidos de forma bastante centralizada pelos órgãos de licenciamento federal, sendo poucos os grandes processos que são conduzidos pelos estados e menos frequentes ainda os municipais.

Primordial, portanto, é a governança na estruturação e articulação entre os diferentes órgão e instituições para uma atuação que cubra todos os temas inclusive dentro da socioeconômica, de forma a fazer frente às demandas e transformações que um grande empreendimento pode trazer para um município sem que a qualidade de vida das comunidades seja afetada.

Houve, sem dúvidas, avanços e um conhecimento adquirido por parte dos órgãos e da sociedade que se reflete na forma de licenciar.

Como melhorias e ações já implementadas destacamos a maior participação da sociedade, dos órgãos intervenientes e a estruturação do órgão ambiental federal. Dos pontos que ainda necessitam ser melhorados temos os associados à qualidade dos estudos, como disponibilidade de informações, a quantificação dos impactos e a retroalimentação com analise da efetividade, além da dificuldade de coordenação entre as instituições envolvidas e a falta de planejamento integrado do licenciamento com políticas públicas.

O monitoramento pós-licenciamento, inclusive com o uso de indicadores e a retroalimentação da efetividade dos programas em muito poderia contribuir para o aperfeiçoamento do processo.

\section{Dificuldades encontradas durante os estudos}

O Processo de Licenciamento Ambiental é avaliado no Brasil por diferentes segmentos da sociedade. Embora não fosse possível estabelecer as melhorias de forma direta, indiretamente pelos pontos que ainda precisam ser melhorados podese verificar que houve progressos e avanços.

Infelizmente poucos são os órgão e secretarias, além do órgão licenciador federal (Ibama) que fornecem informações por meio de sítios na internet. O estudo de caso foi por tanto, baseado em EIA/RIMA disponíveis no sítio eletrônico do Ibama. O acesso a outros documentos, mesmo públicos, como os Termos de Referência e Licenças com suas condicionantes não estão disponíveis nem mesmo no órgão federal brasileiro. 
Uma das propostas iniciais de fazer comparação entre licenciamentos conduzidos pelos órgãos estaduais e o federal precisou ser descartada pela falta de informações nos sítios dos órgãos estaduais.

No meio acadêmico, prevaleceram as dissertações e teses que avaliam os processos de licenciamento de determinado setor. Os mais frequentes são relacionados ao setor energético. Estudos que avaliem o processo de licenciamento fazendo comparações entre diferentes tipologias não foram encontrados.

A falta de uniformidade na identificação dos impactos e nos programas propostos dificultou uma análise direta e comparativa entre os estudos mesmo dentro de uma mesma tipologia.

\section{Replicabilidade do estudo e Sugestões de estudos futuros}

O estudo de caso pode ser replicado em outros períodos temporais e com outros EIA/Rimas. Embora ele não traga uma relação direta com a eficiência do processo pode demonstrar tendências de determinados órgão ambientais, ou mesmo grupos de análise específica dentro de um órgão, como foi o caso. O ideal é que estas diferenciações fossem ligadas aos impactos e não as variações na análise.

À medida que mais informações sobre o processo de licenciamento estejam disponíveis, como Termo de Referencia, LP, LI, LO e haja um efetivo monitoramento dos indicadores socioeconômicos e ambientais dos municípios, será possível analisar as reais consequências dos programas propostos e implementados em determinada localidade e a efetiva contribuição para o desenvolvimento/alteração local.

Este tipo de análise é de extremo interesse não somente acadêmico, mas para toda a sociedade uma vez que está associado ao principio mais básico da avaliação de impacto que é a identificação dos impactos e a sua mitigação ou compensação.

A pesquisa sistemática realizada nesta dissertação pode servir para diferentes análises do processo de licenciamento, além daquela a que foi proposta neste estudo. Diante dos dados e informações completas que se encontram no anexo é possível avaliar os empreendimentos de forma integrada ou por tipologia.

Adicionalmente será interessante verificar as consequências de se aproximar os responsáveis pelo processo de licenciamento ao público que mais sofre os impactos, com a maior frequência de licenciamentos estaduais e municipais. 


\section{Propostas}

De aplicação e melhoria imediata sugerimos a padronização da matriz de impacto, estabelecendo relações mais estreitas entre os impactos e os programas com a verificação da efetividade, criando um ciclo de aperfeiçoamento continuo por meio de lições aprendidas. Focando na quantificação da matriz de impacto já estabelecida, teremos estudos mais curtos, mais rápidos de serem analisados e com maior profundidade já que o estágio do projeto de engenharia poderá já ser mais detalhado.

Seria, portanto, possível uma maior parametrização dos temas do meio biótico e físico na forma de procedimentos e matriz de impacto. Unificando entendimentos e termos.

Já para os impactos e programas do meio socioeconômico o que se verifica é que por serem em geral também mais complexos e indiretos, embora também passíveis de parametrização e uso de indicadores, há a necessidade de envolvimento de mais atores na mitigação dos impactos, extrapolando assim o processo de licenciamento como está hoje estabelecido legalmente no Brasil.

Essencial também seria necessário a implementação de outros instrumentos para as demais demandas não associadas a impactos diretos, mas que afetam a implantação de grandes empreendimentos em ambientes urbanos. 


\section{6 \\ Referências bibliográficas}

ABEMA, 2013 - Associação Brasileira de Entidades Estaduais de Meio Ambienta. Novas propostas para o licenciamento ambiental no Brasil. Organização José Carlos Carvalho - Brasília: Adema, 2013. P.92. Disponível em http://www.abema.org.br/site/arquivos_anexo/Livro_Relatorio_Final_2.pdf

AHAMMED, R.; HARVEY, N. Evaluation of environmental impact assessment procedures and practices in Bangladesh. Impact assessment and Project appraisal, v.22, n. 1, p. 63-78, 2004 In: SÁNCHEZ, L.E.; Avaliação de Impacto Ambiental: Conceitos e Métodos. $2^{2}$ Ed. Oficina de Textos,2013.

ANTUNES, P. B.; Direito Ambiental, $4^{\underline{a}}$ ed. Lumen Juris.Rio de Janeiro,2007.

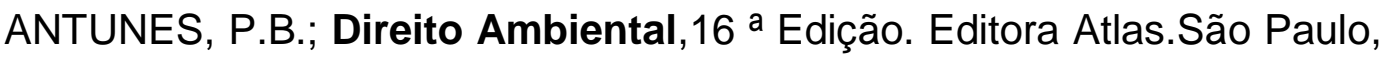
2014.

ASSUNÇÃO, F.N.A.; BURSZTYN, M.A.A; ABREU, T.L.M.- Participação social na avaliação de impacto ambiental: lições da experiência da Bahia, 2010.

BRASIL.Constituição da República Federativa do Brasil de 1988.

Decreto Lei 1.413 de 14/08/1975. Dispõe sobre o controle da poluição do meio ambiente provocada por atividades industriais.

Decreto 88.351/ 01/06/1983 Regulamenta a Política Nacional de Meio Ambiente.

_Decreto 99.274/1990. Regulamenta a Política Nacional de Meio Ambiente.

Instrução Normativa Ibama 65/2005. Estabelece os procedimentos para o licenciamento de UHEs e PCHs, consideradas de significativo impacto ambiental.

Instrução Normativa Ibama 96/2006. Dispões sobre a obrigatoriedade de registro npo Cadastro Técnico Federal de Instrumentos de Defesa Ambiental de pessoas físicas e jurídicas.

Instrução Normativa Ibama 184/2008. Estabelece, no âmbito desta Autarquia, os procedimentos para o licenciamento ambiental federal.

Instrução Normativa Ibama 11/10. Cria, no âmbito da Administração Central, a Comissão de Avaliação e Aprovação de Licenças Ambientais. 
Instrução Normativa Ibama 13/2013. Estabelece os procedimentos para padronização metodológica dos planos de amostragem de fauna exigidos nos estudos ambientais necessários para o licenciamento ambiental de rodovias e ferrovias.

Lei 6.803 de 02/07/1980. Dispõe sobre as diretrizes básicas para o zoneamento industrial nas áreas críticas de poluição.

Lei n. ${ }^{\circ}$ 6.938, de 31 de agosto de 1981. Dispõe sobre a Política Nacional do Meio Ambiente,seus fins e mecanismos de formulação e aplicação, e dá outras providências. Diário Oficial da República Federativa do Brasil, Brasília, DF, 02/09/1981.

_Lei 7347/85. Disciplina a ação civil pública de responsabilidade por danos causados ao meio-ambiente.

_ Lei 9605/98. Lei de Crimes Ambientais. Dispõe sobre as sanções penais $\bar{e}$ administrativas derivadas de condutas e atividade lesivas ao meio ambiente.

Lei n. ${ }^{\circ}$ 9.985, de 18 de julho de 2000. Regulamenta o art. 225, § 10, incisos I, II, III e VII da Constituição Federal, institui o Sistema Nacional de Unidades de Conservação da Natureza e dá outras providências. Diário Oficial da República Federativa do Brasil, Brasília, DF, 19/07/2000.

Lei Complementar 140/2011. Firma normas para a cooperação entre a União, Estados, o Distrito Federal e os Municipuios nas ações administrativas decorrentes do exercício da competência comum relativas à proteção do meio ambiente.

_Lei Complementar 8437/2015. Estabelece a tipologia de empreendimento e atividades cujo licenciamento ambiental será de competência da União.

Portaria Interministerial MMA/MJ/MS 419/2011. Regulamenta a atuação dos órgãos e entidades da Administração Pública Federal envolvidas no licenciamento ambiental.

Portaria Interministerial MMA/MJ/MS 60/2015. Estabelece procedimentos administrativos que disciplinam a atuação dos órgãos e entidades da Administração Pública Federal em processos de licenciamento ambiental de competência do Instituto Brasileiro de Meio Ambiente e dos Recursos Naturais Renováveis - Ibama.

Resolução Conama 01/86. Estabelece as condições no qual estudo de impacto ambiental e Rima são exigidos e escopo mínimo dos estudos. Diário Oficial da República Federativa do Brasil, Brasília, DF, 17/02/1986.

Resolução Conama 237/97. Estabelece a revisão dos procedimentos e critérios utilizados no licenciamento ambiental. Diário Oficial da República Federativa do Brasil, Brasília, DF, 22/12/1997. 
_ Resolução Conama 357/2005. Dispõe sobre a classificação e diretrizes ambientais para o enquadramento dos corpos de água superficiais, bem como estabelece as condições e padrões de lançamento de efluentes.

Resolução Conama 382/2006.Estabelece limites máximos de emissões de poluentes atmosféricos para fontes fixas.

BANCO MUNDIAL, 2008; Licenciamneto ambiental de empreendimentos hidrelétricos no Brasil: uma contribuição para o debate. www.mme.gov.br

BARÃO, M.A.; Avaliação Crítica do Licenciamento Ambiental como Ferramenta para o Desenvolvimento Sustentável - Estudo de Caso do Setor Hidrelétrico - Universidade Federal do Paraná -2007.

BRITTO, Fabio Giusti Azevedo de- Análise Crítica do Licenciamento Ambiental de UHEs na Amazônia Brasileira, COPPE, 2014.

BURMANN, Alexandre- Estudo Crítico do Licenciamento Ambiental Municipal no Estado do Rio Grande do Sul, UNILASALLE, 2012.

CARVALHO,José Carlos, em Seminário sobre Licenciamento Ambiental em outubro de 2013, (www.mma.gov.br/port/conama/reuniao/dir1641/transcricao_seminario.pdf em 18/02/2015)

CNI, 2014 disponível em http://economia.estadao.com.br/noticias/geral.licenca-ambiental-tem-30mil-normas-imp.1531397 . Acesso em 01/04/2015

COELHO, M.C.N.; Impactos Ambientais em áreas urbanas- teoria, conceitos e métodos de pesquisa- In: GUERRA, A.J.T.\& CUNHA, S.B. ( Org.). Impactos Ambientais Urbanos no Brasil. 2a Ed, Berthand Brasil. Rio de Janeiro, 2004.

ESMPU - Escola Superior do Ministério Público da União. Deficiências em estudos de impacto ambiental: síntese de uma experiência. Brasília: Ministério Público Federal, 4ª Câmara de Coordenação e Revisão, 2004.

HOFFMANN,R.M.; Garagalos do Licenciamento Ambiental Federal no Brasil. Camara dos deputados, Brasília, 2015.

IBAMA; Licenciamento Ambiental Federal - Manual de Procedimentos, Brasília, 2002.

LIMA, T. M. Avaliação crítica do licenciamento ambiental do ramal ferroviário em Treviso - SC, UNESC, 2009.

LUTZEMBERGER,J. Fim do Futuro? Manifesto ecológico brasileiro. Porto Alegre:Editora da URGS/Movimeno, 1980. 


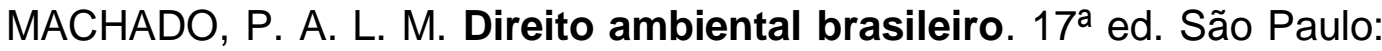
Malheiros, 2009.

MAGALHÃES, Sergio. A Cidade que Queremos.O Globo, Rio de Janeiro, 20 julho de 2014. Caderno Economico, p 19.

MAO, W.; HILLS, P. Impacts of the economic- political reformo $n$ environmental impact assessment implementation in China. Impact assessment and Project appraisal, v. 20, n. 2, p. 101-111, 2002. In: SÁNCHEZ, L.E.; Avaliação de Impacto Ambiental: Conceitos e Métodos. $2^{\mathrm{a}}$ Ed. Oficina de Textos,2013.

MEMON, P.A. Devolution of environmental regulation: environmental impact assessment in Malaysia. Impact assessment and project appraisal, v. 18 , n. 4, p. 283-293, 2000. In: SÁNCHEZ, L.E.; Avaliação de Impacto Ambiental: Conceitos e Métodos. $2^{\mathrm{a}}$ Ed. Oficina de Textos,2013.

MILARÉ, E.; Direito do Ambiente: 5aed. Revista dos Tribunais. 2007.

MILARÉ, É.; Direito Ambiental 6ª Edição, Revista dos Tribunais, 2009.

MMA; Manual do Licenciamneto Ambiental do Ministério do Meio Ambiente. Brasília,2002.

MONOSOSKY, E. Avalaição de impacto ambiental na perspectiva do desenvolvimento sustentável. In SÁNCHEZ, L.E. (Orgs.). Avaliação de impacto ambiental: situação atual e perspectivas. São Paulo: Epusp, 1993.

MOREIRA, I.V.D. EIA in Latin America. In:WATHERN, P.(Org.). Environmental impact assessment:theory and practice.London:Unwin Hyman, 1988. In: SÁNCHEZ, L.E.; Avaliação de Impacto Ambiental: Conceitos e Métodos. 2ª Ed. Oficina de Textos,2013.

MOTA, S.;Introdução à Engenharia Ambiental. $1^{\text {a}}$ ed.Rio de Janeiro: ABES, 1997.

OLIVEIRA, Antônio Inagê de Assis , Introdução à Legislação Ambiental Brasil e Licenciamento Ambiental, Ed. Lumen Juris, 2005.

PEREIRA, A. L. A. B.; Análise crítica dos impactos ambientais ocasionados pela linha de transmissão 500 kV Miracema - Sapeaçu e Subestações Associadas, UFRJ, 2014.

PURNAMA,D. Review of the EIAA process in Indonsis: improving the role of public involvement. Environmental impact assessment review, v. 23, p. 415-439, 2003 In: In: SÁNCHEZ, L.E.; Avaliação de Impacto Ambiental: Conceitos e Métodos. $2^{\mathrm{a}}$ Ed. Oficina de Textos,2013.

RAMOS, Marilene, em entrevista ao jornal “ O Estadão" de 30/05/2015,p 23. 
REIS, D. C.; Análise Crítica do Processo de Licenciamento ambiental de Usinas Fotovoltáicas, UFMG, 2015.

RUNNALS, D. Factors influencing environmental policies in international development agencies. In: ASIAN DEVELOPMENT BANK. Environmental planning and management. Manila: ADB, 1986. In: SÁNCHEZ,L.E.; Avaliação de Impacto Ambiental: Conceitos e Métodos. $2^{\mathrm{a}}$ Ed. Oficina de Textos,2013.

SAE; Secretaria de Assuntos Estratégicos da Presidência da República Liceniamento Ambiental. Brasília, 2009.

SÁNCHEZ, L.E. A diversidade dos conceitos de impacto ambiental e avaliação de impacto ambiental segundo diferentes grupos profissionais. In: VII ENCONTRO ANUAL DA SEÇÃO BRASILEIRA DA IAIAINTERNATIONAL ASSOCIATION FOR IMPACT ASSESSMENT. Rio de Janeiro, 1993.

SANCHÉZ, L.E.; Avaliação de Impacto Ambiental: Conceitos e Métodos. $1^{\mathrm{a}} \mathrm{Ed}$. Oficina de Textos, 2006.

SANCHEZ, L.E.; Avaliação de Impacto Ambiental: Conceitos e Métodos. $2^{\mathrm{a}}$ Ed. Oficina de Textos,2013.

SANCHEZ, L.E.; Modernização do Licenciamento Ambiental no Brasil, palestra durante o Seminário Proposta para Modernização do licenciamento Ambiental " ABAl- associação Brasileira de Avaliação de Impacto - São Paulo, 30 de janeiro de 2014.

SILVA-SÁNCHEZ, S.S. Cidadania ambiental: novos direitos no Brasil.São Paulo: Annablume/Humanitas, 2aㅡ Ed. 2010.

SINDSEP-DF; Sindicato dos Servidores públicos Federais no DF. Carta Aberta:"licenciamento ambiental:o barato que sai mais caro para todos". Brasília, 2015

TCU, Tribunal de Contas da União. A Cartilha de Licenciamento Ambiental. Brasilia, 2004. http://www.tcu.gov.br consultado em 8 fevereiro 2013.

TCU Acódão 2212/2009. Análise dos instrumentos de controle ambiental adotados pelo Ibama para compatibilizar o desenvolvimento econômicosocial com a preservação da qualidade do meio ambiente e so equilíbrio ecológico.

TCU Acódão 2828/2011. Reestruturação do Ibama, normatização de procedimentos e implantação de soluções de tecnologia de informação.

TCU Acódão 3413/2012. Existência de Falhas pontuais no processo de licenciamento ambiental das Usinas Hidrelétricas de Jirau e Santo Antônio. 
TOLEDO, Thomaz; Diretor de Licenciamento do Ibama em Seminário promovido pelo MPF em 6 de novembro de 2015 em Brasília.

VIOLA, E.O movimento ecológico no Brasil (1974-1986):do ambientalismo à ecopolítica. In: PÁDUA, J.A.(Org.). Ecologia e política no Brasil. Rio de Janeiro:Espaço e Tempo/luerj, 1987.

VIOLA, E. O movimento ambientalista no Brasil (1971-1991): da denúncia e conscientização pública para a institucionalização e desenvolvimento sustentável. In: GOLDENBERG, M. (Org.).Ecologia, ciência e política. Rio de Janeiro:Revan, 1992.

VOLNEY, Zanardi; Avaliação de impacto em http://avaliacaodeimpacto.org.br/wp-content/uploads/2014/11/PalestraVolney-Zanardi-J\%C3\%BAnior.pdf

ZHU, T.; LAM, K.C. Environmental impact assessment in China. Nankai University, The Chinese University of Hong Kong, 2ª . Ed., 2010 In: SÁNCHEZ, L.E.; Avaliação de Impacto Ambiental: Conceitos e Métodos. $2^{\mathrm{a}} \mathrm{Ed}$. 


\section{Anexos}

\section{1}

\section{Empreendimentos Pontuais}

Tabela A - Empreendimentos Pontuai

\begin{tabular}{|c|c|c|c|c|c|c|c|c|}
\hline $\begin{array}{l}\text { Órgão } \\
\text { Licenciado } \\
\text { r Tipologia }\end{array}$ & $\begin{array}{c}\text { Empreendimento/ } \\
\text { empreendedor/ } \\
\text { Estado }\end{array}$ & \begin{tabular}{|l} 
Características do \\
empreendimento
\end{tabular} & $\begin{array}{c}\text { Ano de } \\
\text { apresentação } \\
\text { ao órgão }\end{array}$ & $\begin{array}{c}\text { Empresa } \\
\text { Consultora }\end{array}$ & $\begin{array}{c}\text { Quantidade de } \\
\text { impactos/programas } \\
\text { para cada meio }\end{array}$ & Físico & Biótico & Antropico \\
\hline Ibama Porto & $\begin{array}{l}\text { Brasil Terminal } \\
\text { Portuário Santos SP }\end{array}$ & $\begin{array}{c}\text { Ampliação, } \\
\text { Terminal Publico } \\
\text { de Uso } \\
\text { Multiplo, } 620 \\
\text { atracaçōes por ano } \\
\text { e } 130 \text { caminhōes } \\
\text { por hora, } 660 \\
\text { diretoos na obra e } \\
3000 \text { diretos e } \\
\text { indiretos na } \\
\text { operação }\end{array}$ & 2008 & $\begin{array}{l}\text { MKR Engenharia } \\
\text { de Recursos } \\
\text { Ambientais }\end{array}$ & $\begin{array}{c}\text { Impacto } \\
13 \text { fisico, } 11 \text { biótico e } \\
22 \text { socioeocnomico }\end{array}$ & $\begin{array}{l}\text { Alterações no escoamento superficial; } \\
\text { desencadeamento de processos erosivos; } \\
\text { assoreamento de drenagens; } \\
\text { impactos decorrentes de recalques e } \\
\text { rupturasas de solos moles na fundacão de } \\
\text { aterros e pilhas de resíduos e materiais; } \\
\text { impactos decorrentes do atrito negativo } \\
\text { em estacas; } \\
\text { impactos decorrentes das rupturas de } \\
\text { taludes; } \\
\text { interceptação do aquífero frético; } \\
\text { contaminação das águas superficiais e } \\
\text { subterranneas; } \\
\text { impactos decorrentes das atividades de } \\
\text { dragagem; } \\
\text { alteracãão da qualidade do ar; } \\
\text { geracãao de rúdos e vibracōes; } \\
\text { qualidade do ar- fontes móveis; } \\
\text { qualidade do ar - fontes fixas. }\end{array}$ & $\begin{array}{l}\text { Perda de vegetação de mangue; } \\
\text { perda de vegetação secundária em estágio } \\
\text { inicial; } \\
\text { degradação do fragmento remanescente de } \\
\text { manguezal; } \\
\text { geração de resíduos vegetais; } \\
\text { perda de indivíduos da fauna terrestre } \\
\text { durante a supressão de vegetação; } \\
\text { perda de habitat; } \\
\text { perda de habitat para a fauna terrestre que se } \\
\text { utiliza de ambiente aquático; } \\
\text { conflitos com a fauna; } \\
\text { aumento do lancamento de hidrocarbonetos } \\
\text { e outros contaminantes, bem como da } \\
\text { turbidez; } \\
\text { afugentamento da fauna demersalpelágica; } \\
\text { criação de novos habitats. }\end{array}$ & 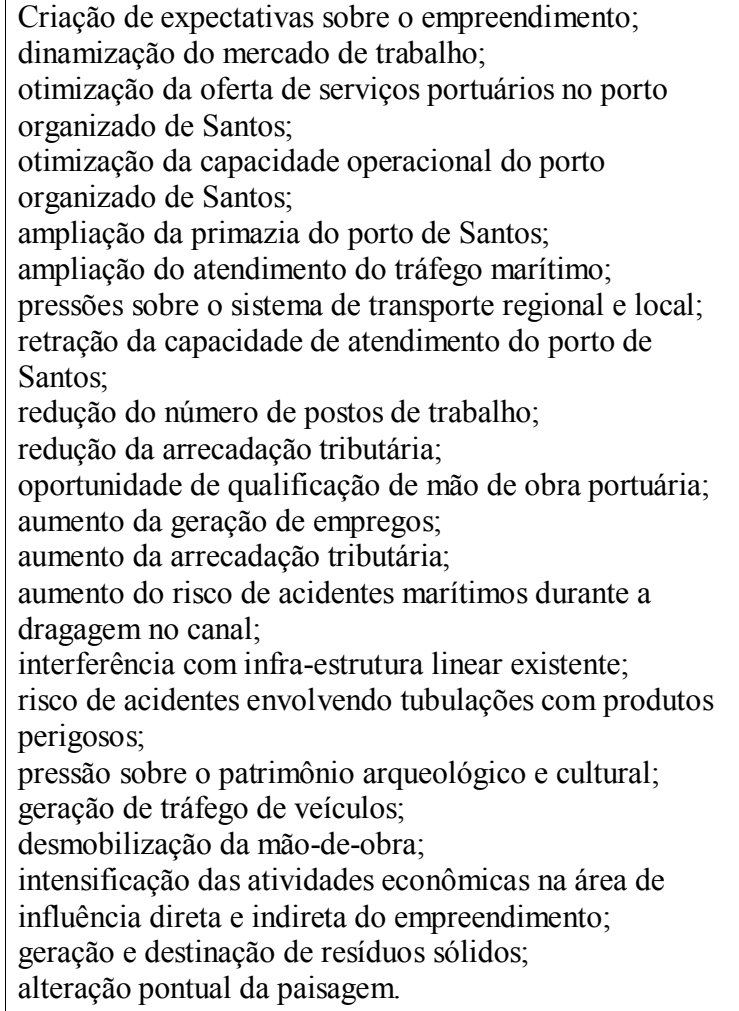 \\
\hline Ibama Porto & $\begin{array}{l}\text { Brasil Terminal } \\
\text { Portuário Santos SP }\end{array}$ & $\begin{array}{c}\text { Ampliação, } \\
\text { Terminal Publico } \\
\text { de Uso } \\
\text { Multiplo, } 620 \\
\text { atracaçoos por ano } \\
\text { e } 130 \text { caminhões } \\
\text { por hora, } 660 \\
\text { diretoson na obra e } \\
3000 \text { diretos e } \\
\text { indiretos na } \\
\text { operação }\end{array}$ & 2008 & $\begin{array}{l}\text { MKR Engenharia } \\
\text { de Recursos } \\
\text { Ambientais }\end{array}$ & $\begin{array}{l}\text { Programa } \\
13 \text { fisico, } 4 \text { biótico, } 4 \\
\text { socioeconomico }\end{array}$ & $\begin{array}{l}\text { Programa de Gestão Ambiental; } \\
\text { Programa de Auditoria Ambiental; } \\
\text { Programa de Procedimentos de } \\
\text { Gerenciamento dos Riscos de Poluicão; } \\
\text { Programa de Controle Ambiental da } \\
\text { Construção; } \\
\text { Programa de Gerenciamento de Resíduos; } \\
\text { Programa de Gerenciamento de Efluentes; } \\
\text { Programa de Controle e Monitoramento da } \\
\text { Qualidade de Águas Superficiais e } \\
\text { Subterraneas; } \\
\text { Programa de Monitoramento de } \\
\text { Dragagem; Programa de Verificacaão do } \\
\text { Gerenciamento da Água de Lastro de } \\
\text { Navios; } \\
\text { Programa de Gerenciamento de Risco; } \\
\text { Plano de Emergencia Individual; } \\
\text { Plano de Acão de Emergência - Fase de } \\
\text { Implantacãao; } \\
\text { Programa de Controle Ambientalda } \\
\text { Operação. }\end{array}$ & $\begin{array}{l}\text { Programa de Controle e Monitoramento das } \\
\text { Condicoós do Meio Biotico; } \\
\text { Programa de Acompanhamento da } \\
\text { Supressão Vegetal; } \\
\text { Programa de Compensação Florestal; } \\
\text { Programa de Compensação Ambiental. }\end{array}$ & $\begin{array}{l}\text { Programa de Comunicação Social; } \\
\text { Programa de Educação Ambiental, Saude e Segurança do } \\
\text { Trabalhador; } \\
\text { Programa de Mitigação da Interferencias no Sistema } \\
\text { Viário; } \\
\text { Programa de Monitoramento Arqueologico e de } \\
\text { Educação Patrimonial. }\end{array}$ \\
\hline
\end{tabular}


Tabela A - Empreendimentos Pontuais

(Continuação)

\begin{tabular}{|c|c|c|c|c|c|c|c|c|}
\hline $\begin{array}{c}\text { Órgão } \\
\text { Licenciador } \\
\text { Tipologia }\end{array}$ & $\begin{array}{l}\text { Empreendimento/ } \\
\text { empreendedor/ } \\
\text { Estado }\end{array}$ & $\begin{array}{c}\text { Características do } \\
\text { empreendimento }\end{array}$ & \begin{tabular}{|c|} 
Ano de \\
apresentação ao \\
orgão
\end{tabular} & $\begin{array}{c}\text { Empresa } \\
\text { Consultora }\end{array}$ & $\begin{array}{c}\text { Quantidade de } \\
\text { impactos/programas } \\
\text { para cada meio }\end{array}$ & Físico & Biótico & Antropico \\
\hline Ibama Porto & $\begin{array}{c}\text { Brites Santos - } \\
\text { Triunfo Santa Rita SP }\end{array}$ & $\begin{array}{l}\text { cais de } 11 \mathrm{~km}, 1 \text { pier } \\
\text { com } 3 \text { berços, área de } \\
\text { estocagem de } \\
600.000 \mathrm{~m} 2 \text {. obra } 1600 \\
\text { diretos e } 3200 \text { indiretos, } \\
\text { operação } 1200 \text { diretose } \\
3000 \text { indiretos. }\end{array}$ & 2009 & $\begin{array}{c}\text { CPEA } \\
\text { Consultoria, } \\
\text { Planejamento e } \\
\text { Estudos } \\
\text { Ambientais }\end{array}$ & $\begin{array}{l}\text { Impactos } \\
12 \text { fisico, } 10 \text { biótico e } \\
18 \text { socioeconomico }\end{array}$ & $\begin{array}{l}\text { Elevação dos níveis de ruídos; } \\
\text { elevação dos níveis de vibrações; } \\
\text { aumento da geracãão de residuos sollidos; } \\
\text { alterações no escoamento superficial; } \\
\text { incremento dos processos erosivos; } \\
\text { assoreamento de drenagens; } \\
\text { recursos hídricos; } \\
\text { redução do estoque de contaminantes no } \\
\text { ambiente estuarino; } \\
\text { aumento da concentracãão de sólidos totais } \\
\text { em suspensão na coluna d'água; } \\
\text { alteração da qualidade da água e sedimento } \\
\text { por derramamentos de óleos e graxas;; } \\
\text { alteração no padrão de circulação das águas } \\
\text { no largo de Santa Rita; } \\
\text { alteração da diNâmica sedimentar no } \\
\text { interior do largo de Santa Rita. }\end{array}$ & $\begin{array}{l}\text { Perda da vegetação; } \\
\text { perda de habitat para vertebrados } \\
\text { terrestres; } \\
\text { fragmentação dos remanescentes } \\
\text { vegetacionais; } \\
\text { afugentamento da fauna de } \\
\text { vertebrados terrestres; } \\
\text { criação de novos habitat com a } \\
\text { disponibilizacãão de substrato para a } \\
\text { colonização; } \\
\text { organismos incrustradores; } \\
\text { perda de habitat para a fauna } \\
\text { aquática; } \\
\text { afugentamento da fauna aquática; } \\
\text { alteracãão das dinâmicas reprodutivas } \\
\text { e/ou do recrutamento de espécies; } \\
\text { desaparecimento, redução numérica } \\
\text { ou pressão sobre espécies raras, } \\
\text { pouco conhecidas ou ameaçadas de } \\
\text { extinção ou sobreexplotação. }\end{array}$ & 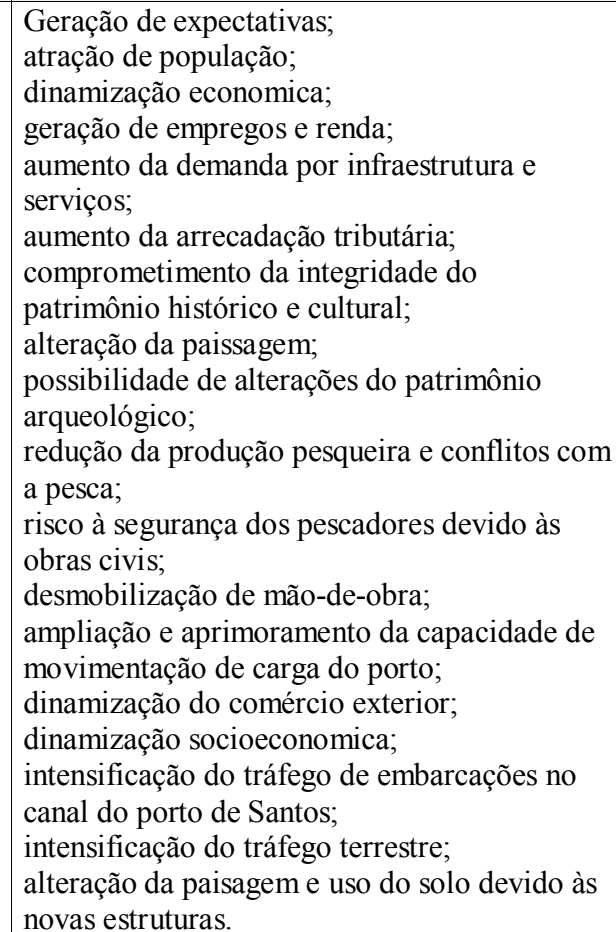 \\
\hline Ibama Porto & $\begin{array}{c}\text { Brites Santos - } \\
\text { Triunfo Santa Rita SP }\end{array}$ & $\begin{array}{l}\text { cais de } 11 \mathrm{~km}, 1 \text { pier } \\
\text { com } 3 \text { berços, área de } \\
\text { estocagem de } \\
600.000 \mathrm{~m} 2 \text {. obra } 1600 \\
\text { diretos e } 3200 \text { indiretos, } \\
\text { operação } 1200 \text { diretose } \\
3000 \text { indiretos. }\end{array}$ & 2009 & $\begin{array}{c}\text { CPEA } \\
\text { Consultoria, } \\
\text { Planejamento e } \\
\text { Estudos } \\
\text { Ambientais }\end{array}$ & $\begin{array}{l}9 \text { fisico, } 12 \text { biotico e } 8 \\
\text { socioeconomico }\end{array}$ & $\begin{array}{l}\text { Programa de Gestão Ambiental; } \\
\text { Programa de Auditoria Ambiental; } \\
\text { Programa Ambiental da Construcãá; } \\
\text { Programa de Controle da Poluicão; } \\
\text { Programa de Gestão dos Recursos Hídricos; } \\
\text { Programa de Gerenciamento de Risco; } \\
\text { Programa de Monitoramento da Dragagem; } \\
\text { Programa de Monitoramento dos } \\
\text { Sedimentos; } \\
\text { Programa de Monitoramento e Modelagem } \\
\text { de Parametros Hidrodinâmicos e } \\
\text { Oceanográficos. }\end{array}$ & $\begin{array}{l}\text { Programa de Monitoramento da } \\
\text { Flora; } \\
\text { Programa de Monitoramento da } \\
\text { Fauna Terrestre; } \\
\text { Programa de Acompanhamento da } \\
\text { Supressão da Vegetação; } \\
\text { Programa de Compensąãa por } \\
\text { Supressão da Vegetação; } \\
\text { Subprograma do Monitoramento de } \\
\text { Organismos Bioindicadores - } \\
\text { Bioacumulação; } \\
\text { Subprograma de Monitoramento do } \\
\text { Ictioplanton, Carcinoplanton e da } \\
\text { Atividade Reprodutiva no Estuário; } \\
\text { Subprograma de Monitoramento da } \\
\text { Abundancia de Quelônios; } \\
\text { Programa de Estudo de Populações } \\
\text { Pouco Conhecidas Cephalocarida e } \\
\text { Cindária; } \\
\text { Subprograma do Camarão Branco; } \\
\text { Subprograma de Conservacãa } \\
\text { Ambiental do Estuário de Santos; } \\
\text { Subprograma do Banco de } \\
\text { Sedimento e Produtividade dos } \\
\text { Bancos do Sururu; } \\
\text { Programa de Compensação } \\
\text { Ambiental. }\end{array}$ & $\begin{array}{l}\text { Programa de Comunicacãão Social; } \\
\text { Programa de educaacão Ambiental; } \\
\text { Programa de Saude e Segurança do } \\
\text { trabalhador; } \\
\text { Programa de Desenvolvimento } \\
\text { Socioeconomico da Região; } \\
\text { Programa de Trafego; } \\
\text { Programa de Apoio à Pesca; } \\
\text { Programa de Gestão Estratégica do Patrimonio } \\
\text { Arqueológico; } \\
\text { Programa de Valorização do Pratrimonio } \\
\text { Historico e Cultural. }\end{array}$ \\
\hline
\end{tabular}


Tabela A - Empreendimentos Pontuais

(Continuação)

\begin{tabular}{|c|c|c|c|c|c|c|c|c|}
\hline $\begin{array}{c}\text { Órgão } \\
\text { Licenciador } \\
\text { Tipologia }\end{array}$ & $\begin{array}{l}\text { Empreendimento/ } \\
\text { empreendedor/ } \\
\text { Estado }\end{array}$ & $\begin{array}{l}\text { Características do } \\
\text { empreendimento }\end{array}$ & \begin{tabular}{|c|} 
Ano de \\
apresentação ao \\
orgão
\end{tabular} & $\begin{array}{l}\text { Empresa } \\
\text { Consultora }\end{array}$ & $\begin{array}{c}\text { Quantidade de } \\
\text { impactos/programas } \\
\text { para cada meio }\end{array}$ & Físico & Biótico & Antropico \\
\hline Ibama Porto & $\begin{array}{l}\text { Porto Sul BA - Dep } \\
\text { de Infra Estrutura de } \\
\text { Transporte da Bahia }\end{array}$ & $\begin{array}{c}\text { Porto Público e Terminal } \\
\text { de Uso privado, } 4 \text { peras, } \\
2 \text { canais, } 2 \text { pier, } 1560 \\
\text { diretos bora e } 1714 \text { na } \\
\text { operação }\end{array}$ & o o & $\begin{array}{c}\text { Hydros } \\
\text { Engenharia e } \\
\text { Planejamento }\end{array}$ & $\begin{array}{l}\text { Impactos } \\
20 \text { fisico, } 26 \text { biótico e } \\
24 \text { socioeconômico }\end{array}$ & 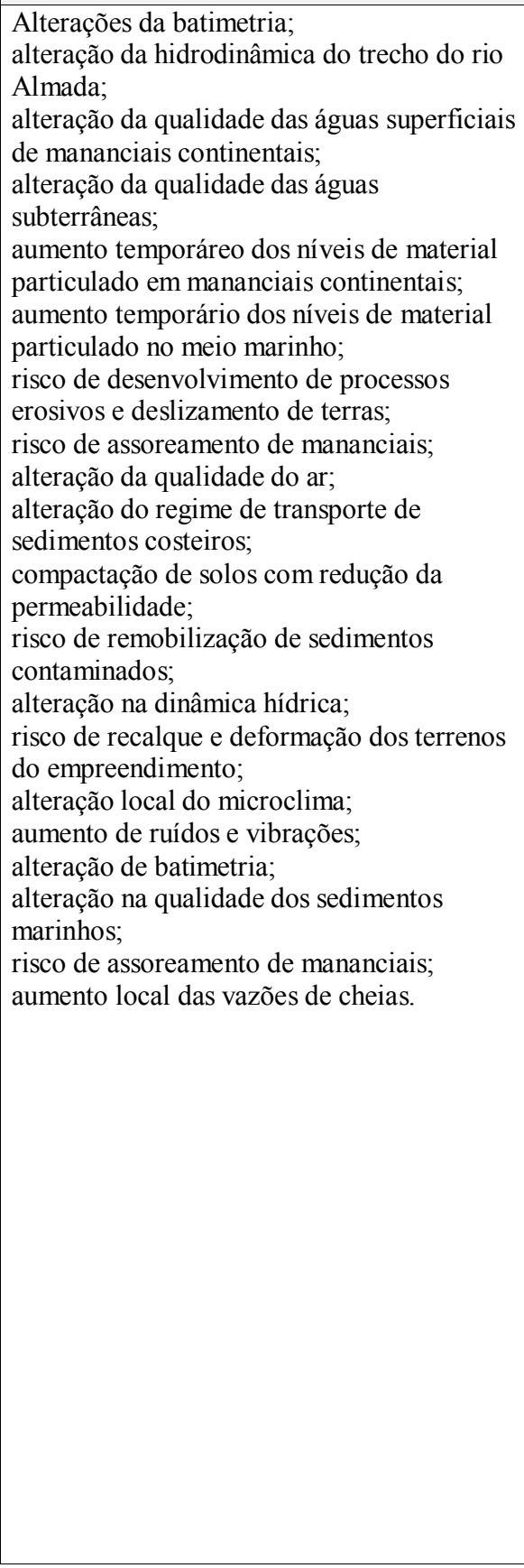 & 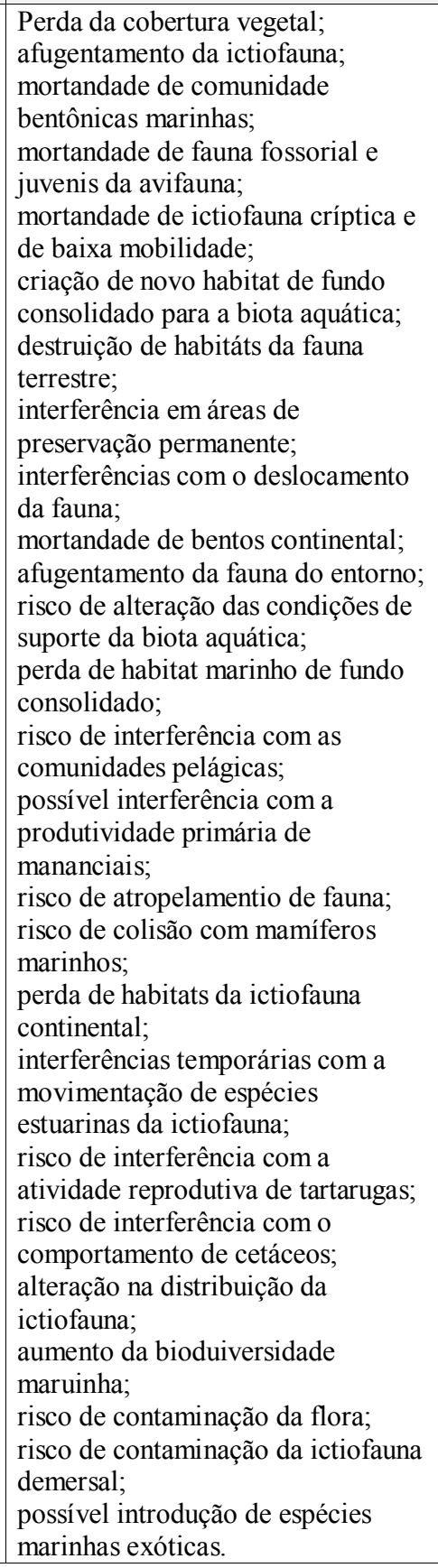 & 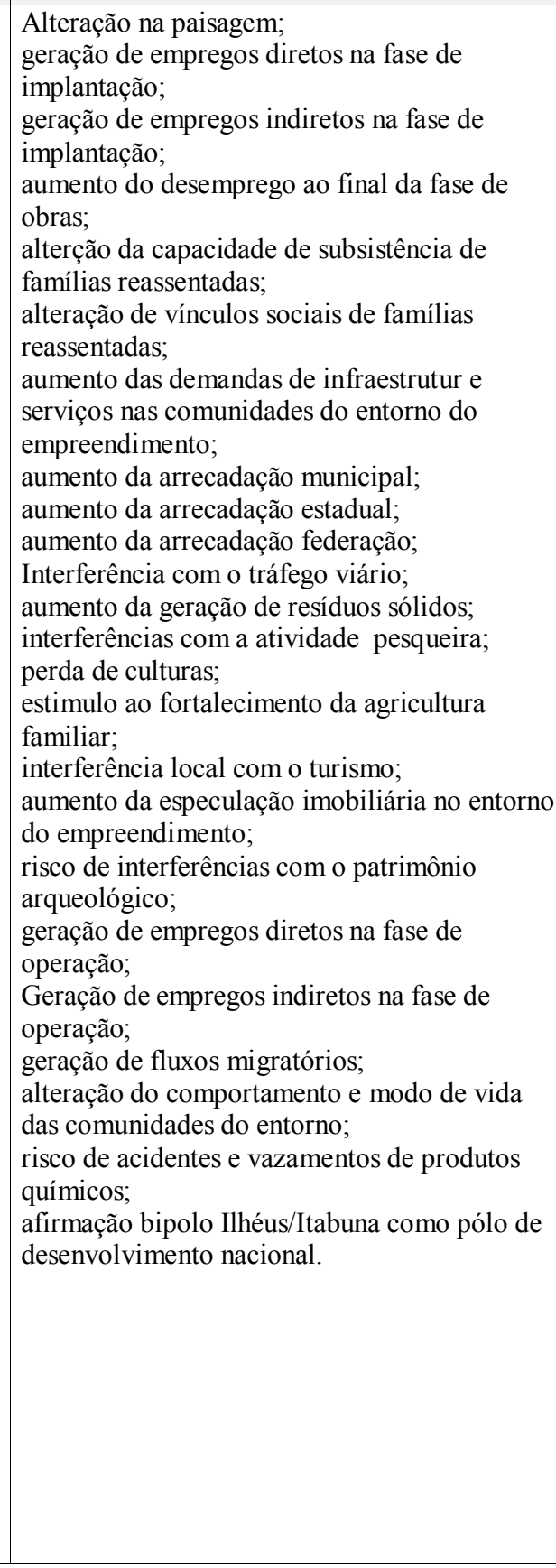 \\
\hline
\end{tabular}


Tabela A - Empreendimentos Pontuais

(Continuação)

\begin{tabular}{|c|c|c|c|c|c|c|c|c|}
\hline $\begin{array}{c}\text { Órgão } \\
\text { Licenciador } \\
\text { Tipologia }\end{array}$ & $\begin{array}{l}\text { Empreendimento/ } \\
\text { empreendedor/ } \\
\text { Estado }\end{array}$ & $\begin{array}{c}\text { Características do } \\
\text { empreendimento }\end{array}$ & \begin{tabular}{|c} 
Ano de \\
apresentação ao \\
orgão
\end{tabular} & $\begin{array}{c}\text { Empresa } \\
\text { Consultora }\end{array}$ & $\begin{array}{c}\text { Quantidade de } \\
\text { impactos/programas } \\
\text { para cada meio }\end{array}$ & Físico & Biótico & Antropico \\
\hline Ibama Porto & $\begin{array}{l}\text { Porto Sul BA - Dep } \\
\text { de Infra Estrutura de } \\
\text { Transporte da Bahiia }\end{array}$ & $\begin{array}{l}\text { Porto Público e Terminal } \\
\text { de Uso privado, } 4 \text { peras, } \\
2 \text { canais, } 2 \text { pier, } 1560 \\
\text { diretos bora e } 1714 \text { na } \\
\text { operação }\end{array}$ & 2011 & $\begin{array}{l}\text { Hydros } \\
\text { Engenharia e } \\
\text { Planejamento }\end{array}$ & $\begin{array}{c}\text { Programas } \\
15 \text { fisico, } 8 \text { biotico e } 14 \\
\text { socioeconomico }\end{array}$ & $\begin{array}{l}\text { Programa de Gestão Ambiental; } \\
\text { Programa de Auditoria Ambiental; } \\
\text { Programa Ambiental da Construção; } \\
\text { Programa de Gerenciamento de Riscos; } \\
\text { Programa de Gerenciamento de Eluuentes; } \\
\text { Programa de Gerenciamento de Resíduos } \\
\text { Sólidos; } \\
\text { Plano de Emergencia Individual; } \\
\text { Programa de Monitoramento da Qualidade } \\
\text { dos Sedimentos Marinhos; } \\
\text { Programa de Verificação do Gerenciamento } \\
\text { de Aguas de Lastro dos Navios; } \\
\text { Programa de Monitoramento da Qualidade } \\
\text { do Ar, Ruidos e Vibracãa na Construção; } \\
\text { Programa de Investigacãa Geotecnica; } \\
\text { Programa de Controle da Erossão e de } \\
\text { Assoreamento; } \\
\text { Programa de Monitoramento da } \\
\text { Qualidadedas Águas; } \\
\text { Programa de Monitoramento da Linha de } \\
\text { Costa; } \\
\text { Programa de Monitoramento da Batimetria; }\end{array}$ & $\begin{array}{l}\text { Programa de Recuperação de Áreas } \\
\text { Degradadas; } \\
\text { Programa de Monitoramento da } \\
\text { Flora; Programa de Mitigacão de } \\
\text { Impactos pela Perda de Indivíduos } \\
\text { da Fauna por atropelamento/Colisão. } \\
\text { Programa de Resgate da liora; } \\
\text { Programa de Reposição da } \\
\text { Vegetação de Nascentes,Matas } \\
\text { Ciliares e Manguezais; } \\
\text { Programa de Afugentamento e } \\
\text { Resgate de Fauna Terrestre; } \\
\text { Programa de Monitoramento da } \\
\text { Biota Aquatica; } \\
\text { Programa de Monitoramento da } \\
\text { Ictiofauna. }\end{array}$ & 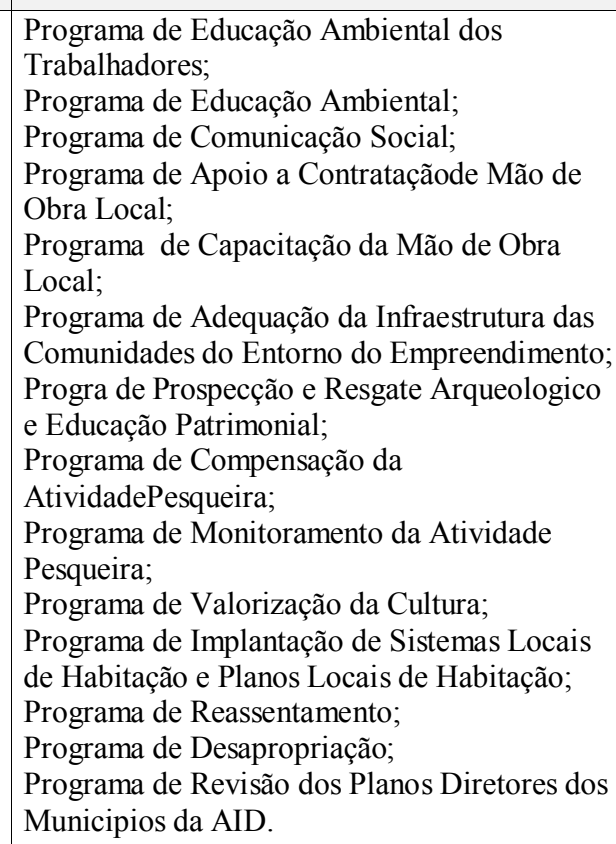 \\
\hline Ibama Porto & Ferrous - ES & $\begin{array}{c}\text { pier } 520 \mathrm{~m} \text { e quebra mar } \\
\text { de } 1 \mathrm{~km} \text {, patio para } \\
\text { 50Mtano de Minerio de } \\
\text { Ferro }\end{array}$ & 2010 & $\begin{array}{c}\text { Cepemar } \\
\text { Serviços de } \\
\text { Consultoria em } \\
\text { Meio } \\
\text { Ambiente }\end{array}$ & $\begin{array}{l}\text { Impactos } \\
4 \text { físico, } 10 \text { biótico e } 19 \\
\text { socioeconomico }\end{array}$ & $\begin{array}{l}\text { Alteração na qualidade dos recursos hídricos } \\
\text { superficiais; } \\
\text { alteraçao na qualidade dos recursos hídricos } \\
\text { subterrâneas; } \\
\text { alteraçōos morfodinâmicas e sedimentares; } \\
\text { alteraçôes na qualidade da água. }\end{array}$ & $\begin{array}{l}\text { Interferência na biota marinha } \\
\text { devido ao lançamento acidental de } \\
\text { óleo no mar; } \\
\text { perda de cobertura vegetal; } \\
\text { perda da diversidade da fauna } \\
\text { terrestre; } \\
\text { perda de habitats para a fauna } \\
\text { terrestre; } \\
\text { perturbação e afugentamento da } \\
\text { fauna; } \\
\text { atropelamento de animais; } \\
\text { interferência na comunidade } \\
\text { pelágica; } \\
\text { aumento da pressão de caça e } \\
\text { captura de animais; } \\
\text { aumento da pressão sobre recursos } \\
\text { florestais; } \\
\text { introdução de espécies exóticas. }\end{array}$ & 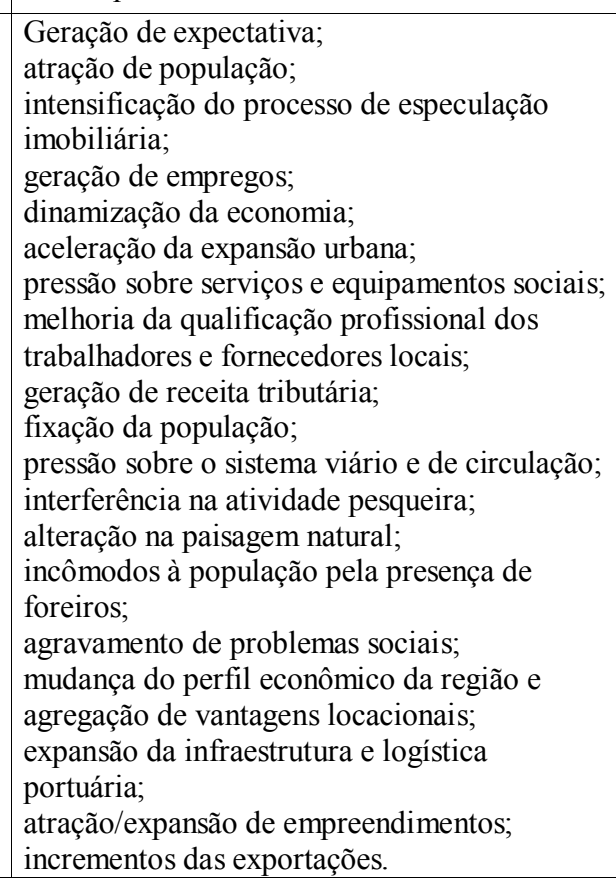 \\
\hline
\end{tabular}


Tabela A - Empreendimentos Pontuais

(Continuação)

\begin{tabular}{|c|c|c|c|c|c|c|c|c|}
\hline $\begin{array}{c}\text { Órgão } \\
\text { Licenciador } \\
\text { Tipologia }\end{array}$ & $\begin{array}{l}\text { Empreendimento/ } \\
\text { empreendedor/ } \\
\text { Estado }\end{array}$ & $\begin{array}{l}\text { Características do } \\
\text { empreendimento }\end{array}$ & $\begin{array}{c}\text { Ano de } \\
\text { apresentação ao } \\
\text { órgão }\end{array}$ & $\begin{array}{l}\text { Empresa } \\
\text { Consultora }\end{array}$ & $\begin{array}{c}\text { Quantidade de } \\
\text { impactos/programa } \\
\text { para cada meio }\end{array}$ & Físico & Biótico & Antropico \\
\hline Ibama Porto & Ferrous- ES & $\begin{array}{l}\text { pier } 520 \mathrm{~m} \text { e quebra mar } \\
\text { de } 1 \mathrm{~km} \text {, patio para } \\
50 \text { Mtano de Minerio de } \\
\text { Ferro }\end{array}$ & 2010 & $\begin{array}{c}\text { Cepemar } \\
\text { Serviços de } \\
\text { Consultoria er } \\
\text { Meio } \\
\text { Ambiente }\end{array}$ & \begin{tabular}{c|c} 
Programas \\
$\mathrm{n}$ & 14 fisico, 5 biológico \\
8 socioeconomico
\end{tabular} & $\begin{array}{l}\text { Programa de Gestão Ambiental; } \\
\text { Programa de Auditoria Ambiental; } \\
\text { Programa de Monitoramento de Lençol } \\
\text { Freatico; } \\
\text { Prgrama de Monitoramento de Recursos } \\
\text { Hidricos Superficial; } \\
\text { Programa de Controle da Poluicãa; } \\
\text { Programa de Controle de Emissão de Poeira; } \\
\text { Programa de Monitoramento da Qualidade } \\
\text { de Aguas Marinhas; } \\
\text { o, } \\
\text { Programa de Monitoramento das Plumas de } \\
\text { Turbidez; } \\
\text { Programa de Monitoramento Batimetrico; } \\
\text { Programa de Monitoramento } \\
\text { Morfodinamico da Linha de Costa; } \\
\text { Programa de Monitoramento } \\
\text { Sedimentológico; } \\
\text { Programa de Verificacacão do Gerenciamento } \\
\text { da Agua de Lastro de Navios; } \\
\text { Plano de Emergencia Individual; } \\
\text { Programa de Gerenciamento de Risco. }\end{array}$ & $\begin{array}{l}\text { Programa de Recuperação de Areas } \\
\text { Degradadas; } \\
\text { Programa de Monitoramento da } \\
\text { Fauna Terrestre; } \\
\text { Programa de Segurança e Alerta ( } \\
\text { picada de peçonhentos e } \\
\text { atropelamento de fauna); } \\
\text { a Programa de Monitoramento da } \\
\text { Fauna Aquática; } \\
\text { Programa de Compensação } \\
\text { Ambiental. }\end{array}$ & 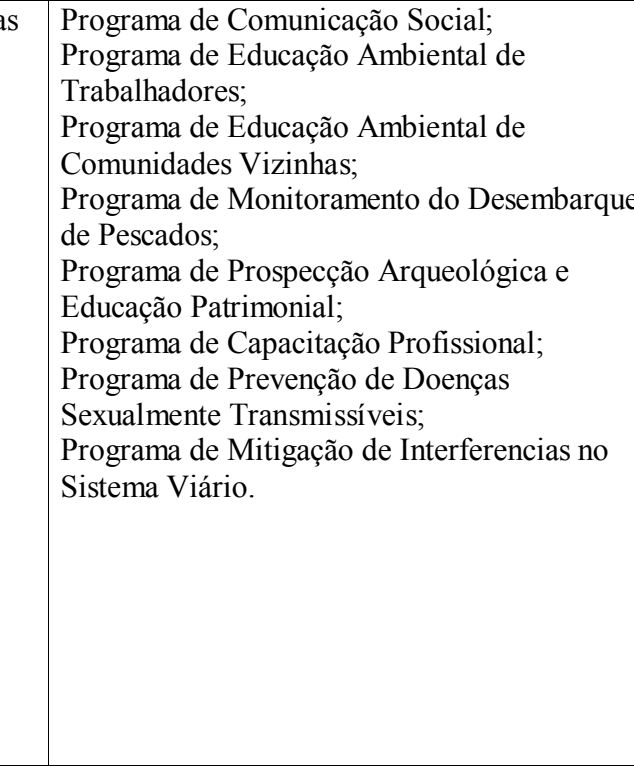 \\
\hline $\begin{array}{l}\text { Ibama } \\
\text { Mineração }\end{array}$ & $\begin{array}{l}\text { Plato Bacaba - } \\
\text { Mineracacã Rio do } \\
\text { Norte- PA }\end{array}$ & $\begin{array}{l}\text { 8,6 Mta }-168 \text { empregos } \\
\text { diretos }\end{array}$ & 2007 & $\begin{array}{c}\text { STCP } \\
\text { Engenharia } \\
\text { de Projetos }\end{array}$ & $\begin{array}{c}\text { Impactos } \\
11 \text { fisico, } 11 \text { biótico e } \\
10 \text { socioeconômico }\end{array}$ & 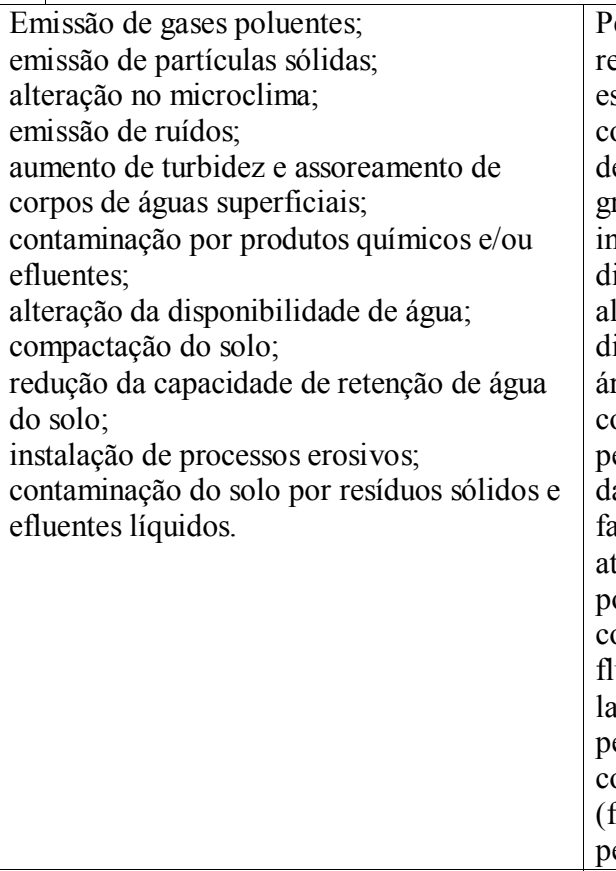 & 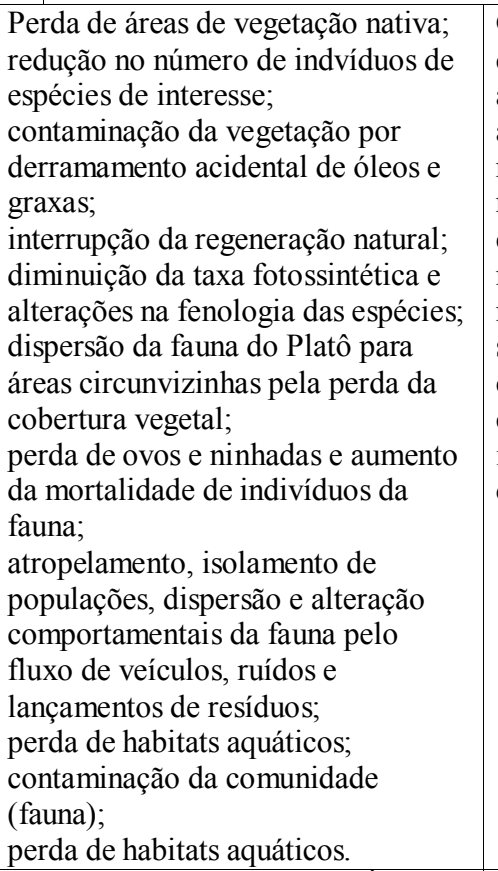 & $\begin{array}{l}\text { Geração de expectativas e insegurança nas } \\
\text { comunidades; } \\
\text { alteracaão da paisagem } \\
\text { aumento do fluxo migratório; } \\
\text { risco de acidentes de trabalho; } \\
\text { redução da bacaba e de remanescentes de } \\
\text { castanhais para a atividade de extrativismo; } \\
\text { manutenção dos níveis de bem-estar social; } \\
\text { manutenção do quadro atual de empregos e } \\
\text { serviços; } \\
\text { capacitacão profisssional dos funcionários e/ou } \\
\text { contratados; } \\
\text { incremento nos níveis de renda pública; } \\
\text { danos a patrimônio arqueológico local; }\end{array}$ \\
\hline $\begin{array}{l}\text { Ibama } \\
\text { Mineração }\end{array}$ & $\begin{array}{l}\text { Plato Bacaba - } \\
\text { Mineracacã Rio do } \\
\text { Norte- PA }\end{array}$ & $\begin{array}{l}\text { 8,6 Mta }-168 \text { empregos } \\
\text { diretos }\end{array}$ & 2007 & \begin{tabular}{|c|} 
STCP \\
Engenharia \\
de Projetos
\end{tabular} & $\begin{array}{c}\text { Programas } \\
4 \text { fisico, } 5 \text { biótico e } 3 \\
\text { socioeconômico }\end{array}$ & 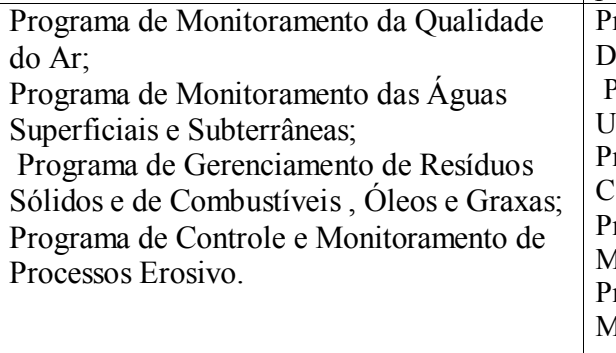 & $\begin{array}{l}\text { Programa de Recuperação de Áreas } \\
\text { Degradadas; } \\
\text { Programa de Compensacãão para } \\
\text { Unidades de Conservacaá; } \\
\text { Programa de Aproveitamento } \\
\text { Científico e Resgate da Fauna; } \\
\text { Programa de Pesquisa e } \\
\text { Monitoramento da Flora; } \\
\text { Programa de Pesquisa e } \\
\text { Monitoramento da Fauna. }\end{array}$ & $\begin{array}{l}\text { Programa de Capacitação da Mão de Obra } \\
\text { Local; } \\
\text { Programa de Educação Ambiental; } \\
\text { Programa de Comunicação Social. }\end{array}$ \\
\hline
\end{tabular}


Tabela A - Empreendimentos Pontuais

(Continuação)

\begin{tabular}{|c|c|c|c|c|c|c|c|c|}
\hline $\begin{array}{c}\text { Órgão } \\
\text { Licenciador } \\
\text { Tipologia }\end{array}$ & $\begin{array}{l}\text { Empreendimento/ } \\
\text { empreendedor/ } \\
\text { Estado }\end{array}$ & $\begin{array}{c}\text { Características do } \\
\text { empreendimento }\end{array}$ & \begin{tabular}{|c} 
Ano de \\
apresentação ao \\
orgão
\end{tabular} & $\begin{array}{c}\text { Empresa } \\
\text { Consultora }\end{array}$ & \begin{tabular}{|c|}
$\begin{array}{c}\text { Quantidade de } \\
\text { impactos/programas } \\
\text { para cada meio }\end{array}$ \\
\end{tabular} & Físico & Biótico & Antropico \\
\hline $\begin{array}{c}\text { Ibama } \\
\text { Mineração }\end{array}$ & $\begin{array}{c}\text { Ferro Carajás S11D- } \\
\text { Vale PA }\end{array}$ & 0 & 2010 & $\begin{array}{c}\text { Golder } \\
\text { Associates }\end{array}$ & $\begin{array}{c}\text { Impactos } \\
8 \text { físico, 11 biótico e } 15 \\
\text { socioeconomico }\end{array}$ & $\begin{array}{l}\text { Alteração da qualidade do ar; } \\
\text { alteração nos niveis acústicos e de } \\
\text { vibracoces; } \\
\text { alteração na dinâmica erosiva; } \\
\text { perda de solos; } \\
\text { alteraçãa na dinâmica hídrica superficial; } \\
\text { alteração da disponibilidade hídrica } \\
\text { superficial e subterrânea; } \\
\text { alteraçãie supressão da morfologia fluvial; } \\
\text { alteraçãa da qualidade das águas superficiais } \\
\text { e subterrâneas. }\end{array}$ & $\begin{array}{l}\text { Fragmentação e efeito de borda; } \\
\text { alteração nas comunidades bióticas } \\
\text { das savanas estépicas; } \\
\text { eliminaçãa ode espécies vegetais e } \\
\text { redução nas populações vegetais; } \\
\text { redução da biomassa vegetal; } \\
\text { alteração de funções fisiológicas } \\
\text { vegetais; } \\
\text { perda de habitat da fauna; } \\
\text { afugentamento da fauna; } \\
\text { alteraçãa oda pressão de caça, pesca e } \\
\text { coleta clandestina da fauna; } \\
\text { desequilibrio das comunidades } \\
\text { faunísticas receptoras; } \\
\text { perda de riqueza e diversidade e } \\
\text { declínio populacional de espécies da } \\
\text { fauna; } \\
\text { criação de sítios artificiais para o } \\
\text { abrigo esou reprodução de insetos e } \\
\text { vetores. }\end{array}$ & 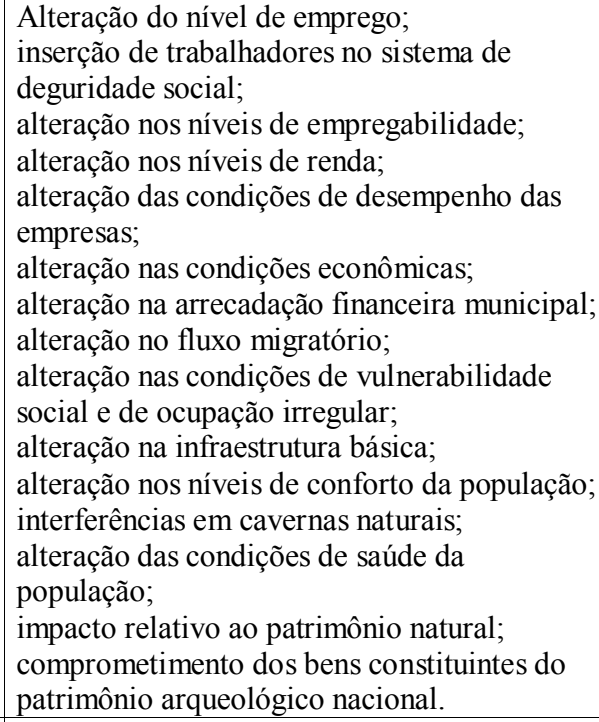 \\
\hline $\begin{array}{l}\text { Ibama } \\
\text { Mineração }\end{array}$ & $\begin{array}{l}\text { Ferro Carajás S11D- } \\
\text { Vale PA }\end{array}$ & 0 & 2010 & $\begin{array}{c}\text { Golder } \\
\text { Associates }\end{array}$ & $\begin{array}{l}\text { Programas } \\
5 \text { fisico, } 6 \text { biotico e } 11 \\
\text { socioeconomico }\end{array}$ & $\begin{array}{l}\text { Plano de Gestão dos Recursos Hídricos } \\
\text { Superficiais, } \\
\text { Plano de Gestão de Recursos Hídricos } \\
\text { Subaterrâneo; } \\
\text { Plano de Gestão da Qualidade do Ar; } \\
\text { Plano de Gerenciamento de Resíduos } \\
\text { Sólidos; } \\
\text { Plano de Monitoramento de Ruídos e } \\
\text { Vibrações. }\end{array}$ & $\begin{array}{l}\text { Programa de Banco de Dados da } \\
\text { Biodiversidade de Carajás; } \\
\text { Programa de Conservação da } \\
\text { Biodiversidade Florística de Carajás; } \\
\text { Programa de Conservacãa e } \\
\text { Biodiversidade Faunistica de } \\
\text { Carajás; } \\
\text { Programa de Pesquisa das } \\
\text { Comunidades de Ambientes } \\
\text { Úmidos; } \\
\text { Programa de Criação de Unidade de } \\
\text { Conservação; } \\
\text { Plano de Compensação Ambiental. }\end{array}$ & $\begin{array}{l}\text { Programa de Acompanhamento da Migracãa; ; } \\
\text { Programa de Monitoramento de Indicadores } \\
\text { Socioeconômicos; } \\
\text { Programa de Fomento ao Desenvolvimento } \\
\text { Socioeconômico; } \\
\text { Programa de Apoio à Infraestrutura; } \\
\text { Programa de Capacitação e Formação da Mão } \\
\text { de Obra; } \\
\text { Programa de Desenvolvimento de } \\
\text { Fornecedores; } \\
\text { Programa de Saúde e Seguranças; } \\
\text { Programa de Educação Ambiental; } \\
\text { Programa de Comunicacão Social; } \\
\text { Programa de Arqueologia Preventiva; } \\
\text { Programa de Educação Patrimonial. }\end{array}$ \\
\hline $\begin{array}{l}\text { Ibama } \\
\text { Mineração }\end{array}$ & $\begin{array}{l}\text { Projeto Retiro - Rio } \\
\text { Grande Mineração - } \\
\text { RS }\end{array}$ & $\begin{array}{l}\text { Minérios pesados, } 1500 \\
\text { pico e } 350 \text { operação }\end{array}$ & 2014 & $\begin{array}{l}\text { HAR Eng e } \\
\text { Meio } \\
\text { Ambiente/ } \\
\text { CPEA }\end{array}$ & $\begin{array}{c}\text { Impactos } \\
5 \text { físico, } 6 \text { biótico e } 14 \\
\text { socioeconomico }\end{array}$ & $\begin{array}{l}\text { Alteração da qualidade do solo e recursos } \\
\text { hídricos; } \\
\text { perda da barreira contra ação do vento; } \\
\text { alteração da qualidade do ar; } \\
\text { alteração do regime de escoamento } \\
\text { superficial; } \\
\text { alteração do nível e/ou fluxo das águas } \\
\text { subterrâneas. }\end{array}$ & $\begin{array}{l}\text { Alteração da estrutura e composição } \\
\text { da biota aquática; } \\
\text { perda da cobertura vegetal existente; } \\
\text { perturbacão, afugentamento e perda } \\
\text { de indvíduos de fauna terrestre; } \\
\text { alteração da paisagem; } \\
\text { degradação deàreas de Preservação } \\
\text { Permanente; } \\
\text { recuperacão da cobertura vegetal e } \\
\text { de àreas de Preservação Permanente. }\end{array}$ & $\begin{array}{l}\text { Geracãão de expectativas na população; } \\
\text { alteração da paisagem; } \\
\text { valorização imobiliária; } \\
\text { dinamizacacão da economia; } \\
\text { geração de empregos; } \\
\text { aumento da renda; } \\
\text { aumento da arrecadacãõo tributária; } \\
\text { aumento da demanda por habitação; } \\
\text { incremento das ocupações irregulares; } \\
\text { aumento da demanda sobre a infraestrutura e } \\
\text { serviços públicos; } \\
\text { aumento da tráfego de veículos pesados; } \\
\text { aumento do risco de acidentes; } \\
\text { manutenção da acessibilidade às propriedades; } \\
\text { melhoria da balança comercial. }\end{array}$ \\
\hline
\end{tabular}


Tabela A - Empreendimentos Pontuais

(Continuação)

\begin{tabular}{|c|c|c|c|c|c|c|c|c|}
\hline $\begin{array}{c}\text { Órgão } \\
\text { Licenciador } \\
\text { Tipologia }\end{array}$ & $\begin{array}{l}\text { Empreendimento/ } \\
\text { empreendedor/ } \\
\text { Estado }\end{array}$ & $\begin{array}{c}\text { Características do } \\
\text { empreendimento }\end{array}$ & \begin{tabular}{|c} 
Ano de \\
apresentação ao \\
orgão
\end{tabular} & $\begin{array}{c}\text { Empresa } \\
\text { Consultora }\end{array}$ & $\begin{array}{c}\text { Quantidade de } \\
\text { impactos/programas } \\
\text { para cada meio }\end{array}$ & Físico & Biótico & Antropico \\
\hline $\begin{array}{c}\text { Ibama } \\
\text { Mineração }\end{array}$ & $\begin{array}{l}\text { Projeto Retiro - Rio } \\
\text { Grande Mineraçẫo - } \\
\text { RS }\end{array}$ & $\begin{array}{l}\text { Minérios pesados, } 1500 \\
\text { pico e } 350 \text { operação }\end{array}$ & 2014 & $\begin{array}{l}\text { HAR Eng e } \\
\text { Meio } \\
\text { Ambiente/ } \\
\text { CPEA }\end{array}$ & $\begin{array}{l}\text { Programas } \\
4 \text { físico, } 8 \text { biótico e } 6 \\
\text { socioeconomico }\end{array}$ & $\begin{array}{l}\text { Programa de Controle Ambiental da Obra; } \\
\text { Programa de Monitoramento da Qualidade } \\
\text { da Água Superficial; } \\
\text { Programa de Gestão Ambiental da } \\
\text { Operação; } \\
\text { Programa de Gestão de Áreas para } \\
\text { Mineração. }\end{array}$ & $\begin{array}{l}\text { Programa de Resgate da Flora; } \\
\text { Programa de Monitoramento da } \\
\text { Flora; } \\
\text { Programa de Recuperação de Áreas } \\
\text { Degradadas; } \\
\text { Programa de Afugentamento e } \\
\text { Resgate da Fauna; } \\
\text { Programa de Prevenção de } \\
\text { Atropelamento de Fauna Silvestre; } \\
\text { Programa de Monitoramento da } \\
\text { Fauna Terrestre e Aquática; } \\
\text { Programa de Gestão da Supressão de } \\
\text { Vegetação e Intervenção em APP; } \\
\text { Programa de Compensação } \\
\text { Ambiental. }\end{array}$ & $\begin{array}{l}\text { Programa de Educação Ambiental dos } \\
\text { Trabalhadores; } \\
\text { Programa de Comunicacãã Social; } \\
\text { Programa de Contratação da Mão de Obra; } \\
\text { Programa de Potencialização dos Beneficios } \\
\text { Econônicos; } \\
\text { Programa de Controle do Tráfego; } \\
\text { Programa de Gestão do Patrimônio } \\
\text { Arqueológico. }\end{array}$ \\
\hline $\begin{array}{c}\text { Ibama } \\
\text { Mineração }\end{array}$ & $\begin{array}{l}\text { Consórcio Santa } \\
\text { Quitéria CE }\end{array}$ & $\begin{array}{l}\text { Fosfatocom Uranio, } 20 \\
\text { anos, pico de obra com } \\
920 \text { ( } 300 \text { não locais) } \\
\text { operação com } 620 . \\
\text { atraçãa de } 2223 \text { pessoas } \\
\text { (13\% pop) }\end{array}$ & 2014 & $\begin{array}{c}\text { Arcadis } \\
\text { Consultoria } \\
\text { Ambiental } \\
\text { Brasil }\end{array}$ & $\begin{array}{c}\text { Impactos } \\
13 \text { fisico, } 11 \text { biótico e } \\
21 \text { socioeconomico }\end{array}$ & 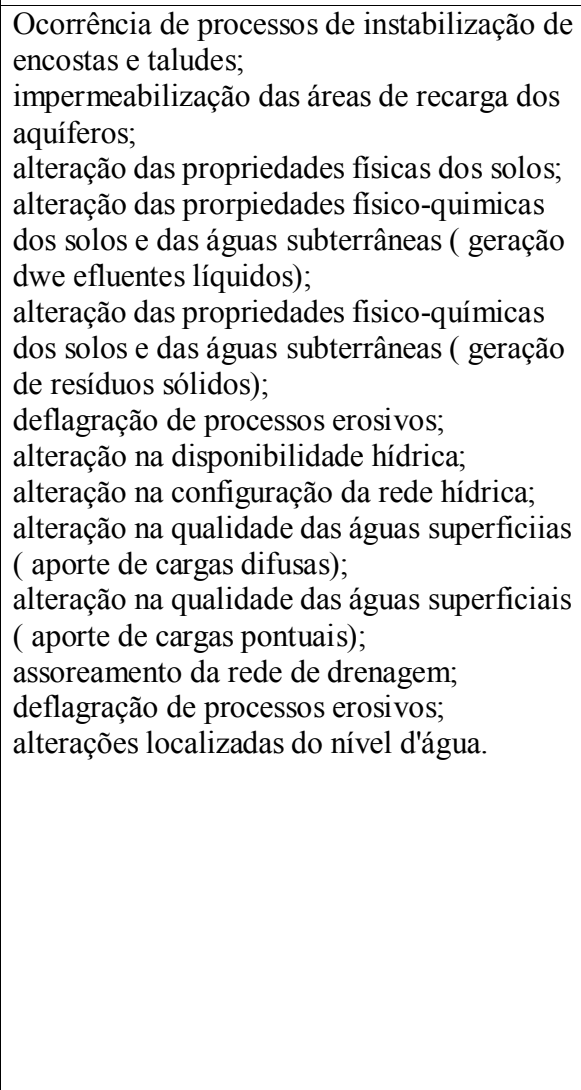 & 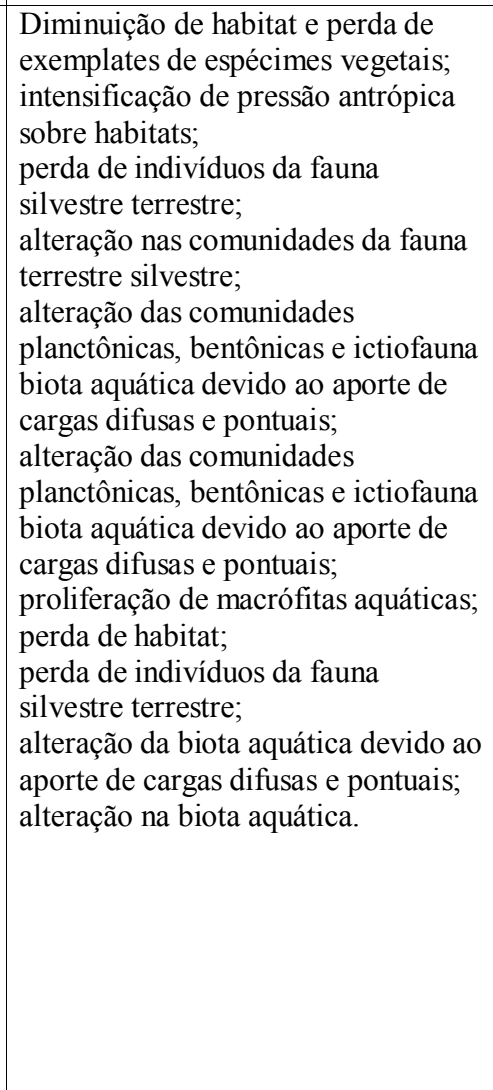 & 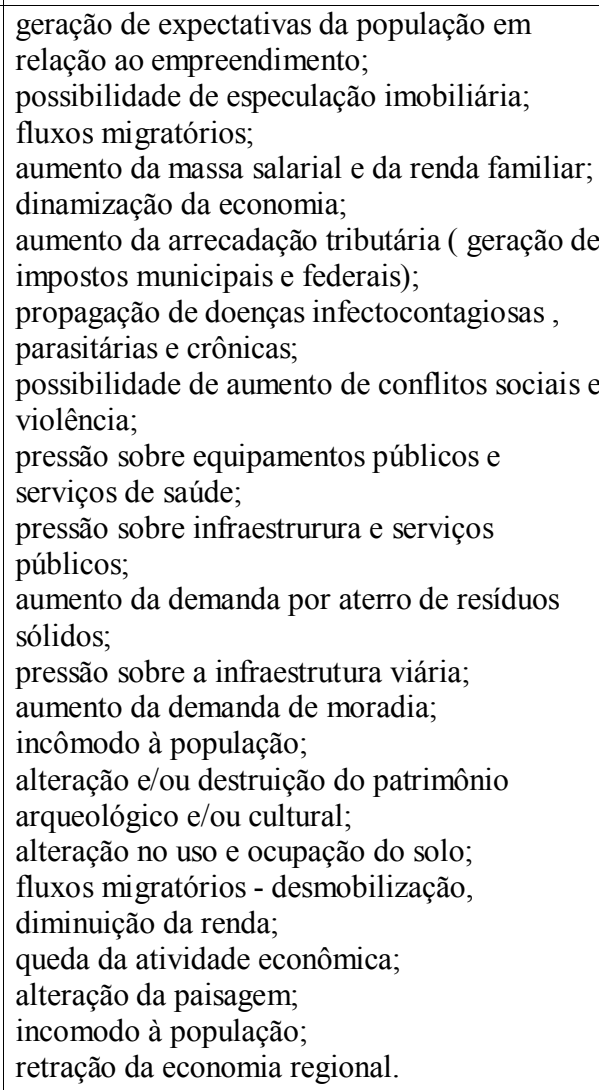 \\
\hline
\end{tabular}


Tabela A - Empreendimentos Pontuais

(Continuação)

\begin{tabular}{|c|c|c|c|c|c|c|c|c|}
\hline $\begin{array}{c}\text { Órgão } \\
\text { Licenciador } \\
\text { Tipologia }\end{array}$ & $\begin{array}{l}\text { Empreendimento/ } \\
\text { empreendedor/ } \\
\text { Estado }\end{array}$ & $\begin{array}{l}\text { Características do } \\
\text { empreendimento }\end{array}$ & \begin{tabular}{|c|} 
Ano de \\
apresentação ao \\
orgão
\end{tabular} & $\begin{array}{c}\text { Empresa } \\
\text { Consultora }\end{array}$ & $\begin{array}{c}\text { Quantidade de } \\
\text { impactos/programas } \\
\text { para cada meio }\end{array}$ & Físico & Biótico & Antropico \\
\hline $\begin{array}{l}\text { Ibama } \\
\text { Mineração }\end{array}$ & $\begin{array}{l}\text { Consórcio Santa } \\
\text { Quitéria CE }\end{array}$ & $\begin{array}{c}\text { Fosfatocom Uranio, } 20 \\
\text { anos, pico de obra com } \\
920 \text { (300 não locais) } \\
\text { operacãao com } 620 . \\
\text { atraçâa de } 2239 \text { pessoas } \\
\text { (13\% pop) }\end{array}$ & 2014 & $\begin{array}{c}\text { Arcadis } \\
\text { Consultoria } \\
\text { Ambiental } \\
\text { Brasil }\end{array}$ & $\begin{array}{l}\text { Programas } \\
15 \text { fisico, 8 bítico e } 9 \\
\text { socioeconômico }\end{array}$ & 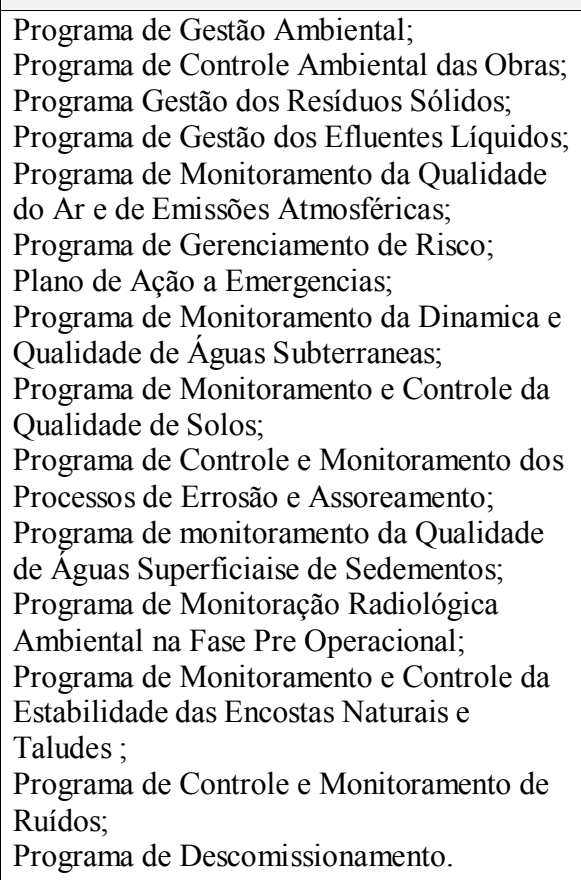 & $\begin{array}{l}\text { Programa de Recuperação de Áreas } \\
\text { Degradadas; } \\
\text { Programa de Afugentamento e } \\
\text { Manejo de Fauna durante a } \\
\text { Supressão da Vegetação; } \\
\text { Programa de Controle da Supressão } \\
\text { Vegetal; } \\
\text { Programa de Monitoramento de } \\
\text { Fauna e Bioindicadorese e Controle } \\
\text { da Alterações de Comunidades } \\
\text { Faunísticas; } \\
\text { Programa de Monitoramento da } \\
\text { Biota Aquatica; } \\
\text { Programa de Resgate do } \\
\text { Germoplasma Vegetal; } \\
\text { Programa de Recomposição da } \\
\text { Áreas de Preservacacâo Permanente; } \\
\text { Programa de Compensação } \\
\text { Ambiental. }\end{array}$ & $\begin{array}{l}\text { Programa de Comunicacão Social; } \\
\text { Programa de Educąão Ambiental; } \\
\text { Programa de Gestão Estratégica do Patrimônio } \\
\text { Arqueológico; } \\
\text { Programa de gestão da Mão de Obra; } \\
\text { Programa de Apoio Técnico e Institucional as } \\
\text { Áreas Urbanas Afetadas pelo } \\
\text { Empreendimento; } \\
\text { Programa de Monitoramento das Interferências } \\
\text { em Infraestruturas e Servicos Públicos; } \\
\text { Programa de Promocão da Saúde; } \\
\text { Programa de Monitoramento do Trafego; } \\
\text { Programa de Migração. }\end{array}$ \\
\hline $\begin{array}{l}\text { Ibama } \\
\text { Industrial }\end{array}$ & $\begin{array}{l}\text { Complexo Industrial } \\
\text { Pecem- Gov do Ceará }\end{array}$ & 0 & 2009 & $\begin{array}{l}\text { Centec - } \\
\text { Instituto } \\
\text { Tecnológico }\end{array}$ & $\begin{array}{l}\text { Impactos ( adaptado) } \\
6 \text { fisiso, } 5 \text { biótico e } 4 \\
\text { socioeconomico }\end{array}$ & $\begin{array}{l}\text { estabilidade e qualidade dos solos; } \\
\text { entiquecimento de registros cartográficos; } \\
\text { alteração na qualidade atmosferrica; } \\
\text { movimentacãao de solos; } \\
\text { mudanças nos recursos hídricos; } \\
\text { geraçâo de resíduos sólidos. }\end{array}$ & $\begin{array}{l}\text { perda de vegetação; } \\
\text { redução de barigo e fonte de } \\
\text { alimentação para fauna terrestre; } \\
\text { mudanças nas APP; } \\
\text { introdução de propágulos nativos ou } \\
\text { exóticos para paisagismo funcional; } \\
\text { risco a ecossistemas pela disposição } \\
\text { final de resíduos sólidos. }\end{array}$ & $\begin{array}{l}\text { incremento em ocupacãão e renda; } \\
\text { inetferência com tráfego; } \\
\text { incremento em arrecadação tributária; } \\
\text { incremento em educação, saúde e segurana } \\
\text { pública. }\end{array}$ \\
\hline $\begin{array}{l}\text { Ibama } \\
\text { Industrial }\end{array}$ & $\begin{array}{l}\text { Complexo Industrial } \\
\text { Pecem- Gov do Ceará }\end{array}$ & 0 & 2009 & $\begin{array}{l}\text { Centec - } \\
\text { Instituto } \\
\text { Tecnológico }\end{array}$ & $\begin{array}{l}\text { Programas } \\
13 \text { fisico, } 6 \text { biótico e } 11 \\
\text { socioeconomico }\end{array}$ & $\begin{array}{l}\text { Plano Ambiental para Construção das } \\
\text { Obras; } \\
\text { Programa de Gerenciamento de Residuos } \\
\text { Solidos; } \\
\text { Plano de Gerenciamento de Risco; } \\
\text { Plano de Resposta a Emergencias; } \\
\text { Programa de Auditoria Ambiental; } \\
\text { Plano de Monitoramento da Qualidade da } \\
\text { Água; } \\
\text { Plano de Monitoramento da Qualidade do } \\
\text { Ar; } \\
\text { Plano de Monitoramento da Qualidade de } \\
\text { Solo; } \\
\text { Plano de Reuso da Água; } \\
\text { Plano de Uso oo Lodo; } \\
\text { Plano de Monitoramento da Qualidade e } \\
\text { Quantidade de Sedimentos; } \\
\text { Plano de Monitoramento dos Níveis de } \\
\text { Ruidos e Vibracōes; } \\
\text { Plano de Monitoramento da Qualidade de } \\
\text { Efluentes e Lodos de ETA's e de ETE's. }\end{array}$ & $\begin{array}{l}\text { Plano de Recuperação de Áreas } \\
\text { Degradadas; } \\
\text { Plano de Paisagismo Funcional; } \\
\text { Plano de Desmatamento Racional; } \\
\text { Plano de Proteção e Manejo do } \\
\text { Bioma; } \\
\text { Plano de Monitoramento Biológico; } \\
\text { Programa de Compensação. }\end{array}$ & 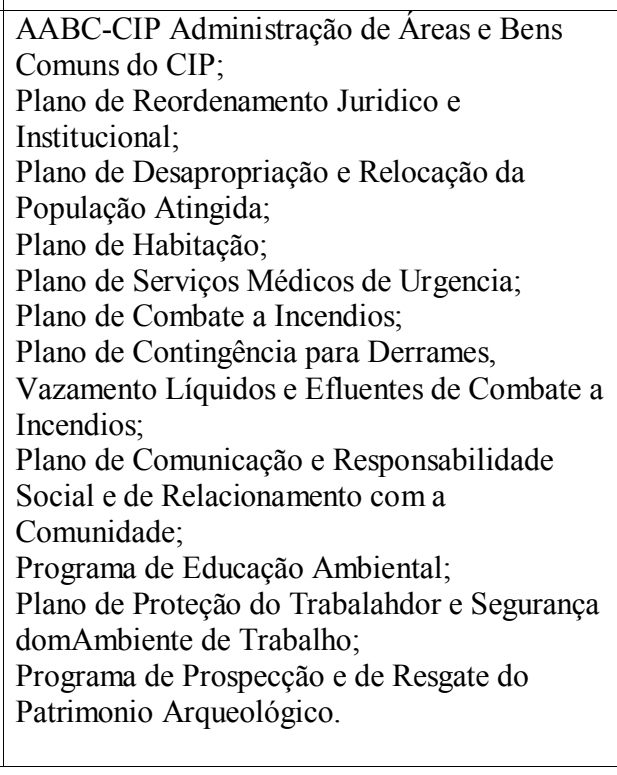 \\
\hline
\end{tabular}


Tabela A - Empreendimentos Pontuais

(Continuação)

\begin{tabular}{|c|c|c|c|c|c|c|c|c|}
\hline $\begin{array}{c}\text { Órgão } \\
\text { Licenciador } \\
\text { Tipologia }\end{array}$ & $\begin{array}{l}\text { Empreendimento/ } \\
\text { empreendedor/ } \\
\text { Estado }\end{array}$ & $\begin{array}{l}\text { Características do } \\
\text { empreendimento }\end{array}$ & $\begin{array}{c}\text { Ano de } \\
\text { apresentação ao } \\
\text { orgão }\end{array}$ & $\begin{array}{c}\text { Empresa } \\
\text { Consultora }\end{array}$ & $\begin{array}{l}\text { Quantidade de } \\
\text { impactos/programas } \\
\text { para cada meio }\end{array}$ & Físico & Biótico & Antropico \\
\hline Ibama UHE & $\begin{array}{l}\text { UHE Paulista - } \\
\text { Furnas GO/MG }\end{array}$ & $217 \mathrm{Mw}$ & 2005 & $\begin{array}{l}\text { Biodinâmica } \\
\text { Engenharia e } \\
\text { Meio } \\
\text { Ambiente }\end{array}$ & $\begin{array}{c}\text { Impactos } \\
7 \text { físico, } 5 \text { biótico e } 14 \\
\text { socioeconomico }\end{array}$ & $\begin{array}{l}\text { Modificacãao do regime fluvial; } \\
\text { alteracãão da qualidade da áaua; } \\
\text { alteração do comportamento } \\
\text { hidrossedimentalógico do Rio São Marcos; } \\
\text { interferênciaia de áreas de autorização e } \\
\text { concessão minerárias com o futuro } \\
\text { reservatório; } \\
\text { instabilidadade das encostas marginais do } \\
\text { reservatório; } \\
\text { possibilidade da ocorrência de sismos } \\
\text { induzidos; } \\
\text { possível interferência do enchimento do } \\
\text { reservatório sobre o nível do lençol freático. }\end{array}$ & $\begin{array}{l}\text { Alterações na dinâmica da } \\
\text { ictiofauna; } \\
\text { perda da vegetação nativa; } \\
\text { perda de habitats da fauna terrestre; } \\
\text { alteração da estrutura de população } \\
\text { de espécies da fauna terrestre; } \\
\text { aumento da caça de animais } \\
\text { silvestres. }\end{array}$ & 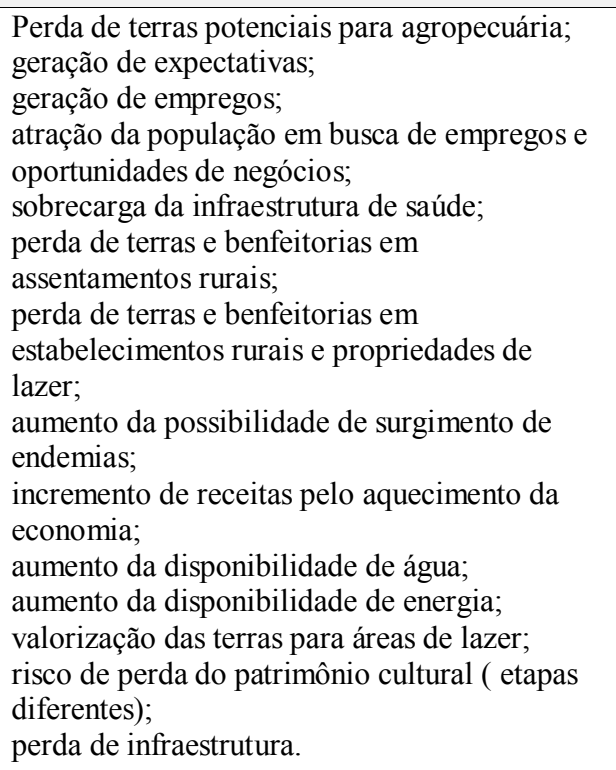 \\
\hline Ibama UHE & $\begin{array}{l}\text { UHE Paulista - } \\
\text { Furnas GO/MG }\end{array}$ & $217 \mathrm{Mw}$ & 2005 & $\begin{array}{l}\text { Biodinâmica } \\
\text { Engenharia e } \\
\text { Meio } \\
\text { Ambiente }\end{array}$ & $\begin{array}{l}\text { Programas } \\
8 \text { fisico, } 4 \text { biótico e } 6 \\
\text { socioeconômico }\end{array}$ & $\begin{array}{l}\text { Programa de Gestão Ambiental; } \\
\text { Programa de Monitoraamento Limnológico } \\
\text { Hidossedimentológico e de Qualidade da } \\
\text { Água; } \\
\text { Programa de Limpeza Seletiva da Bacia de } \\
\text { Acumulação; } \\
\text { Programa de Monitoramento do Nível de } \\
\text { Lençol Freatico; } \\
\text { Programa de Monitoramento das Condições } \\
\text { de Erosão; } \\
\text { Programa de Acompanhamento dos Direitos } \\
\text { Minerários; } \\
\text { Programa de Monitoramento Sismológico; } \\
\text { Programa de Monitoramento Climatológico. }\end{array}$ & $\begin{array}{l}\text { Programa de Conservação da } \\
\text { Ictiofauna; } \\
\text { Programa de Conservação da Flora; } \\
\text { Programa de Conservacãao da Fauna; } \\
\text { Programa deCompensação } \\
\text { Ambiental. }\end{array}$ & 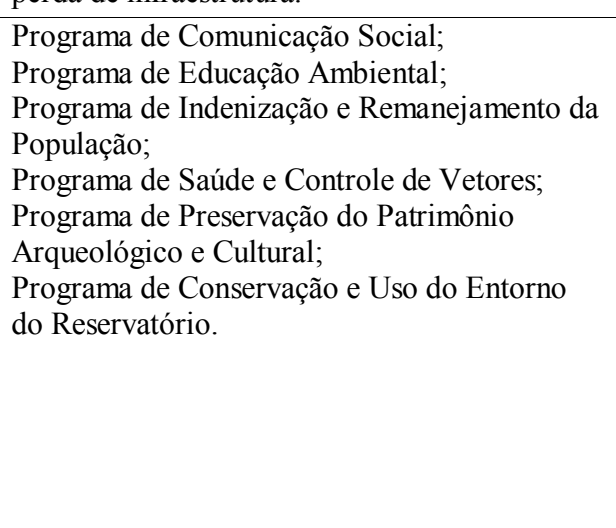 \\
\hline
\end{tabular}


Tabela A - Empreendimentos Pontuais

(Continuação)

\begin{tabular}{|c|c|c|c|c|c|c|c|c|}
\hline $\begin{array}{c}\text { Órgão } \\
\text { Licenciado } \\
\text { r Tipologia } \\
\end{array}$ & $\begin{array}{c}\text { Empreendimento/ } \\
\text { empreendedor/ } \\
\text { Estado }\end{array}$ & $\begin{array}{l}\text { Características do } \\
\text { empreendimento }\end{array}$ & $\begin{array}{c}\text { Ano de } \\
\text { apresentação } \\
\text { ao órgão }\end{array}$ & $\begin{array}{c}\text { Empresa } \\
\text { Consultora }\end{array}$ & $\begin{array}{c}\text { Quantidade de } \\
\text { impactos/ } \\
\text { programas para } \\
\text { cada meio }\end{array}$ & Físico & Biótico & Antropico \\
\hline Ibama UHE & $\begin{array}{l}\text { UHE Santo } \\
\text { Antonio do Jirau }\end{array}$ & 0 & 2009 & $\begin{array}{l}\text { Ecology } \\
\text { Brasil }\end{array}$ & $\begin{array}{c}\text { Impactos } \\
22 \text { fisico, } 46 \\
\text { bí́tico e } 44 \\
\text { socioeconomico }\end{array}$ & 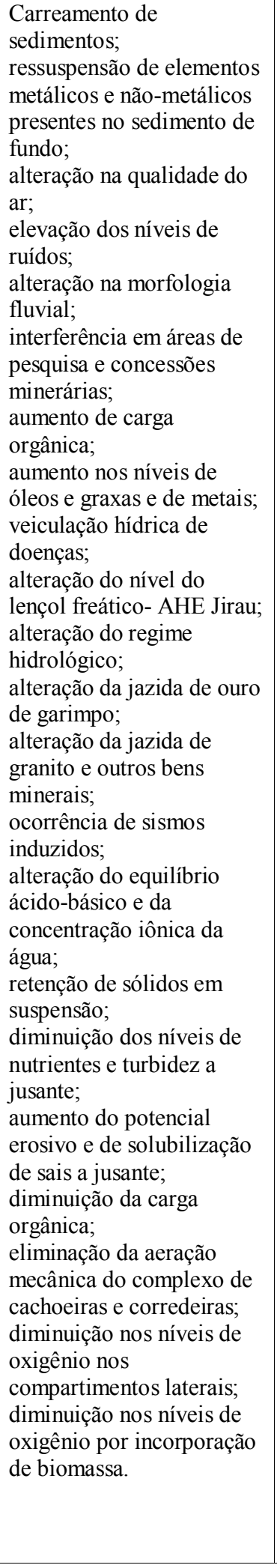 & 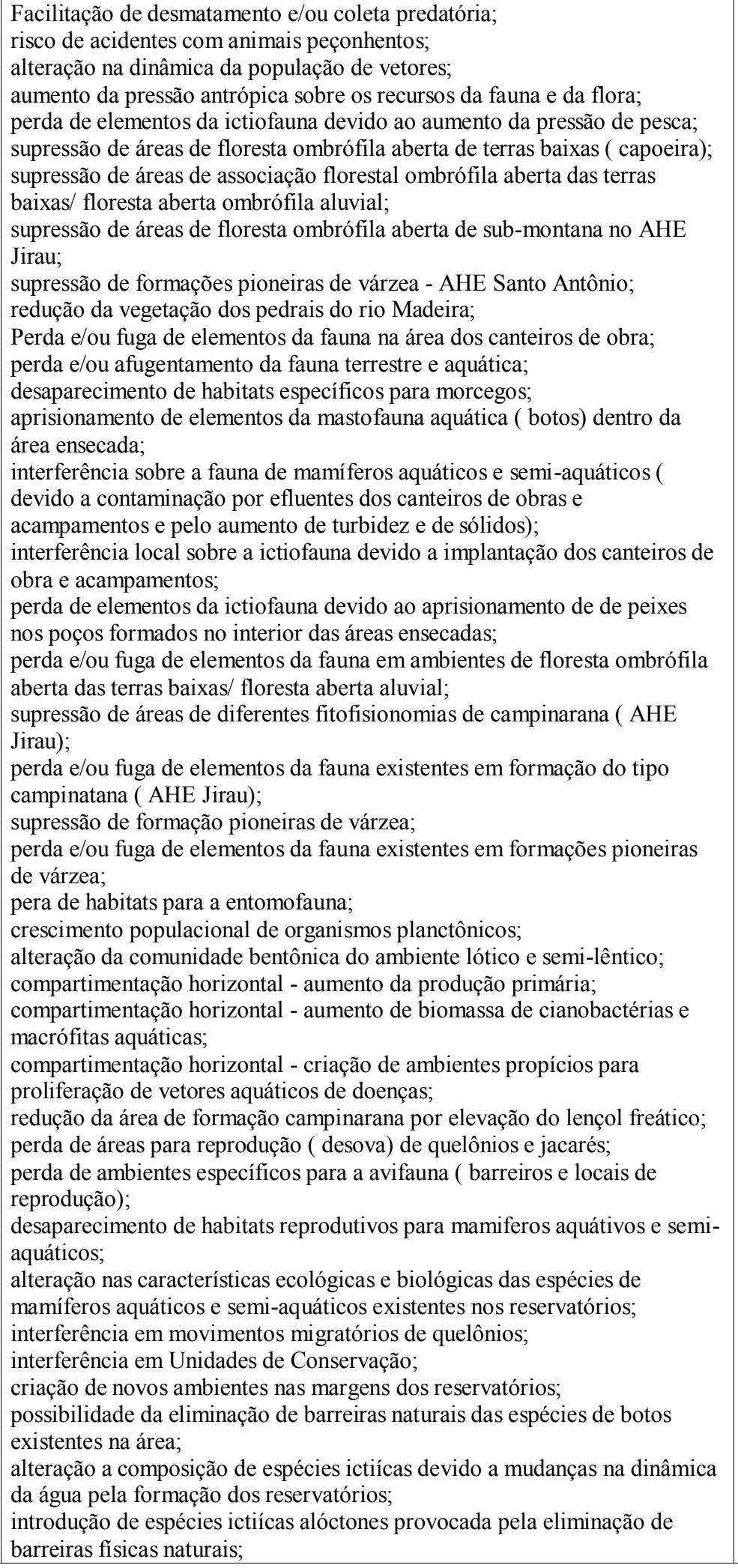 & 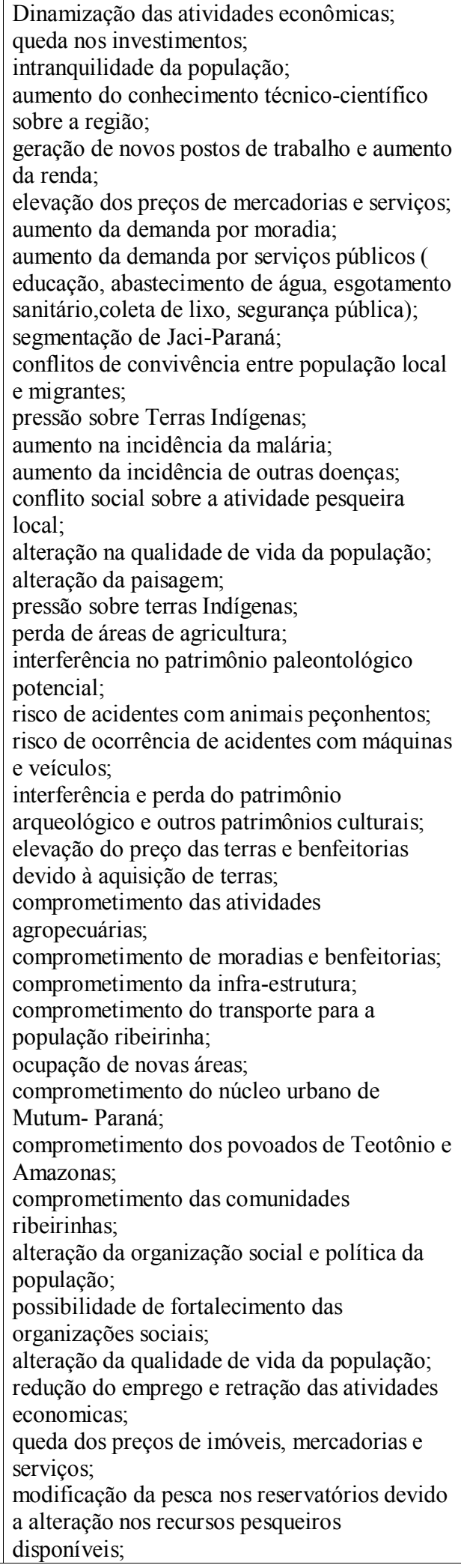 \\
\hline
\end{tabular}




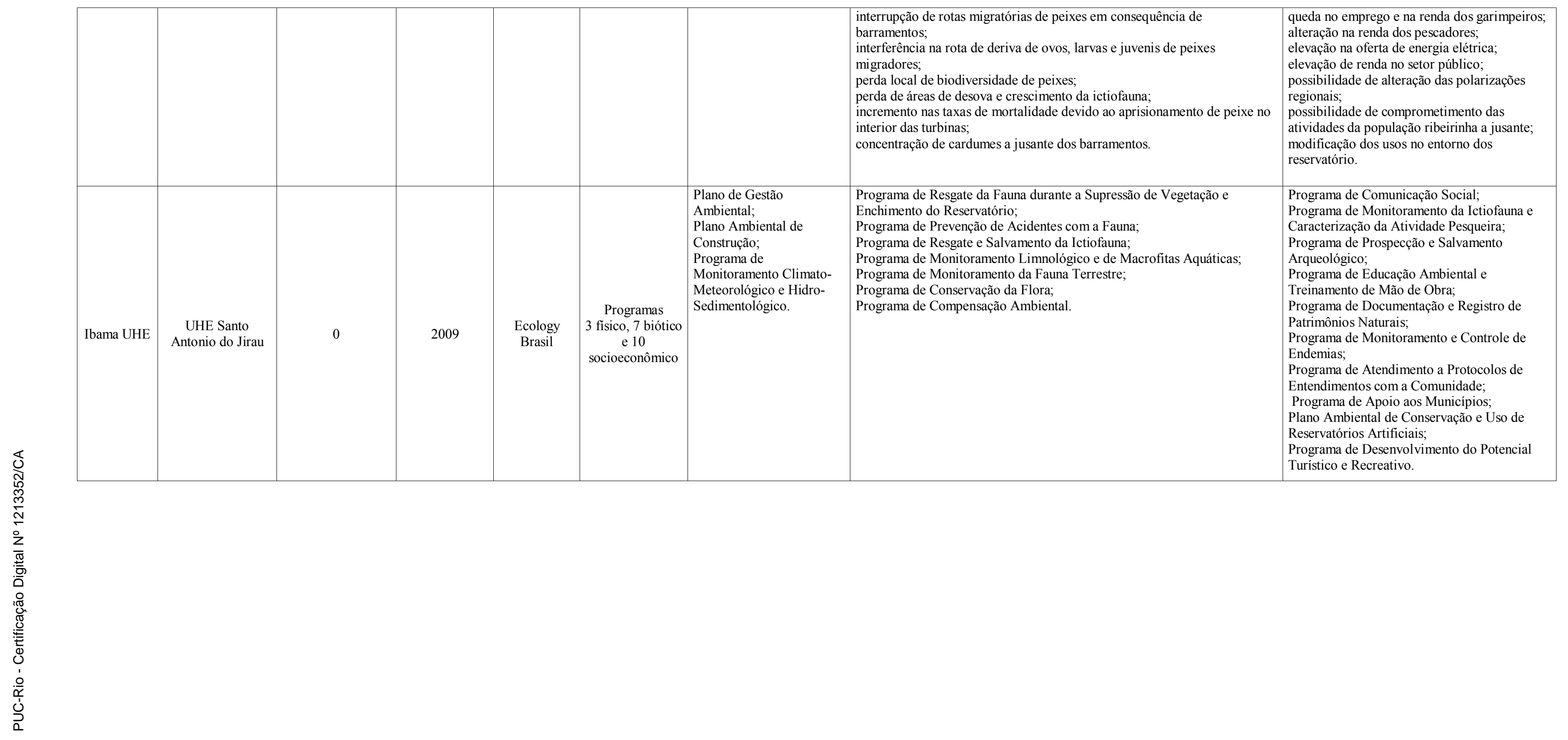


Tabela A - Empreendimentos Pontuais

(Continuação)

\begin{tabular}{|c|c|c|c|c|c|c|c|c|}
\hline $\begin{array}{c}\text { Órgão } \\
\text { Licenciador } \\
\text { Tipologia }\end{array}$ & $\begin{array}{l}\text { Empreendimento/ } \\
\text { empreendedor/ } \\
\text { Estado }\end{array}$ & $\begin{array}{l}\text { Características do } \\
\text { empreendimento }\end{array}$ & \begin{tabular}{|c} 
Ano de \\
apresentaçã \\
0 ao órgão
\end{tabular} & $\begin{array}{c}\text { Empresa } \\
\text { Consultora }\end{array}$ & $\begin{array}{c}\text { Quantidade de } \\
\text { impactos/programas } \\
\text { para cada meio }\end{array}$ & Físico & Biótico & Antropico \\
\hline Ibama UHE & $\begin{array}{c}\text { UHE Pai Querê - SC } \\
\text { e RS }\end{array}$ & $\begin{array}{l}3 \text { trubina, } \\
\text { reservatório de } 62 \\
\text { km2 e potencia de } \\
292 \text { MW obra } 3000 \\
\text { diretos }\end{array}$ & 2011 & $\begin{array}{l}\text { Bourscheid } \\
\text { Engenharia e } \\
\text { Meio } \\
\text { Ambiente }\end{array}$ & $\begin{array}{l}\text { Impactos } \\
12 \text { fisico, } 21 \text { biótico e } \\
22 \text { socioeconomico }\end{array}$ & 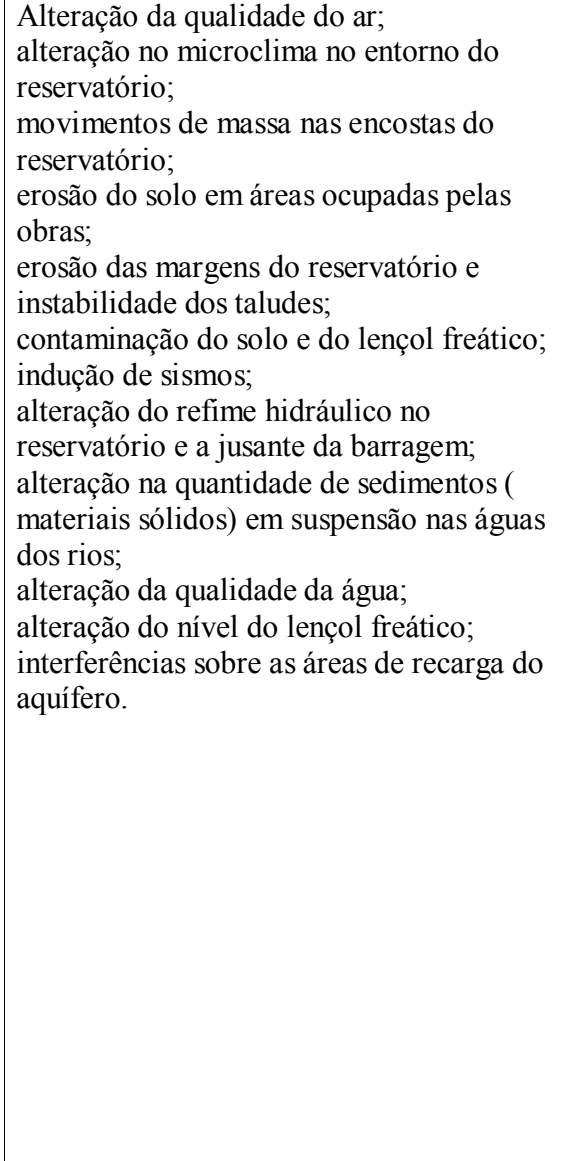 & 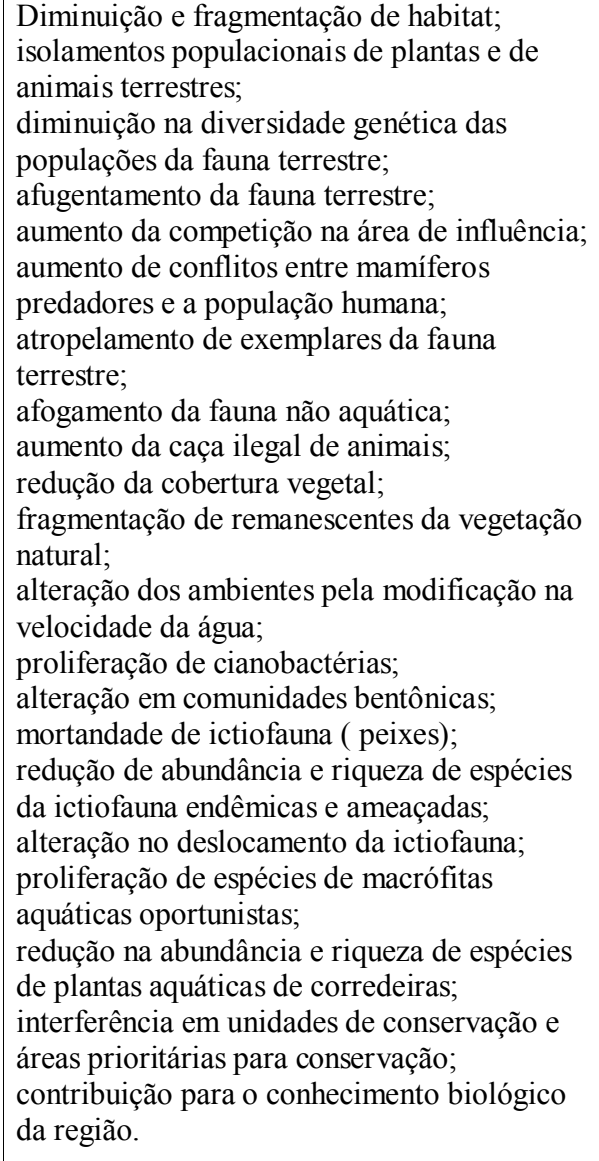 & 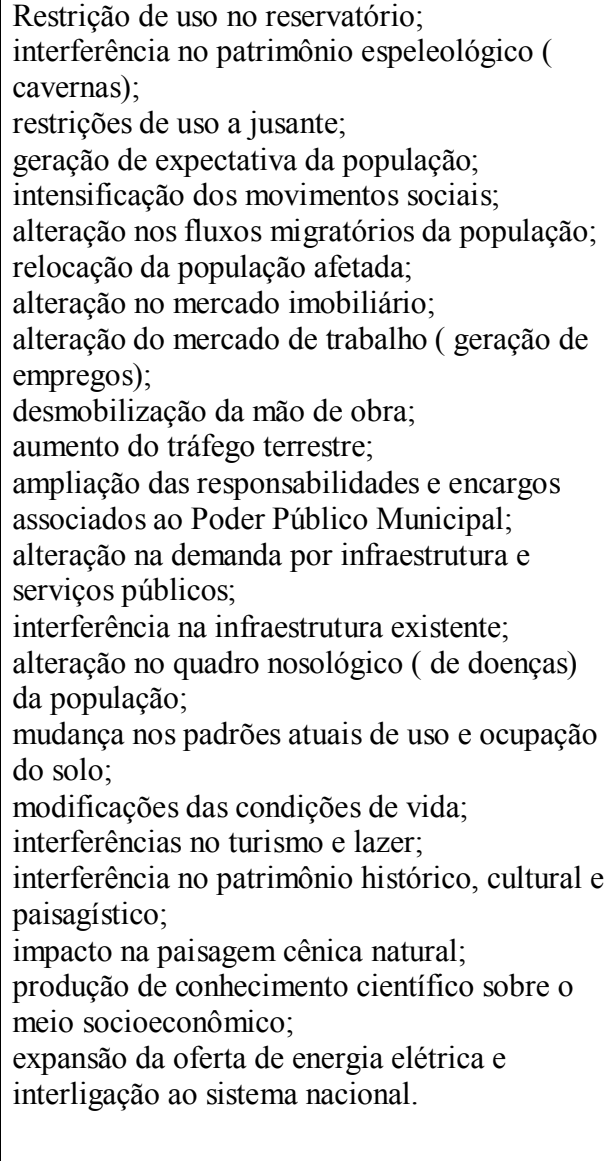 \\
\hline Ibama UHE & $\begin{array}{c}\text { UHE Pai Querê - SC } \\
\text { e RS }\end{array}$ & $\begin{array}{c}3 \text { trubina, } \\
\text { reservatório de } 62 \\
\text { km2 e potencia de } \\
292 \text { MW obra } 3000 \\
\text { diretos }\end{array}$ & 2011 & $\begin{array}{l}\text { Bourscheid } \\
\text { Engenharia e } \\
\text { Meio } \\
\text { Ambiente }\end{array}$ & $\begin{array}{c}\text { Programas } \\
6 \text { fisico, } 9 \text { biótico e } 8 \\
\text { socioeconômico }\end{array}$ & $\begin{array}{l}\text { Programa de Gestão Ambiental; } \\
\text { Programa de Monitoramento Climático; } \\
\text { Programa Ambiental de Construção; } \\
\text { Programa de Preservação e } \\
\text { Monitoramento de Erosões e Movimentos } \\
\text { de Massa; } \\
\text { Programa de Monitoramento da Qualidade } \\
\text { de Aguas e Limnologia; } \\
\text { Programa de Monitoramento de Águas } \\
\text { Subterrâneas. }\end{array}$ & $\begin{array}{l}\text { Programa de Recuperação de Áreas } \\
\text { Degradadas; } \\
\text { Programa de Resgate de Fauna; } \\
\text { Programa de Monitoramento de Fauna; } \\
\text { Programa de Resgate e Conservaçăo de } \\
\text { Reófitas; } \\
\text { Programa de Reposição Florestal; } \\
\text { Programa de Resgate e Conservação da Flora } \\
\text { Nativa; } \\
\text { Programa de Monitoramento de Ictiofauna; } \\
\text { Programa de Monitoramento de Macrofitas } \\
\text { Aquaticas; } \\
\text { Programa de Compensação Ambiental. }\end{array}$ & $\begin{array}{l}\text { Programa de Comunicação Social; } \\
\text { Programa de Educação Ambiental; } \\
\text { Programa de Remanejamento e } \\
\text { Monitoramento da População Diretamente } \\
\text { Afetada; } \\
\text { Programa de Saúde; } \\
\text { Plano Ambiental de Conservação e Uso de } \\
\text { Reservatórios Artificiais; } \\
\text { Programa de Redimensionamento e } \\
\text { Recomposição da Infraestrutura; } \\
\text { Programa de Apoio ao Planejamento; } \\
\text { Programa de Desenvolvimento Local } \\
\text { Integrado e Sustentável. }\end{array}$ \\
\hline
\end{tabular}


Tabela A - Empreendimentos Pontuais

(Continuação)

\begin{tabular}{|c|c|c|c|c|c|c|c|c|}
\hline $\begin{array}{c}\text { Órgão } \\
\text { Licenciador } \\
\text { Tipologia }\end{array}$ & $\begin{array}{l}\text { Empreendimento/ } \\
\text { empreendedor/ } \\
\text { Estado }\end{array}$ & $\begin{array}{l}\text { Características do } \\
\text { empreendimento }\end{array}$ & $\begin{array}{c}\text { Ano de } \\
\text { apresentação } \\
\text { ao órgão }\end{array}$ & $\begin{array}{c}\text { Empresa } \\
\text { Consultora }\end{array}$ & $\begin{array}{c}\text { Quantidade de } \\
\text { impactos/ } \\
\text { programas para } \\
\text { cada meio }\end{array}$ & Físico & Biótico & Antropico \\
\hline Ibama UHE & $\begin{array}{l}\text { UHE Davinopolis - } \\
\text { Cemig MG }\end{array}$ & $74 \mathrm{MW}$ & 2012 & $\begin{array}{c}\text { Gestão } \\
\text { Ambiental } \\
\text { Agua e Terra }\end{array}$ & $\begin{array}{c}\text { Impactos } \\
7 \text { fisico, } 8 \text { biótico e } \\
16 \text { socioeconômico }\end{array}$ & 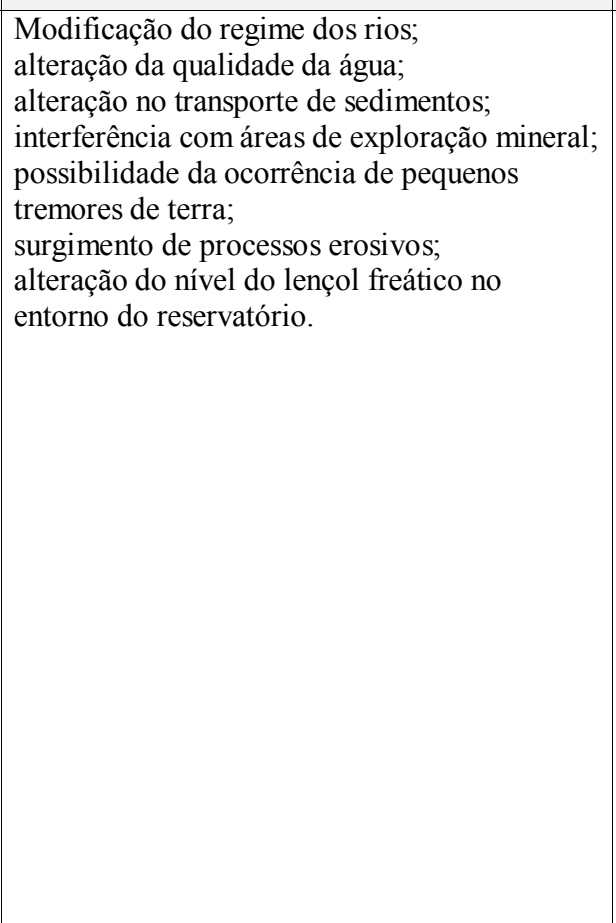 & $\begin{array}{l}\text { Perda de diversidade da flora; } \\
\text { perda de habitat da fauna terrestre, } \\
\text { fragmentacãao de habitats e perda da } \\
\text { conectividade entre fragenentos; } \\
\text { redução da diversidade da fauna terrestre e } \\
\text { afugentamento da fauna; } \\
\text { pressão sobre a caca de animais silvestres e } \\
\text { aumento do risco de atropelamento de } \\
\text { animais; } \\
\text { alteracão da composição da fauna aquática; } \\
\text { interrupcão do fluxo migratório das espécies } \\
\text { de peixes de piracema; } \\
\text { possibilidadede ocorrência de mortalidade } \\
\text { localizada de peixes; } \\
\text { possibilidade de interferência em prováveis } \\
\text { sitios de reprodução da andorinha-de-coleira. }\end{array}$ & 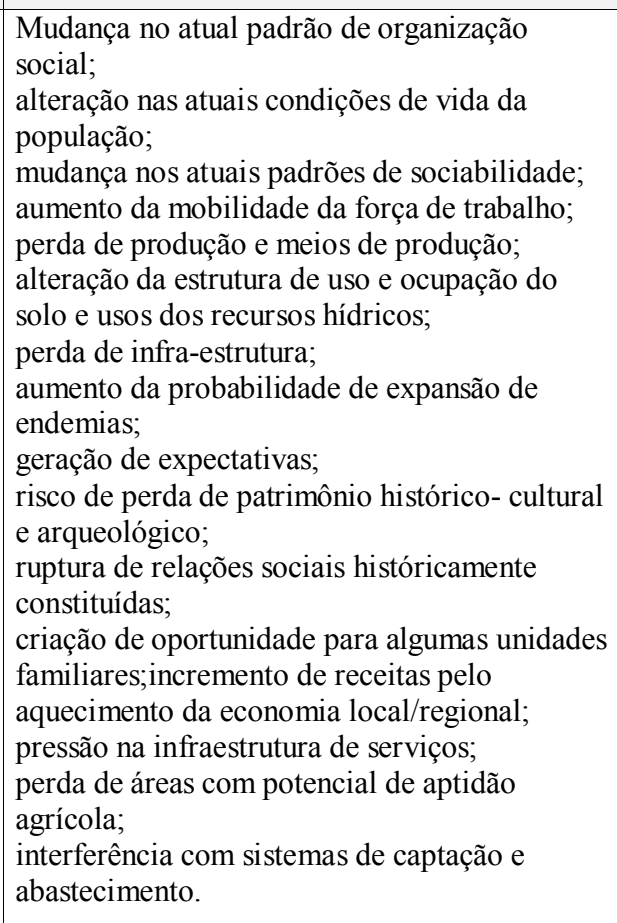 \\
\hline Ibama UHE & $\begin{array}{l}\text { UHE Davinopolis - } \\
\text { Cemig MG }\end{array}$ & $74 \mathrm{MW}$ & 2012 & $\begin{array}{c}\text { Gestão } \\
\text { Ambiental } \\
\text { Agua e Terra }\end{array}$ & $\begin{array}{c}\text { Programas } \\
7 \text { fisico, } 7 \text { biótico e } \\
10 \text { socioeconomico }\end{array}$ & $\begin{array}{l}\text { Programa dos Processos } \\
\text { Hidrossedimentológicos e das Vazões } \\
\text { Afluentese e Defluentes e do Assoreamento do } \\
\text { Reservatorio; } \\
\text { Programa de Monitoramento Limnológico e } \\
\text { da Qualidade da Água; } \\
\text { Programa dos Processos Erosivos e } \\
\text { Estabilização da Movimentação de Massas; } \\
\text { Programa de Monitoramento do Lençol } \\
\text { Freatico; } \\
\text { Programa de Segurança e Alerta; } \\
\text { Programa de Modelagem Sismológico; } \\
\text { Programa de Acompanhamento dos Direitos } \\
\text { Minerais e Revalidaçăo. }\end{array}$ & $\begin{array}{l}\text { Programa de Monitoramento da Ictiofauna e } \\
\text { outros Organismos Aquáticos; } \\
\text { Programa de Recuperação de Áreas } \\
\text { Degradadas; } \\
\text { Programa de Conservação da Flora; } \\
\text { Programa de Resgate e Monitoramento de } \\
\text { Fauna Terrestre; } \\
\text { Programa de Monitoramento da Fauna } \\
\text { Ameacada; } \\
\text { Programa de Resgate da Ictiofauna; } \\
\text { Programa de Monitoramento das Andorinha } \\
\text { de Coleira. }\end{array}$ & 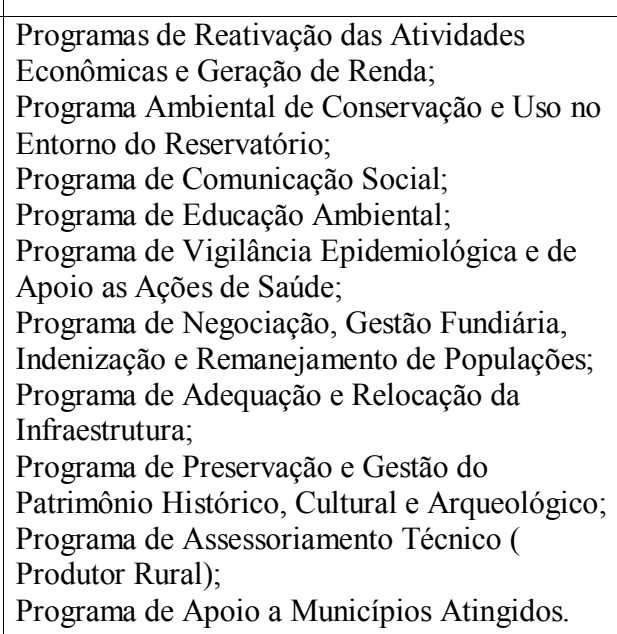 \\
\hline
\end{tabular}


Tabela A - Empreendimentos Pontuais

(Continuação)

\begin{tabular}{|c|c|c|c|c|c|c|c|c|}
\hline $\begin{array}{c}\text { Órgão } \\
\text { Licenciador } \\
\text { Tipologia }\end{array}$ & $\begin{array}{l}\text { Empreendimento/ } \\
\text { empreendedor/ } \\
\text { Estado }\end{array}$ & $\begin{array}{l}\text { Características do } \\
\text { empreendimento }\end{array}$ & $\begin{array}{c}\text { Ano de } \\
\text { apresentação } \\
\text { ao órgão }\end{array}$ & $\begin{array}{c}\text { Empresa } \\
\text { Consultora }\end{array}$ & $\begin{array}{c}\text { Quantidade de } \\
\text { impactos } / \\
\text { programas para } \\
\text { cada meio }\end{array}$ & Físico & Biótico & Antropico \\
\hline Ibama UHE & UHE Itaocara RJ MG & $195 \mathrm{MW}$ & 2014 & $\begin{array}{c}\text { Ecology } \\
\text { Brasil }\end{array}$ & $\begin{array}{c}\text { Impactos } \\
21 \text { fisico, } 13 \\
\text { biotico e } 38 \\
\text { socioeconomico }\end{array}$ & 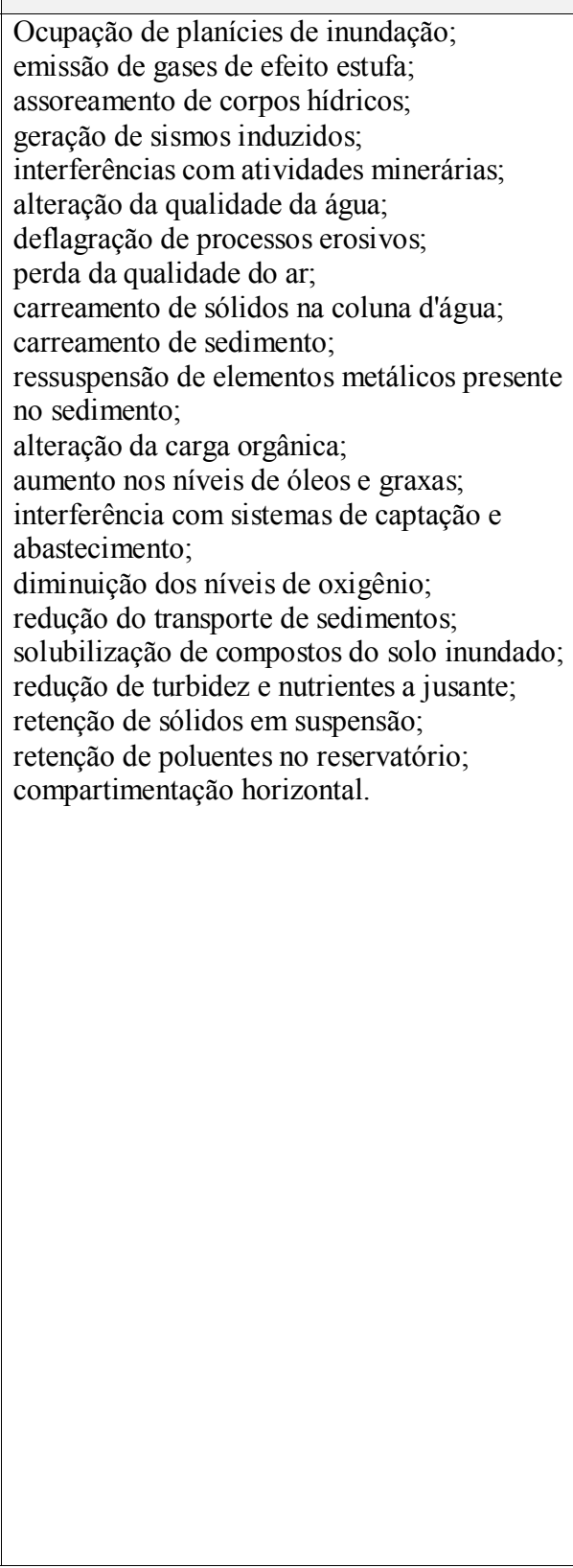 & 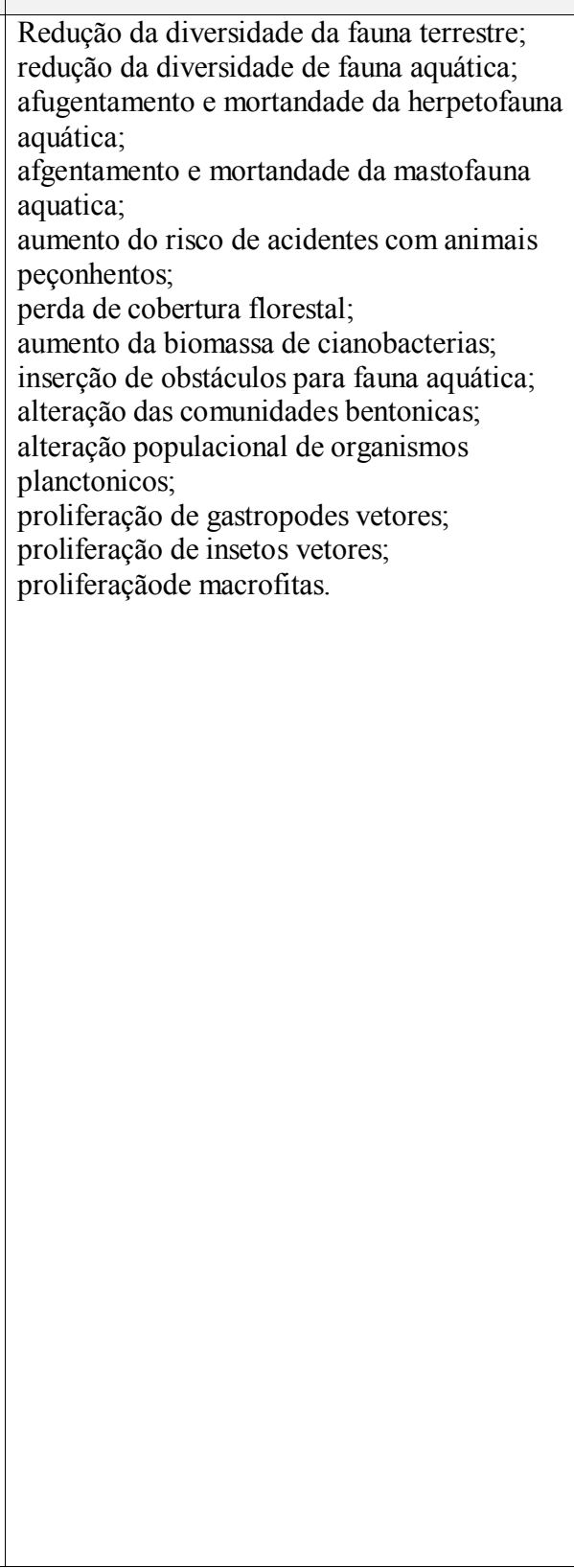 & 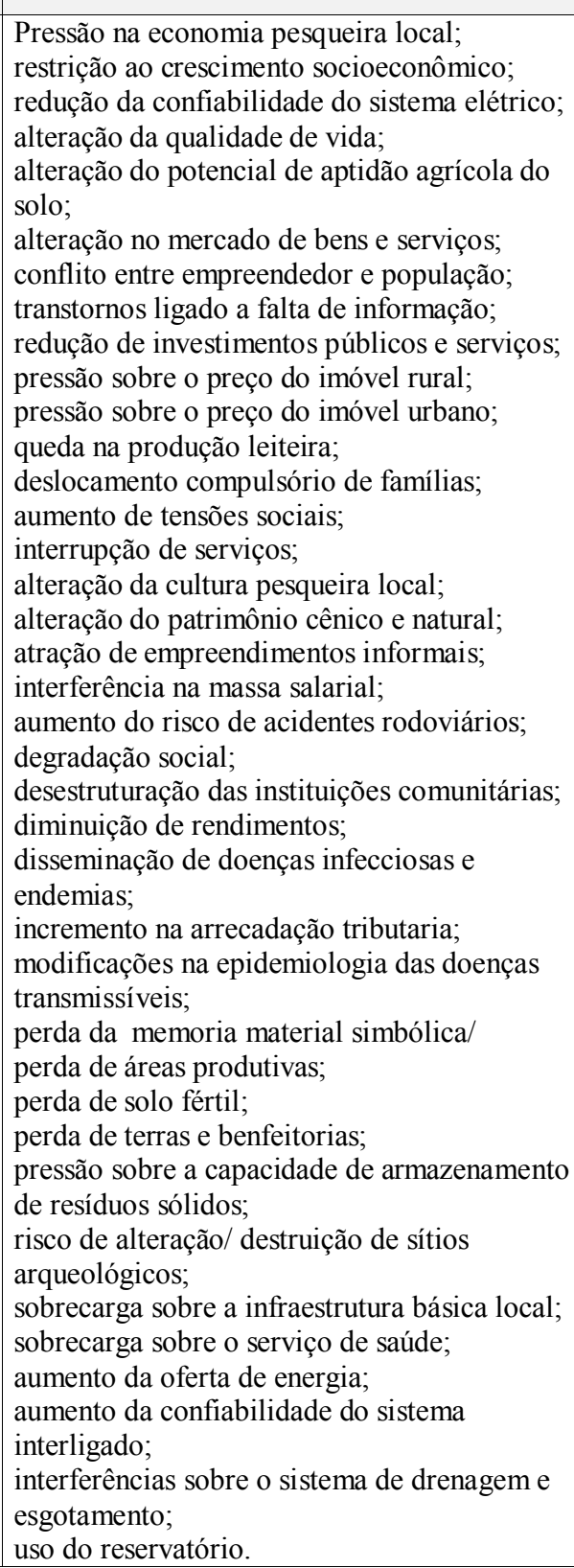 \\
\hline
\end{tabular}


Tabela A - Empreendimentos Pontuais

(Continuação)

\begin{tabular}{|c|c|c|c|c|c|c|c|c|}
\hline $\begin{array}{c}\text { Órgão } \\
\text { Licenciador } \\
\text { Tipologia }\end{array}$ & $\begin{array}{l}\text { Empreendimento/ } \\
\text { empreendedor/ } \\
\text { Estado }\end{array}$ & $\begin{array}{l}\text { Características do } \\
\text { empreendimento }\end{array}$ & \begin{tabular}{|c|} 
Ano de \\
apresentaçã \\
o ao órgão
\end{tabular} & $\begin{array}{c}\text { Empresa } \\
\text { Consultora }\end{array}$ & $\begin{array}{l}\text { Quantidade de } \\
\text { impactos/programas } \\
\text { para cada meio }\end{array}$ & Físico & Biótico & Antropico \\
\hline Ibama UHE & UHE Itaocara RJ MG & $195 \mathrm{MW}$ & 2014 & Ecology Brasil & $\begin{array}{l}\text { Programas } \\
8 \text { fisico, } 15 \text { biotico e } \\
14 \text { socioeconômico }\end{array}$ & $\begin{array}{l}\text { Plano Ambiental para Construção; } \\
\text { Programa de Monitoramento e Controle } \\
\text { de Processos Erosivos; } \\
\text { Programa de Monitoramento Sismológico; } \\
\text { Programa de Monitoramento } \\
\text { Hidrossedimentológico; } \\
\text { Programa de Monitoramento } \\
\text { Topobatimétrico; } \\
\text { Programa de Fluxos Subterrâneos; } \\
\text { Programa de Monitoramento Climato- } \\
\text { Meteorologico; } \\
\text { Programa de Monitoramento Limnologico } \\
\text { e da Qualidade das Águas. }\end{array}$ & $\begin{array}{l}\text { Programa de Recuperação de Áreas } \\
\text { Degradadas; } \\
\text { Subprograma de Supressão da Vegetação e } \\
\text { Limpeza do Reservatório; } \\
\text { Subprograma de Prevenção de Acidentes com } \\
\text { a Fauna; } \\
\text { Programa de Resgate da Fauna Terrestre; } \\
\text { Programa de Resgate da ctitiofauna; } \\
\text { Programa de Monitoramento da Ictiofauna; } \\
\text { Programa de Avaliacãa da Eficiência da } \\
\text { Instalacãão de Mecanismos de Transposição de } \\
\text { Peixes; } \\
\text { Programa de Compensação Ambiental; } \\
\text { Programa de Monitoramento do } \\
\text { Aproveitamento da Macrofitas; } \\
\text { Programa de Reflorestamento; } \\
\text { Programa de Monitoramento da Fauna; } \\
\text { Programa de Monitoramento do Cágado de } \\
\text { Hogel; } \\
\text { Programa de Monitoramento do Jacará de } \\
\text { Papo Amarelo; } \\
\text { Programade Monitoramento da Lontra; } \\
\text { Programa de Monitoramento de Carcinofauna. }\end{array}$ & $\begin{array}{l}\text { Programa de Educação Ambiental; } \\
\text { Programa de Comunicacaão Social; } \\
\text { Programa de Acompanhamento da População } \\
\text { Atingida; } \\
\text { Programa de Estimulo a Participação da } \\
\text { População Atingida; } \\
\text { Programa de Monitoramento e Controle de } \\
\text { Endemas, } \\
\text { Programa de Resgate e Valorização de } \\
\text { Aspectos Culturais; } \\
\text { Programa de Prospecção, Resgate e } \\
\text { Monitoramento do Patrimônio Histórico; } \\
\text { Programa de Relocação de Estruturas e } \\
\text { Saneamento; } \\
\text { Programa de Relocacacão do Cemitério; } \\
\text { Programa de Gestão Institucional; } \\
\text { Programa de Gestão Fundiária; } \\
\text { Pacuera- Plano de Uso do Entorno do } \\
\text { Reservatório; } \\
\text { Programa de Reativacãao de Atividade } \\
\text { Econômica e Geracaão de Renda; } \\
\text { Programa de Readequação da Atividade } \\
\text { Pesqueira. }\end{array}$ \\
\hline Ibama UTE & $\begin{array}{l}\text { UTE Tres Lagoas } \\
\text { MS Petrobras }\end{array}$ & $\begin{array}{l}350 \mathrm{MW} \text { pico obra } \\
280 \text { diretos }\end{array}$ & 2001 & \begin{tabular}{|c|} 
Cepemar \\
Serviços de \\
Consultoria em \\
Meio \\
Ambiente
\end{tabular} & $\begin{array}{l}\text { Impactos } \\
6 \text { fisico, } 3 \text { biótico e } 5 \\
\text { socioeconômico }\end{array}$ & $\begin{array}{l}\text { Alteração de qualidade do ar pela emissão } \\
\text { de material particulado decorrente da } \\
\text { terraplenagem; } \\
\text { desencadeamento de processos erosivos; } \\
\text { alteracão da qualidade da água; } \\
\text { contaminação do solo por resíduos } \\
\text { diversos; } \\
\text { alteração da qualidade do ar pela emissão } \\
\text { de efluentes gasosos; } \\
\text { alteração da qualidade da água pelo } \\
\text { descarte de efluentes liqquidos. }\end{array}$ & $\begin{array}{l}\text { Supressão da vegetacãão; } \\
\text { perturbacãa/evaãa da fauna; } \\
\text { alteracãa da comunidade aquática pelo } \\
\text { descarte de efluentes líquidos. }\end{array}$ & $\begin{array}{l}\text { Aumento do risco de acidentes pela } \\
\text { movimentação de máquinas e veículos nas } \\
\text { estradas de acesso; } \\
\text { geracãão de empregos; } \\
\text { geração de tributos; } \\
\text { dinamizacáo da economia regional e melhoria } \\
\text { do nível de vida; } \\
\text { geração/disponibilização de energia. }\end{array}$ \\
\hline Ibama UTE & $\begin{array}{l}\text { UTE Tres Lagoas } \\
\text { MS Petrobras }\end{array}$ & $\begin{array}{l}350 \mathrm{MW} \text { pico obra } \\
280 \text { diretos }\end{array}$ & 2001 & \begin{tabular}{|c|} 
Cepemar \\
Serviços de \\
Consultoria em \\
Meio \\
Ambiente
\end{tabular} & $\begin{array}{l}\text { Programas } \\
4 \text { fisico, } 1 \text { bítico e } 2 \\
\text { socioeconômico }\end{array}$ & $\begin{array}{l}\text { Programa de Monitoramento Hídrico; } \\
\text { Programa de Gerenciamento de Emissões } \\
\text { Atmosféricas; } \\
\text { Programa de Gerenciamento de Efluentes } \\
\text { Líquidos; } \\
\text { Programa de Gerenciamento de Resíduos } \\
\text { Sólidos. }\end{array}$ & $\begin{array}{l}\text { Programa de Recuperação de Áreas } \\
\text { Degradadas. }\end{array}$ & $\begin{array}{l}\text { Programa de Comunicação Social; } \\
\text { Programa de Educação Ambiental para o } \\
\text { Trabalhador. }\end{array}$ \\
\hline
\end{tabular}


Tabela A - Empreendimentos Pontuais

\begin{tabular}{|c|c|c|c|c|c|c|c|c|}
\hline $\begin{array}{c}\text { Órgão } \\
\text { Licenciador } \\
\text { Tipologia }\end{array}$ & $\begin{array}{l}\text { Empreendimento/ } \\
\text { empreendedor/ } \\
\text { Estado }\end{array}$ & $\begin{array}{l}\text { Características do } \\
\text { empreendimento }\end{array}$ & \begin{tabular}{|c} 
Ano de \\
apresentaçã \\
o ao órgão
\end{tabular} & $\begin{array}{l}\text { Empresa } \\
\text { Consultora }\end{array}$ & $\begin{array}{c}\text { Quantidade de } \\
\text { impactos/programa } \\
\text { s para cada meio }\end{array}$ & Físico & Biótico & Antropico \\
\hline Ibama UTE & $\begin{array}{l}\text { UTE Porto de Itaqui- } \\
\text { MPX }\end{array}$ & $360 \mathrm{MW}$ & 2008 & $\begin{array}{c}\text { Environmental } \\
\text { Resources } \\
\text { Management - } \\
\text { ERM Brasil }\end{array}$ & $\begin{array}{l}\text { Impactos } \\
9 \text { físico, } 5 \text { biótico e } \\
21 \text { socioeconômico }\end{array}$ & 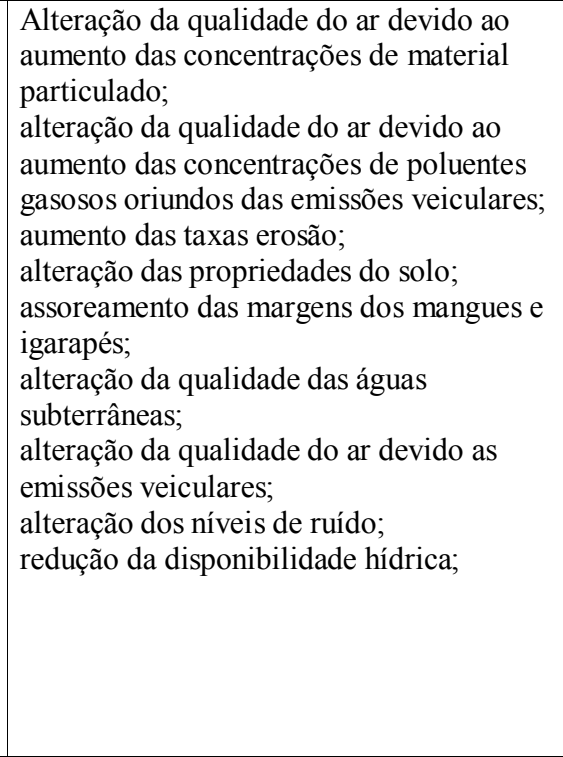 & $\begin{array}{l}\text { Perda local de espéciese e indivíduos vegetais; } \\
\text { fragmentacąão de habitit; } \\
\text { aumento da pressão sobre populações das } \\
\text { espécies terrestres e aquáticas com valor } \\
\text { alimentar; } \\
\text { aumento do risco de atropelamento da fauna; } \\
\text { alteração na composição e estrutura das } \\
\text { biocenoses aquáticas. }\end{array}$ & 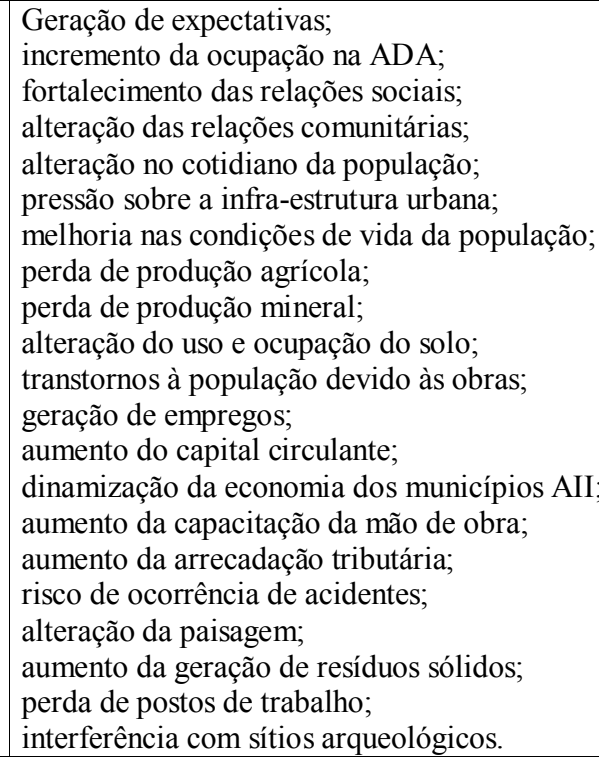 \\
\hline Ibama UTE & $\begin{array}{l}\text { UTE Porto de Itaqui- } \\
\text { MPX }\end{array}$ & $360 \mathrm{MW}$ & 2008 & $\begin{array}{c}\text { Environmental } \\
\text { Resources } \\
\text { Management - } \\
\text { ERM Brasil }\end{array}$ & $\begin{array}{c}\text { Programas } \\
7 \text { físico, } 4 \text { biótico e } \\
7 \text { socioeconômico }\end{array}$ & $\begin{array}{l}\text { Programa Ambiental da Construção; } \\
\text { Programa de Monitoramento de Emissões } \\
\text { Atmosféricas; } \\
\text { Programa de Controle de Erosão e } \\
\text { Sedimentos; } \\
\text { Programa de Monitoramento de Águas } \\
\text { Subterrâneas; } \\
\text { Programa de Monitoramento da Qualidade } \\
\text { da Agua Costeira; } \\
\text { Programa de Controle e Monitoramento de } \\
\text { Efluentes; } \\
\text { Programa de Monitoramento e Controle de } \\
\text { Ruídos. }\end{array}$ & $\begin{array}{l}\text { Programa de Monitoramento da Ictiofauna; } \\
\text { Programa de Recuperação de Áreas } \\
\text { Degradadas; } \\
\text { Programa de Monitoramento da Fauna } \\
\text { Terrestre; } \\
\text { Programa de Compensação Ambiental. }\end{array}$ & $\begin{array}{l}\text { Programa de Comunicação Social e } \\
\text { Relacionamento com as Partes Interessadas; } \\
\text { Programa de Relocação da Populacão; } \\
\text { Programa de Monitoramento e Apoio } \\
\text { Socioeconômico; } \\
\text { Programa de Conscientização para o Tráfego; } \\
\text { Programa de Contratação e Capacitação da } \\
\text { Mão de Obra; } \\
\text { Programa de Controle e Monitoramento das } \\
\text { Condicões de Saudde; } \\
\text { Programa de Educação Ambiental. }\end{array}$ \\
\hline
\end{tabular}


Tabela A - Empreendimentos Pontuais

(Conclusão)

\begin{tabular}{|c|c|c|c|c|c|c|c|c|}
\hline $\begin{array}{c}\text { Órgão } \\
\text { Licenciador } \\
\text { Tipologia }\end{array}$ & $\begin{array}{l}\text { Empreendimento/ } \\
\text { empreendedor/ } \\
\text { Estado }\end{array}$ & $\begin{array}{l}\text { Características do } \\
\text { empreendimento }\end{array}$ & $\begin{array}{c}\text { Ano de } \\
\text { apresentação } \\
\text { ao órgão }\end{array}$ & $\begin{array}{c}\text { Empresa } \\
\text { Consultora }\end{array}$ & $\begin{array}{c}\text { Quantidade de } \\
\text { impactos/programas } \\
\text { para cada meio }\end{array}$ & Físico & Biótico & Antropico \\
\hline Ibama UTE & UTE Pampa Sul-RS & $\begin{array}{c}680 \mathrm{MW} \text { - pico de } \\
\text { obra } 1848 \text { diretos e } \\
8.094 \text { indiretos e } \\
\text { operação } 300 \text { diretos }\end{array}$ & 2013 & $\begin{array}{c}\text { HAR } \\
\text { Engenharia e } \\
\text { Meio } \\
\text { Ambiente }\end{array}$ & $\begin{array}{l}\text { Impactos } \\
13 \text { fisico, } 12 \text { bítico e } \\
12 \text { socioeconômico }\end{array}$ & 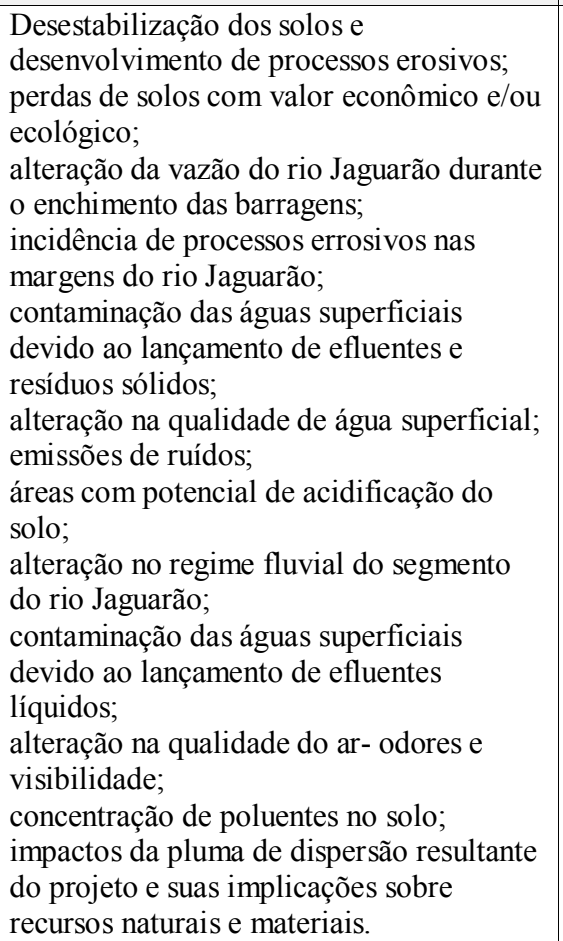 & 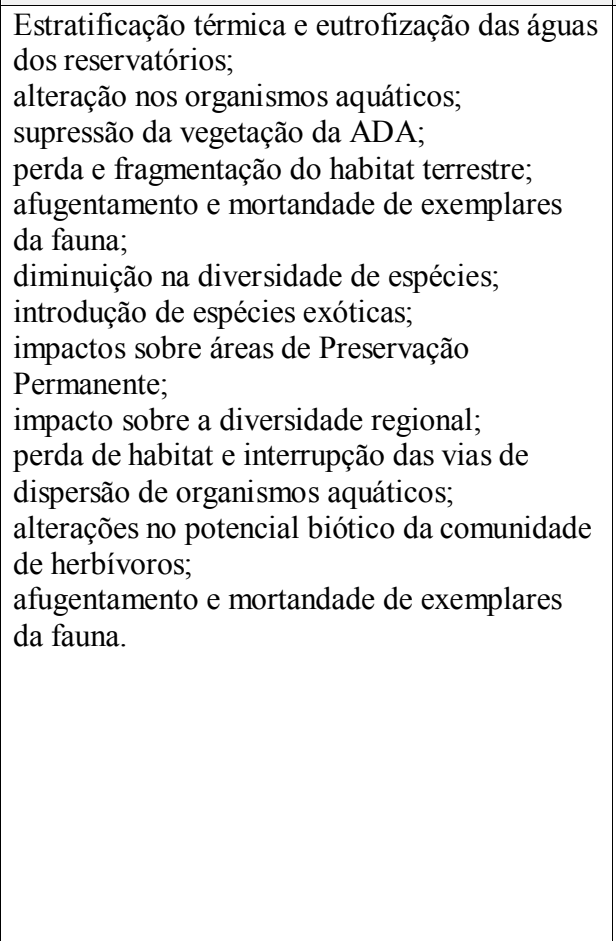 & $\begin{array}{l}\text { Conflitos quanto ao uso dos recursos hídricos } \\
\text { superficiais; } \\
\text { habitação e moradia; } \\
\text { sáde pública; } \\
\text { educacão; } \\
\text { segurançá pública; } \\
\text { infraestrutura local e regional; } \\
\text { atividades industriais e comerciais; } \\
\text { atividades recreacionais; } \\
\text { renda e tributos; } \\
\text { usos tradicionais da terra e implicações sociais } \\
\text { e culturais; } \\
\text { reursos históricos, arqueológicos, } \\
\text { paleontológicos; } \\
\text { disponibilidade qualidade dos serviços de } \\
\text { saneamento. }\end{array}$ \\
\hline Ibama UTE & UTE Pampa Sul-RS & $\begin{array}{c}680 \mathrm{MW} \text { - pico de } \\
\text { obra } 1848 \text { diretos e } \\
8.094 \text { indiretos e } \\
\text { operação } 300 \text { diretos }\end{array}$ & 2013 & $\begin{array}{c}\text { HAR } \\
\text { Engenharia e } \\
\text { Meio } \\
\text { Ambiente }\end{array}$ & $\begin{array}{l}\text { Programas } \\
7 \text { fisico, } 7 \text { biótico e } 6 \\
\text { socioeconômico }\end{array}$ & $\begin{array}{l}\text { Programa de Gestão Ambiental; } \\
\text { Programa de Controle de Obra; } \\
\text { Programa de Controle e Monitoramento } \\
\text { Ambiental; } \\
\text { Programa de Monitoramento da Qualidade } \\
\text { do Ar e Emissóes Atmosféricas; } \\
\text { Programa de Monitoramento e Qualidade } \\
\text { de Aguaa Superficial e Efluentes; } \\
\text { Programa de Monitoramento dos Recursos } \\
\text { Hídricos Subterrâneos; } \\
\text { Programa de Monitoramento da Qualidade } \\
\text { dos Solos. }\end{array}$ & $\begin{array}{l}\text { Programa de Recuperaç̃ão de Áreas } \\
\text { Degradadas; } \\
\text { Programa de Reposição Florestal e na Área de } \\
\text { Preservacaão Permanente do Reservatório das } \\
\text { Propriedades; } \\
\text { Programa de Implantação da Cortina Vegetal; } \\
\text { Programa de Supressaso da Vegetação e } \\
\text { Limpeza de Areas de Alague; } \\
\text { Programa de Resgate da Fauna Sivestre; } \\
\text { Programa de Monitoramento de Fauna. }\end{array}$ & $\begin{array}{l}\text { Programa de Educacãa Ambiental; } \\
\text { Programa de Comunicação Social; } \\
\text { Programa de Segurança e Saúde da Mão de } \\
\text { Obra; } \\
\text { Programa de Acompanhamento e Salvamento } \\
\text { do Patrimônio Arqueológico; } \\
\text { Programa de Desapropriação e Indenização de } \\
\text { Propriedades Atingidas; } \\
\text { Programa de Melhorias no Sistema Viário } \\
\text { Local } \\
\text { Pacuera - Programa de Conservação e Uso das } \\
\text { águas do entorno dos reservatórios (usos } \\
\text { recepcionais e socioeconômicos). }\end{array}$ \\
\hline
\end{tabular}


7.2.

\section{Empreendimentos Lineares}

Tabela B - Empreendimentos Lineares

(Continua)

\begin{tabular}{|c|c|c|c|c|c|c|c|c|}
\hline $\begin{array}{l}\text { Órgão Licenciador } \\
\text { Tipologia }\end{array}$ & $\begin{array}{c}\text { Empreendimento } \\
\text { Empreendedor/Estado }\end{array}$ & $\begin{array}{c}\text { Características do } \\
\text { empreendimento }\end{array}$ & $\begin{array}{c}\text { Ano de apresentação ao } \\
\text { órgão }\end{array}$ & $\begin{array}{l}\text { Empresa } \\
\text { Consultora }\end{array}$ & $\begin{array}{l}\text { Quantidade de } \\
\text { impactos/programas para } \\
\text { cada meio }\end{array}$ & Físico & Biótico & Antropico \\
\hline Ibama Ferrovias & FNS Norte Sul Valec & $210 \mathrm{~km}$ & 2002 & $\begin{array}{l}\text { Oikos Consultoria e } \\
\text { Projetos }\end{array}$ & $\begin{array}{c}\text { Impactos } \\
5 \text { fisico, } 6 \text { biótico e } 4 \\
\text { socioeconômico }\end{array}$ & $\begin{array}{l}\text { Perda de solo; } \\
\text { poluição sonora; } \\
\text { poluição atmosférica; } \\
\text { poluição hídrica; } \\
\text { poluição provocada por } \\
\text { acidente com carga perigosa. }\end{array}$ & $\begin{array}{l}\text { Reduc̃ão da diversidade biológica devido a } \\
\text { desmatamentos, alagamentos, erosõos e } \\
\text { assoreamentos; } \\
\text { reducaão da diversidade biológica provocada por } \\
\text { incêndios; } \\
\text { alterações comportamento da fauna; } \\
\text { fragmentação de habitats; } \\
\text { risco de atropelamento de animais; } \\
\text { descaracterização das matas ciliares por alteração } \\
\text { em drenagens naturais. }\end{array}$ & $\begin{array}{l}\text { Desapropriações; } \\
\text { geração empregos } \\
\text { diretos/indiretos; } \\
\text { expectativa de crescimento } \\
\text { regional; } \\
\text { perda de patrimônio } \\
\text { arqueológico. }\end{array}$ \\
\hline Ibama Ferrovias & FNS Norte Sul Valec & $210 \mathrm{~km}$ & 2002 & $\begin{array}{l}\text { Oikos Consultoria e } \\
\text { Projetos }\end{array}$ & $\begin{array}{l}\text { Programas } \\
4 \text { fisico, } 5 \text { biótico e } 3 \\
\text { socioeconômico }\end{array}$ & $\begin{array}{l}\text { Programa de Controle da } \\
\text { Poluiçãa e da Degradação } \\
\text { Ambiental na Construção; } \\
\text { Programa de Prevenção } \\
\text { /Contenção de Processos } \\
\text { Erosivos e de Instabilização; } \\
\text { Programa de Controle da } \\
\text { Qualidade das Águas; } \\
\text { Programa de Gestão } \\
\text { Ambiental. }\end{array}$ & $\begin{array}{l}\text { Programa de Prevenção de Queimadas; } \\
\text { Programa de Recomposiaño da Vegetacão em } \\
\text { Áreas Degradadas e Plantios Paisagísticos; } \\
\text { Programa de Recuperacãao de Matas Ciliares; } \\
\text { Programa de Construção de Passagens para a } \\
\text { Fauna; } \\
\text { Programa de Monitoramento da Fauna. }\end{array}$ & $\begin{array}{l}\text { Programa de Salvamento } \\
\text { Arqueológico; } \\
\text { Programa de } \\
\text { Desapropriações; } \\
\text { Programa de Educação } \\
\text { Ambiental. }\end{array}$ \\
\hline Ibama Ferrovias & EF334 TO BA Valec & $1500 \mathrm{~km}$ & 2009 & $\begin{array}{l}\text { Oikos Consultoria e } \\
\text { Projetos }\end{array}$ & $\begin{array}{l}\text { Impactos } \\
1 \text { físico, } 2 \text { biótico e } 7 \\
\text { socioecononmico }\end{array}$ & $\begin{array}{l}\text { Economia nas emissões de } \\
\text { gases do efeito estufa. }\end{array}$ & $\begin{array}{l}\text { Criação do efeito barreira; } \\
\text { desmatamento e alterações de comportamento } \\
\text { dos animais silvestres. }\end{array}$ & $\begin{array}{l}\text { Geração de empregos para a } \\
\text { mão-de-obra local não } \\
\text { especializada; } \\
\text { risco de interferência com } \\
\text { cavernas; } \\
\text { dinamizacão econômica; } \\
\text { redução oo número de } \\
\text { acidentes nas rodovias; } \\
\text { alteraçôes no uso do solo e } \\
\text { deslocamentos de pessoas; } \\
\text { risco de perda de patrimônio } \\
\text { arqueológico; } \\
\text { intercepcão de pequenas } \\
\text { propriedades rurais. }\end{array}$ \\
\hline Ibama Ferrovias & EF334 TO BA Valec & $1500 \mathrm{~km}$ & 2009 & $\begin{array}{l}\text { Oikos Consultoria e } \\
\text { Projetos }\end{array}$ & $\begin{array}{l}\text { Programas } \\
6 \text { fisico, } 5 \text { biótico e } 5 \\
\text { socioeconômico }\end{array}$ & $\begin{array}{l}\text { Programa de Controle da } \\
\text { Poluicão e da Degradação } \\
\text { Ambiental na Construção; } \\
\text { Programa de Redução de } \\
\text { Impactos na Instalacãão e } \\
\text { Operação de Acampamentos e } \\
\text { Canteiros de Serviços; } \\
\text { Programa de Proteção Contra } \\
\text { Erosão; } \\
\text { Programa de Gerenciamento } \\
\text { de Passivos Ambientais; } \\
\text { Programa de Gerenciamento } \\
\text { de Riscos Ambientaise Plano } \\
\text { de Ação ; } \\
\text { Programa de Gestão, } \\
\text { Monitoramento e Controle da } \\
\text { Qualidade } \\
\text { AmbientalEmergenciais; }\end{array}$ & $\begin{array}{l}\text { Programa de Plantio Compensatório ; } \\
\text { Programa de Compensação pela Emissão de } \\
\text { Gases de Efeito Estufa; } \\
\text { Programa de Apoio a Áreas de Conservação da } \\
\text { Natureza; } \\
\text { Programa de proteção a Flora; } \\
\text { Programa de Proteção a Fauna; }\end{array}$ & $\begin{array}{l}\text { Programad de Gerenciamento } \\
\text { da Mão de Obra; } \\
\text { Programa de Comunicação } \\
\text { Social e Educação } \\
\text { Ambiental; } \\
\text { Programa de Levantamento } \\
\text { de Sítios Arqueológicos e } \\
\text { Posterior Resgate; } \\
\text { Programade Relocação de } \\
\text { Infraestrutura; } \\
\text { Programa de Indenização, } \\
\text { Reassentamento e } \\
\text { Desapropriação; }\end{array}$ \\
\hline
\end{tabular}


Tabela B - Empreendimentos Lineares

(Continuação)

\begin{tabular}{|c|c|c|c|c|c|c|c|c|}
\hline $\begin{array}{l}\text { Órgão Licenciador } \\
\text { Tipologia }\end{array}$ & $\begin{array}{c}\text { Empreendimento } \\
\text { Empreendedor/Estado }\end{array}$ & $\begin{array}{l}\text { Características do } \\
\text { empreendimento }\end{array}$ & $\begin{array}{c}\text { Ano de apresentação ao } \\
\text { órgão }\end{array}$ & $\begin{array}{c}\text { Empresa } \\
\text { Consultora }\end{array}$ & $\begin{array}{c}\text { Quantidade de } \\
\text { impactos/programas para } \\
\text { cada meio }\end{array}$ & Físico & Biótico & Antropico \\
\hline Ibama Ferrovias & $\begin{array}{l}\text { EF 354GO-RO Integração } \\
\text { Centro Oeste Valec }\end{array}$ & $1700 \mathrm{~km}$ & 2010 & STE Meio Ambiente & $\begin{array}{l}\text { Impactos } \\
13 \text { físico, } 9 \text { biótico e } 11 \\
\text { socioecononmico }\end{array}$ & 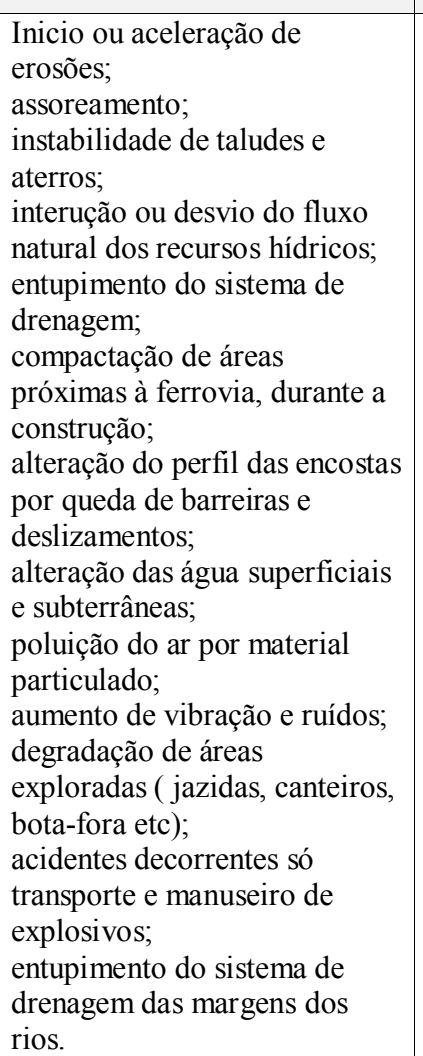 & $\begin{array}{l}\text { Fragmentacão e perda de habitats; } \\
\text { redução na diversidade de espécies da fauna e de } \\
\text { ecossistemas; } \\
\text { aumento da pressão antrópica sobre os recursos } \\
\text { naturais dos remanescentes e áreas de } \\
\text { preservacăao; } \\
\text { facilitaçao ao tráfico ilegal de animais silvestres; } \\
\text { intensificacacão da pressão de caca; } \\
\text { aumento da presença de animais domésticos e } \\
\text { exóticos; } \\
\text { proliferacãa de zoonose; } \\
\text { acréscimo do risco de queimadas descontroladas; } \\
\text { aumento de incidência de atropolamentos de } \\
\text { animais silvestres. }\end{array}$ & 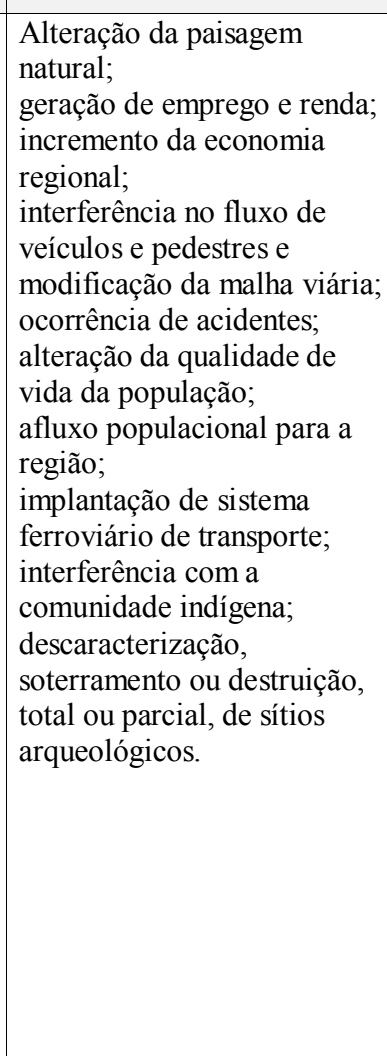 \\
\hline Ibama Ferrovias & $\begin{array}{l}\text { EF 354GO-RO Integração } \\
\text { Centro Oeste Valec }\end{array}$ & $1700 \mathrm{~km}$ & 2010 & STE Meio Ambiente & $\begin{array}{c}\text { Programas } \\
5 \text { físico, } 6 \text { biótico e } 10 \\
\text { socioeconômico }\end{array}$ & $\begin{array}{l}\text { Plano de Gestão e Supervisão } \\
\text { Ambiental; } \\
\text { Plano Ambiental para a } \\
\text { Construção; } \\
\text { Programa de Monitoramento } \\
\text { da Qualidade das Águas; } \\
\text { Programa de Monitoramento e } \\
\text { Controle de Ruidos e } \\
\text { Vibraçeses na Fase de } \\
\text { Construção; } \\
\text { Programa de Gerenciamento } \\
\text { de Riscose ellano de Ação de } \\
\text { Emergencia. }\end{array}$ & $\begin{array}{l}\text { Programa de Plantio e Revegetação das Áreas } \\
\text { Afetadas pela Ferrovia e de Outras Áreas } \\
\text { Degradadas; } \\
\text { Programa de Resgate ( Germoplasma); } \\
\text { Programa de Apoio a Averbação e/ou Relocação } \\
\text { de Reservas Legais Interceptadas; } \\
\text { Programa de Recuperação de Áreas Degradadas } \\
\text { e Passivos Ambientais; } \\
\text { Programa de Monitoramento de Espécies da } \\
\text { Fauna Ameaçada, Raras, Endemicas e } \\
\text { Bioindicadoras; } \\
\text { Programa de Monitoramento e Mitigação de } \\
\text { Atropelamento de Fauna. }\end{array}$ & 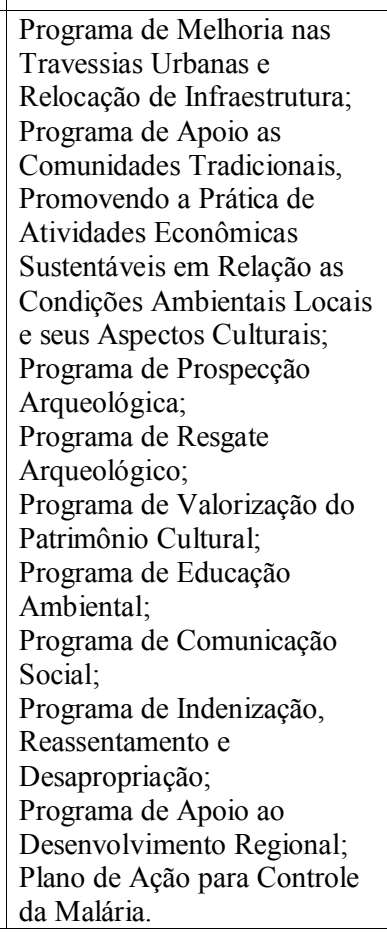 \\
\hline
\end{tabular}


Tabela B - Empreendimentos Lineares

(Continuação)

\begin{tabular}{|c|c|c|c|c|c|c|c|c|}
\hline $\begin{array}{l}\text { Órgão Licenciador } \\
\text { Tipologia }\end{array}$ & $\begin{array}{l}\text { Empreendimento } \\
\text { Empreendedor/Estado }\end{array}$ & $\begin{array}{l}\text { Características do } \\
\text { empreendimento }\end{array}$ & $\begin{array}{c}\text { Ano de apresentação ao } \\
\text { órgão }\end{array}$ & $\begin{array}{c}\text { Empresa } \\
\text { Consultora }\end{array}$ & $\begin{array}{c}\text { Quantidade de } \\
\text { impactos/programas para } \\
\text { cada meio }\end{array}$ & Físico & Biótico & Antropico \\
\hline Ibama Ferrovias & $\begin{array}{l}\text { Seg III FerroNortee } \\
\text { Terminal Rondonópolis } \\
\text { ALL }\end{array}$ & $250 \mathrm{~km}$ & 2010 & Cia Ambiental & $\begin{array}{l}\text { Impactos } \\
8 \text { físico, } 12 \text { biótico e } 17 \\
\text { socioeconomico }\end{array}$ & 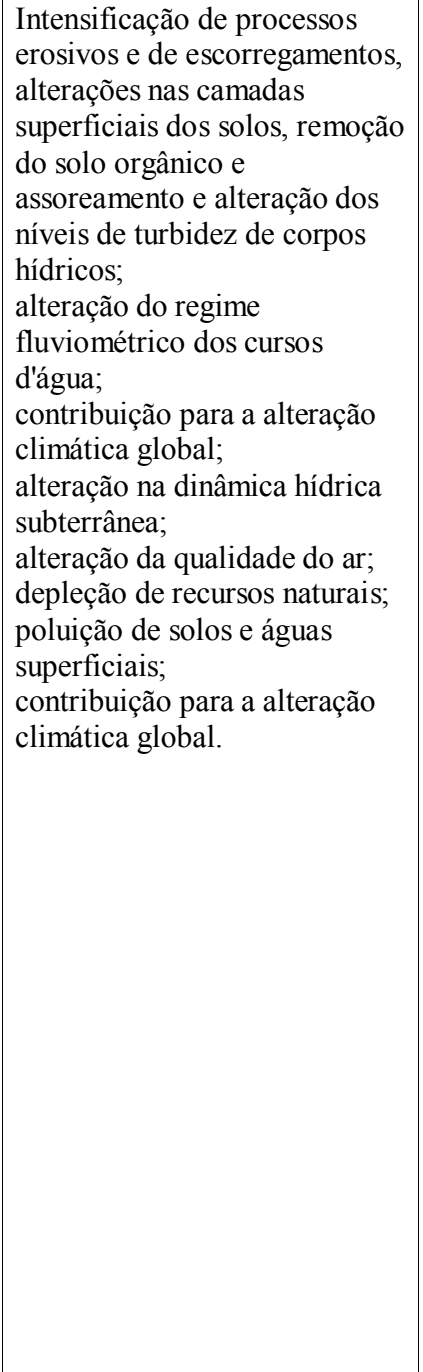 & $\begin{array}{l}\text { redução da cobertura vegetal nativa; } \\
\text { atropelamento de fauna; } \\
\text { disseminação de espécies vegetais exóticas; } \\
\text { fragmentação florestal; } \\
\text { alteração da tipologia ou fisionomia vegetal; } \\
\text { alteracão do fluxo gênico de espécies da flora; } \\
\text { perda de habitat da faunna; } \\
\text { prejuizo a fauna aquática e semi-aquática; } \\
\text { aumento do nivel de estresse, afugentamento e } \\
\text { disturbio à fauna; } \\
\text { aumento da exploracão da flora nativa; } \\
\text { atração da faunna sinantrópica; } \\
\text { degradaçãa da vegetaçẫo nativa remanescente. }\end{array}$ & 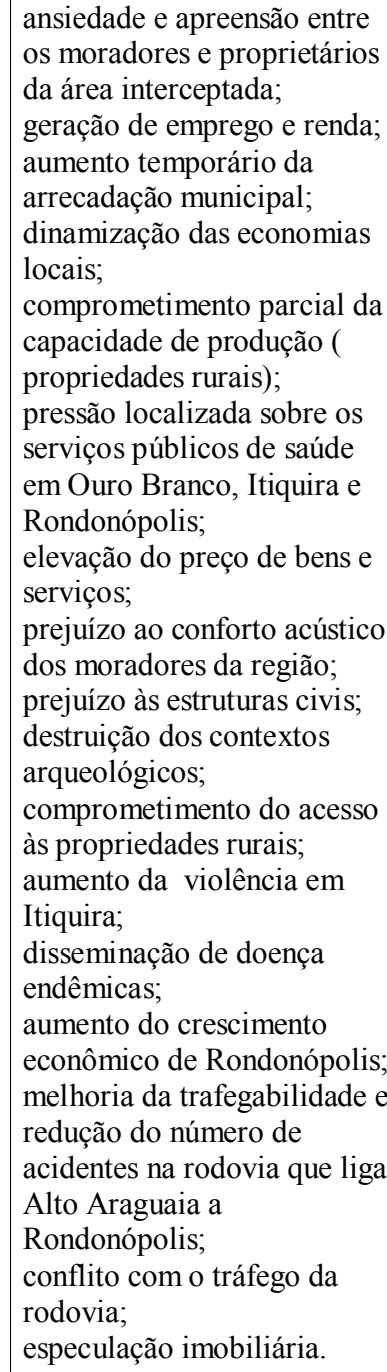 \\
\hline
\end{tabular}


Tabela B - Empreendimentos Lineares

(Continuação)

\begin{tabular}{|c|c|c|c|c|c|c|c|c|}
\hline $\begin{array}{l}\text { Órgão Licenciador } \\
\text { Tipologia }\end{array}$ & $\begin{array}{c}\text { Empreendimento } \\
\text { Empreendedor/Estado }\end{array}$ & $\begin{array}{l}\text { Características do } \\
\text { empreendimento }\end{array}$ & $\begin{array}{c}\text { Ano de apresentação ao } \\
\text { órgão }\end{array}$ & $\begin{array}{c}\text { Empresa } \\
\text { Consultora }\end{array}$ & $\begin{array}{c}\text { Quantidade de } \\
\text { impactos/programas para } \\
\text { cada meio }\end{array}$ & Físico & Biótico & Antropico \\
\hline Ibama Ferrovias & $\begin{array}{l}\text { Seg III FerroNortee } \\
\text { Terminal Rondonópolis } \\
\text { ALL }\end{array}$ & $250 \mathrm{~km}$ & 2010 & Cia Ambiental & $\begin{array}{l}\text { Programas } \\
7 \text { físico, } 6 \text { biótico e } 11 \\
\text { socioeconômico }\end{array}$ & $\begin{array}{l}\text { Programa de Gestão e } \\
\text { Supervisão Ambiental; } \\
\text { Plano Ambiental para a } \\
\text { Construção; } \\
\text { Programa de Monitoramento } \\
\text { da Qualidade das Águas; } \\
\text { Programa de Controle e; } \\
\text { Compensação de Emissões } \\
\text { Atmosféricas; } \\
\text { Programa de Monitoramento e } \\
\text { Controle de Ruídos na Fase de } \\
\text { Operacãao; } \\
\text { Programa de Gerenciamento } \\
\text { de Riscos Ambiental e Plano } \\
\text { de Ação de Emergência. }\end{array}$ & $\begin{array}{l}\text { Programa de Monitoramento de Flora e de Áreas } \\
\text { Úmidas; } \\
\text { Programa de Recuperação de Áreas Degradadas } \\
\text { e Passivos Ambientais; } \\
\text { Programa de Plantio Compensatório de Áreas de } \\
\text { Preservação Permanente; } \\
\text { Programa de Reggate de Flora; } \\
\text { Programa de Monitormento da Fauna } \\
\text { Bioindicadora; } \\
\text { Programa de Monitoramento e Mitigação de } \\
\text { Atropelamento de Fauna. }\end{array}$ & $\begin{array}{l}\text { Programa de Prospecção e } \\
\text { Resgate Arrueologico; } \\
\text { Programa de Educação } \\
\text { Ambiental; } \\
\text { Programa de Comunicacãão } \\
\text { Social e Relacionamento } \\
\text { Institucional; } \\
\text { Programa de Indenização, } \\
\text { Reassentamento e } \\
\text { Desapropriação; } \\
\text { Programa de Contratacãão da } \\
\text { Mão de Obra Local; } \\
\text { Programa de Appio a } \\
\text { Elaboracãão de Plano Diretor } \\
\text { de Itiquira; } \\
\text { Programa de Apoio a } \\
\text { Atualizacão do Plano Direto } \\
\text { de Rondonópolis; } \\
\text { Programa de Apoio ao } \\
\text { Serviço de Saúde; } \\
\text { Programa de Saúde e } \\
\text { Seguranca do Trabalho; } \\
\text { Plano Viário de Acesso ao } \\
\text { Terminal de Rondonópolis; } \\
\text { Programa de Alternativa } \\
\text { Tecnológica para a Redução } \\
\text { dos Impactos na Saúdde do } \\
\text { Trabalhador e no Meio } \\
\text { Ambienta. }\end{array}$ \\
\hline Ibama Mineroduto & MMX Minas - Rio & $\begin{array}{c}525 \mathrm{~km}, \text { e estações } \\
\text { bombeamento, 33 } \\
\text { municipios ( } 26 \mathrm{MG} \\
\text { e } 7 \mathrm{RJ}) .14 \text { meses } \\
\text { obra com picos de } \\
1574 \text { diretos e } 4722 \\
\text { indiretos }(1 \times 3) \mathrm{e} \\
104 \text { na operação }\end{array}$ & 2006 & $\begin{array}{l}\text { Brandt Meio } \\
\text { Ambiente }\end{array}$ & $\begin{array}{l}\text { Impactos } \\
5 \text { físico, } 10 \text { biótico e } 6 \\
\text { socioeconomico }\end{array}$ & $\begin{array}{l}\text { Alteração da qualidade do ar; } \\
\text { intensificação de processos } \\
\text { erosivos e de assoreamento; } \\
\text { alteracaão da qualidade das } \\
\text { águas; } \\
\text { alteração das propriedades do } \\
\text { solo; } \\
\text { alteracãao da dinâmica hídrica } \\
\text { superficial. }\end{array}$ & $\begin{array}{l}\text { Supressão de vegetação lenhosa; } \\
\text { supressão de vegetação de orquídeas e bromélias } \\
\text { específicas nos ambientes preservados de maior } \\
\text { complexidad; } \\
\text { fragmentação de áreas de vegetação nativa; } \\
\text { redução de habitats da herpetofauna; } \\
\text { mortandade de epécies da herpetofauna; } \\
\text { redução de habitats da avifauna; } \\
\text { aumento da pressão antrópica sobre a fauna; } \\
\text { redução de habitats da mastofauna; } \\
\text { mortandade de espécies da mastofauna; } \\
\text { redução de habitats para a a ictiofauna. }\end{array}$ & $\begin{array}{l}\text { Expectativa da população; } \\
\text { alteração do cotidiano das } \\
\text { populaçõs; } \\
\text { pressão obre a infraestrutur; } \\
\text { local; so } \\
\text { geração de empregos; } \\
\text { incremento na renda; } \\
\text { perdas e incômodos } \\
\text { decorrentes de alterações no: } \\
\text { espaços compreendidos pela } \\
\text { faixa de domínio. }\end{array}$ \\
\hline
\end{tabular}


Tabela B - Empreendimentos Lineares

(Continuação)

\begin{tabular}{|c|c|c|c|c|c|c|c|c|}
\hline $\begin{array}{l}\text { Órgão Licenciador } \\
\text { Tipologia }\end{array}$ & \begin{tabular}{|c|} 
Empreendimento \\
Empreendedor/Estado
\end{tabular} & $\begin{array}{l}\text { Características do } \\
\text { empreendimento }\end{array}$ & \begin{tabular}{|c|} 
Ano de apresentação ao \\
órgão
\end{tabular} & $\begin{array}{c}\text { Empresa } \\
\text { Consultora }\end{array}$ & $\begin{array}{c}\text { Quantidade de } \\
\text { impactos/programas para } \\
\text { cada meio }\end{array}$ & Físico & Biótico & Antropico \\
\hline Ibama Mineroduto & MMX Minas - Rio & $\begin{array}{c}525 \mathrm{~km}, \text { e estações } \\
\text { bombeamento, } 33 \\
\text { municipios ( } 26 \mathrm{MG} \\
\text { e } 7 \mathrm{RJ}) \text {. } 14 \text { meses } \\
\text { obra com picos de } \\
1574 \text { diretos e } 4722 \\
\text { indiretos ( } 1 \times 3) \mathrm{e} \\
104 \text { na operação }\end{array}$ & 2006 & $\begin{array}{l}\text { Brandt Meio } \\
\text { Ambiente }\end{array}$ & $\begin{array}{l}\text { Programas } \\
6 \text { fisico, } 11 \text { biótico e } 11 \\
\text { socioeconômico }\end{array}$ & $\begin{array}{l}\text { Programa de Gestão } \\
\text { Ambiental da Obra do } \\
\text { Mineroduto; } \\
\text { Programa de Gestão dos } \\
\text { Recursos Hídricos; } \\
\text { Gestão e Controle de } \\
\text { Efluentes; } \\
\text { Sistemas de Controle do } \\
\text { Carregamento de Sedimentos; } \\
\text { Programa de Gestão de } \\
\text { Resíduos Sólidos; } \\
\text { Programa de Controle de } \\
\text { Processos Erosivos. }\end{array}$ & $\begin{array}{l}\text { Programa de Reabilitação de Áreas Degradadas; } \\
\text { Programa de Compensação Ambiental; } \\
\text { Programa de Recuperação e Manejo de Áreas de } \\
\text { Preservação Permanente (APPS); } \\
\text { Monitoramento da Qualidade da Água e das } \\
\text { Comunidades Aquáticas; } \\
\text { Programa de Resgate de Flora (Salvamento de } \\
\text { Germoplasma); } \\
\text { Programa de Introdução de Espécies Nativas para } \\
\text { Desenvolvimento de Processo de Sucessão } \\
\text { Ecologica; } \\
\text { Programa de Resgate de Fauna; } \\
\text { Programa de Monitoramento da Herpetofauna } \\
\text { (Anfibios e Répteis); } \\
\text { Programa de Monitoramento da Avifauna } \\
\text { (Aves); } \\
\text { Programa de Monitoramento da Mastofauna } \\
\text { (Mamíferos); } \\
\text { Programa de Monitoramento da Ictiofauna } \\
\text { (Peixes). }\end{array}$ & $\begin{array}{l}\text { Programa de Comunicação } \\
\text { Social; } \\
\text { Expectativa da Populacãão; } \\
\text { Aumento do Tráfego de } \\
\text { Veículos; } \\
\text { Aumento da Circulação de } \\
\text { Pessoas; } \\
\text { Alteração da Paisagem; } \\
\text { Programade Absorcão e } \\
\text { Qualificacão da Mão-de- } \\
\text { Obra Local; } \\
\text { Programa de Monitoramento } \\
\text { Socio-Ambiental; } \\
\text { Programa de Educação } \\
\text { Ambiental; } \\
\text { Programa Prospecção e } \\
\text { Resgate Arqueológico; } \\
\text { Programa de Educacaãao } \\
\text { Patrimonial; } \\
\text { Programa de Monitoramento } \\
\text { dos Sítios Arqueológicos. }\end{array}$ \\
\hline Ibama Mineroduto & $\begin{array}{l}\text { Ferrous Mineroduto } \\
\text { Pres Kennedy ES }\end{array}$ & $\begin{array}{c}396 \mathrm{~km}, 22 \\
\text { municipios MG, RJ, } \\
\text { ES } 2000 \text { obra e } 60 \\
\text { operaçãa }\end{array}$ & 2010 & $\begin{array}{l}\text { Brandt Meio } \\
\text { Ambiente }\end{array}$ & $\begin{array}{l}\text { Impactos } \\
9 \text { fisico, } 15 \text { biótico e } 11 \\
\text { socioeconomico }\end{array}$ & 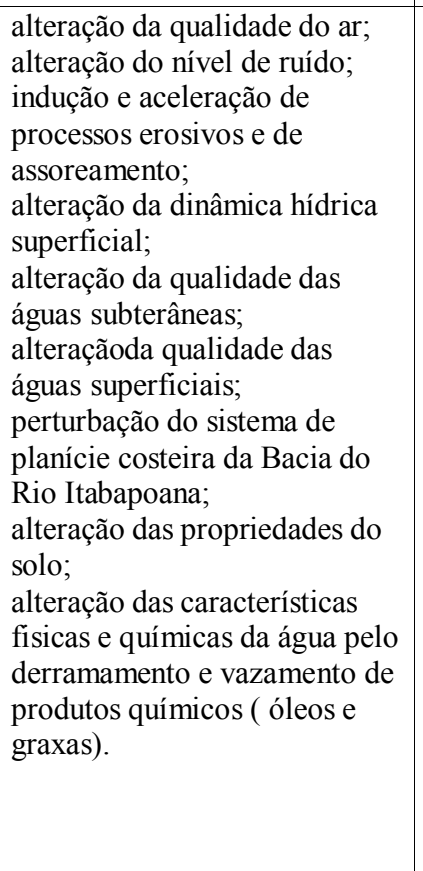 & 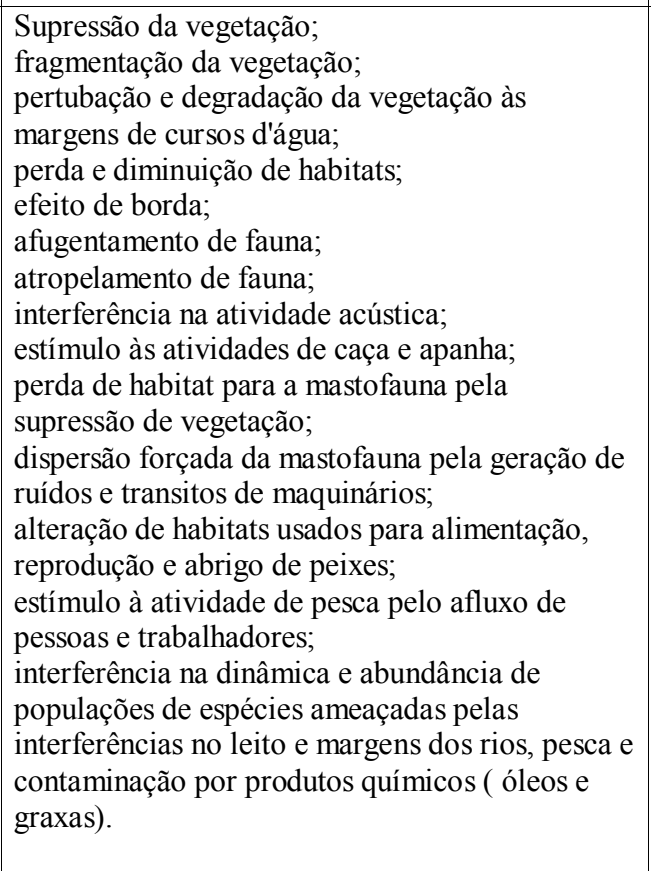 & 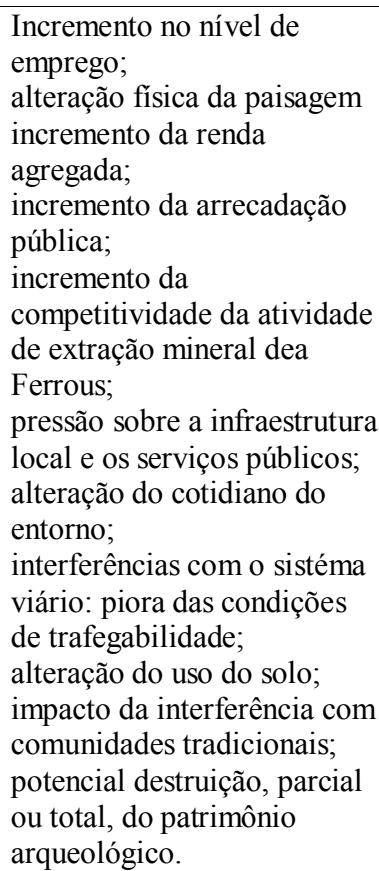 \\
\hline
\end{tabular}


Tabela B - Empreendimentos Lineares

(Continuação)

\begin{tabular}{|c|c|c|c|c|c|c|c|c|}
\hline $\begin{array}{l}\text { Órgão Licenciador } \\
\text { Tipologia }\end{array}$ & \begin{tabular}{|c|} 
Empreendimento \\
Empreendedor/Estado
\end{tabular} & $\begin{array}{l}\text { Características do } \\
\text { empreendimento }\end{array}$ & $\begin{array}{c}\text { Ano de apresentação ao } \\
\text { órgão }\end{array}$ & $\begin{array}{c}\text { Empresa } \\
\text { Consultora }\end{array}$ & $\begin{array}{c}\text { Quantidade de } \\
\text { impactos/programas para } \\
\text { cada meio }\end{array}$ & Físico & Biótico & Antropico \\
\hline Ibama Mineroduto & $\begin{array}{l}\text { Ferrous Mineroduto } \\
\text { Pres Kennedy ES }\end{array}$ & $\begin{array}{c}396 \mathrm{~km}, 22 \\
\text { municipios MG, RJ, } \\
\text { ES 2000 obra e } 60 \\
\text { operação }\end{array}$ & 2010 & $\begin{array}{l}\text { Brandt Meio } \\
\text { Ambiente }\end{array}$ & $\begin{array}{l}\text { Programas } \\
8 \text { físico, } 12 \text { biótico e } 9 \\
\text { socioeconomico }\end{array}$ & $\begin{array}{l}\text { Programa de Gestão } \\
\text { Ambiental do } \\
\text { Empreendimento; } \\
\text { Programa de Gerenciamento } \\
\text { de Residuos Solidos; } \\
\text { Programa de Gerenciamento e } \\
\text { Controle de Efluentes; } \\
\text { Programa de Controle de } \\
\text { Processos Erosivos e } \\
\text { Movimentacão de Massa; } \\
\text { Programa de Monitoramento } \\
\text { da Qualidade das Aguas } \\
\text { Superficiais; } \\
\text { Programa de Monitoramento } \\
\text { de Ruídos; } \\
\text { Programa de Gerenciamento } \\
\text { de Risco; } \\
\text { Programa de Atendimento a } \\
\text { Emergencias. }\end{array}$ & $\begin{array}{l}\text { Programa de Resgate de Fauna; } \\
\text { Subprograma de Afugentamento e Resgate de } \\
\text { Mastofauna; } \\
\text { Subprograma de Afugentamento e Resgate de } \\
\text { Herpetofauna; } \\
\text { Subprograma de Resgate de Ictiofauna; } \\
\text { Subprograma de Resgate de Entomofauna e } \\
\text { Pedofauna; } \\
\text { Programa de Reabilitação de Áreas Degradadas; } \\
\text { Subprograma de Monitoramento da Mastofauna; } \\
\text { Subprograma de Monitoramento da Avifauna; } \\
\text { Subprograma de Monitoramento da } \\
\text { Herpetofauna; } \\
\text { Subprograma de Monitoramento da Ictiofauna; } \\
\text { Subprograma de Monitoramento da } \\
\text { Entomofauna; } \\
\text { Programa de Compensação Ambiental. }\end{array}$ & $\begin{array}{l}\text { Programa de Educação } \\
\text { Ambiental; } \\
\text { Programade Comunicação } \\
\text { Social; } \\
\text { Programa de Priorização da } \\
\text { Mão de Obra e Fornecedores } \\
\text { Locais; } \\
\text { Ação para Garantir a } \\
\text { Abertura de CNPJ dos } \\
\text { Maiores Fornecedores nos } \\
\text { Municipios da Area de } \\
\text { Influencia; } \\
\text { Programa de Negociação } \\
\text { Fundiária; } \\
\text { Programa de Mitigação da } \\
\text { Pressão sobre a } \\
\text { Infraestrutura Local e } \\
\text { Serviços Públicos; } \\
\text { Programad de Manutenção da } \\
\text { Trafecabilidade e de } \\
\text { Sinalização Viária; } \\
\text { Programa de Prospecção e } \\
\text { Resgate Arqueologico; } \\
\text { Programa de Educação } \\
\text { Patrimonial. }\end{array}$ \\
\hline Ibama Gasoduto & $\begin{array}{l}\text { Gasoduto Caraguatatuba } \\
\text { - taubate Petrobras }\end{array}$ & $\begin{array}{l}94 \mathrm{~km}, 2000 \text { obra, } 6 \\
\text { municipios }\end{array}$ & 2006 & $\begin{array}{c}\text { Biodinamica } \\
\text { Engenharia e Meio } \\
\text { Ambiente }\end{array}$ & $\begin{array}{l}\text { Impactos } \\
3 \text { físicos }, 2 \text { bióticos e } 8 \\
\text { socioeconomicos }\end{array}$ & $\begin{array}{l}\text { alteração da rede de drenagem; } \\
\text { início e/ou aceleracacão de } \\
\text { processos erosivos, transporte } \\
\text { sólido e assoreamento; } \\
\text { interferêncaic com áreas de } \\
\text { autorizaçōes e concessões } \\
\text { minerárias; }\end{array}$ & $\begin{array}{l}\text { alteracão nos remanescentes florestais; } \\
\text { pressão sobre a biota ( fauna e flora). }\end{array}$ & 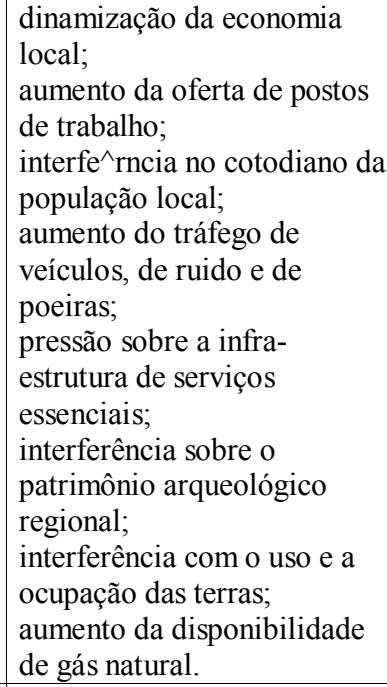 \\
\hline Ibama Gasoduto & $\begin{array}{l}\text { Gasoduto Caraguatatuba } \\
\text { - taubate Petrobras }\end{array}$ & $\begin{array}{l}94 \mathrm{~km}, 2000 \text { obra, } 6 \\
\text { municipios }\end{array}$ & 2006 & $\begin{array}{l}\text { Biodinamica } \\
\text { Engenharia e Meio } \\
\text { Ambiente }\end{array}$ & $\begin{array}{l}\text { Programas } \\
5 \text { fisicos, } 4 \text { bioticos e } 5 \\
\text { socioeconomicos }\end{array}$ & $\begin{array}{l}\text { Programa de Gestão de } \\
\text { Interferênciias com Atividade } \\
\text { de Mineracaão; } \\
\text { Programa de Controle de } \\
\text { Processos Erosivo; } \\
\text { Plano Ambiental para a } \\
\text { Construção; } \\
\text { Programa de Gerenciamento } \\
\text { de Resíduos; } \\
\text { Programa de Gerenciamento } \\
\text { de Risco e Plano de Ação a } \\
\text { Emergências. }\end{array}$ & $\begin{array}{l}\text { Programa de Supressão de Vegetação; } \\
\text { Programa de Salvamento de Germoplasma; } \\
\text { Programa de Recuperacãa de Áreas Degradadas; } \\
\text { Programa de Monitoramento da Fauna e da } \\
\text { Flora. }\end{array}$ & $\begin{array}{l}\text { Programa de Educação } \\
\text { Ambiental; } \\
\text { Programa de Comunicação } \\
\text { Social; } \\
\text { Programa de Prospecção } \\
\text { Arqueológico; } \\
\text { Programa de Educação } \\
\text { Patrimonial; } \\
\text { Programa de } \\
\text { Estabelecimento de Faixa de } \\
\text { Servidão e de Indenização. }\end{array}$ \\
\hline
\end{tabular}


Tabela B - Empreendimentos Lineares

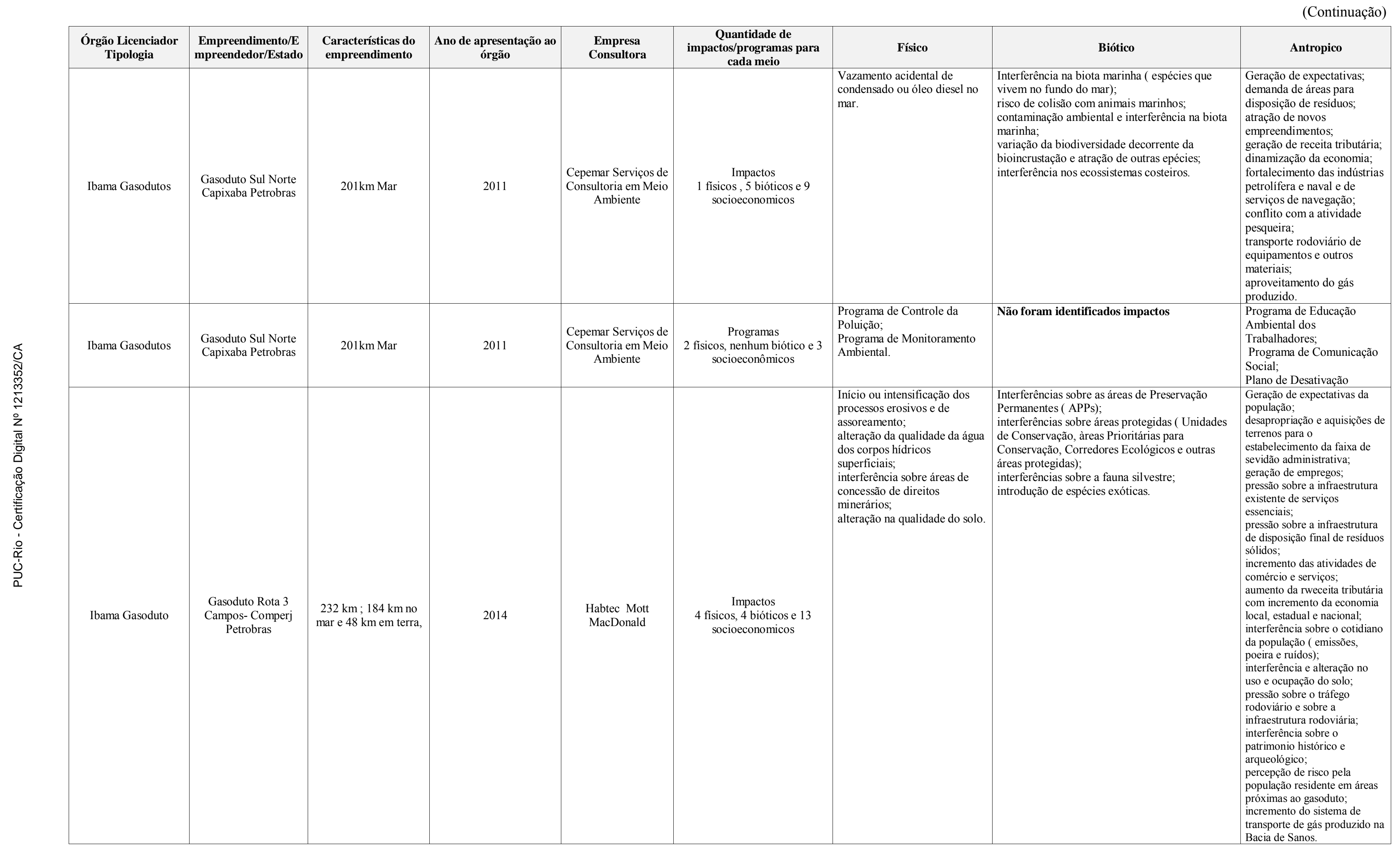


Tabela B - Empreendimentos Lineares

(Continuação)

\begin{tabular}{|c|c|c|c|c|c|c|c|c|}
\hline $\begin{array}{l}\text { Órgão Licenciador } \\
\text { Tipologia }\end{array}$ & \begin{tabular}{|c|} 
Empreendimento \\
Empreendedor/Estado
\end{tabular} & $\begin{array}{l}\text { Características do } \\
\text { empreendimento }\end{array}$ & \begin{tabular}{|c|} 
Ano de apresentação ao \\
órgão
\end{tabular} & $\begin{array}{c}\text { Empresa } \\
\text { Consultora }\end{array}$ & $\begin{array}{c}\text { Quantidade de } \\
\text { impactos/programas para } \\
\text { cada meio }\end{array}$ & Físico & Biótico & Antropico \\
\hline Ibama Gasoduto & $\begin{array}{c}\text { Gasoduto Rota } 3 \\
\text { Campos- Comperj } \\
\text { Petrobras }\end{array}$ & $\begin{array}{c}232 \mathrm{~km} ; 184 \mathrm{~km} \mathrm{no} \\
\text { mar e } 48 \mathrm{~km} \mathrm{em} \\
\text { terra, }\end{array}$ & 2014 & $\begin{array}{l}\text { Habtec Mott } \\
\text { MacDonald }\end{array}$ & $\begin{array}{l}\text { Programas } \\
6 \text { fisicos, } 5 \text { bióticos e } 5 \\
\text { socioeconomicos }\end{array}$ & $\begin{array}{l}\text { Programa de } \\
\text { Acompanhamento da } \\
\text { Atividade de Mineração; } \\
\text { Programa de Controle da } \\
\text { Poluição; } \\
\text { Plano Ambiental para a } \\
\text { Construção; } \\
\text { Programa de Controle e } \\
\text { Prevencão de Erosão, } \\
\text { Assoreamento e Instabilizade } \\
\text { de Terrenos; } \\
\text { Programa de Monitoramento } \\
\text { Ambiental. }\end{array}$ & $\begin{array}{l}\text { Programa de Controle de Supressão; } \\
\text { Programa de Resgate de Germoplasma; } \\
\text { Programa de Conservção da Fauna Silvestre; } \\
\text { Programa de Recuperaçãa de Areas Degradadas; } \\
\text { Programa de Reposição Florestal. }\end{array}$ & $\begin{array}{l}\text { Programa de Educação } \\
\text { Ambiental; } \\
\text { Programa de Comunicação } \\
\text { Social; } \\
\text { Plano de Desativação; } \\
\text { Programa de } \\
\text { Estabelecimento de Faixa de } \\
\text { Servidão; } \\
\text { Programa de Avaliação e } \\
\text { Salvamento do Patrimonio } \\
\text { Arqueológico. }\end{array}$ \\
\hline Ibama LT & $\begin{array}{l}\text { Linha Taubaté - Taubate } \\
\text { SP Nova Iguaçu RJ }\end{array}$ & $\begin{array}{l}500 \mathrm{kV}, 257 \mathrm{Km} ; 22 \\
\text { Municipios }\end{array}$ & 2012 & $\begin{array}{l}\text { Biodinamica } \\
\text { Engenharia e Meio } \\
\text { Ambiente }\end{array}$ & $\begin{array}{l}\text { Impactos } \\
5 \text { fisicos, } 4 \text { bióticos e e } 11 \\
\text { socioeconomicos }\end{array}$ & $\begin{array}{l}\text { alteração da rede de drenagem; } \\
\text { inicio e/ou aceleração de } \\
\text { processos erosivos; } \\
\text { interferência com áreas de } \\
\text { autorizaçōes e concessões } \\
\text { minerárias; } \\
\text { interferências } \\
\text { eletromagnéticas; } \\
\text { geração de resíduos e } \\
\text { efluentes. }\end{array}$ & $\begin{array}{l}\text { alteração na biodiversidade; } \\
\text { perda de áreas de vegetação nativa; } \\
\text { pressãa sobre a fauna; } \\
\text { colisão da avifauna com cabos de LT. }\end{array}$ & 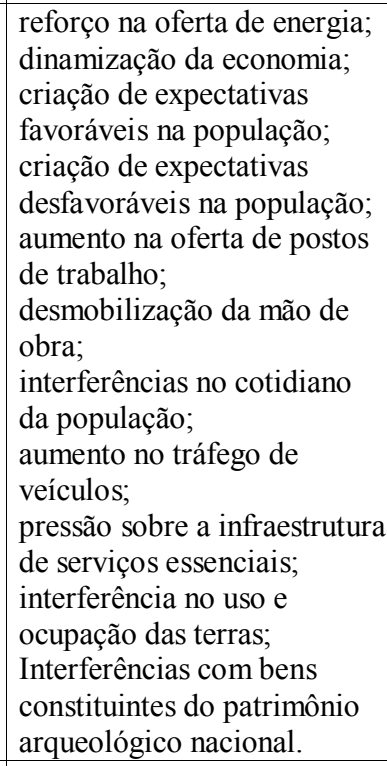 \\
\hline Ibama LT & $\begin{array}{l}\text { Linha Taubaté - Taubate } \\
\text { SP Nova Iguaçu RJ }\end{array}$ & $\begin{array}{l}500 \mathrm{kV}, 257 \mathrm{Km} ; 22 \\
\text { Municipios }\end{array}$ & 2012 & $\begin{array}{c}\text { Biodinamica } \\
\text { Engenharia e Meio } \\
\text { Ambiente }\end{array}$ & $\begin{array}{l}\text { Programas } \\
5 \text { físicos, } 5 \text { bióticos e } 5 \\
\text { socioeconomicos }\end{array}$ & $\begin{array}{l}\text { Plano de Ação de } \\
\text { Emergências; } \\
\text { Programa de Gestão das } \\
\text { Interfarencias das Atividades } \\
\text { de Mineracão; } \\
\text { Plano Ambiental para a } \\
\text { Construção; } \\
\text { Programa de Prevenção, } \\
\text { Monitoramento e Controle de } \\
\text { Processos Erosivos; } \\
\text { Programa de Monitoramento } \\
\text { das Interferencias } \\
\text { Eletromagneticas. }\end{array}$ & $\begin{array}{l}\text { Programa de Supressão da Vegetação; } \\
\text { Programa de Salvamento do Germoplasma } \\
\text { Vegetal; } \\
\text { Programa de Manejo de Fauna; } \\
\text { Programa de Recuperação de Areas Degradadas; } \\
\text { Programa de Reposição Florestal. }\end{array}$ & $\begin{array}{l}\text { Programa de Educação } \\
\text { Ambiental; } \\
\text { Programa de Comunicação } \\
\text { Social; } \\
\text { Programa de Getão do } \\
\text { Patrimonio Cultural e } \\
\text { Arqueológico; } \\
\text { Programa de Liberação da } \\
\text { Faida de Servidão } \\
\text { Administrativa e } \\
\text { Indenizaçôes; } \\
\text { Programa de Gestão da } \\
\text { Saude OCupacional e } \\
\text { Segurança do Trabalho. }\end{array}$ \\
\hline
\end{tabular}


Tabela B - Empreendimentos Lineares

(Continuação)

\begin{tabular}{|c|c|c|c|c|c|c|c|c|}
\hline $\begin{array}{l}\text { Órgão Licenciador } \\
\text { Tipologia }\end{array}$ & \begin{tabular}{|c|} 
Empreendimento \\
Empreendedor/Estado
\end{tabular} & $\begin{array}{l}\text { Características do } \\
\text { empreendimento }\end{array}$ & Ano de apresentação ao & $\begin{array}{c}\text { Empresa } \\
\text { Consultora }\end{array}$ & $\begin{array}{c}\text { Quantidade de } \\
\text { impactos/programas para } \\
\text { cada meio }\end{array}$ & Físico & Biótico & Antropico \\
\hline Ibama LT & $\begin{array}{l}\text { ATEXVI - Milagres Ce, } \\
\text { PB Assu RN }\end{array}$ & $\begin{array}{l}500 \mathrm{kV} ; 336 \mathrm{Km} ; 19 \\
\text { Municipios }\end{array}$ & 2014 & $\begin{array}{l}\text { Bourscheid } \\
\text { Engenharia e Meio } \\
\text { Ambiente }\end{array}$ & $\begin{array}{l}\text { Impactos } \\
5 \text { fisicos, } 8 \text { bióticos e } 24 \\
\text { socioeconomicos }\end{array}$ & $\begin{array}{l}\text { Instalação e aceleração dos } \\
\text { processos erosivos; } \\
\text { contaminação do solo; } \\
\text { contaminação de corpos } \\
\text { hídricos e alteraçãa da } \\
\text { qualidade da água; } \\
\text { alteração das propriedades } \\
\text { físicas do solo; } \\
\text { interferência com atividades } \\
\text { minerárias. }\end{array}$ & $\begin{array}{l}\text { Perda ou alteração da cobertura vegetal; } \\
\text { afugentamento da fauna; } \\
\text { riscos de acidentes e morte de fauna; } \\
\text { aumento da caça e captura de individuos da } \\
\text { fauna; } \\
\text { aumento do risco de acidentes causados por } \\
\text { animais peconhentos; } \\
\text { aumento da ocorrência de doenças de propagação } \\
\text { vetoriali; } \\
\text { interferências em unidades de Conservação e } \\
\text { demais áreas legalmente protegidas; } \\
\text { perda de individuos da avifauna. }\end{array}$ & 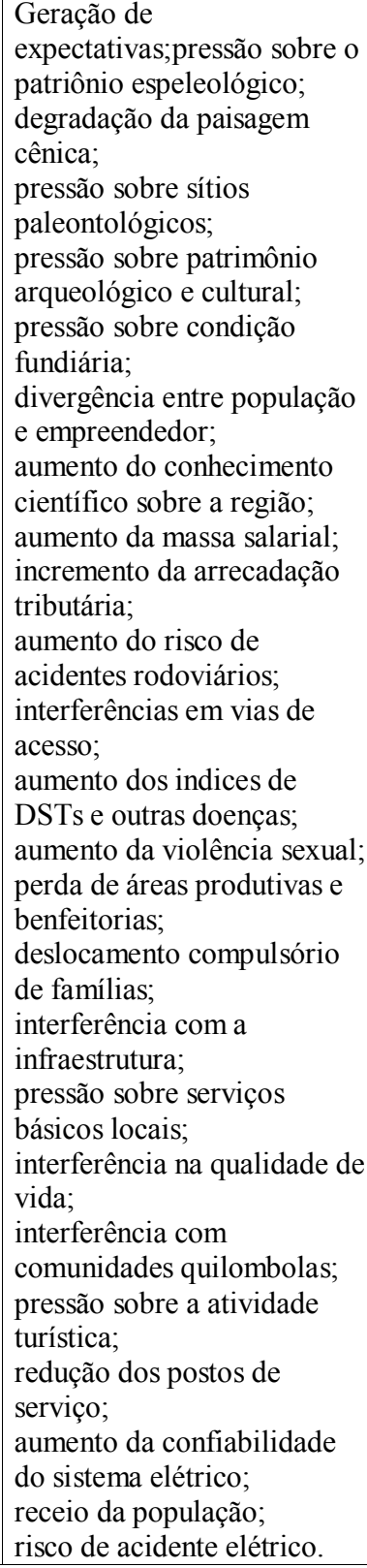 \\
\hline
\end{tabular}


Tabela B - Empreendimentos Lineares

(Continuação)

\begin{tabular}{|c|c|c|c|c|c|c|c|c|}
\hline $\begin{array}{l}\text { Órgão Licenciador } \\
\text { Tipologia }\end{array}$ & $\begin{array}{l}\text { Empreendimento } \\
\text { Empreendedor/Estado }\end{array}$ & $\begin{array}{l}\text { Características do } \\
\text { empreendimento }\end{array}$ & $\begin{array}{l}\text { Ano de } \\
\text { apresentação } \\
\text { ao órgão }\end{array}$ & $\begin{array}{l}\text { Empresa } \\
\text { Consultora }\end{array}$ & $\begin{array}{c}\text { Quantidade de } \\
\text { impactos/programas } \\
\text { para cada meio }\end{array}$ & Físico & Biótico & Antropico \\
\hline Ibama LT & $\begin{array}{c}\text { ATEXVI - Milagres Ce, } \\
\text { PB Assu RN }\end{array}$ & $\begin{array}{l}500 \mathrm{kV} ; 336 \mathrm{Km} ; \\
19 \text { Municipios }\end{array}$ & 2014 & $\begin{array}{c}\text { Bourscheid } \\
\text { Engenharia e } \\
\text { Meio Ambiente }\end{array}$ & $\begin{array}{l}\text { Programas } \\
5 \text { físicos, } 8 \text { bióticos e } 8 \\
\text { socioeconomicos }\end{array}$ & $\begin{array}{l}\text { Plano Ambiental para a Construção; } \\
\text { Programa de Gerenciamento de } \\
\text { Resíduos Sólidose Effluentes } \\
\text { Líquidos nos Canteiros e Frentes de } \\
\text { Obra; } \\
\text { Programa de Controle da Poluição ( } \\
\text { Projeto de Controle da Poluição } \\
\text { Atmosférica e Projeto de Prevenção } \\
\text { de Ruídos); } \\
\text { Programa de Gestão da Interferencia } \\
\text { com a Atividade Mineraraias; } \\
\text { Programa de Identificação, } \\
\text { Monitoramento e Controle de } \\
\text { Processos Erosivos. }\end{array}$ & $\begin{array}{l}\text { Programa de Supressão de Vegetação; } \\
\text { Programa de Coleta do Germoplasma e } \\
\text { Resgate de Epifitas; } \\
\text { Programa de Reposição Florestal; } \\
\text { Programa de Monitoramento da Fauna; } \\
\text { Programa de Afugentamento e Resgate da } \\
\text { Fauna; } \\
\text { Programa de Recuperação de Áreas } \\
\text { Degradadas; } \\
\text { Programa de Manutenção da Faixa de } \\
\text { Servidão; } \\
\text { Programa de Compensação Ambiental. }\end{array}$ & $\begin{array}{l}\text { Programa de Sinalização Viária; } \\
\text { Programa de Proteção ao Trabalhor e Segurança no } \\
\text { Trabalho; } \\
\text { Programa de Saude Ocupacional; } \\
\text { Programa de Instituição da Faixa de Servidão; } \\
\text { Programa de Educação Ambiental; } \\
\text { Programa de Comunicacaão Social; } \\
\text { Programa de Prospecçãa, Resgate e Guarda do } \\
\text { Patrimonio Historico e Arqueologico; } \\
\text { Programa de Preservaçâo do Patrimonio } \\
\text { Paleontológico; }\end{array}$ \\
\hline Ibama LT & IEGuaranhuns PE,Al & $500 \mathrm{kV}, 646 \mathrm{Km}$ & 2012 & $\begin{array}{l}\text { JGP Gestão } \\
\text { Ambiental }\end{array}$ & $\begin{array}{c}\text { Impactos } \\
9 \text { físico, } 6 \text { biótico e } 23 \\
\text { socioeconomico }\end{array}$ & $\begin{array}{l}\text { Aumento da turbidez dos corpos } \\
\text { d'água; } \\
\text { interferênciacia com direitos } \\
\text { minerários já concedidos ou em } \\
\text { concessão; } \\
\text { assoreamentodos cursos d'água; } \\
\text { alteraçãa dos cursos d'água; } \\
\text { alteraçãa do risco de contaminação } \\
\text { de águas subterrâneas; } \\
\text { alteração do relevo, instabilização de } \\
\text { encostas e indução de processos } \\
\text { erosivos; } \\
\text { alteracão dos riscos de contaminação } \\
\text { do solo; } \\
\text { ressuspensão de poeira; } \\
\text { alteração na qualidade do ar por } \\
\text { emissões atmosféricas de fontes } \\
\text { móveis. }\end{array}$ & $\begin{array}{l}\text { Redução da cobertura vegetal; } \\
\text { aumento do risco de interferências sobre } \\
\text { áreas legalmente protegidas } \\
\text { inibicãao da regeneraçăao espontânea na faixa } \\
\text { de servidão; } \\
\text { alteração nos habitats naturais e } \\
\text { afugentamento de fauna durante a } \\
\text { construção; } \\
\text { aumento do risco de acidentes com avifauna } \\
\text { durante a operação; } \\
\text { risco de aumento da caça durante as obras. }\end{array}$ & 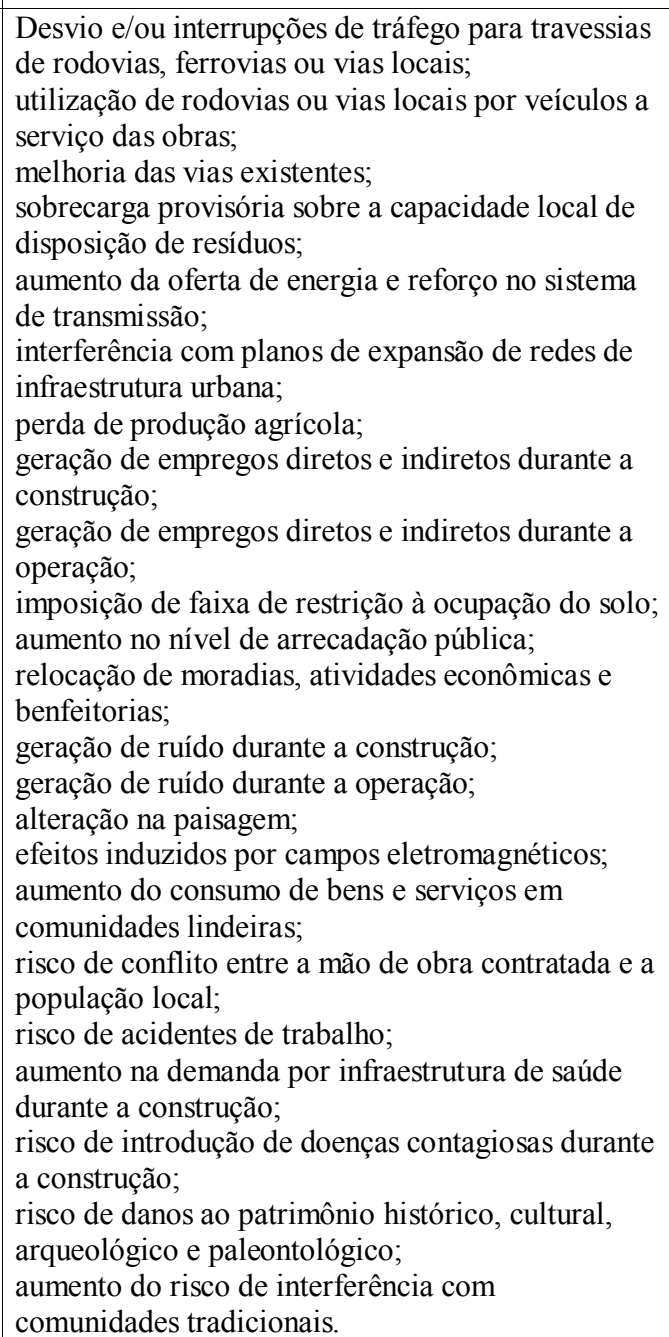 \\
\hline
\end{tabular}


Tabela B - Empreendimentos Lineares

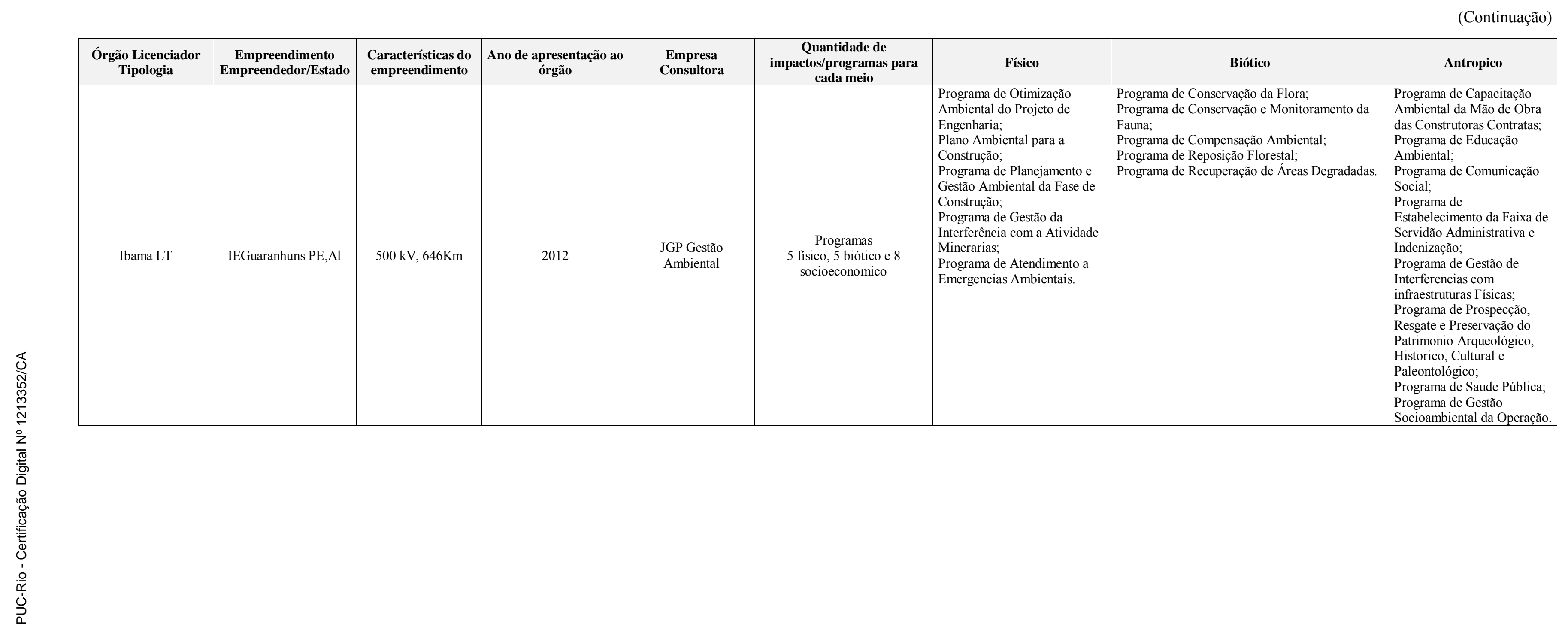


Tabela B - Empreendimentos Lineares

(Continuação)

\begin{tabular}{|c|c|c|c|c|c|c|c|c|}
\hline $\begin{array}{l}\text { Órgão Licenciador } \\
\text { Tipologia }\end{array}$ & \begin{tabular}{|c|} 
Empreendimento \\
Empreendedor/Estado
\end{tabular} & $\begin{array}{l}\text { Características do } \\
\text { empreendimento }\end{array}$ & $\begin{array}{c}\text { Ano de apresentação ao } \\
\text { órgão }\end{array}$ & $\begin{array}{l}\text { Empresa } \\
\text { Consultora }\end{array}$ & $\begin{array}{c}\text { Quantidade de } \\
\text { impactos/programas para } \\
\text { cada meio }\end{array}$ & Físico & Biótico & Antropico \\
\hline Ibama LT & $\begin{array}{l}\text { TransNorte - Manaus } \\
\text { Boa Vista }\end{array}$ & $\begin{array}{c}500 \mathrm{kV}, 721 \mathrm{~km} 2 \\
\text { estados, } 9 \\
\text { municipios }\end{array}$ & 2014 & Ecology Brasil & $\begin{array}{l}\text { Impactos } \\
7 \text { físico, } 6 \text { biótico e } 24 \\
\text { socioeconomico }\end{array}$ & $\begin{array}{l}\text { Indução de processos erosivos } \\
; \text { contaminação do solo; } \\
\text { contaminação de corpos } \\
\text { hídricos e alteração qualidade } \\
\text { da água; } \\
\text { alteração das propriedades } \\
\text { fisicas do solo; } \\
\text { geracãão e abandono de } \\
\text { resíduos sólidos; } \\
\text { derramamento de efluentes } \\
\text { líquidos; } \\
\text { interferencia com atividades } \\
\text { minerárias. }\end{array}$ & $\begin{array}{l}\text { Alteração ou perda de habitats; } \\
\text { afugentamento da fauna; } \\
\text { risco de acidentes e morte da fauna; } \\
\text { aumento do risco de acidentes com animais } \\
\text { peçonhentos; } \\
\text { aumento do indice de doenças de propagação } \\
\text { vetorial; } \\
\text { aumento no índice de DST e AIDS e outras } \\
\text { Doenças; } \\
\text { risco de colisão da avifauna. }\end{array}$ & 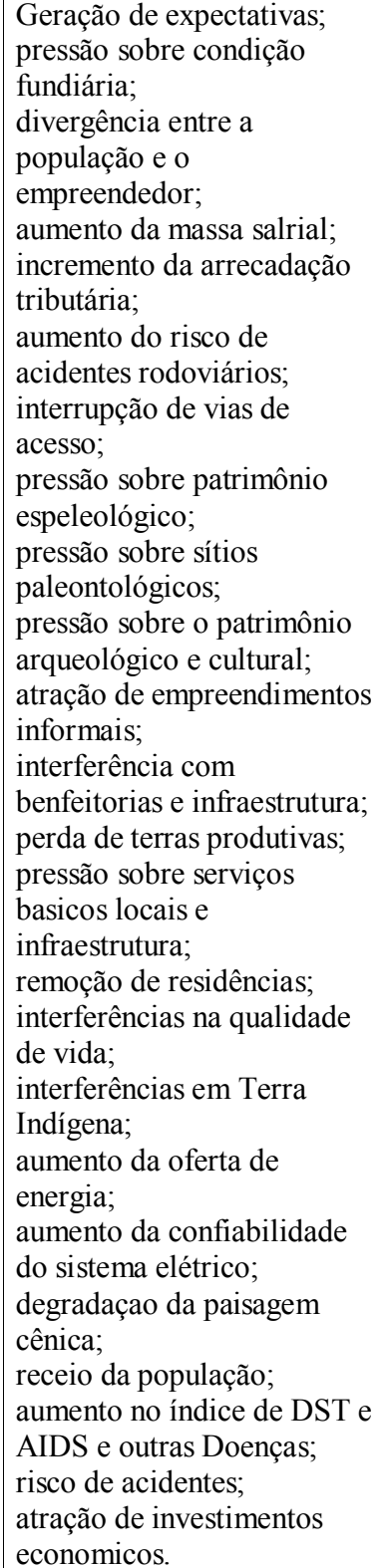 \\
\hline Ibama LT & $\begin{array}{l}\text { TransNorte - Manaus } \\
\text { Boa Vista }\end{array}$ & $\begin{array}{l}500 \mathrm{kV}, 721 \mathrm{~km} 2 \\
\text { estados, } 9 \\
\text { municipios }\end{array}$ & 2014 & Ecology Brasil & $\begin{array}{l}\text { Programas } \\
3 \text { físico, } 8 \text { biótico e } 6 \\
\text { socioeconomico }\end{array}$ & $\begin{array}{l}\text { Plano Ambiental para a } \\
\text { Construção; } \\
\text { Programa de Prevenção e } \\
\text { Controle de Erosão; } \\
\text { Programa de } \\
\text { Acompanhamento de } \\
\text { Processos de Mineração; }\end{array}$ & $\begin{array}{l}\text { Programa de Recuperação de Áreas Degradadas; } \\
\text { Programa de Supressão de Vegetação; } \\
\text { Programa de Salvamento de Germoplasma; } \\
\text { Programa de Reposição Florestal; } \\
\text { Programa de Montoramento de Fauna; } \\
\text { Programa de Afugentamento, Resgate e Manejo } \\
\text { de Fauna; } \\
\text { Programa de Prevenção de Acidente com a } \\
\text { Fauna; } \\
\text { Programa de Compensação Ambiental. }\end{array}$ & $\begin{array}{l}\text { Programa de Educação } \\
\text { Ambiental; } \\
\text { Programa de Educacãão } \\
\text { Ambiental para Trabalhadores; } \\
\text { Programa de Comunicação } \\
\text { Social; } \\
\text { Programa de Segurança no } \\
\text { Transito e Mobilidade Urbana; } \\
\text { Programa de Instalacãoo da } \\
\text { Faixa de Servidão; } \\
\text { Programa de Preservação de } \\
\text { Sítios Paleontológicos. }\end{array}$ \\
\hline
\end{tabular}


Tabela B - Empreendimentos Lineares

(Continuação)

\begin{tabular}{|c|c|c|c|c|c|c|c|c|}
\hline $\begin{array}{l}\text { Órgão Licenciador } \\
\text { Tipologia }\end{array}$ & $\begin{array}{c}\text { Empreendimento } \\
\text { Empreendedor/Estado }\end{array}$ & $\begin{array}{l}\text { Características do } \\
\text { empreendimento }\end{array}$ & $\begin{array}{c}\text { Ano de apresentação ao } \\
\text { órgão }\end{array}$ & $\begin{array}{c}\text { Empresa } \\
\text { Consultora }\end{array}$ & $\begin{array}{c}\text { Quantidade de } \\
\text { impactos/programas para } \\
\text { cada meio }\end{array}$ & Físico & Biótico & Antropico \\
\hline Ibama LT & $\begin{array}{l}\text { ATE XVI -Miracema } \\
\text { To - Sapeaçu BA }\end{array}$ & $\begin{array}{l}500 \mathrm{kV}, 1854 \mathrm{~km}, 47 \\
\text { Municipios, }\end{array}$ & 2013 & Ecology Brasil & $\begin{array}{l}\text { Impactos } \\
5 \text { físico, } 8 \text { biótico e } 24 \\
\text { socioeconomico }\end{array}$ & $\begin{array}{l}\text { Instalação e aceletração de } \\
\text { processos erosivos; } \\
\text { contaminaçãao do solo; } \\
\text { contaminação de corpos } \\
\text { hídricos e alteração da } \\
\text { qualidade da água; } \\
\text { alteração das propriedades } \\
\text { fisicas do solo; } \\
\text { interferência com atividades } \\
\text { minerárias. }\end{array}$ & $\begin{array}{l}\text { perda ao alteracãadoda cobertura vegetal; } \\
\text { afugentamento da fauna; } \\
\text { risco de acidentes e morte da fauna; } \\
\text { aumento da caça e captura de indivíduos da } \\
\text { fauna; } \\
\text { aumento do risco de acidentes causados por } \\
\text { animais peçonhentos; } \\
\text { aumento da ocorrencia de doenças de propagação } \\
\text { vetorial; } \\
\text { interferências em Unidades de Conservação e } \\
\text { demais áreas legalmente protegidas; } \\
\text { perda de indivíduos da avifauna. }\end{array}$ & 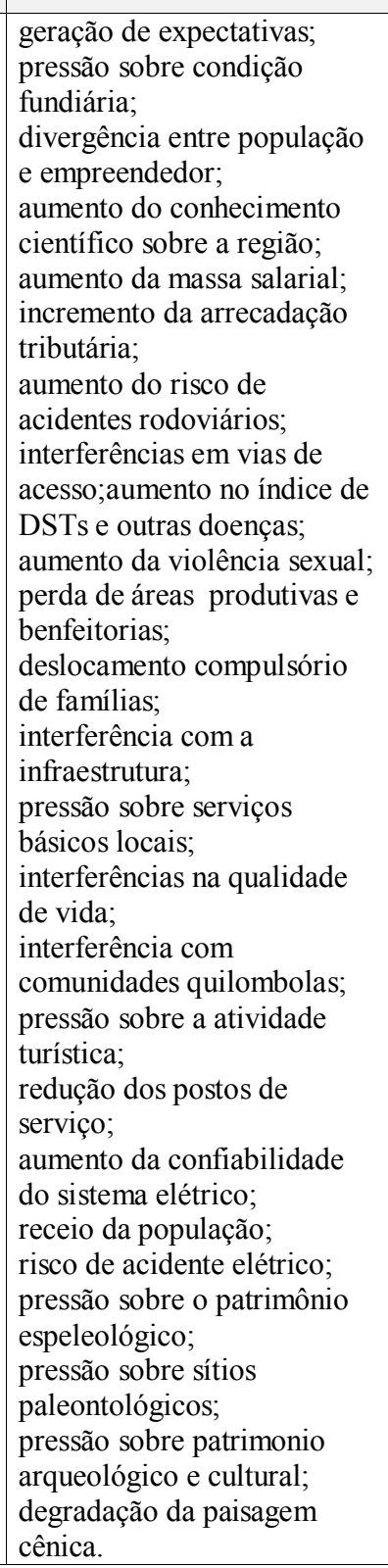 \\
\hline
\end{tabular}


Tabela B - Empreendimentos Lineares

(Continuação)

\begin{tabular}{|c|c|c|c|c|c|c|c|c|}
\hline $\begin{array}{l}\text { Órgão Licenciador } \\
\text { Tipologia }\end{array}$ & \begin{tabular}{|c|} 
Empreendimento \\
Empreendedor/Estado
\end{tabular} & $\begin{array}{l}\text { Características do } \\
\text { empreendimento }\end{array}$ & $\begin{array}{l}\text { Ano de apresentação ao } \\
\text { órgão }\end{array}$ & $\begin{array}{c}\text { Empresa } \\
\text { Consultora }\end{array}$ & $\begin{array}{l}\text { Quantidade de } \\
\text { impactos/programas para } \\
\text { cada meio }\end{array}$ & Físico & Biótico & Antropico \\
\hline Ibama LT & $\begin{array}{l}\text { ATE XVI -Miracema } \\
\text { To - Sapeaçu BA }\end{array}$ & $\begin{array}{l}500 \mathrm{kV}, 1854 \mathrm{~km}, 47 \\
\text { Municipios, }\end{array}$ & 2013 & Ecology Brasil & $\begin{array}{l}\text { Programas } \\
4 \text { fisico, } 8 \text { biótico e } 13 \\
\text { socioeconômico }\end{array}$ & $\begin{array}{l}\text { Programa de Gerenciamento } \\
\text { de Resíduos Sólidos e } \\
\text { Efluentes Liquidos nos } \\
\text { Canteiros e Frentes de Obra; } \\
\text { Programa de Controle da } \\
\text { Poluçãa; } \\
\text { Programa de Readequacãoo e } \\
\text { Indenizacãa de Atividades } \\
\text { Minerárias; } \\
\text { Programa de Identificacãao, } \\
\text { Monitoramento e Controle de } \\
\text { Processos Erosivos. }\end{array}$ & $\begin{array}{l}\text { Programa de Supressão de Vegetação; } \\
\text { Programa de Coleta do germoplasma e Resgate } \\
\text { de Epífitas; } \\
\text { Programa de Reposição Florestal; } \\
\text { Programa de Monitoramento da Fauna; } \\
\text { Programa de Afugentamento e Resgate da Fauna; } \\
\text { Programa de Recuperacãão de Areas Degradadas; } \\
\text { Programa de Manutenção da Faixa de Servidão; } \\
\text { Plano de Compensação Ambiental. }\end{array}$ & 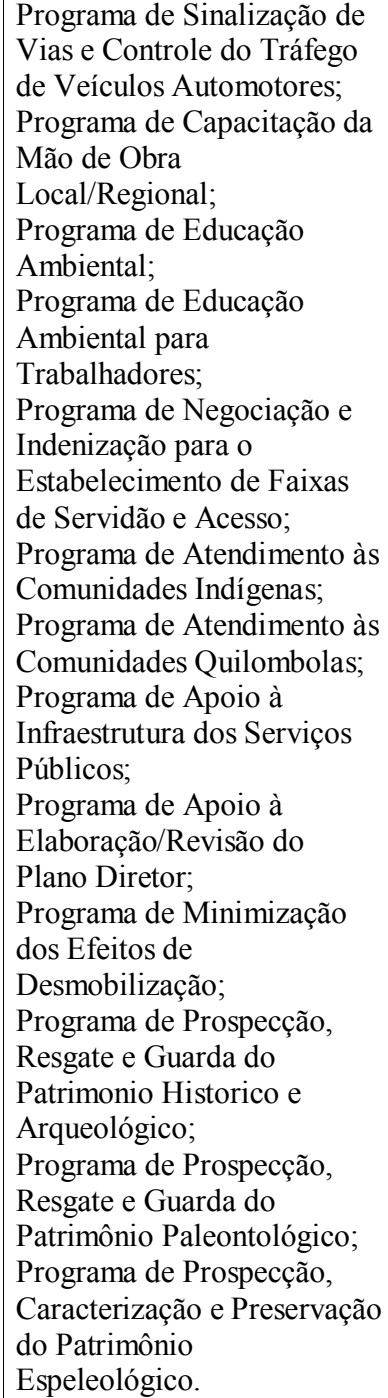 \\
\hline Ibama Rodovias & $\begin{array}{c}\text { DNIT BR } 101 \text { AL, SE e } \\
\text { BA }\end{array}$ & $\begin{array}{l}487 \mathrm{~km} 47 \\
\text { municípios }\end{array}$ & 2007 & $\begin{array}{l}\text { Oikos Consultoria e } \\
\text { Projetos }\end{array}$ & $\begin{array}{l}\text { Impactos } \\
6 \text { físico, } 5 \text { biótico e } 10 \\
\text { socioeconômico }\end{array}$ & $\begin{array}{l}\text { Alteracãão dos níveis de ruído e } \\
\text { vibraçōes; } \\
\text { alagamento e represamentos; } \\
\text { contaminacãão solos e águas } \\
\text { por esgotos, óleos, graxas e } \\
\text { por acidentes cargas perigosas; } \\
\text { degradacãao das áreas } \\
\text { exploradas; } \\
\text { erosão,assoreamento, } \\
\text { compactação dos solos; } \\
\text { poluicacão aérea por } \\
\text { particulados e gases. }\end{array}$ & $\begin{array}{l}\text { Subtração e impactos na cobertura vegetal e } \\
\text { fauna nativa; } \\
\text { atropelamento de animais; } \\
\text { facilidade para a colonização por espécies } \\
\text { invasoras; } \\
\text { intensificacãa do efeito barreira; } \\
\text { risco de incêndios. }\end{array}$ & 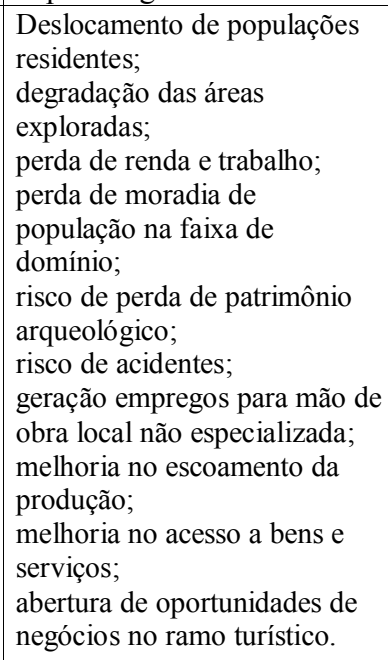 \\
\hline
\end{tabular}


Tabela B - Empreendimentos Lineares

(Continuação)

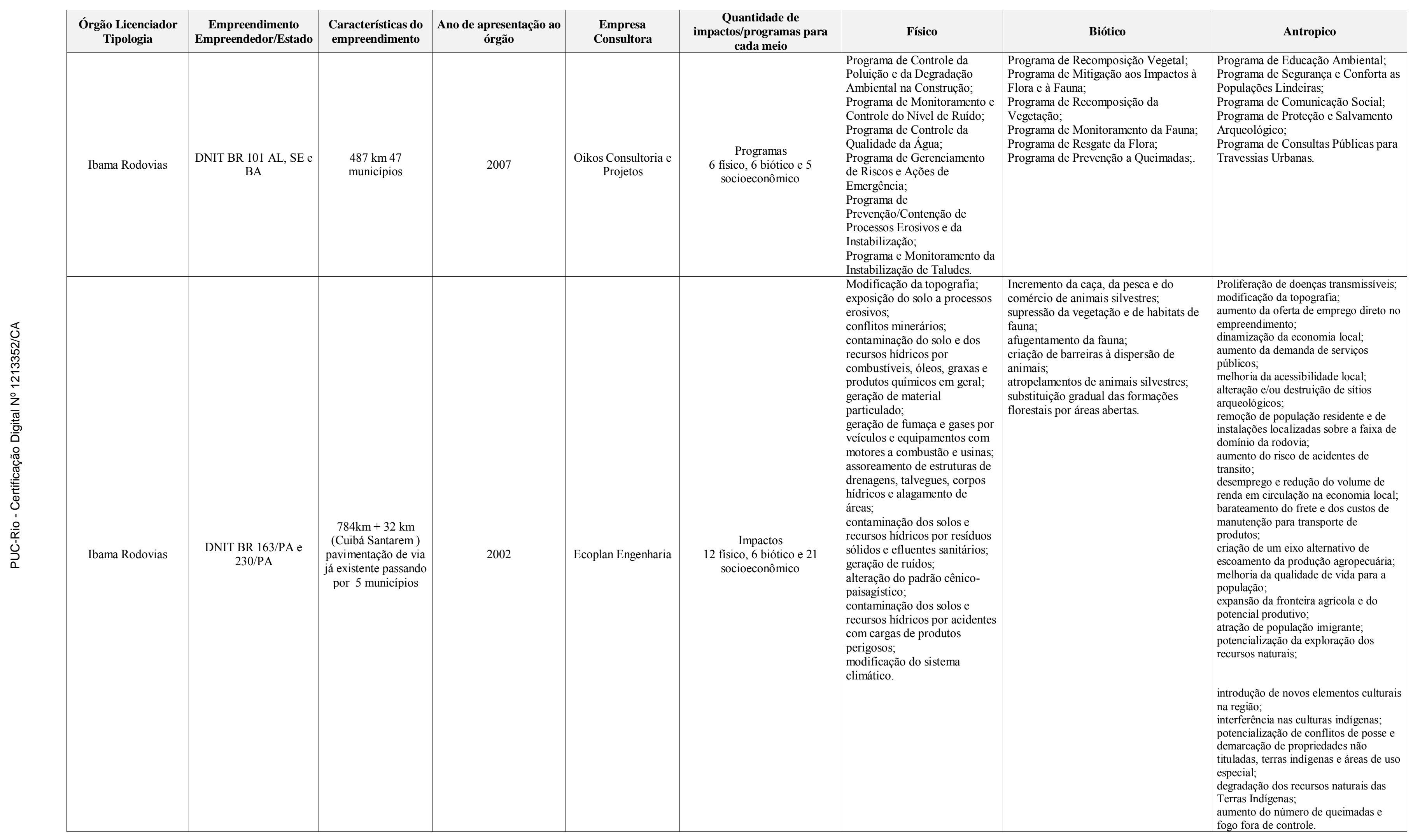


Tabela B - Empreendimentos Lineares

(Continuação)

\begin{tabular}{|c|c|c|c|c|c|c|c|c|}
\hline $\begin{array}{l}\text { Órgão Licenciador } \\
\text { Tipologia }\end{array}$ & $\begin{array}{c}\text { Empreendimento } \\
\text { Empreendedor/Estado }\end{array}$ & $\begin{array}{l}\text { Características do } \\
\text { empreendimento }\end{array}$ & $\begin{array}{l}\text { Ano de apresentação ao } \\
\text { órgão }\end{array}$ & $\begin{array}{c}\text { Empresa } \\
\text { Consultora }\end{array}$ & $\begin{array}{l}\text { Quantidade de } \\
\text { impactos/programas para } \\
\text { cada meio }\end{array}$ & Físico & Biótico & Antropico \\
\hline Ibama Rodovias & $\begin{array}{l}\text { DNIT BR 163/PA e } \\
\text { 230/PA }\end{array}$ & $\begin{array}{c}784 \mathrm{~km}+32 \mathrm{~km} \\
\text { (Cuibá Santarem) } \\
\text { pavimentação de } \\
\text { via já existente } \\
\text { passando por } 5 \\
\text { municípios }\end{array}$ & 2002 & Ecoplan Engenharia & $\begin{array}{l}\text { Programas } \\
3 \text { fisico, } 3 \text { biótico e } 9 \\
\text { socioeconômico }\end{array}$ & $\begin{array}{l}\text { Plano Ambiental para } \\
\text { Construção; } \\
\text { Programa de Proteção e } \\
\text { Emergência para Cargas } \\
\text { Perigosas; } \\
\text { Programa de Gestão } \\
\text { Ambiental. }\end{array}$ & $\begin{array}{l}\text { Programa de Recuperacã̃o de áreas Degradadas; } \\
\text { Programa de Proteção à Fauna e à Flora; } \\
\text { Programa de Compensaçãa Ambiental. }\end{array}$ & $\begin{array}{l}\text { Programa de } \\
\text { Regulamentação e Controle } \\
\text { da Faixa de Domínio; } \\
\text { Programa de Treinamento e } \\
\text { Capacitação de Mão de } \\
\text { Obra; } \\
\text { Programa de Segurança e } \\
\text { Saúde dos trabalhadores; } \\
\text { Programa de Identificaçẫo e } \\
\text { Salvamento de Patrimônio } \\
\text { Arqueológico; } \\
\text { Programa de Comunicação } \\
\text { Social; } \\
\text { Programa de Educação } \\
\text { Ambiental; } \\
\text { Programa de Apoio a } \\
\text { Comunidades Indígenas; } \\
\text { Programa de Apoio Técnico } \\
\text { às Prefeituras; } \\
\text { Programa de Apoio ao } \\
\text { Desenvolvimento Regional. }\end{array}$ \\
\hline Ibama Rodovias & DNIT BR 290 RS & $115,7 \mathrm{~km}$ & 2010 & $\begin{array}{l}\text { MRS Estudos } \\
\text { Ambientais }\end{array}$ & $\begin{array}{l}\text { Impactos } \\
8 \text { físico, } 11 \text { biótico e } 12 \\
\text { socioeconômico }\end{array}$ & $\begin{array}{l}\text { Geração de resíduos sólidos; } \\
\text { alteração das condições } \\
\text { naturais dos solos e } \\
\text { desvalorização de suas } \\
\text { funções; } \\
\text { carreamento de resíduos } \\
\text { provenientes da obra para os } \\
\text { corpos hídricos; } \\
\text { instalação de processos } \\
\text { erosivos; } \\
\text { alteracão da qualidade da } \\
\text { água; } \\
\text { assoreamento dos corpos } \\
\text { d'água; } \\
\text { aumento na emissão de ruídos } \\
\text { e poeiras; } \\
\text { alteração na qualidade do ar. }\end{array}$ & $\begin{array}{l}\text { Alteração na paisagem natural; } \\
\text { pressão sobre Areas de Preservação Permanente; } \\
\text { supressão da vegetação/redução da biomassa } \\
\text { vegetal; } \\
\text { criação de ambientes favoráveis à proliferação de } \\
\text { vetores indesejáveess; } \\
\text { atropelamento e/ou colisão com animais; } \\
\text { supressão de espécies vegetais imunes ao corte e } \\
\text { ameaças de extinção; } \\
\text { fragmentação de habitat; } \\
\text { acidentes com materiais contaminantes; } \\
\text { aumento do risco de queimadas acidentais; } \\
\text { aumento da dispersão de epécies exóticas; } \\
\text { aumento da incidência de animais atropelados da } \\
\text { fauna silvestre. }\end{array}$ & 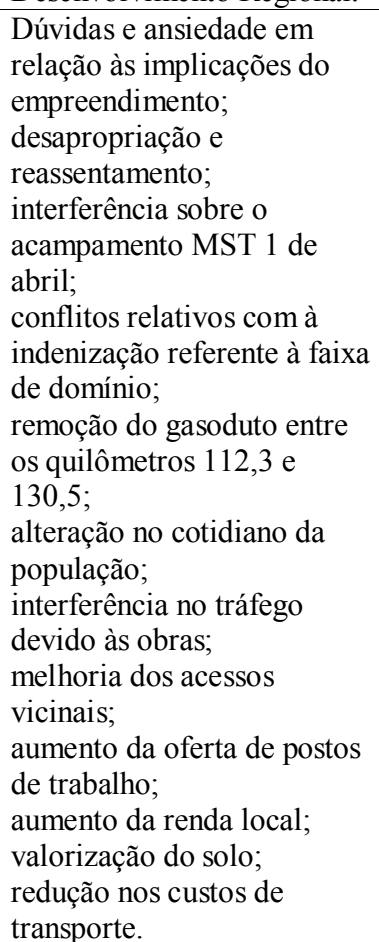 \\
\hline
\end{tabular}


Tabela B - Empreendimentos Lineares

(Continuação)

\begin{tabular}{|c|c|c|c|c|c|c|c|c|}
\hline $\begin{array}{l}\text { Órgão Licenciador } \\
\text { Tipologia }\end{array}$ & $\begin{array}{c}\text { Empreendimento } \\
\text { Empreendedor/Estado }\end{array}$ & $\begin{array}{l}\text { Características do } \\
\text { empreendimento }\end{array}$ & $\begin{array}{c}\text { Ano de apresentação ao } \\
\text { órgão }\end{array}$ & $\begin{array}{c}\text { Empresa } \\
\text { Consultora }\end{array}$ & $\begin{array}{c}\text { Quantidade de } \\
\text { impactos/programas para } \\
\text { cada meio }\end{array}$ & Físico & Biótico & Antropico \\
\hline Ibama Rodovias & DNIT BR 290 RS & $115,7 \mathrm{~km}$ & 2010 & $\begin{array}{l}\text { MRS Estudos } \\
\text { Ambientais }\end{array}$ & $\begin{array}{l}\text { Programas } \\
10 \text { fisico, } 6 \text { biótico e } 5 \\
\text { socioeconômico }\end{array}$ & $\begin{array}{l}\text { Programa de Gestão e } \\
\text { Supervisão Ambiental; } \\
\text { Programa Ambiental de } \\
\text { Construção; } \\
\text { Programa de Prevenção e } \\
\text { Controle de Processos } \\
\text { Erosivos; } \\
\text { Programa de Monitoramento } \\
\text { de Impactos Diretos e } \\
\text { Indiretos ( Monitoramentos } \\
\text { Sistemáticos); } \\
\text { Programa de Gerenciamento } \\
\text { de Resíduos } \\
\text { SŚlidos e Efluentes Líquidos; } \\
\text { Programa de Monitoramento e } \\
\text { Controle de Ruído durante a } \\
\text { Construção; } \\
\text { Programa de Monitoramento e } \\
\text { Controle de Poluição } \\
\text { Atmosf́ricica an fase da } \\
\text { Construção; } \\
\text { Programa de Monitoramento } \\
\text { da Qualidade da Ãgua; } \\
\text { Programa de Ačess de } \\
\text { Emergência (Transporte de } \\
\text { Produtos Perigosos); } \\
\text { Programa de Gerenciamento } \\
\text { de Riscos Ambientais. }\end{array}$ & $\begin{array}{l}\text { Programa de Recuperação de Áreas Degradadas } \\
\text { e Passivos Ambientais; } \\
\text { Programa de Monitoramento de Fauna e } \\
\text { Bioindicadores; } \\
\text { Programa de Monitoramento e Controle de } \\
\text { Atropelamento de Fauna; } \\
\text { Programa de Controle da Supressão Vegetal; } \\
\text { Programa de Apoio a Averbação ou Relocação } \\
\text { de Reservas Legais; } \\
\text { Programa de Monitoramento e Conservação da } \\
\text { Flora. }\end{array}$ & $\begin{array}{l}\text { Programa de Educação } \\
\text { Ambiental; } \\
\text { Programa de Monitoramento } \\
\text { Arqueologico; } \\
\text { Programa de Prevenção de } \\
\text { Acidentes; } \\
\text { Programa de Comunicação } \\
\text { Social; } \\
\text { Programa de Indenização, } \\
\text { Reassentamento e } \\
\text { Desapropriaçao. }\end{array}$ \\
\hline
\end{tabular}


Tabela B - Empreendimentos Lineares

(Continuação)

\begin{tabular}{|c|c|c|c|c|c|c|c|c|}
\hline $\begin{array}{l}\text { Órgão Licenciador } \\
\text { Tipologia }\end{array}$ & $\begin{array}{c}\text { Empreendimento } \\
\text { Empreendedor/Estado }\end{array}$ & $\begin{array}{c}\text { Características do } \\
\text { empreendimento }\end{array}$ & $\begin{array}{l}\text { Ano de } \\
\text { apresentação } \\
\text { ao órgão }\end{array}$ & $\begin{array}{l}\text { Empresa } \\
\text { Consultora }\end{array}$ & $\begin{array}{c}\text { Quantidade de } \\
\text { impactos/programa } \\
\text { s para cada meio }\end{array}$ & Físico & Biótico & Antropico \\
\hline Ibama Rodovias & $\begin{array}{l}\text { DNIT B } \\
\text { R 135 MG }\end{array}$ & $48,7 \mathrm{~km}$ & 2013 & $\begin{array}{l}\text { CSL-Magna } \\
\text { Consultoria }\end{array}$ & $\begin{array}{c}\text { Impactos } \\
13 \text { fisico, } 9 \text { biótico e } \\
32 \text { socioeconômica }\end{array}$ & 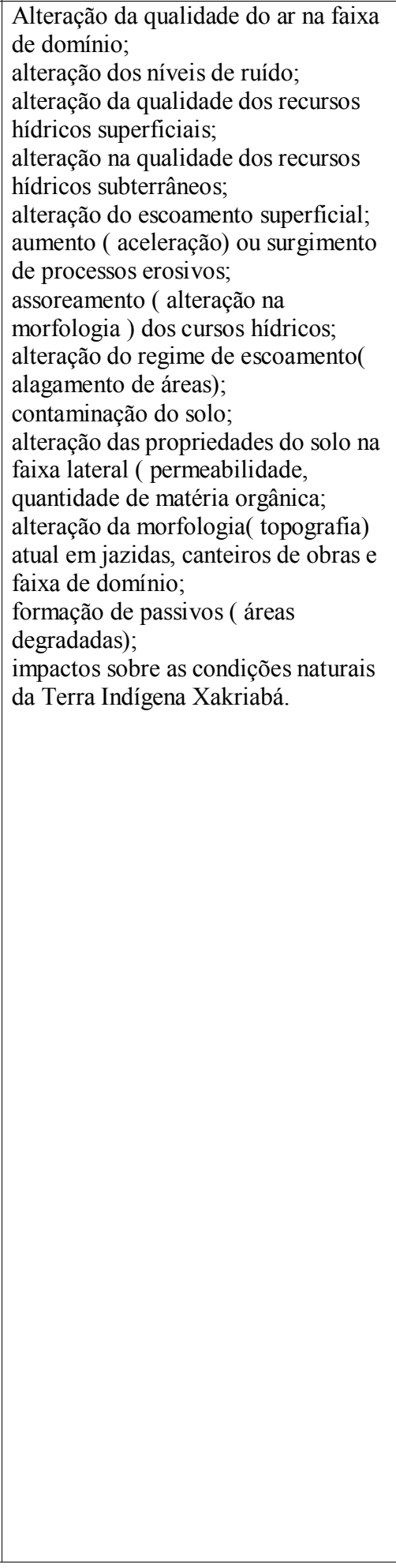 & $\begin{array}{l}\text { Redução da cobertura vegetal nativa; } \\
\text { aumento do risco de incêndios em } \\
\text { remanescentes nativos; } \\
\text { aumento da pressão antrópica sobre } \\
\text { os remanescentes nativos da AID e } \\
\text { AII; } \\
\text { alteração e/ou redução de habitats da } \\
\text { fauna; } \\
\text { perda de indivíduos da fauna } \\
\text { decorrentes de atropelamentos; } \\
\text { perda de indivíluos da fauna } \\
\text { decorrentes da caça e/ou captura; } \\
\text { alterações e/ou redução de habitats } \\
\text { da ictiofauna; } \\
\text { proliferação de insetos vetores de } \\
\text { doenças; } \\
\text { aumento do risco de incidentes com } \\
\text { fogo. }\end{array}$ & 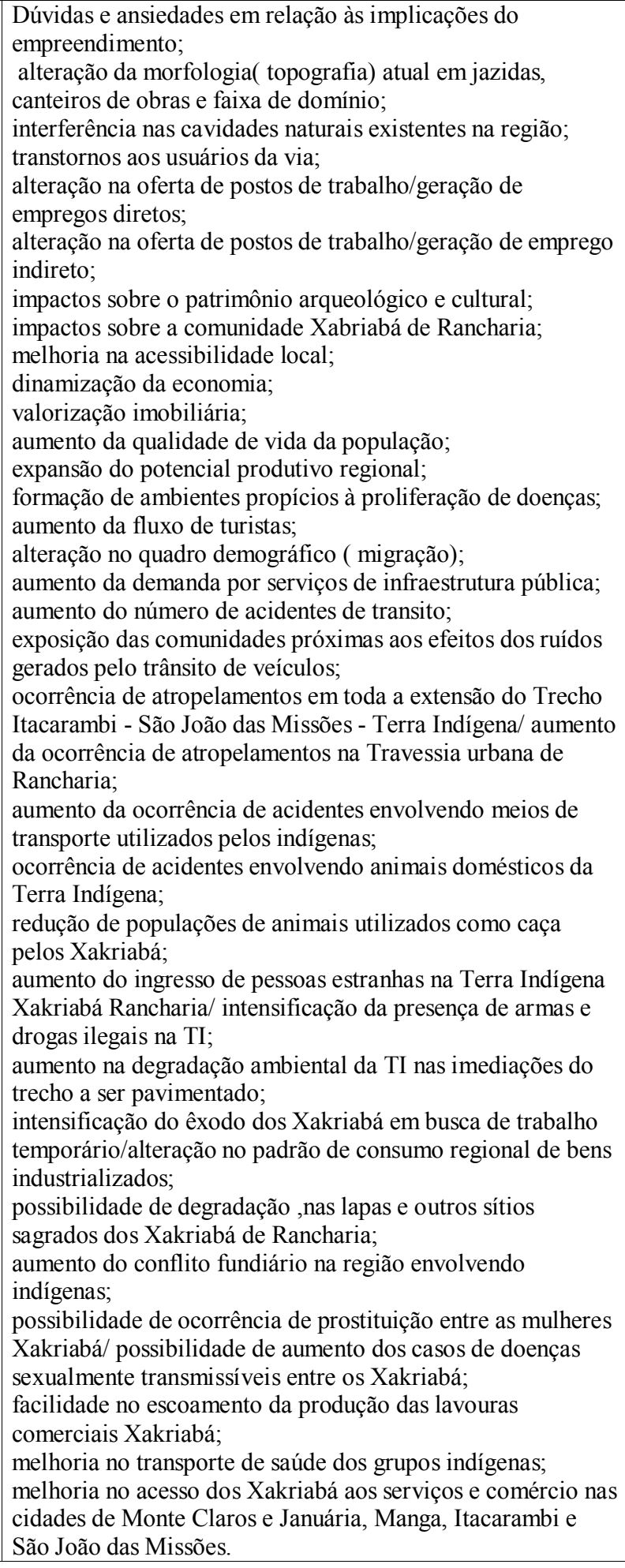 \\
\hline
\end{tabular}


Tabela B - Empreendimentos Lineares

(Conclusão)

\begin{tabular}{|c|c|c|c|c|c|c|c|c|}
\hline $\begin{array}{l}\text { Órgão Licenciador } \\
\text { Tipologia }\end{array}$ & $\begin{array}{c}\text { Empreendimento } \\
\text { Empreendedor/Estado }\end{array}$ & $\begin{array}{l}\text { Características do } \\
\text { empreendimento }\end{array}$ & $\begin{array}{c}\text { Ano de apresentação ao } \\
\text { órgão }\end{array}$ & $\begin{array}{c}\text { Empresa } \\
\text { Consultora }\end{array}$ & $\begin{array}{c}\text { Quantidade de } \\
\text { impactos/programas para } \\
\text { cada meio }\end{array}$ & Físico & Biótico & Antropico \\
\hline Ibama Rodovias & DNIT BR 135 MG & 48,7 km & 2013 & $\begin{array}{l}\text { CSL-Magna } \\
\text { Consultoria }\end{array}$ & $\begin{array}{l}\text { Programas } \\
4 \text { fisico, } 8 \text { biótico e } 7 \\
\text { socioeconômico }\end{array}$ & $\begin{array}{l}\text { Programa Ambiental de } \\
\text { Construção; } \\
\text { Programa de Monitoramento } \\
\text { de Rúdos na fase de } \\
\text { Construção; } \\
\text { Programa de Monitoramento e } \\
\text { Controle de Poluição } \\
\text { Atmosférica; } \\
\text { Programa de Monitoramento } \\
\text { da Qualidade da Água. }\end{array}$ & \begin{tabular}{|l|} 
Programa de Resgate da Flora; \\
Programa de Monitoramento e Combate a \\
Incêndio; \\
Programa de Controle da Supressão da \\
Vegetação; \\
Programa de Monitoramento do Uso e Ocupação \\
do Solo e da Cobertura Vegetal da AID; \\
Programa de Acompanhamento da Fauna \\
Durante a Supressão da Vegetação; \\
Programa de Monitoramento da Fauna; \\
Programa de Compensação Ambiental.
\end{tabular} & $\begin{array}{l}\text { Programa de Recuperação de } \\
\text { areas Degradadass; } \\
\text { Programa de Monitoramento } \\
\text { de Insetos Vetores de } \\
\text { Doenças; } \\
\text { Programa de Educação } \\
\text { Ambiental; } \\
\text { Programa de Comunicação } \\
\text { Social; } \\
\text { Programa de Saúde; } \\
\text { Programa de Apoio às } \\
\text { Prefeituras Municipais; } \\
\text { Programa Relacionado ao } \\
\text { Patrimônio Arqueológico; } \\
\text { Programa de Medidas } \\
\text { Especificasa à Comunidade } \\
\text { Indigena. }\end{array}$ \\
\hline
\end{tabular}

